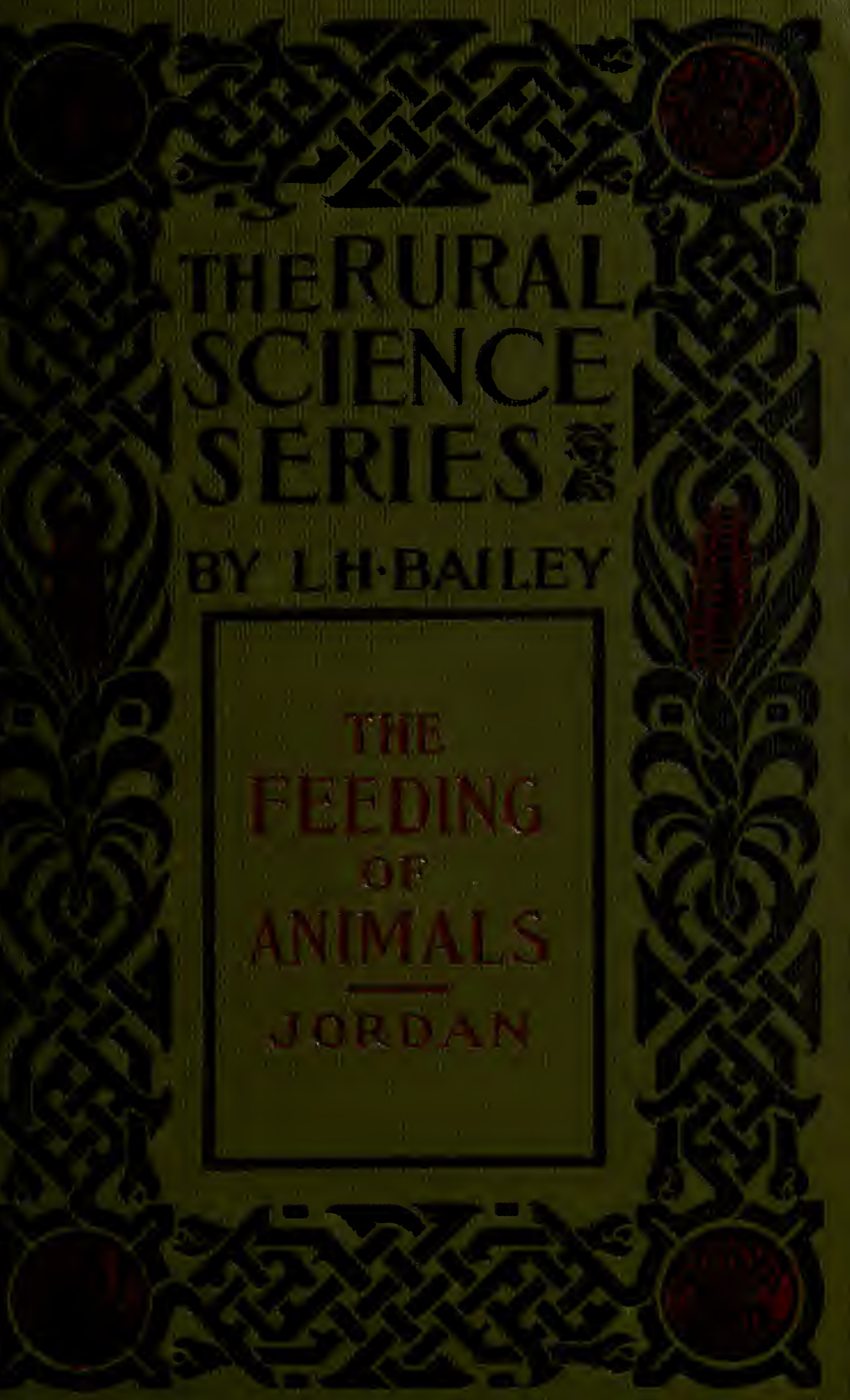




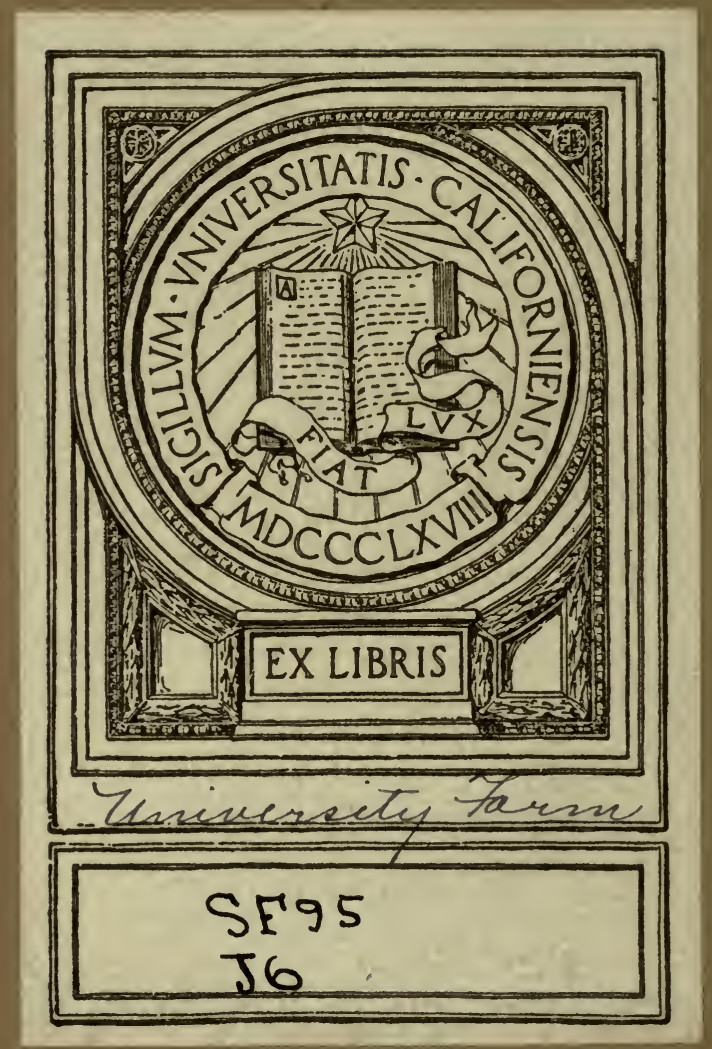






\section{Digitized by the Internet Archive in 2007 with funding from Microsoft Corporation}





\section{The latal stience serieg}

EDITED BX L. H. BAILEY

\section{THE FEEDING OF ANIMALS}




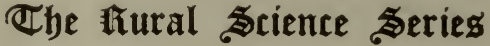

THE SoIL.

The Spraying of Plants.

Milk and Its Products.

'The Fertility of the Land.

The Principles of Frutt Growing.

Bush-Fruits.

Fertilizers.

The Principles of Agriculture.

Rural Wealth and Welfare.

The Farmstead.

The Principles of Vegetable-Garuening. Farm Poultry.

The Feeding of Animals.

The Farmer's Business Handbook.

IRRIGATION AND DRAINAGE.

The Care of animals.

The HoRse.

How to Choose a Farm.

Forage Crops.

Bacteria in Relation to Country Life.

The Nursery-Book.

Plant-Breeding.

THE Forcing-Book.

Garden-Making.

The Pruning-Book.

The Practical Garden-Book. 


\section{THE \\ FEEDING OF ANIMALS}

BY

\section{WHITMAN HOWARD JORDAN}

Director of the Now York Agricultural Experiment Station

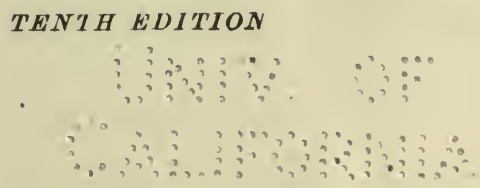

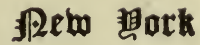

\section{THE MACMILLAN COMPANY}

LONDON: MACMILLAN \& CO., LTD.

1914

$\Delta l l$ rights reserved 


\section{COPYRIGHT, 1901 \\ By THE MACMILLAN COMPANY}

Set up and electrotyped June, 1901

Reprinted September, 1903; February, 1905; October, 1906; February, 1908;

Jauuary and July, 1909; October, 1910; February, 1912

January, 1914
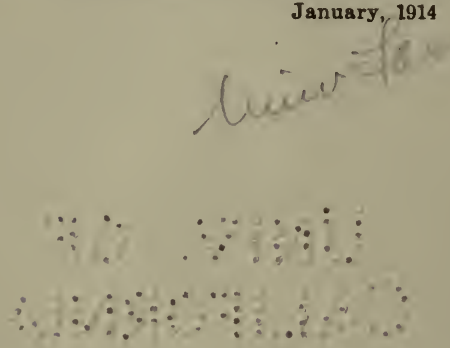


\section{PREFACE}

THis volume is the result of an effort to present the main facts and principles fundamental to the art of feeding animals, as they are now understood. It is not a statement of rules or of the details of practice, for even if the author regarded himself as competent to discuss these he would hold it to be unwise to attempt to discriminate in practical matters so varied and so complex.

Neither has an effort been made to harmonize the whole mass of experimental data relating to animal nutrition. Many of these data are of no value, many are very incomplete, and many are apparently conflicting, so that more useful lessons can often be drawn from single events in the field of experiment and investigation than from the frequently doubtful testimony of summaries.

The author expresses the hope that what he has written will not be regarded as having for its ultimate object the mere exposition of feeding formulas. It is to be feared that the German standard rations are unfortunately accepted by many as nutrition pre- 
scriptions "to be given according to directions." It is time to break away, if we have not already done so, from an undiscriminating adherence to mathematical doses of nutrients, the accuracy of which is supposed by some to outweigh all other considerations and to determine success in feeding. The study of animal nutrition may not wisely center around feeding standards, as seems to have been the tendency of late years. While these formulas are certainly an aid in selecting adequate and uniform rations, they are nevertheless merely an imperfect expression of relations not fully understood that have a greatly variable application in practice, an application judiciously made only through the exercise of a judgment enlightened by familiarity with fundamental facts and principles. Rational cattle feeding is not to be attained through a blind acceptance of existing standard rations but by means of a broad understanding of the scientific and practical knowledge in which these standards had their rise.

Much of the matter introduced in this connection bears no immediate relation to the practical operations of feeding. No apology is made for this departure from the business aspects of the subject. A study of the practical relations of science should not only promote our material well-being but should also lend itself to intellectual stimulus and culture. 
The chapter on The Feeding of Poultry was written by Mr. William P. Wheeler, who also executed the several drawings which appear as illustrations. The author is under great obligations to his associates, Dr. L. L. Van Slyke and Mr. Frank H. Hall, for reading the proof sheets.

\section{W. H. JORDAN.}

New York State Experiment Station,

Geneva, N. Y., June 1, 1901. 



\section{CONTENTS}

\section{PART I \\ THE PRINCIPLES OF FEEDING}

\section{CHAPTER I}

Introduction: Man's Relation to Animal Life . . . . 1-6

The conditions and problems, involved in feeding animals . . 3

\section{CHAPTER II}

The Relations of Plant and Animal Life . . . . . 7-10

\section{CHAPTER III}

The Chemical Elements of Nutrition . . . . . . . . 11-24

The elements and their sources: Carbon, Oxygen, Нуdrogen, Nitrogen, Sulfur, Phosphorus, Chlorine, Potassium, Sodium, Calcium, Iron ... . . . 12

Proportions of elements in plants and animals . . . . 21

In plants .............. 21

In animals ...................... 22

\section{CHAPTER IV}

The Compounds of animal Nutrition . . . . . 25-50

Classes of matter . . . . . . . . . . 2 26 
The cldsses of compounds . . . . . . . . . . 28

Water . . . . . . . . . . . 30

Water in living plants........ 33

Water in feeding stuffs ........ . . 36

Water in the animal ........ 38

Ash ................ . . 4 41

The mineral compounds of plants ...... 43

Variations due to species ......... 43

The distribution of mineral compounds in the dif-

ferent parts of the plant . . . . . . 45

Influence of manufacturing processes on the ash constituents ............. 47

The mineral compounds of animal bodies . . . 48

The distribution of inorganic compounds in the animal body ............ 49

\section{CHAPTER V}

The Compounds of Animal Nutrition (continued) . . 51-70

The nitrogen compounds ........... 51

Protein . . . . . . . . . . . 52

The proteids.............. 55

The albuminoids . . . . . . . . . 57

The alburnins . . . . . . . . . . 58

The globulins . . . . . . . . . . 59

The modified albuminoids . . . . . . . 62

Coagulating ferments ....... 63

Heat . . . . . . . . . . 64

Action of acids and alkalies . . . . . 65

Ferments of digestion ........ 65

Combinations . . . . . . . . 66

The gelatinoids . . . . . . . . . . . 68

Keratin and similar substances. . . . . . 69

Protein: The non-proteids ... . . . . . . . 69

Amides . . . . . . . . . . . . 69

Extractives .............. 70 


\section{CHAPTER VI}

The Compounds of Animal Nutrition (concluded) . . 71-92

The nitrogen-free compounds . . . . . . . . 71

Crude fiber . . . . . . . . . . . . . 72

Nitrogen-free extract . . . . . . . . . 74

The starches............ . . 75

The vegetable gums .......... . . 78

The pectin bodies......... . . 80

The sugars ............. 80

The acids . . . . . . . . . . . 83

Animal earbohydrates. . . . . . . . . . 84

Chemical relations and characteristics of the carbohydrates ............. 85

Fats or oils ............ . . . 88

\section{CHAPTER VII}

The Composition of the Bodies of Farm Animals . . 93-97

CHAPTER VIII

The Digestion of Food . . . . . . . . 98-125

Ferments . . . . . . . . . . . . . . 99

The mouth .............. . . 104

The stomach .............. . . 108

The intestines . . . . . . . . . . . 114

Absorption of the food . . . . . . . . . 119

Feces . . . . . . . . . . . . . . 121

Relation of the different feeding stuff compounds to the digestive processes ............ 121

CHAPTER IX

Conditions Influencing Digestion ...... . 126-141

Palatableness . . . . . . . . . . . 126

Influence of quantity of ration . . . . . . . 127 
Effect of drying fodders . . . . . . . . . . . . . . 128

Influence of the conditions and methods of preserving

fodders . . . . . . . . . . . . . . 129

Influence of the stage of growth of the plant. . . . . 130

Influence of methods of preparation of food . . . . 131

Influence of grinding . . . . . . . . . . 133

Effect of common salt ............. . 133

Influence of frequency of feeding and watering animals . 134

Influence of certain other conditions . . . . . . . . . 134

Influence of the combination of food nutrients . . . . 135

Conditions pertaining to the animal: species, breed,

age and individuality ........... 137

Determination of digestibility . . . . . . . . 139

\section{CHAPTER $\mathrm{X}$}

The Distribution and Use of the Digested Food . 142-150

The blood . . . . . . . . . . . . 142

The heart . . . . . . . . . . . . . 144

The lungs . . . . . . . . . . . . . . 146

The use of food . . . . . . . . . . . 147

Elimination of wastes . . . . . . . . . . 148

The liver ............... 150

\section{CHAPTER XI}

The Functions of the Nutrients. . . . . . . 151-169

Funetions of the mineral compounds of the food . . . 152

Functions of protein . . . . . . . . . . . 153

Functions of carbohydrates . . . . . . . . . 155

Functions of the fats and oils . . . . . . . . 157

Food as a source of energy . . . . . . . . 157

Available energy ............. 163

Net energy . . . . . . . . . . . . . 164

Energy relations of the several nutrients . . . . . 166

Heat relations ............ 167 


\section{CHAPTER XII}

Physiological Values of the Nutrients . . . . . 170-181

Relative energy and production values of the nutrients,

singly and as classes. . . . . . . . 171

Relative energy values ............ 171

Relative production values of the different nutrients. 175

Relative importance of the protein compounds . . . 178

CHAPTER XIII

LAWS OF NUTRITION . . . . . . . . . 182-185

\section{CHAPTER XIV}

SOURCES OF KNowledGE . . . . . . . . . . 186-202

Conclusions of practice . . . . . . . . . 187

Practical feeding experiments . . . . . . . . 188

Chemical and physiological studies ......... 191

More accurate methods of investigation . . . . . . 192

Relation of food to production . . . . . . . . 194

The respiration apparatus .......... . . 196

Determination of energy values . . . . . . . 198

Calculation of energy value of a ration . . . . . 198

Energy value of digested nutrients . . . . . . 199

Measurement of food combustion . . . . . . 200

Respiration calorimeter ........... 201

\section{PART II}

\section{THE PRACTICE OF FEEDING}

\section{CHAPTER XV}

Catthe Foods - Natural Products . . . . . . 203-226

Forage crops . . . . . . . . . . . . 204

Green vs. dried fodders ......... . 205

The harvesting of forage crops . . . . . . 207 
PAGES

Sllage . . . . . . . . . . . . . . . . . 212

Nature of changes in silo . . . . . . . . . . 213

Extent of loss in the silo . . . . . . . . . . . 215

Ensiling vs. field-curing . . . . . . . . . . . 217

Crops for ensilage . . . . . . . . . . . . 218

Construction of silos . . . . . . . . . . . . 219

Filling the silo . . . . . . . . . . . . . 220

The straws . . . . . . . . . . . . . . . 223

Roots and tubers ... . . . . . . . . . . . 224

Grains and seeds... . . . . . . . . . . 225

\section{- chapter XVI}

Cattle Foods-Commercial Feeding Stuffs . . . . . 227-257

Classes of commercial by-product feeding stuffs . . . . . 228

Wheat offals . . . . . . . . . . . . 228

Residues from breakfast foods . . . . . . . . 232

Brewers' by-products . . . . . . . . . . 236

Residues from starch and glucose manufacture . . . . 236

Residues from the manufacture of beet-sugar . . . . 240

The oil meals in general . . . . . . . . . . 241

Cottonseed meal ............ . 242

Linseed meal . . . . . . . . . . . . 245

Chemical distinctions in cattle foods . . . . . . . . 248

Coarse foods vs. grains and grain products . . . . . 249

Classification according to the proportions of nutrients . 249

Foods of animal origin............ . . 252

Milk . . . . . . . . . . . . 252

Dairy by-products . . . . . . . . . . . 254

Slaughter-house and other animal refuses . . . . 256

\section{CHAPTER XVII}

The Production of Cattle Foods . . . . . . . 258-267

Soiling crops.............. . 263 


\section{CHAPTER XVIII}

PAGES

The Valuation of Feeding Stuffs . . . . . 268-279

Commercial values . . . . . . . . . . 269

Physiological values . . . . . . . . . . 272

Selection of feeding stuffs. . . . . . . . 273

Other standards of valuation . . . . . . . 277

CHAPTER XIX

The Selection and Compounding of Rations . . . 280-294

\section{CHAPTER XX}

Maintenance Rations . . . . . . . . . 295-303

Maintenance food for bovines . . . . . . . 297

Maintenance food for horses . . . . . . . 300

\section{CHAPTER XXI}

Milk Production . . . . . . . . . . 304-323

Milk secretion . . . . . . . . . . 306

Sources of milk solids . . . . . . . . 307

The rate of formation of milk solids . . . . . 308

The amount and character of the ration for milk production 309

The sources of protein for milk production . . . . 313

The relation of food to the composition and quality of milk 316

Effect of food upon the composition of milk . . . . 316

Effect of food upon the flavors of milk and its products . 321

\section{CHAPTER XXII}

Fleding Growing Animals . . . . . . . . 324-338

The feeding of calves . . . . . . . . . 328

The feeding of lambs ............. 331

Feeding colts .............. 333

Feeding the dam ............ 834

Feeding the colt ........... 335 


\section{CHAPTER XXIII}

Feeding Animals for the Production of Meat . . . 339-366

The nature and extent of the growth in beef production . 340

The food needs of the fattening steer . . . . . . 341

The selection of a fattening ration... . . . . . 347

Mutton production . . . . . . . . . . . . 349

The nature and extent of the growth in fattening sheep . 350

Food needs of fattening sheep......... . . 351

The selection of a ration for sheep . . . . . . . 355

Pork production .............. . 357

Character of the growth in pork production . . . . 358

Food requirements for pork production. . . . . . 360

Feeding the dam . . . . . . . . . . 360

Feeding pigs for the market ........ 361

\section{CHAPTER XXIV}

FeEding Working Animals. . . . . . . 367-378

The horse a machine . . . . . . . . . . 367

The work performed by a hors6 . . . . . . . . 368

The food requirements of a working horse . . . . . 371

Source of the ration for working horses ...... . 374

\section{CHAPTER XXV}

The Feeding of Poultry - By William P. Wheeler . . 379-399

Kinds of foods . . . . . . . . . . . 379

Incidental effects of the fooc. . . . . . . . 382

Digestive apparatus . . . . . . . . . . 383

Constituents of the body. . . . . . . . . . 387

Necessity for considering the water . . . . . . 389

The organic and mineral nutrients in food . . . . 389

The study of rations and deduction of standards . . . 392

Maintenance rations . . . . . . . . . . . 393

Rations for laying hens........... . 393

Rations for young birds........... 394 


\section{CHAPTER XXVI}

The Relation of Food to Production . . . . . . 400-407

\section{CHAPTER XXVII}

General Management......... . . . 408-418

Selection of animals ........... . . 4409

Selection of cows . . . . . . . . . . . . 409

The selection of animals for meat produetion ... . 411

Manipulation of the ration ........... 413

Quantity of the ration ............. 414

Environment and treatment of animals . . . . . . 415

\section{APPENDIX}

Composition and Digestion Tables . . . . . . . 419-443

1. Average composition of American feeding stuffs . . 419-427

2. Average coefficients of digestion ....... . 427-435

3. Feeding standards . . . . . . . . . . . . . 435-438

4. Fertilizing constituents, American feeding stuffs . 439-443

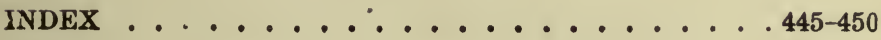





\section{THE FEEDING OF ANIMALS}

\section{PART I-THE PRINCIPLES OF FEEDING}

\section{CHAPTER I}

\section{INTRODUCTION: MAN'S RELATION TO ANIMAL LIFE}

THERE was a time somewhere in the dim past when the beast of the field knew no master. The only obedience which he rendered to a superior power was an unconscious submission to Nature's stern forces. He wandered forth at will to find in the untilled pastures such food as the wild herbage afforded, and, unrestrained, he sought a place of rest in the tangled thicket. He knew no refuge from the winter's cold and storm but some sheltered nook or forest recess to which his brute intelligence guided him, and he was his own defense against the dangers which beset him.

Man had not come to be a controlling factor in the development of the various forms of animal life. If the brute knew him at all, it was as the huntsman, as an enemy, but not as a superior to whom must be paid a tribute of service or of food and elothing. The wild ox and horse possessed those characteristics which best fitted them to cope with the untoward conditions of their environment; but there had not yet appeared 
those specialized capacities of growth, draft, speed or production which now render these animals so very valuable for the service and sustenance of the human family.

The qualities developed were those demanded by the necessities of existence without reference to utility as measured by the needs of a higher form of life. The fiber of the body must possess endurance, and it mattered little whether or not the muscle could furnish a juicy steak. The brute mother must defend her young and supply it with milk, and this being accomplished, her materual functions ceased. She was neither so endowed that she could open the fountains of her life to feed generously a not too grateful master, nor so submissive that she would. The wild horse must be fleet and enduring that he might escape the enemy, but not that he might bear heavy burdens or win a contest in the prescribed form of the race-track.

In the lapse of centuries there have been many changes in the relation of man to the animal creation. Bird and beast in various forms have come to minister to man's wants, and in their present domesticated condition are, in their turn, utterly dependent upon him for the food and shelter which are necessary to their physical welfare, or even existence. It is not too much to assert that the domestic animal, in the artificial environment imposed upon it, is entirely at man's mercy, even in the development of those attributes and characteristics which otherwise would be determined by the demands of an unaided warfare with nature. The juicy sirloin of the shorthorn, the almost abnormal milk 
glands of the champion butter cow, the delicate fiber of merino wool, and the marvelous speed of the modern race-horse are evidences of man's skill in recasting natural types into forms of greater usefulness to him. From the animal of nature, under the direction of a higher intelligence, has proceeded the animal of civilization, an organism obedient to the environment which has been created for it.

This interdependence of man and the lower orders of life has a vast economic significance. A large part of human activity is devoted to the production and transportation of food for animals and to the traffic in the products of the dairy, slaughter-house and sheepfold, and to their utilization in various ways. The prosperity of every farm is maintained to a greater or less extent by feeding domestic animals, and our railroads, our markets, in fact, nearly all our important business enterprises, are more or less dependent upon the extent and prosperity of animal husbandry.

\section{THE CONDITIONS AND PROBLEMS INVOLVED IN} FEEDING ANIMALS

The first and simplest form of animal husbandry is that which was practiced by the nomad. His flocks and herds subsisted wholly by grazing and were moved from place to place according to the supply of forage afforded by different localities. No shelter was provided for the animals and no food was stored for their use. The only intelligence or special knowledge that was brought to bear upon the business of the herdsman 
was a familiarity with the traditions and superstitions touching the care of cattle and the acquaintance which a roving life would give with the pastures furnishing the most abundant and sweetest wild grasses during the various seasons of the year. There was not then even a dim promise of the modern traffic in meats or of the fine art of dairying as we now know it. As man began to give up this wandering life, erect permanent dwellings and confine his ownership of land to definite limits, he acquired the art of tillage, not only that he might have food for his family but also for his cattle. He then began to store fodder in stacks, and later in barns, to meet the demands of the inclement portions of the year.

For centuries, however, grazing was the chief dependence for securing the production of meat and milk because the foods supplied during the cold season were not in such abundance or so nutritious as to sustain continuous growth or milk secretion. Even within the remembrance of men now living, live stock was not expected to produce an increase during the winter months but was simply maintained from autumn until spring in order that profits might be realized from summer pasturage. Formerly the demands of the market were much simpler than they are now. Butter and cheese were produced almost wholly from summer dairying, and no such variety of fresh meats was offered to consumers during the entire year as is now the case. But great changes have occurred during the last fifty years, more especially during the past twenty-five. First of all, we have a modern type of animal, greatly unlike that 
of previous times. The ideal dairy cow of to-day is a high-pressure milk machine extremely sensitive to her environment and demanding a degree of care in management and feeding, if she is to do her safe maximum work, which was not necessary with coarser and less delicate organisms. Every successful dairyman must now provide proper winter quarters for his herd and throughout the entire year must supply rations that will support continuous, generous production. He must do this, too, by the use of a greater variety of foods than was formerly available. Not only has the number of useful forage crops greatly increased, but the average farmer no longer produces all the food which his animals consume. He now buys numerous kinds of commercial feeding stuffs. These purchased materials are not wholly the cereal grains whose value through long experience has come to be measured by certain practical standards, but they consist in part of comparatively new by-products from the inanufacture of oils, starch and human food preparations,-feeding stuffs which differ greatly in their nutritive properties. Besides all these changes, animal husbandry is now called upon as never before to feed the prosperous part of humanity with high-class products having special qualities of texture and flavor that depend to some extent upon feeding. Certainly the conditions and problems to be met in this branch of human industry have grown more and more complex.

We must add to this the fact that, as is true with every department of man's activity, science has laid her hands upon the business of the farmer and has 
forced him into a new range of thought and practice. This influx of knowledge has greatly influenced the requirements for meeting a sharpened competition and has rendered it imperative for the practitioner to bring to bear upon a great variety of agricultural problems a clear understanding of fundamental facts and principles.

The feeding of animals involves many difficult questions. These begin with the production of forage and grain crops where it is necessary to discover what ones will yield the largest food values per unit of expenditure. Economy demands that the several feeding stuffs which are at command shall be so combined that there shall be no waste of material or energy. With several considerations in view, a decision must be reached as to the most profitable commercial foods to purchase when the number is large and the range of prices is wide. The influence of the various foods upon the quality of the product, especially dairy products, has in recent years become an important matter. These and related problems confront the stockman and dairyman, and they demand for their wise solution more than what is ordinarily designated as practical experience. The investigator who shall successfully inquire into these matters must possess scientific qualifications of a high order; and the practical man, who, in a business way, conforms his methods to the highest standard which scientific research has already made possible must be familiar with the knowledge fundamental to the feeder's art. 


\section{CHAPTER II}

THE RELATIONS OF PLANT AND ANIMAL LIFE

THE foundations of animal life are laid in the plant, and with the plant must begin a study of the fundamental facts of animal nutrition. The first step toward supplying animals with food is taken when the farmer drops seed into the warm earth. As soon as the young rootlets from a germinating seed come in contact with the soil and the first leaves reach the air, assimilative growth begins. During the hours of sunlight matter is constantly gathered in an invisible way, which, after transformation into various compounds, is added to the enlarging tissues of the plant. This continues, perhaps for a season, until the stalk of grain has reached its full height and has attained the ultimate object of its existence in the production of seed, or it may go on for centuries, so that where now is only the acorn there will be the giant oak. The farmer carries to the field a few pounds of seed and he returns to his storehouses laden with tons of new material, perhaps hay, perhaps grain. From somewhere, in some way, the plant has gathered various substances, often no less than ten thousand pounds per acre in a single year, and has manufactured them into forms that are useful to the husbandman. 
Plant life not only builds tissue: it stores energy, as we may easily discover. The farmer's boy learns this when he feels the hot glow of the fire that is fed by forest wood. The wood disappears, but he is warmed by the radiant energy. It has occurred that when fuel was scarce and costly and grain was abundant and cheap, the western farmer has burned his corn. All he realized in this case for his labor was the warmth which was necessary to make himself and family comfortable. As with the wood, the materials which were collected from the soil and air have been dispersed in invisible forms during the combustion which liberated the heat energy, except a small heap of ashes on the hearth. The farmers who raised corn for fuel were no richer in storehouse or in pocket. They had simply used an available supply of heat, derived from the energy which was stored in the plant during its growth.

But ordinarily, grass and grain are produced, not for fuel but for food purposes, and in this use of vegetable matter we come in contact with a set of phenomena equally complex and equally important and interesting to those of its growth. The calf of to-day weighing, perhaps, a hundred pounds, becomes in a few years the immense bullock. What is the source of this mass of bone and flesh? It is merely plant substance which in other combinations was collected from soil and air. This animal eats his daily ration and makes his daily gain of tissue. When his food is withheld, his body wastes and he dies. If his food varies in amount, his growth is somewhat proportional to the 
quantity eaten. We, therefore, cannot resist the conclusion that the bones, blood and flesh of this ox are derived from what he eats.

The plant does more than to supply building material for the animal body. This living organism is kept warm. No matter how cold the surrounding atmosphere, we find by the use of a thermometer that in health the ox's temperature remains at about $101^{\circ} \mathrm{F}$., with but small variation. Just as the western farmer obtained heat by burning corn in the fireplace, so does the cattle-owner maintain the body temperature of his animals at the necessary degree by supplying food to be burned. The combustion is not so rapid as occurs in the fireplace, still the changes are the same but more slowly carried on.

Food not only builds the ox and warms him,-it furnishes him with motive power. The energy which the plant acquires during its time of growth is, through his vital processes, transformed in part into motion. The animal is a living mechanism, a combination of muscles and levers which are moved not by means of a spontaneous internal generation of energy, but through a supply from without, the energy stored in the plant.

If we use the plant for fuel we get heat alone; if we feed it to the animals we get heat, motion and the production of other forms of matter that have a relatively high commercial value. In the first instance the plant substance, except the mineral portion, is wholly broken up into simpler compounds which in unseen gaseous forms escape from our possession, the 
liberated energy becoming manifest as heat. With the animal, a greatly varying proportion of the dry matter of the plant is retained to form his body substance, and the remaining part suffers decomposition, largely into the same compounds that are carried away by the draft from the fire on the hearth. As a result there is built a living organism that is warmed to a temperature generally much above that of the surrounding air, which is the seat of complex internal activities and is capable of performing external work. 


\section{CHAPTER III}

THE CHEMICAL ELEMENTS OF ANIMAL NUTRITION

The facts which are fundamentally necessary to a broad understanding of tue economy of cattle feeding, pertain, first of all, to the materials out of which vegetable and animal tissues are constructed. It is important to know both what these are and what are their sources.

About seventy substances are now believed to be chemical elements, i. e., substances that cannot be resolved into two or more simpler ones, and of which, so far as known, all forms of matter are composed, the variety of combinations being almost infinite. It is remarkable that comparatively few of these fundamental substances, - about one-fifth, - are intimately related to the growth of plants; and those that occupy a prominent place in animal nutrition are even less in number.

It is necessary to mention only fifteen elements in this connection, some of which are of minor importance: carbon, oxygen, hydrogen, nitrogen, sulfur, phosphorus, chlorine, silicon, fluorine, potassium, sodium, calcium, magnesium, iron and manganese.

At ordinary temperatures, four of these, oxygen, hydrogen, nitrogen and chlorine, are gases, and the remaining ones are solids. Four are constant and im- 
portant ingredients of the atmosphere; viz., carbon, oxygen, hydrogen and nitrogen, and they also exist in the soil in gases, as well as in combination in liquids and solids; the other eleven, though sometimes present in the air in minute quantities; are found to no appreciable extent except as fixed compounds in water and in the crust of the earth, or in plants and animals. Nearly all of these elementary substances are absolutely essential to the existence of animal life as now constituted. From the standpoint of necessity, they are, therefore, nearly all of equal value, but if we take into consideration the relative ease and abundance of the supply, certain ones rise to a position of supreme importance.

\section{THE ELEMENTS AND THEIR SOURCES}

Carbon.-This is a familiar substance in common life. Anthracite coal and charcoal are examples of impure carbon. Graphite in lead pencils is also carbon, and so are diamonds. When wood chars or food is burned in an overheated oven the partially decomposed materials become black, revealing the presence of carbon, the other elements with which it was associated being driven out. The humus of the soil is vegetable matter, which, from other causes, has undergone somewhat the same change.

An immense quantity of carbon exists in the air, combined with oxygen as carbon dioxid or carbonic acid gas. The average proportion by weight of this compound in the atmosphere is stated to be .06 per 
cent, and as the weight of a column of air one inch square is fifteen pounds, it follows that over every acre of land there is 28.2 tons of carbon dioxid, or 7.7 tons of carbon. As we know that plants draw their supply of this element from the atmosphere, and as vegetable tissue is its only source to the animal, we are able to assert, with confidence, that the carbon in the tissues of animal life was once floating in space.

A long time ago, Boussingault determined the average yearly amount of carbon which was withdrawn from the air by the crops grown on a particular field during a period of five years, and found it to be 4,615 pounds. This is no more than is acquired by a large crop of maize. As a matter of fact, plants, as well as animals, contain a larger proportion of this element than of any other, and the amount of this substance which enters into the processes of growth and decay in the vegetable and animal kingdoms is almost beyond comprehension. It is natural to wonder whether the atmospheric supply is equal to the demand. Any anxieties we may have concerning this should be removed by learning that during many years the percentage of atmospheric carbon has not changed appreciably. The processes of decay on the earth's surface, the combustion of wood and coal as fuel and of carbon compounds by animal life are returning carbon to the air as rapidly as it is being withdrawn. This is the round traveled,-from the air to the plant, from the plant to the animal, and from the animal back to the air, - a cycle in which this element has been moving since life began, and in which it will continue to move so long as life exists. 
Oxygen.-This element is, next to carbon, the most abundant component of vegetable and animal tissues, and it stands second to none in its relation to the vital processes of nearly all forms of life. It is not a substance with which we are familiar by sight, because we ordinarily come in contact with it as a transparent, colorless gas. We live and move in it, for it is an important and uniformly abundant constituent of the atmosphere. The air is over one-fifth oxygen by volume, the proportion by weight being slightly larger. More than twenty-one million pounds of this element are contained in the air above a single acre of land, a quantity which remains remarkably constant, and which is surprisingly uniform over the entire surface of the globe. While it is being continuously withdrawn from the air for the uses of life and to maintain fuel combustion and processes of decay, it is, like carbon, as continuously returned.

Vast quantities of oxygen are also contained in water, as this compound, which fills the ocean and lakes, and is abundant in the crust of the earth, is nearly 89 per cent oxygen. It is estimated also that the solids in the crust of the earth are one-half oxygen. That which enters directly into the nses of animal life is, however, chiefly that which is derived from the atmosphere and water.

Not a plant grows or animal lives excepting through the circulation of oxygen, during which it passes into fixed combinations and back again to the free form. The animal uses the free oxygen in breathing and returns it to the air in part combined with carbon as car- 
bonic acid, This compound the plant appropriates, retaining the earbon for its tissues and giving back the uncombined oxygen to the atmosphere to be again used by animals. All decay and many other chemical changes require the presence of this element. What we speak of as fire is due to its union with the elements of the fuel. It bears an indispensable relation to the mechanical forces that man now employs, for it is the agent which maintains combustion in the furnaces of our industries. All the activities of life are intimately related to it. When a plant grows, oxygen is torn from its union with other elements by the dominating power of the sun's rays, and energy is stored in vegetable tissue. When this tissue is used as food the oxygen returns to its former combinations through the opportunities offered by the vital processes of the animal, and the hidden forces of the plant compounds are thus manifested in a variety of ways. The animal labors and man toils and thinks because of the energy thus stored and liberated.

Hydrogen.-This element, which, in a free state, is the lightest known gas, is found abundantly in nature only in combination with other elements. The minute quantities which exist in the air are due to volcanic action and possibly to decay under certain conditions. As a manufactured product, it has an important use in producing intense heat and in filling balloons. Hydrogen constitutes about one-ninth of water by weight, and is found in a large number of soil compounds. It is an essential constituent of vegetable and animal tissues, although it exists in the compounds 
of living organisms in a much smaller proportion than carbon or oxygen. Plants obtain it largely from water, and it is furnished to the animal body in water and in other compounds.

Nitrogen.-Probably no element has been given more attention in its relations to agriculture from the scientific and practical standpoints than has nitrogen as such and in its compounds. Like oxygen it is an invisible, tasteless, and odorless gas which forms in the free state a large part of the earth's atmosphere. The air has been considered to be approximately $77 \mathrm{per}$ cent free nitrogen by weight, but the discovery of the new element, argon, which has heretofore passed as nitrogen, will slightly modify previous determinations.

Nowhere outside of the air and the tissues of living organisms does nitrogen exist in any form in comparatively large quantities. The soil spaces contain it and it is taken into solution in small proportions in all natural waters. It is found in the mineral, as well as organic compounds of the soil, but in quantities which seem insignificant as compared with other elements, such as oxygen and silicon. Few agricultural soils contain over one-half of one per cent of combined nitrogen. Minute quantities of its compounds exist in the atmosphere which are being constantly carried to the soil in rain-water and as constantly replaced by the ammonia from decomposing animal and vegetable matter and by the products of the oxidation of nitrogen through electrical action and combustion. Notwithstanding this comparatively small supply of nitrogen compounds, they play a prominent part in agriculture, 
both commercially and physiologically. The nitrogen balance of the farm must be carefully considered both by the crop producer and by the cattle feeder.

Nitrogen compounds are especially important because the available supply is often dangerously near the demand or even below it. The nitrogen found in the air is inert for animal uses, and is ignored by a large majority of plants. Much of that in the soil is also unavailable. Moreover, its immediately useful compounds on the farm are constantly subject to loss,first by processes of fermentation which the farmer cannot wholly prevent, and second by soil losses which are to some extent beyond control. Many of the commercial products of the farm also carry away much nitrogen. The sources of supply to balance this outgo are the nitric acid and ammonia of the rainfall, the free nitrogen captured by legumes and whatever comes from purchased fertilizers and foods. These facts relate primarily to plant production, but they also sustain an essential relation to the maintenance of animal life and cannot be ignored in a rational and well-directed system of animal husbandry.

Physiologically, the nitrogen compounds stand in the front rank. They are necessary building material for the fundamental tissues of the animal and are intimately related to the prominent chemical changes which are involved in growth and in the maintenance of life. It is safe to assert, too, that variations of these compounds in the food may have an important influence on the character of the body structure or on the amount of a particular product. 
As a result of these conditions which relate to the supply of useful nitrogen and to its important role, we find that it has assumed a prominent place in commerce. It is the most costly ingredient of fertilizers, and the value of commercial eattle foods is sometimes based almost wholly upon their content of this element. For these reasons, the control, even though only partial, which the farmer may now assume over the income and outgo of the nitrogen compounds valuable to agriculture is a triumph of modern science. and an important feature of farm economics.

Sulfur is a common and familiar substance. As an element it is not widely distributed in nature, but its compounds are found in all soils and natural waters, and in all the higher forms of animal and vegetable life. We know it as "brimstone" when fused in sticks and as "flowers of sulfur" when in a finely divided form. Its most common commercial compounds are sulfuric acid and the sulfates of potash, soda, lime and magnesia. This element is an essential part of some of the most important tissues of the animal body, and is supplied in food in the form of the sulfates and in its proteid combinations.

Phosphorus occupies an important place among the elements of nutrition. In the uncombined form it does not exist in nature, as that found in laboratories is produced only by chemical means. Its compounds are found everywhere. The phosphates of calcium, magnesium and iron are widely distributed in soils and large deposits of calcium phosphate are known, from which is obtained the crude phosphatic rock that serves 
as a basis for the manufacture of commercial fertilizers. All feeding stuffs in their natural forms contain phosphorus, either as phosphates, $*$ or as combined in certain fats and nitrogen compounds which stand in close relation to the vital processes. It is distributed in the flesh of animals, and combined with lime constitutes a large part of bone.

Chlorine, which is a constituent of common salt, is essential to the nutrition of the animal. At ordinary temperatures it is, in the free state, a greenish-colored, disagreeable gas. When combined with hydrogen it forms hydrochloric acid, a compound which is necessary to tha digestion of food. Any ordinary mixed ration contains this element in a quantity sufficient for the animal's needs.

Potassium combined with oxygen and hydrogen gives us the caustic potash of the market. The ashes of all plants contain this element, a familiar illustration of this fact being the potassium carbonate leached from wood ashes by hot water in the old-fashioned way of making soft soap. The saleratus formerly used in bread-making is a potassium compound. This element is found in the flesh of animals, mostly in the form of the phosphate, and is abundantly supplied for the purposes of nutrition by all feeding stuffs that are not by-products.

Sodium is the basal element of common salt, and in this form it is very generally supplied to domestic animals. In this connection, sodium chloride (common salt) is about the only sodium compound we need to mention, for this is the one that serves almost wholly

* See note 1, p. 50. 
as a source of this element to the animal whether it is supplied directly as such or is obtained from the food. Sodium plays an important part in the digestion of food, because it is the basis of certain bile salts and is concerned in other ways in the digestive processes.

Calcium, when united with oxygen, forms lime, which is one of our commonest commercial articles. Large masses of lime rock, or calcium carbonate, exist in many parts of the earth's surface, and every soil contains more or less of lime compounds. As compounds of this element are usually found in plants and in the milk of all animals, normal food nearly always furnishes a supply sufficient to meet the demands of animal life. The growing animal makes a generous use of lime, because in union with phosphoric acid it is the chief building material of the bony framework. A deficiency of food lime is sure to cause abnormal development of the bony structures. With birds, it is especially in demand during egg formation, egg shells being mostly a lime compound.

Iron, one of the elements of living organisms, needs no description, because its common properties are familiar to every one. Iron rust and iron ore are oxides of this element, and when the oxygen is removed from these, we have the bright gray metal of commerce. Though taken up by plants and animals in small quantities only, iron is absolutely essential to their growth and welfare, but because of its abundance the imperative character of the demand is never realized in ordinary experience. 


\section{PROPORTIONS OF THE ELEMENTS IN PLANTS AND}

\section{ANIMALS}

The facts which have been reviewed concerning the elements out of which the tissues of plants and animals are built are properly supplemented by a statement of the proportions in which these are found in living organisms. This information is necessary to an understanding of the relations of supply and demand which exist between the vegetable and animal kingdoms and the raw materials of the inorganic world.

In Plants. - It is estimated by a German scientist, Knop, that if all the species of the vegetable kingdom, exclusive of the fungi, were fused into one mass, the ultimate composition of the dry matter of this mixture would be the following:

Per cent

Carbon.. .......................... 45 .

Oxygen ............................... 42

Hydrogen .......................... 6.5

Nitrogen ............................ 1.5

Mineral compounds (ash) $\ldots \ldots \ldots \ldots \ldots \ldots \ldots \ldots, 5$

The composition of various single species or of parts of a plant, such as the fruit or straw, shows considerable variations from these average figures:

\begin{tabular}{lrrrrr} 
& \multicolumn{4}{c}{ Carbon } & \multicolumn{2}{c}{ Oxygen } & Percentages & & \\
& Hydrogen & Nitrugen & (Ash) \\
Clover hay........ & 47.4 & 37.8 & 5. & 2.1 & 7.7 \\
Wheat kernel.... & 46.1 & 43.4 & 5.8 & 2.3 & 2.4 \\
Wheat straw....... & 48.4 & 38.9 & 5.3 & .4 & 7.0 \\
Fodder beets ..... & 42.8 & 43.4 & 5.8 & 1.7 & 6.3 \\
Fodder beet leaves & 38.1 & 30.8 & 5.1 & 4.5 & 21.5
\end{tabular}


Carbon constitutes a larger proportion of the dry substance of plants than any other element, and there is certainly no species that is an exception to this rule. Oxygen stands next in order, followed by hydrogen, and then nitrogen. It is an important fact in the economy of nature that those elements which, on the average, make up 93.5 per cent of the dry matter of plants have as their main source either the atmosphere or water. Only a small percentage of the dry matter of the farmer's crops is drawn from the soil, and it therefore follows that it is this small proportion of the mass of matter that makes up the inorganic world which sustains the most important economic and financial relations to the farmer's business.

The elements of the ash vary somewhat in different plants. For illustration, their proportions in the dry matter of the maize plant in bloom are given in this connection:

Per cent

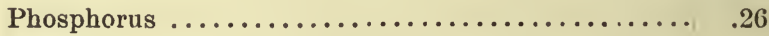

Silicon .............................. 51

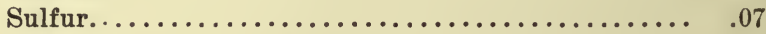

Chlorine ................................$_{29}$

Potassium ........................... 1.78

Sodium ............................. . 19

Calcium............................ .72

Magnesium .......................... . 39

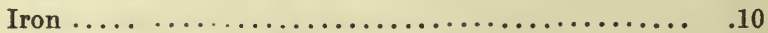

Oxygen combined with the above............ 1.73

Total per cent ... ................ 6.04

In animals.-We are not ignorant of the proportions of the chemical elements in the bodies of our 
larger animals. Lawes and Gilbert, of England, and the Maine Experiment Station, in this country, have made analyses of the entire bodies, or nearly so, of steers and other domestic animals. These results, combined with our knowledge of the constitution of the compounds of the animal tissues, enable us to calculate very closely the proportions of carbon and other elements in the entire body of an ox:

\begin{tabular}{|c|c|c|}
\hline Law & $\begin{array}{l}\text { Fat ox } \\
\text { es and Gilbert } \\
\text { Per cent }\end{array}$ & $\begin{array}{l}\text { Two steers, } 2 \text { yrs. old } \\
\text { Maine Station } \\
\text { Per cent }\end{array}$ \\
\hline Carbon & . 63 & 60 \\
\hline Oxygen $\ldots \ldots \ldots \ldots \ldots \ldots \ldots$ & 13.8 & 14.1 \\
\hline 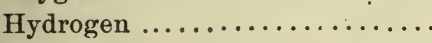 & 9.4 & 9. \\
\hline Nitrogen...$\ldots \ldots \ldots \ldots \ldots$ & 5. & 5.8 \\
\hline Mineral compounds (ash) $\ldots . .$. & 8.8 & 11.1 \\
\hline
\end{tabular}

As the proportion of carbon is much larger in the fats than in the other compounds of the animal body, it is easy to see that the ultimate composition of the ox would vary with his condition, whether lean or very fat. The figures given suffice to show, however, that animals, like plants, contain much more carbon than of any other element, and that the quantities of the remaining elements stand in the same order in the plant and in the animal, the striking differences being the greater proportion of oxygen in the former and of carbon and nitrogen in the latter. The plant and animal are alike, therefore, in consisting chiefly of those elements which are derived from air and water. Carbon, oxygen and hydrogen constitute from 83 to 86 per cent of the bodies of fat oxen and steers, raw materials which nature supplies without cost to the farmer, leav-' 
ing less than one-sixth of the animal to be built from elements that have, in part, a commercial value for crop production, which is the fundamental consideration in animal husbandry.

As has been stated previously, one of these elements, which in its various compounds bears a market value, is nitrogen. The others having commercial importance belong to what is termed the ash of the plant or animal. For this and other reasons it is desirable to consider the elements found in the ash or mineral portion of the animal body. We will return for this information to the analysis of a fat ox made by Lawes and Gilbert. These investigators found that the ash, constituting 8.8 per cent of the dry substance of the entire body, was made up as follows:

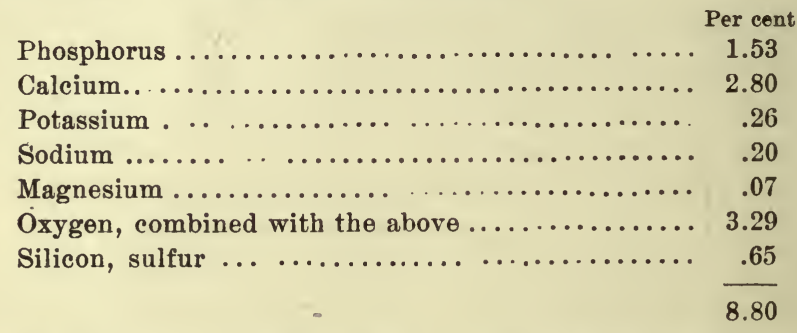

Of the elements other than oxygen which appear in the ash, phosphorus and calcium take a leading place as to quantity, although sulfur, potassium and sodium are essential, even if present in relatively small amounts. Phosphorus, potassium and calcium have a commercial prominence in their agricultural relations, a fact which is to be considered chiefly in their uses as plant-foods. 


\section{CHAPTER IV}

THE COMPOUNDS OF ANIMAL NUTRITION

THE animal body consists primarily of elements, but we ordinarily regard it as made up of compounds. These are groups of elements united in such fixed and constant proportions that they have as uniform properties, under given conditions, as the elements themselves. In discussing the composition and uses of cattle foods and the structure, composition and functions of the animal as an organism, we refer chiefly to the compounds of carbon rather than to carbon itself. To be sure, the investigator of the problems of nutrition often conducts his researches and formulates his conclusions with reference to the elements, but when the information he secures reaches the language of practice, we speak of albuminoids, carbohydrates and fats. Commerce recognizes these compounds also. It is necessary, therefore, for the student of animal nutrition, whether as a scientist or as one who would thoroughly understand the art of feeding, to become well informed about those substances that in various proportions form the organized structure of plants, and that furnish not only the energies that are manifested by animal life, but all the materials out of which animal tissues are built. 
Before passing to a consideration in detail of the proximate constituents of plants and animals, it is desirable to reach a clear understanding of certain broad divisions into which we classify all matter, either living or dead, which has been organized by the vital forces of the various forms of life.

One of the most common and familiar phenomena of the physical world is the destruction of vegetable or animal matter by combustion, with the result that only a small portion of the original material is left behind in visible and solid forms. Fuel, such as wood or coal, is largely consumed when ignited, and we have as a residue the ashes. If we incinerate hay, corn or wheat we get the same result. The gradual decomposition of exposed dead vegetable matter that occurs in warm weather is a process essentially similar to the combustion of fuel, only more prolonged. In view of these facts, it is customary to classify all the tissues of plants and animals into the combustible and incombustible portions, the former being that part of the ignited or decayed substance which disappears in the air as gases, and the latter the residue or ash. It should be well understood that combustion does not involve a loss of matter; only a change into other forms. If we were to collect the gases which pass off from a stick of wood that is burned, consisting mostly of carbon dioxid, vapor of water, ammonia and, perhaps, certain other compounds of nitrogen, we would find that their total weight, plus that of the ash residue, is even greater 
than that of the dry wood, because the carbon and the hydrogen of the wood have taken to themselves from the air, during the combustion, an increased amount of oxygen. The carbon, oxygen, hydrogen and nitrogen of the plant or animal tissue belong to the combustible portion, although small amounts of two of these elements are found in the ash, as it is usually estimated. The remainder of the fifteen elements previously named are supposed to appear wholly in the ash.

The relation in quantity of the combustible and incombustible parts of vegetable and animal dry matter is illustrated below:

\begin{tabular}{|c|c|c|}
\hline & $\begin{array}{c}\text { Combustible } \\
\text { Per cent }\end{array}$ & $\begin{array}{c}\text { Incombustible } \\
\text { (Ash) } \\
\text { Per cent }\end{array}$ \\
\hline 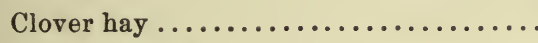 & 92.8 & 7.2 \\
\hline Potato tubers.......... & .. $9 \overline{3} .5$ & 4.5 \\
\hline 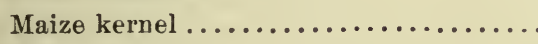 & . $\quad 98.3$ & 1.7 \\
\hline Wheat kernel $\ldots \ldots \ldots \ldots \ldots \ldots \ldots \ldots$ & 98. & 2. \\
\hline 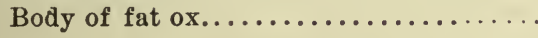 & . 91.2 & 8.8 \\
\hline
\end{tabular}

The significance of these facts in their relation to cattle feeding is, that the chemical change which we call combustion is one of the phenomena of animal nutrition. Substances which may suffer either slow or rapid oxidation outside the animal may undergo complete or partial combustion in the animal; or, stated in another way, the part of the plant which "burns up" in the fireplace or crucible is the part which in general undergoes the same change within the animal organism in so far as the food is digested.

The terms combustible and incombustible are less used, perhaps, than two others, which represent prac- 
tically the same divisions of plant or animal substance; viz., organic and inorganic. In chemical literature, the portion of a plant or animal which suffers combustion is called the organic, and the ash is known as the inorganic part. These terms are evidently based upon the erroneous assumption that the compounds which burn and break up into simpler ones are peculiarly those which sustain necessary and vital relations to life, and are formed through the functions of living organisms. To be sure, the dry substance of the plant is organized chiefly by building up compounds of carbon, oxygen, hydrogen and nitrogen, which suffer combustion; but compounds of sulfur, phosphorus, chlorine, potassium, sodium and calcium are also constant and essential constituents of the juices and tissues of the plant and animal; and, although the latter elements may finally wholly appear in the incombustible part or ash, they have, nevertheless, sustained in other com. binations important relations to nutrition and growth. It is true, however, that the portion of a food material which is commonly spoken of as organic embraces those compounds that furnish practically all the energy which is utilized by animal life and much the larger part of the building material.

\section{THE CLASSES OF COMPOUNDS}

The known compounds that belong to life in all its forms are almost innumerable, and doubtless many are yet to be discovered. These sustain a variety of relations to human needs, some serving as food, some 
as medicine and some in the arts. It is fortunate that comparatively few must be considered in discussing the science and art of cattle-feeding. Moreover, it is convenient that the compounds which play a leading part in animal nutrition are designated, especially for practical purposes, in classes rather than singly, even though this custom tends to more or less looseness of expression and definition.

The same classification is used for the compounds of both the vegetable and animal kingdoms, and it is now customary to divide them into the following groups:

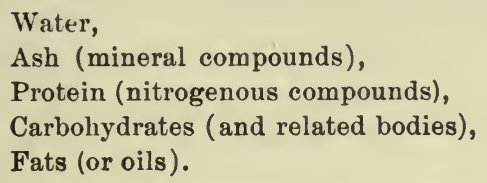

In this instance, accuracy is sacrificed to convenience. The class names have come to be regarded, more or less, as representing entities having fixed properties and functions, whereas each class contains numerous compounds differing widely in their characteristics and in their nutritive value and office. Moreover, these terms have a variable significance as used under different conditions. No one of them except water uniformly represents just the same mixture of compounds when applied to unlike feeding stuffs.

Before passing to a detailed description of these compounds, singly or in groups, it will be well to gain a clear understanding of the relation which the fifteen elements mentioned sustain to these classes of substances. This can be seen most readily by a tabular display: 


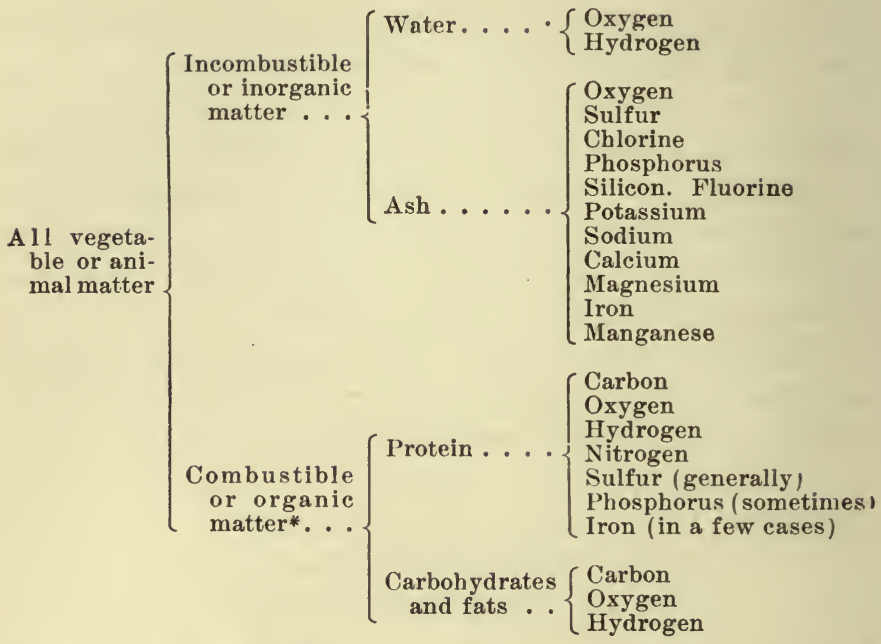

The ash, which, on the average, constitutes about onetwentieth of the plant, and never more than one-tenth of the animal, may contain thirteen of the fifteen elements, while the larger proportion of living matter consists mostly of the compounds of three or four elements, in no case of more than six or seven. From this point of view, it becomes strikingly evident that the dominant elements of life, quantity alone considered, are those derived from the air and water.

\section{WATER}

Water fills a very important place in agriculture. It is everywhere present, generally in some useful way. All plant substance, all animal tissue, foods and nearly 
all the material things with which man comes in contact in his daily life are made up of more or less water, or are associated with it. Sometimes this is very evident, as with green plants or juicy fruits. It is not so evident with straw and cornmeal. If, however, we submit almost any substance, no matter how dry it may appear, except perhaps, glass and metals, to the heat of an oven at $212^{\circ} \mathrm{F}$., we find that a material loss of weight occurs: and if we so arrange that whatever is driven off is first drawn through some substance that entirely absorbs the water which has been vaporized, we learn that the decrease in weight is nearly all accounted for by the water thus collected.

This fact suggests to us the chemist's way of determining the proportion of water which any particular material contains. He weighs out a certain amount of the substance and then keeps it in an oven at $212^{\circ} \mathrm{F}$. for five hours perhaps, after which it is reweighed. The difference in the two weights, or the loss, is assumed to be all water, and the percentage in the original substance is easily calculated. That portion of the material which is left behind after the water is evaporated, we call the dry substance.

Water is associated with plant and animal tissues in two ways, hygroscopically and physiologically. It is easy to illustrate the former way by an object lesson. If an ounce of cornmeal were to be dried in an oven as described, it would, as stated, lose in weight. If it were subsequently allowed to remain exposed in the open air in a barn or out of doors, it would return quite or nearly to its original weight. The loss would 
be due to water driven out, and the gain to water absorbed from the atmosphere, which we call hygroscopic moisture.

All solids attract moisture up to a certain proportion, which varies with the substance and with the conditions that prevail. The surfaces of the particles of matter are ordinarily covered with a thin film of water, which is thicker on a cold, wet day than on a warm, dry day, and so the same quantity of hay or grain weighs less at one time than at another, because the percentage of hygroscopic water varies. An equilibrium will always be established between the attraction of a substance for moisture and the tension of the vapor of water in the surrounding air, which accounts for the effect of temperature and of the degree to which the air is saturated with water vapor. As all substances do not have the same attraction for moisture, therefore, under similar atmospheric conditions, one feeding stuff may retain more water than another.

Water that is held physiologically is that which is a constant and essential part of living organisms, in which relation it is necessary to life and performs certain important functions. These functions are of three kinds: (1) The presence of water in the tissues of plants and animals gives them more or less firmness or rigidity combined with elasticity; (2) water acts as a food solvent; (3) water is the great carrier of food materials and of waste products from one part to another of the vegetable or animal organism. 
Water in living plants. - Water constitutes a large proportion of the weight of all living plants, especially during the period of active growth. The cured hay, as any farmer's boy knows, weighs much less than did the green grass when it was cut, and this loss in weight is due almost wholly to evaporation of water from the tissues of the plant under the influence of the sun and wind. This water, which is contained in the tubes and intercellular spaces of the stalk or leaf, is exactly the same chemical compound as pure water found anywhere else, and has no more value for the animal, excepting that it is pure and is not subject to the contamination which sometimes occurs in streams and wells. There is no such thing as the so-called natural water of plants, and which has a peculiar nutritive value or function. Vegetation water should be distinguished from sap or plant juice. Sap is more than water; it is water holding in solution certain substances such as sugars and mineral salts. When the plant is dried, these soluble compounds do not pass off, but remain behind as part of the dry matter.

The proportion of water in plants varies greatly in different species, and in the same species according to the stage of growth or the surrounding conditions. These facts have more importance than is generally recognized, because the food value of vegetable substances is influenced by the proportion of dry matter. It is always necessary to know the percentage of water in a green plant before we can estimate its worth for feeding purposes.

The variations in water content of the living tissues 
of different species of plants or parts of plants is well illustrated by the following figures:

\section{Water in green plants}

Pasture grass (mixed) ................... 80

Timothy grass ........................ 61.6

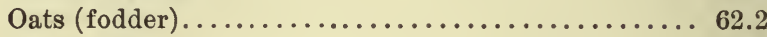

Rye (fodder).......................... 76.6

Sorghum (fodder) ...... . . . . . . . . . . . 79.4

Fodder corn, dent, kernels glazed............ 73.4

Fodder corn, flint, kernels glazed............ 77.1

Red clover ........................ 70.8

Alfalfa.............................. 71.8

Horse bean.......................... 84.2

Potatoes (tubers) .................... 78.9

Beets (mangels)....................... 90.9

Turnips ............................ 90.5

Immature plants contain more water than older or mature ones. Young pasture grass is more largely water than the same plants would be after the seed is formed. This fact is consistent with the very rapid transference of building material during the active stages of growth. Analyses of samples of timothy grass cut at the Maine State College in 1879 , and at the Pennsylvania State College in 1881 show the marked influence of the stage of growth upon the water content of the living plant:

\section{Timothy}

Nearly headed out ..................... 78.7

In full blossom........................ 71.9

Out of blossom ............................ 65.2

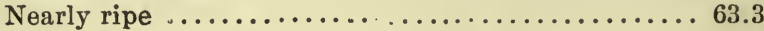


Pennsylvania State College

Percentage of water

Highly No manured manure

Cut June 6, heads just appearing ........ $79.7 \quad 76.5$

Cut June 23, just beginning to bloom ..... $69.7 \quad 69.1$

Cut July 5, somewhat past full bloom ..... $61.4 \quad 60$

What is true of timothy is probably true of all forage crops in the perfectly fresh state. We have here an explanation of the difficulty of curing early cut grass. When the farmer begins haying, at least two drving days are needed in order to secure a product that will not ferment in the mow, while later in the season, grass eut in the morning may be safely stored in the mow before night. At the Maine State College in 1880, immature timothy grass lost 56.7 per cent weight in curing and the ripe grass only 12.9 per cent. The extreme succulence of immature corn and other crops previous to the formation of seed, is a fact which the dairyman who feeds soiling crops must consider if he would uniformly maintain a ration up to the desired standard.

The proportion of water in plants is influenced also by the lack or excess of soil moisture. The soil and not the atmosphere is the source of supply of vegetation water, which, taken up by the roots, traverses the plant and passes into the atmosphere through the leaves. If the supply is abundant, the tissues are constantly fully charged, but if, by reason of drought, the soil becomes very dry, the outgo of water by evaporation may exceed the income. What farmer has not seen his corn with rolled leaves during an August drought! The vegetation water had fallen below the 
normal, or below what was necessary to maintain the tissues in their usual condition of rigidity.

This leads to the observation that the water in a growing plant is that which is in transit from the soil to the air. This liquid stream enters the plant with its load of building materials, takes into solution the compounds elaborated in the leaves and aids in transporting them to the points of rapid growth, finally passing into the air from the surface of the foliage. Throughout the entire growing season, the plant acts as a pump, drawing from below through the roots the water which it needs for various purposes, and discharging it into the air. It was found that in Wisconsin 309.8 tons of water was evaporated by the plant for each ton of dry matter in the crop. Four tons of dry matter per acre is not an unusual product with maize, requiring $1,239.2$ tons, or 10.4 inches of water for its growth, the equivalent of about five-eighteenths of an average annual rainfall. This is a fact of great significance to the stock feeder. His success begins with proper husbanding of the plant-food resources of the farm. of which water is an important factor.

Water in feeding stuffs. - Cattle foods, whether in the green or air-dry condition, always contain more or less water. The proportion is greatly variable, depending upon several factors. With the green foods, the range of percentages is similar to that of the living plants previously noted. As, however, forage plants are used at varying lengths of time after cutting, and as a loss of moisture begins immediately after the plant is severed from its source of water supply, the amount of 
dry matter in a green cattle food is somewhat uncertain, unless a water determination is made in the material exactly as it is fed. In all experimental work this precaution is necessary to accuracy. Roots and potatoes contain a large proportion of water, which, owing to their structure, is slowly evaporated. In a cool, moist cellar, their water content will remain practically unchanged for a long time. In a warm, dry room evaporation occurs and they shrivel and lose weight.

The water content of air-dry foods varies with the condition in which they were stored, the length of time after storage and the percentage of moisture in the air. Early cut hay often goes to the barn less perfectly cured than the late cut, and all hay dries out more than is generally realized during the first few months of storage. Concerning these points, the writer has obtained data through experiments at the Maine State and Pennsylvania State Colleges. Fourteen lots of hay, some early cut and some late cut, were weighed when stored and after remaining in the barn for several months. The results follow:

\begin{tabular}{|c|c|c|c|c|c|c|c|}
\hline & & \multicolumn{3}{|c|}{ Early cut } & \multicolumn{3}{|c|}{ Late cut } \\
\hline & & $\underset{\text { stored }}{\mathrm{As}}$ & $\begin{array}{c}\text { After } \\
\text { several } \\
\text { months }\end{array}$ & $\begin{array}{l}\text { Per cent } \\
\text { loss }\end{array}$ & $\underset{\text { stored }}{\text { As }}$ & $\begin{array}{l}\text { After } \\
\text { several } \\
\text { months }\end{array}$ & $\begin{array}{l}\text { Per cent } \\
\text { loss }\end{array}$ \\
\hline Timothy, &, $1881 \ldots$ & 3634 & 2307 & 36.5 & 4234 & 3390 & 19.9 \\
\hline “" & $1882 \ldots$ & 3634 & 2556 & 29.7 & 3802 & 3168 & 16.7 \\
\hline ، & $1881 \ldots$ & 5000 & 3922 & 21.6 & 5270 & 4035 & 23. \\
\hline ، & $1882 \ldots$ & 3570 & 3037 & 14.9 & 4017 & 3413 & 15. \\
\hline Clover, & $1882 \ldots$ & 2110 & 1215 & 42.4 & 1520 & 1130 & 25.6 \\
\hline Timothy, & , $1888 \ldots$ & 2815 & 2470 & 12.2 & 2790 & 2420 & 13.3 \\
\hline ““ & $1889 \ldots$ & 5070 & 4225 & 16.6 & 6208 & 5086 & 18.1 \\
\hline
\end{tabular}


It is probable that hay seldom loses less than oneeighth of its weight during storage, and often much more.

As illustrating the variations in the proportions of water in hay due to changes in air moisture, reference is made to observations by Professor Atwater. He found that dry hay hung in bags in a barn varied in water content between 7.5 per cent and 13.6 per cent during the months of May, June and July. Hay in large masses would change less, but would be affected, doubtless, by long periods either of very dry weather or very wet.

The proportion of moisture in coarse foods and grains has much to do with their preservation in a sound condition. New hay and grains when packed in large masses are subject to fermentations, which injure their quality and diminish their food value. This is due to the fact that sufficient moisture is present to allow the growth of low forms of life with certain attendant chemical changes. Feeding stuffs containing 20 per cent or more of water,-and this is likely to be the case with clover, rowen, field-cured cornfodder and stover, new oats and new corn,-when stored in large quantities are almost certain to heat and become musty or moldy, always involving a loss of nutritive value, a result wholly due to the large proportion of water present.

Water in the animal.-Water is an important and abundant constituent of animal organisms, from the lowest to the highest forms. The blood, which is from one-thirtieth to one-twentieth the weight of the bodies of farm animals, is at least four-fifths water, while the 
soft tissues have been found to contain from 44 per cent to 75 per cent, according to the species and condition of the animal. The most extensive and complete analyses so far made of the entire bodies of animals were performed by Lawes and Gilbert at Rothamsted, England. In this country four steers were analyzed at the Maine Experiment Station, and in the study of human nutrition problems many determinations of water have been made in the carcasses of bovines, swine, sheep, poultry and game. The figures are as follows:

\section{Water in entire body}

Per cent

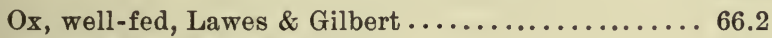

$\mathrm{Ox}$, half fat, Lawes \& Gilbert............. 59

Ox, fat, Lawes \& Gilbert.................. 49.5

Steer, 17 months old, medium fat, M. E. S. ...... 59.

Steer, 17 months old, medium fat, M. E. S........ 56.3

Steer, 27 months old, fat, M. E. S. .......... 51.9

Steer, 27 months old, fat, M. E. S. ........... 52.2

Calf, fat, Lawes \& Gilbert ................. 64.6

Sheep, lean, Lawes \& Gilbert.............. 67.5

Sheep, well-fed, Lawes \& Gilbert ............. 63.2

Sheep, half fat, Lawes \& Gilbert ............ 58.9

Sheep, fat, Lawes \& Gilbert ............... 50.9

Sheep, very fat, Lawes \& Gilbert.............. 43.3

Swine, well-fed, Lawes \& Gilbert............ 57.9

Swine, fat, Lawes \& Gilbert ............... 43.9

Chicken, flesh ......................... 74.2

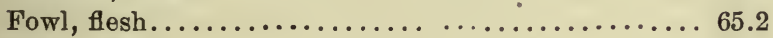

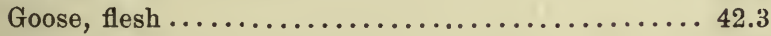

Turkey, flesh....................... 55.5

It is very evident that, in general, considerably more than half of the weight of the bodies of our domestic 
animals consists of water, the limits observed in all species and conditions here mentioned being 42.3 per cent and 67.5 per cent.

The percentage of water varies with the species, age and condition. Swine carry a notably small proportion. The calf's body, even though fat, is comparatively watery. It is very noticeable that with oxen, sheep and swine the lean animals contain a much larger proportion of water than the fat. This does not mean that in the process of fattening the fat is substituted for water, and so expels it from the organism, but that the increase has a much smaller percentage of water than the body in its original lean condition. This is well illustrated by the data from two independent investigations at Rothamsted and at the Mane Experiment Station. The former investigation showed that when swine, sheep and oxen are fattened the increase contained from 20 per cent to 24 per cent of water, this being half the proportion found in the entire bodies of the lean animals. The Maine Station results established the fact that in the increase of two steers from the age of 17 months to 27 months, during which time a fattening ration was fed, there was 42 per cent of water, the bodies of the younger steers having 58.2 per cent. It is a common remark among unscientific people that beef from mature animals "spends" better than that from young, the same observation being made in comparing lean and fat beef. Modern investigation shows clearly that the reason for this lies partly in the difference in water content. Dry matter, and not water, is the measure of food value. 
ASH

The ash or mineral part of plants or animals occupies a minor place in the discussions which pertain to the principles and problems of animal nutrition. Much is said and written about the carbon compounds of living organisms, but the compounds of the mineral world, in their relation to foods and to the processes of growth, are generally passed by with brief comment, much less than would be profitable. It is certainly desirable to gain a clear understanding of the combinations, distribution and functions of these bodies. Their importance as necessary constituents of foods and animals is no less than pertains to the carbon compounds, although their scientific and commercial prominence as related to animal nutrition is much less.

As previously stated, the mineral portion of a plant or animal is measured by the ash or residue after combustion, the principal ingredients of which are the following:

Acids

Hydrochloric acid....HCl.

Sulfuric acid .. ... $\mathrm{H}_{2} \mathrm{SO}_{4}$

Phosphoric acid ...... $\mathrm{H}_{6} \mathrm{P}_{2} \mathrm{O}_{8}$

Silicic acid........... $\mathrm{SiO}_{2}$

Carbonic acid .......... $\mathrm{CO}_{2}$
Bases

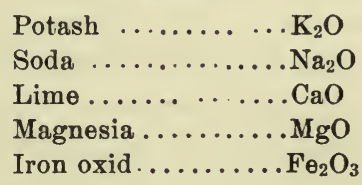

Other mineral compounds are found in the various forms of vegetable life, but those mentioned are all that we need to discuss at length.

The acids and bases do not exist in the ash as 
shown, but they are united to form salts, and so we have the chlorides, sulfates, phosphates, and carbonates of potassium, sodium, calcium and magnesium. These are nearly all familiar objects in common life, as, for instance, sodium chloride (common salt), potassium chloride (the muriate of potash of the market), potassium sulfate (the sulfate of potash of the market), calcium sulfate (of which gypsum or land plaster is composed), calcium phosphate (burned bone is chiefly this compound), potassium phosphate (a compound of phosphoric acid and potash found chiefly at the druggist's) and calcium carbonate (limestone). It should be remembered that the compounds in the ash are not necessarily those of the plant or animal. During the process of ignition of plant or animal substance, organic compounds are broken up, certain acid and basic elements of which enter into combination in the salts of the ash. Much of the lime in the ash is in union with carbonic acid, which in the plant may have been associated with vegetable acids, such as oxalic and tartaric, and at least part of the sulfur and phosphorus of the ash comes from the nitrogen compounds.

The salts of the ash differ greatly in their properties. Some are soluble in water, others are not. To the former class belong all the chlorides, and the potassium and sodium sulfates and phosphates. The normal phosphates of calcium and magnesium are insoluble in water, but soluble in various acids. These facts are important in showing what salts may be found in the plant and animal juices, and what effect leaching with 
water or other solvents might have upon the inorganic portion of eattle foods.

The ash compounds of plants.-Upon incineration all plants and feeding stuffs yield an ash residue which has been termed the mineral part of the plant. The ash elements are important in this connection because they are the main source of the same elements of the animal body. These may be held in plant tissue in three ways: in organic combinations and as the inorganic salts of plant solutions, crystals and incrustations. Outside of phosphorus and sulfur, comparatively little is known of the relations to plant structure of the important ash elements, such as potassium, calcium and magnesium. Their place as bases in organic structures is not well understood.

The ash from different plants and feeding stuffs is by no means uniform in composition and quantity, even in the same species or class of materials, although with the grains there is some degree of uniformity in this respect. Certain factors cause variations, such as species, stage of growth, fertility, the part of the plant, manner of euring or treatment of a feeding stuff and changes due to manufacturing processes, and the variations which exist pertain not only to the amount of ash but also to its composition.

Variations due to species. - Different species of plants, and consequently different feeding stuffs, are greatly unlike in their content of mineral matter. The figures on following page illustrate this fact, further confirmation of which may be had by consulting the table in the appendix: 


\begin{tabular}{|c|c|c|}
\hline & $\begin{array}{l}\text { No of } \\
\text { analyses }\end{array}$ & $\begin{array}{l}\text { Per cent } \\
\text { ash }\end{array}$ \\
\hline Mixed grasses & 106 & 7. \\
\hline 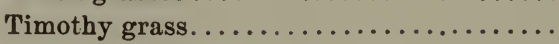 & 9 & 6.8 \\
\hline English ray grass $\ldots \ldots \ldots \ldots \ldots \ldots \ldots$ & 11 & 12.1 \\
\hline Red clover, in bloom ................ & 113 & 6.9 \\
\hline White clover, in bloom ............... & 4 & 7.3 \\
\hline 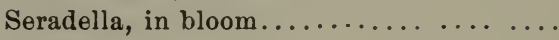 & 3 & 9.8 \\
\hline 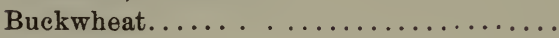 & 17 & 8.2 \\
\hline 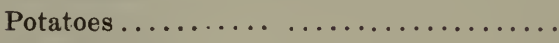 & 59 & 3.8 \\
\hline Sugar beets $\ldots \ldots \ldots \ldots \ldots \ldots \ldots \ldots$ & 149 & 3.8 \\
\hline Mangel-wurzel ........... & 19 & 7.6 \\
\hline 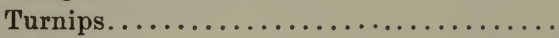 & 32 & 8. \\
\hline Carrots $\ldots \ldots \ldots \ldots \ldots \ldots \ldots \ldots \ldots$ & 11 & 5.8 \\
\hline 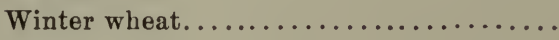 & 110 & 2. \\
\hline Oats $\quad \ldots \ldots \ldots \ldots \ldots \ldots \ldots \ldots \ldots \ldots \ldots \ldots$ & 57 & 3.1 \\
\hline 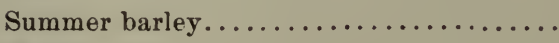 & 57 & 2.6 \\
\hline Maize $\ldots \ldots \ldots \ldots \ldots \ldots \ldots \ldots \ldots$ & 15 & 1.4 \\
\hline 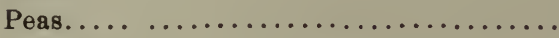 & 40 & 2.7 \\
\hline Field beans...... $\ldots \ldots \ldots \ldots \ldots \ldots$ & 19 & 3.6 \\
\hline
\end{tabular}

It is important to know that these variations pertain not alone to the quantity of ash but to the proportions of compounds which it contains:

The mineral compounds of plants and feeding stuffs (per cent in the dry matter)

\begin{tabular}{|c|c|c|c|c|c|c|c|c|}
\hline $\begin{array}{l}\text { Pot- } \\
\text { ashl }\end{array}$ & Soda & Lime & $\begin{array}{l}\text { Mag- } \\
\text { nesia }\end{array}$ & $\begin{array}{c}\text { Iron } \\
\text { oxide }\end{array}$ & $\begin{array}{l}\text { Phos- } \\
\text { phoric } \\
\text { adid }\end{array}$ & $\begin{array}{l}\text { Sul- } \\
\text { furic } \\
\text { acid }\end{array}$ & Siliea & $\begin{array}{c}\text { Chlor- } \\
\text { ine }\end{array}$ \\
\hline Mixed grasses......1.86 & .26 & 1.11 & .48 & .11 & .50 & .36 & 2. & .43 \\
\hline Timothy hay .....2.37 & .12 & .55 & .22 & .06 & .80 & .19 & 2.19 & .35 \\
\hline Red clover in bloom 2.21 & .13 & 2.39 & .75 & .07 & .66 & .22 & .18 & .26 \\
\hline White clover.......1.57 & .53 & 2.21 & .69 & .15 & .94 & .54 & .33 & .31 \\
\hline Alfalfa.............1.74 & .13 & 3. & .36 & .14 & .63 & .42 & .70 & .22 \\
\hline $\begin{array}{c}\text { Buckwheat .......2.54 } \\
\text { Roots }\end{array}$ & .19 & 3.32 & 1.09 & .12 & .50 & .30 & .09 & .06 \\
\hline Potatoes..........2.27 & .11 & .10 & .19 & .04 & .64 & .25 & .08 & .13 \\
\hline Sugar beets.......2.03 & .34 & .23 & .30 & .04 & .47 & .16 & .09 & .18 \\
\hline Eodder beets .....3.96 & 1.23 & .28 & .83 & .06 & .65 & .23 & .15 & .75 \\
\hline 'Turnips ...........3.64 & .79 & .85 & .30 & .06 & 1.02 & .90 & .15 & .41 \\
\hline Carrots.........2.02 & 1.16 & .62 & .24 & .05 & .70 & .35 & .13 & .25 \\
\hline
\end{tabular}




\begin{tabular}{|c|c|c|c|c|c|c|c|c|}
\hline $\begin{array}{l}\text { Pot- } \\
\text { ash }\end{array}$ & Soda & $\operatorname{Lim} \theta$ & $\begin{array}{l}\text { Mag } \\
\text { nesia }\end{array}$ & $\begin{array}{l}\text { Iron } \\
\text { oxide }\end{array}$ & $\begin{array}{l}\text { Phos. } \\
\text { phoric } \\
\text { acid }\end{array}$ & $\begin{array}{l}\text { Sul- } \\
\text { furic } \\
\text { acid }\end{array}$ & Silica & $\begin{array}{l}\text { Chlor- } \\
\text { ine }\end{array}$ \\
\hline Winter wheat ..... 61 & .04 & .06 & .24 & .03 & .93 & .01 & .04 & \\
\hline Oats .............56 & .05 & .11 & .22 & .04 & .80 & .06 & 1.22 & .03 \\
\hline Summer barley.... .56 & .06 & .07 & .23 & .03 & .92 & .05 & .68 & .03 \\
\hline Maize kernel .......43 & .02 & .03 & .22 & .01 & .66 & .01 & .03 & .01 \\
\hline Peas ............1.18 & .03 & .13 & .22 & .02 & .98 & .09 & .02 & .04 \\
\hline Field beans........1.51 & .04 & .18 & .26 & .02 & 1.41 & .12 & .02 & .06 \\
\hline
\end{tabular}

We cannot fail to observe as we study these figures that potash, lime and phosphoric acid are the prominent mineral compounds of the plant ash, and consequently it is with them that we find the important variations. The true grasses differ from the clovers and related plants in containing much less lime and greatly more silica, the phosphoric acid and potash not being greatly unlike in the two cases. As a source of lime, then, the clover hay is superior. Potatoes and roots are richer in potash and poorer in lime than are the coarse fodders. The grains with hulls contain much silica, and those like wheat and corn but little. The seeds of the legumes are richer in potash and lime than those of the grasses. The maize kernel is especially poor in lime.

The distribution of mineral compounds in the different parts of the plant.-Because the farmer separates his crops into grain and straw, and the manufacturer goes farther and divides the grain into parts, thus modifying the character of feeding stuffs, it is worth while to know just how the mineral compounds are distributed in the stalk, leaves and fruit, especially of the cereal grain plants. A comparison of the straws and grains shows striking dissimilarities: 


\section{Per cent in the dry matter}

\begin{tabular}{|c|c|c|c|c|c|c|c|c|c|c|}
\hline Wheat & $\begin{array}{l}\text { Total } \\
\text { ash }\end{array}$ & $\begin{array}{l}\text { Pot- } \\
\text { ash }\end{array}$ & Soda & $\operatorname{Lim} \theta$ & $\begin{array}{l}\text { Magne- } \\
\text { sium }\end{array}$ & $\begin{array}{l}\text { Iron } \\
\text { oxide }\end{array}$ & $\begin{array}{l}\text { Phos- } \\
\text { phoric } \\
\text { acid }\end{array}$ & $\begin{array}{l}\text { Sul- } \\
\text { furic } \\
\text { acid }\end{array}$ & Silica & $\begin{array}{c}\text { Chlor- } \\
\text { ine }\end{array}$ \\
\hline Straw..... & . 5.4 & .73 & .07 & .31 & .13 & .03 & .26 & .13 & 3.62 & .09 \\
\hline $\begin{array}{c}\text { Kernel..... } \\
\text { Oats }\end{array}$ & . 2. & .61 & .04 & .06 & .24 & .03 & .93 & .01 & .04 & \\
\hline Straw..... & . 7.2 & 2.07 & .24 & .50 & .26 & .08 & .33 & .23 & 3.34 & .31 \\
\hline $\begin{array}{c}\text { Kernel..... } \\
\text { Mraize }\end{array}$ & . 3.1 & .56 & .05 & .11 & .22 & .04 & .80 & .06 & 1.22 & .03 \\
\hline Straw...... & . 5.3 & 1.93 & .06 & .58 & .30 & .12 & .44 & .28 & 1.53 & .07 \\
\hline $\begin{array}{c}\text { Kernel...... } \\
\text { Peas }\end{array}$ & . 1.4 & .43 & .02 & .03 & .22 & .01 & .66 & .01 & .03 & .01 \\
\hline Straw..... & . 5.1 & 1.17 & .21 & 1.89 & .41 & .09 & .41 & .32 & .35 & .29 \\
\hline Kernel..... & 2.7 & 1.18 & .113 & .13 & .22 & .02 & .98 & .09 & .02 & .04 \\
\hline
\end{tabular}

In the first place, the straws contain more mineral matter than the grains. It is very evident also that in the straws there is much more potash, lime and silica than in the grains, while phosphoric acid in most cases exists in larger proportions in the latter.

The roots and leaves of beets and turnips present a striking difference in mineral content:

\section{Per cent in the dry matter}

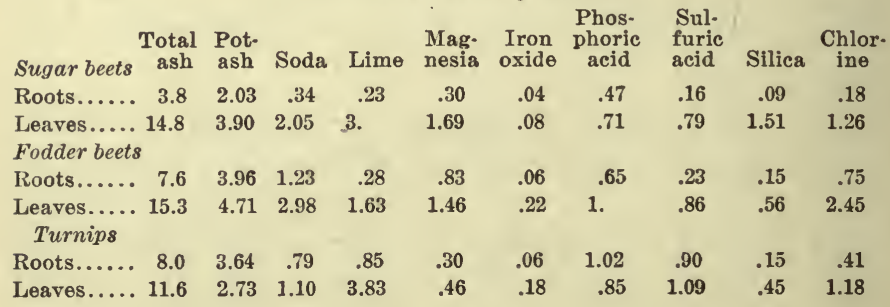

There appears to be a tendency for mineral compounds to accumulate in the leaves of plants, and leafy plants are, as a rule, those which appropriate these most freely. 
The ash of the outside of the stem and of the husks of seeds is in relatively large proportions, due sometimes to an excess of silica. Husked rice kernels contain not over .5 per cent of ash, while the husks contain 39 per cent or over.

Influence of manufacturing processes on the ash constituents. - The cattle food market is abundantly supplied with the residues from certain manufacturing industries, such as milling, brewing and starch production. The most prominent waste product is wheat bran. As this is the outside of the kernel, we would naturally expect, in view of the previous statements, that it would be rich in mineral compounds, and we find such to be the case. The wheat kernel contains about 2 per cent of ash, wheat bran about 6 per cent and wheat flour about .5 per cent. Bran may become, therefore, an important source of mineral compounds in the ration. In brewing, the kernels of barley are subjected to a leaching process, which results in taking out the soluble mineral salts, chiefly the salts of the alkalies, potash and soda, leaving behind, in part, the compounds of lime and magnesia. This fact is made clear by comparing the analysis of the ash of barley with that of brewer's grain:

\begin{tabular}{|c|c|c|c|c|c|}
\hline \multicolumn{6}{|c|}{ Partial composition of ash (per cent) } \\
\hline & Potash & Soda & Lime & $\begin{array}{l}\text { Mag- } \\
\text { nesia }\end{array}$ & $\begin{array}{l}\text { Phos. } \\
\text { acid }\end{array}$ \\
\hline Summer barley. & .56 & .06 & .07 & .23 & .92 \\
\hline Brewer's grains... & .15 &.- & .64 & .45 & 1.69 \\
\hline
\end{tabular}

As a source of phosphoric acid and lime the brewer's grains are more efficient, pound for pound, than 
the original barley grains. Much the same thing occurs in the manufacture of starch and glucose from the maize kernel, as in brewing, for the ground grains are either treated with water or with dilute acid. As the salts in the maize kernel are largely those soluble in water, the gluten meals and feeds, which are the residues, have a very small proportion of ash, not over half that in the original kernel. Analyses show that the potash is practically all extracted, and that the phosphoric acid is materially diminished.

The mineral compounds of animal bodies. - The mineral compounds of animals are nearly similar in kind to those of plants, but are very different in relative proportions. This is made plain by a comparison of the figures given below:

\section{Ash in plants and animals (per cent)}

\begin{tabular}{|c|c|c|c|c|c|c|c|c|c|}
\hline Dry substance & Total & $\begin{array}{l}\text { Pot- } \\
\text { ash }\end{array}$ & Soda & Lime & $\begin{array}{l}\text { Mag- } \\
\text { nesia }\end{array}$ & $\begin{array}{l}\text { Phos. } \\
\text { acid }\end{array}$ & $\begin{array}{l}\text { Sul. } \\
\text { acid }\end{array}$ & $\begin{array}{l}\text { Silicic } \\
\text { acid }\end{array}$ & $\begin{array}{c}\text { Chlor- } \\
\text { ine }\end{array}$ \\
\hline Timothy hay .. & 6.8 & 2.4 & .12 & .55 & .22 & .80 & .19 & 2.2 & .35 \\
\hline Maize kernel .. & 1.4 & .43 & .02 & .03 & .22 & .66 & .01 & .03 & .01 \\
\hline $\begin{array}{l}\text { Wheat kernel.. } \\
\text { Fresh bodies }\end{array}$ & 2.0 & .61 & .04 & .06 & .24 & .93 & .01 & .04 & \\
\hline Fat ox......... & 3.9 & .14 & .12 & 1.74 & .05 & 1.56 & & .01 & \\
\hline Fat sheep ..... & 2.9 & .14 & .13 & 1.19 & .04 & 1.13 & & .02 & \\
\hline Fat swine ..... & 1.8 & .10 & .07 & .77 & .03 & .73 & & & \\
\hline
\end{tabular}

Potash is much less prominent in the composition of the animal than is the case with plants, and phosphoric acid and lime are much more so. In general, more than 80 per cent of the ash of the animal body consists of phosphoric acid and lime in combination as calcium phosphate, whereas these two compcunds constitute less than one-fifth of the ash of 
hay and less than one-half of the ash of maize and wheat kernels.

The distribution of inorganic compounds in the animal body. - The bones contain a very large proportion of the ash constituents found in the animal body, the soft parts being poor in mineral salts. Usually the ash makes up between 60 and 70 per cent of bone, and the bony framework is from 6 to 9 per cent of the entire bodies of domestic animals. More than 80 per cent of the ash of bone is calcium phosphate, which is associated with ealcium carbonate, calcium fluoride, calcium chloride and magnesium phosphate.

The bones of all species of animals show a remarkable similarity of composition, the average of which would not be far from the following:

\section{In 100 parts of the ash of bone (average)}

Calcium phosphate................... 83.9

Calcium earbonate....................... 13.

Calcium in other combinations .............. $\quad .35$

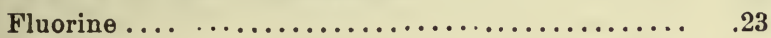

Chlorine............................. $\quad .18$

$\overline{97.66}$

The muscular tissue and other soft parts of the animal body contain less than 1 per cent of incombustible bodies. The ash of flesh is mostly phosphoric acid and potash, accompanied by comparatively small amounts of soda, lime and magnesia and minute quantities of chlorine and iron. Unquestionably, potassium phosphate is the predominating salt in flesh, as calcium phosphate is in bone. 
The blood contains a variety of mineral substances, the chief of which is sodium chloride, or common salt, although a minute amount of iron is present, having a most important function. In the bile, soda is abundant, combined mostly with the peculiar organic acids of this secretion. Chlorine is a constant constituent of the gastric juice, its presence as chlorhydric acid being essential to digestion. The preceding are some of the prominent facts concerning the inorganic compounds of the animal body, but they are only a brief suggestion of the knowledge which pertains to this part of animal chemistry.

Note 1.-Recent studies by Hart and Patten demonstrate the absence of inorganic phosphorus compounds in the grains. Straw, and by-product feeding stuffs that have been submitted to fermentations and other treatment, may contain appreciable amounts of inorganic phosphorus.

NOTE 2.-Certain important elements of the ash, including at least potassium, sodium, calcium and magnesium, sustain basic relations to organic compounds in the plant and animal, but in what proportions and to what extent we do not well understand. 


\section{CHAPTER V}

THE COMPOUNDS OF ANIMAL NUTRITION, CONTINUED - THE NITROGEN COMPOUNDS

THE nitrogen compounds of the vegetable and animal kingdoms have received much attention from scientific investigators and writers during the past fifty years. It is quite the custom to declare that certain members of this class cf substances are the ones most important in the domain of animal nutrition, and many writers give to protein so prominent a place in discussing the relative value of feeding stuffs as to almost ignore the other nutrients. Certain investigators claim, on the other hand, that from the standpoint of results in practice the function and relative value of protein have been unduly magnified. Whatever may be the correct view concerning these antagonistic opinions, it is very evident that the present tendency is towards a fuller discussion of the office and value of the non-nitrogenous bodies.

There can scarcely be any disagreement, however, concerning the general proposition that protein plays a leading part in the processes and economy of animal nutrition. This is true for several reasons:

(1) The nitrogen compounds are those fundamental to the energies of the living cells which make up the tis- 
sues of plants and animals. The basic substance of the active cell is protoplasm, a complex nitrogenous body, which Huxley called "the physical basis of life." Around this primal substance seem to center all vital activities, especially the transformation of the raw materials of the inorganic world into the organized structures of life.

(2) These compounds are structurally essential to the growth of living tissues and to the formation of milk. The significance of this fact is intensified by their paucity in many of the feeding stuffs that are ordinarily produced on the farm.

(3) Nitrogen combinations suitable for use as plant and animal food have reached a position of great commercial importance. They are the most costly of all the plant-building materials, the significance of which is intensified by their scarcity in the soil in useful forms, and by their easy passage beyond reach either through chemical changes which liberate the nitrogen, or through leaching from the soil. Nitrogenous feeding stuffs also bear relatively high market prices.

\section{PROTEIN}

For the sake of brevity and convenience, the nitrogen compounds of cattle foods, both vegetable and animal, are designated as a class by the single term protein. When, therefore, it is stated that a feeding stuff contains a certain percentage of protein, reference is made to the total mass of nitrogen compounds present, which may be many in number and of greatly differing characteristics. 
It should be stated, by way of preliminary explanation, that, in the past, the proportion of protein (total nitrogen compounds) in a feeding stuff has been ascertained by determining the total amount of nitrogen and then multiplying its percentage number by the factor 6.25. This method is based on the assumption that the average percentage of nitrogen in protein compounds is sixteen, which is not true to so close a degree of approximation as was formerly believed to be. the case. It may happen in some instances that a determination made in this way is sufficiently accurate, while in other cases the margin of error is large. Recent investigations with perfected methods show percentages of nitrogen in the numerous single proteid substances found in the grains ranging from 15.25 to 18.78. These are largest in certain oil seeds and lupines and smallest in some of the winter grains. Ritthausen, a prominent German authority, concedes that the factor 6.25 should be discarded, and suggests the use of 5.7 for the majority of cereal grains and leguminous seeds, 5.5 for the oil and lupine seeds, and 6.00 for barley, maize, buckwheat, soja bean, and white bean (Phaseolus), rape, and other brassicas. Nothing short of inability to secure greater accuracy justifies the longer continuance of a method of calculation which is apparently so greatly erroneous.

As previously stated, protein is the accepted name for a class of compounds. Just how there came about such a grouping of a large number of substances under a single head it is not necessary to consider in this connection, but it should be made clear that the individual 
compounds which are included under this term are in part so unlike in chemical and physical properties as to warrant the assertion that they have nothing in common except that they contain nitrogen; and we may believe that their unlikeness in composition is no greater than the differences in their uutritive functions.

It is very evident that it is not only convenient, but necessary, to classify such a heterogeneous group of bodies into subdivisions more nearly alike in their characteristics. When we come to consider doing this we discover a most unfortunate confusion of terms. Our leading chemists evidently have reached no agreement in this matter, and so we find almost as many ways of dividing the nitrogenous compounds of plant and animal life as there are prominent writers.

Nevertheless, some system of classification must be used in this connection, and perhaps none is more convenient or logical than the one reported by a committee on nomenclature, representing the Association of Agricultural Colleges and Experiment Stations.

The classification given here is essentially this one, although there are included in it certain distinctions very clearly set forth by Professor Atwater in a paper associated with the above-mentioned report.

In the arrangement adopted it is recognized that certain nitrogen bodies included under protein are so unlike the main and important members of this group as to be properly styled non-proteid. It is also conceded that there are simple or native proteids which seem to stand in the relation of "mother" substances to a large number of protein bodies that have been 
modified either by various external agencies, or are the result of a union of proteids with compounds of another class. More than all, the classification here used seems to be fairly well adapted to the effort of making clear to the beginner or unscientific reader this most difficult division of our subject. No apology is offered for the hard names that ars used. They are the only ones available, and as they have the merit of conciseness, it is hoped that in time they will come into an intelligent popular use. These are:

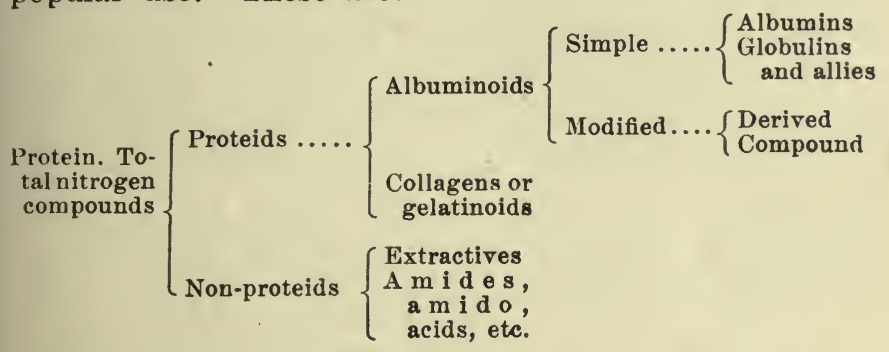

Other nitrogen compounds are included with the protein by the present methods of estimation, such as alkaloids and nitrates, but these are so uncommon in feeding stuffs, or are present in such small quantities, that they may be safely ignored.

\section{PROTEIN - THE PROTEIDS}

Proteids are the main and important nitrogen compounds either in the plant or in the animal. The protein of seeds contains little else than proteids, while that of young fodder plants and especially of roots 
consists more largely of non-proteids. They are also the chief constituents of muscular tissue. The chemical constitution of the proteids is not definitely known. No investigator has yet been wise enough to search out their manner of combination, but it is generally considered to be very complex. It is believed that a certain one of these compounds holds in a single molecule no less than 5,000 atoms. These bodies are constructed from the simpler ones of the inorganic world through the vital energies of plants, and they apparently must come to the animal fully organized.

The ultimate composition of proteids, that is, the proportions of the elements which they contain, has been carefully studied, and while there are material differences among them in this respect, the limits of variation are not especially wide, as can be seen from the following figures taken from Neumeister:

\begin{tabular}{|c|c|c|c|}
\hline \multicolumn{4}{|c|}{ Elementary composition of the proteids } \\
\hline & Per cent & Per cent & Average \\
\hline Carbon & 50. & to 55 . & 52. \\
\hline Hydrogen... & 6.5 & 7.3 & 7. \\
\hline Nitrogen........... & 15. & to 17.6 & 16. \\
\hline Oxygen............. & 19. & to 24 . & 23. \\
\hline Sulphur.......... & .3 & 2.4 & 2. \\
\hline
\end{tabular}

We see that the number of elements ordinarily found in the proteids is five, nitrogen and sulphur being those that chiefly distinguish these bodies from all others which make up the mass of combustible matter. Two other elements are occasionally involved, as, for instance, the phosphorus of casein and the iron of blood. 
These proteids are familiar objects on the farm, and their properties are matters of common observation. When the farmer's boy secures the tenacious cud of gum from the fresh wheat gluten, or when the housewife watches the strings of coagulated albumin separate from the cold water extract of fresh lean beef that is brought to the boiling point, or observes the white of an egg harden into a tough, white mass as it is dropped into boiling water; when we observe the stiffening of the muscular tissue of the slaughtered animal or the rapid formation of strings of fibrin in the cooling blood;-in all these instances there are manifested certain chemical or physical properties which pertain to these most important and useful compounds.

The albuminoids. $-\mathrm{Of}$ all the nitrogen compounds, these exercise the most general and prominent functions in plant and animal life. They not only make up a large part of the protein of feeding stuffs, but their office in the nutrition of animals is definitely under. stood to be of the most important kind.

As has been indicated, the albuminoids are regarded as divisible into groups, the individuals of each group having certain distinguishing common properties. The two subdivisions whose members are most common and widely distributed are the albumins and globulins. Among these and their derivatives and compounds we find albumin, myosin, fibrinogen, albuminates, proteoses, peptones, casein and nuclein, - a formidable lot of names whose use seems necessary to a statement of the facts we wish to discuss. It is hoped that the 
following explanations will clothe them with practical meaning.

(1) The albumins. There are several albumins. They are found in the juice of plants, in certain liquids of the animal body such as the serous fluids, in muscle, blood and milk, and abundantly in eggs. Unlike other proteids, these compounds are soluble in pure cold water, and when such a solution is heated to the boiling point, they separate from the liquid by coagulation and become insoluble unless acted upon by some strong chemical.

When macerated beef is treated with cold water the albumin in it goes into solution, and if this extract is boiled to make beef tea, it is a matter of common observation that the albumin separates in clotted masses. None remains in the tea. It is well for the housewife to know that all lean meat contains this substance, which by prolonged treatment with cold water may be removed to the detriment of the residue, and which, if the exterior surface of the meat is brought in contact with boiling water, at once coagulates in the outer layers of the meat and thus prevents an extensive loss of soluble matter.

The clear serous fluid which is left after removing the clot from blood contains albumin which may also be coagulated by heat. After the casein is removed from milk by acid or rennet, the albumin of the milk remains in the whey. It is this which in part causes milk to clot if brought to the boiling point. One of the most familiar examples of this class of proteids is the white of an egg, which, when cooking in boiling water, be- 
comes a hard, white, coagulated mass. Albumin in the serous fluids and in blood is called serum-albumin, in milk, lact-albumin and in eggs, ova-albumin.

A small proportion of the proteids of plants is found to be albumin; for instance, Osborne found .6 per cent in wheat, .43 per cent in rye, .3 per cent in barley, .5 per cent in soja beans, and some in most seeds. This possesses essentially the same characters as the animal albumin described previously. Whenever a vegetable substance is leached with water, it is probably this proteid which would be the first to suffer removal or destructive fermentation.

(2) The globulins. It is fully recognized that when plant and animal tissues are treated with water but a small part of the proteids dissolve. If, however, we add to the water a mineral salt, especially common salt (sodium chloride), sufficient to secure a 10 per cent solution, an additional and considerable amount of albuminoids is extracted. These compounds are called globulins and differ from the albumins in being insoluble in pure water and in a saturated solution of certain mineral salts, such as sodium chloride. The globulins form an important part of the proteid content of plants and of animal tissues, both in quantity and in having a maximum nutritive usefulness.

In plants these proteids seem to be especially abundant and widespread. Our best and most recent knowledge on this point comes from investigations conducted in the laboratory of the Connecticut Agricultural Experiment Station, chiefly by Osborne. In these researches the seeds of fifteen species of agricultural 
plants were studied, all of which were found to contain globulins. In some the proteids consisted largely of these compounds. The percentage content in certain seeds was determined approximately:

Globulins in certain seeds

Per cent

Per eent

Kidney bean....... 20. Maize...... 0.4

Cottonseed meal... .. 15.8 Lentil ....... 13.

Peas............ 10. Horse bean.... 17.

Lupin........... 26.2 Soy bean ..... Chiefly globulin

The seeds of the legumes, as a rule, have the largest proportion of these albuminoids.

From present knowledge, many seeds appear to have characteristic globulins which are unlike in their chemical properties. These have been given names derived from the general names of the species in which they are found. Thus we have amandin in almonds, avenalin in oats, corylin in walnuts, phaseolin in several species of beans, glycin in the soy bean, maysin in maize, vicilin in horse beans, vignin in the cow-pea, hordein in barley, and tuberin in the potato. One globulin called edestin appears to be quite generally distributed in the seeds of agricultural plants, having been found in a larger number than any other proteid yet discovered, including all the cereals, castor bean, cottonseed, flaxseed, hemp, squash and sunflower, though it is not abundant in any one of these.

The animal globulins of which we have definite knowledge are those that exist in the muscle and in the blood. The names which some of them bear are myosin, fibrinogen, paraglobulin, and, according to 
some authors, vitellin. If finely divided, well-washed muscle (lean meat) is treated with a 10 per cent salt solution, first by rubbing it in a mortar with fine salt, and then adding enough water to secure the proper strength of solution, a globulin is dissolved to which the name myosin has been given. The view has been generally accepted that this compound does not exist as such in living muscle, but forms there by coagulation upon the death of the animal. This change has been looked upon as similar to the coagulation of blood through the formation of fibrin, and is regarded as the explanation of the stiffening of dead muscles (rigor mortis). The theory is held that a "mother" substance exists in the living muscle from which myosin is formed in much the same way as fibrin is developed in clotting blood from a preëxisting body, but no single view as to exactly what occurs is fully accepted. There is, nevertheless, a general agreement that rigor mortis is due to a clotting of the muscle, accompanied by marked chemical transformations, one final product being myosin. The theory is advanced that ferments are present in the muscle, to the influence of which these changes are due, and without which they do not occur, but proof of this view is still lacking. In this whole field much is yet to be learned. Certainly, the chemistry of living and dead muscle is most profound, and offers to the bio-chemist a wonderfully attractive and fruitful field of research.

Another prominent and remarkable globulin is the fibrinogen which is found in the blood. It is common knowledge that when blood is drawn from the veins 
and cools it clots, a phenomenon which is nothing more than the formation of strings of fibrin. Fibrin as such is not found in living blood, but is one of the products into which fibrinogen splits when exposed blood cools, probably because of the influence of a ferment. Stranger than all is the fact that so long as the blood is retained in the arteries and veins, even if the animal dies and grows cold, this clotting does not appear.

Serum globulin is a collective name for several globulins, which exist in blood serum and in the other fluids of the animal body, such as lymph and its allies, including those exudations which pertain to diseased conditions, especially dropsical.

One more proteid has been generally classified as a globulin, although differing in some respects from the other members of this class. Reference is made to vitellin, which is the principal proteid in the yolk of eggs. It is there intimately mixed with certain peculiar phosphorized bodies, which we shall notice later. The modified albuminoids.-All of the proteids previously noticed may properly be called simple, native proteids. This characterization is appropriate because these are the bodies that possess the typical reactions and qualities of the albuminoids as a class, and are the principal ones found in the normal tissues of plants and animals. They are the basal substances from which others appear to be derived after modifications of one kind or another. It seems proper, therefore, to speak of certain other proteids as modified albuminoids, because, through various influences, either natural or artificial, they have acquired chemical and physical 
properties unlike those possessed by the mother substances.

A convenient division of these modified bodies, though perhaps not strictly scientific, may be made in accordance with the cause or manner of change. These causes are: (1) coagulating ferments; (2) heat; (3) action of acids and alkalies; (4) the ferments of digestion; (5) combinations with other compounds.

(1) Coagulating ferments. Reference has been made to that interesting phenomenon, the coagulation or clotting of blood. As stated, this is now known to be due to a formation of a new compound, called fibrin. The mother substance, fibrinogen, and not the fibrin exists in the living blood, and it seems to be well proven that the splitting of the fibrinogen into two substances, one of which is fibrin, is due to the action of a ferment, designated as a fibrin ferment. It would be out of place to review the data upon which this conclusion is based. There are, to be sure, conflicting views, but the one stated seems to be the most fully established. Fibrin, after thorough washing, is an elastic white substance, which, in its chemical properties, stands very close to the albumins that are coagulated by heat.

It has been held by various investigators that other changes in animal fluids and tissues are brought about in the same manner as the formation of fibrin, i. e., by the action of a ferment. In one case, this is certainly true, viz.; the curdling of milk under the influence of the ferment rennin. This ferment, which for cheesemaking purposes is extracted from the fourth stomach 
of a calf, will, when added to milk at a proper temperature, cause the coagulation which gives us the cheese curd.* The probable correct explanation of this familiar phenomenon is that the casein is decomposed into two other substances, one being paracasein and the other an albumin, the first of which subsequently unites with lime salts in the milk and forms the insoluble substance that we know as curd. The occurrence of this latter step appears to be proven by the fact that in the absence of lime salts no curd forms, but it immediately appears when such salts are added to the lime-free solution. As milk always contains sufficient lime to make coagulation possible, this explanation of the coagulation of casein has chiefly a scientific interest.

Mention has been made of the clotting of dead muscle, or rigor mortis. As stated, certain investigators have suggested that the formation of the muscle clot is a process analogous to the coagulation of blood, and is brought about by ferment action. This view is not vet proven and must at present be considered as only hypothetical. If, however, it is found to be correct, myosin would properly be classed as a derived albuminoid, its progenitor being the native proteid.

(2) Heat. The effect of a boiling temperature upon the albumins has already been described. They are coagulated into a mass no longer soluble in water and only redissolve by treatment which changes their chemical constitution. The same thing happens to nearly all the globulins, and as with the albumins, this begins at varying temperatures. These coagu-

* Now held by some that pepsin is the only ferment present and causas these changes. 
lated bodies, which are typified by the white of an egg after contact with boiling water, are materially unlike the original compounds, though the nature of the modification is not understood. We know them simply as coagulated albumins and globulins.

(3) Action of acids and alkalies. When albumins and globulins are treated with dilute mineral acid, such as hydrochloric, they dissolve, through their conversion, into acid albuminates. The action of dilute alkalies is similar, only that alkali-albuminates are formed. Another effect of dilute acids upon proteids is to cause them to take up water, or suffer hydrolysis. These hydrolyzed bodies are called proteoses as a generaı name. This term signifies that they are derived from proteids. More fully specialized names are albumose, from albumin; globulose, from globulin; caseose, from casein, and so on. The important property which the proteoses take on is their greater solubility as compared with the original compounds. This change has an intimate relation to digestive processes, or to the transference of the insoluble albuminoids of the food into the blood circulation, because in the stomach the hydrochloric acid of the gastric juice plays somewhat the same part as in dilute artificial solutions in rendering the proteids soluble.

(4) Ferments of digestion. When we come to a discussion of the processes of digestion we shall learn that nearly every digestive fluid contaıns one or more ferments, whose office appears to be to cause certain necessary modifications of the food proteids. The general effect of these ferments is to induce these proteids 
to take up water, which transforms them to proteoses, and finally to peptones, the latter being so soluble as to pass through the walls of the alimentary canal into the blood. These proteoses are similar to those formed by the action of dilute acids, and in digestion may be considered as products intermediary between the original food proteids and the peptones which are the final result of albuminoid digestion. The acid of the stomach and the alkaline compounds in certain intestinal juices coöperate in bringing about these necessary changè, for we know that in their absence the digestive ferments have no extensive action such as that described. Proteoses, i. e., albumoses, globuloses, caseoses, and the like, are soluble in water, are not coagulated by boiling their solutions, and in other ways are unlike the proteids from which they are derived. They are regarded, however, as not having lost their albuminoid character, and, as will be shown later, they are re-formed by the metabolic energy of the animal into bodies similar to those from which they take their rise.

(5) Combinations. There are many nitrogenous compounds found in plants and animals which it is not possible to classify at present in any exact manner. They are undoubtedly derived from simple proteids, as those to which reference is made consist of albuminoids united to a body of a different kind.

There are, first of all, certain bodies designated as nucleo-albumins, this name signifying that albumin is united to a nuclein, which, in its turn, is a combination of an albumin with phosphoric acid. The best known nucleo-albumin in agriculture is the casein of milk. 
Some of the properties of this body have been noticed in discussing the action of ferments. It has others which it is well to mention. In the first place, casein is not soluble in water. It is not in solution as it exists in milk, but is regarded as being in a swollen condition. Again, it does not coagulate when milk is boiled. While the skin which forms on the surface of milk at a boiling temperature contains casein as one component, the only genuine coagulation that $\mathrm{oc}-$ curs is of the albumin present. Every housewife has noticed that when vinegar is added to milk in a small quantity the milk curdles. This is because the casein is modified by a weakly acid medium. A generous quantity of common salt, or of certain other salts, would have a similar effect.

The nuclein, which forms a part of casein, can be split into an albumin and phosphoric acid, and is an illustration of a class of compounds which are generally distributed in plant and animal tissue. The name is suggestive of the fact that these bodies exist in the nuclei of living cells, having an intimate relation to the protoplasm. Nucleins are also found in milk and eggs, and it appear's quite possible that they take a peculiarly important place in nutrition, especially with young animals and milch cows.

Another compound widely distributed in the animal kingdom is mucin, a prominent constituent of the slimy secretions of the mucous membranes that line the passages of the animal body, such as the throat and the intestines. This substance appears somewhat anomalous in being a combination of a proteid and a 
carbohydrate (animal gum). The fact of such a union is demonstrated by boiling mucin with an acid when an acid albuminate and carbohydrate-like body are produced. The mucin-like bodies are not especially important in nutrition.

The blood contains a modified proteid which has an importance second to none in its relation to the nutritive processes. Reference is made to hæmoglobin, which arises from the union of an albumin called globin and a coloring matter (pigment) called hæmatin. The latter is peculiar in containing iron. The especial function of hæmoglobin is as a carrier of oxygen, and it is enabled to do its work through the property of taking in and releasing oxygen with great readiness. This action will be discussed later when we consider respiration.

The gelatinoids.- It is a matter of common observation in cookery that when meat containing tendons (cartilage) or bones is submitted to the action of boiling water there is obtained in the extract a substance, which, especially when it is cold, we recognize as the one known as gelatine. Gelatine as such is not found in the animal tissues, but is derived from certain constituents of the connective tissues like the collagen of tendons and of bones, that from the latter source being also known as ossein. Collagen is undoubtedly transformed into gelatine by taking up water.

Gelatine is insoluble in cold water, but dissolves in hot. As the dry commercial article, it is a tenacious substance which, when prepared in thin layers, is transparent. When collagen is acted upon by tan- 
nic acid, as for instance, when the skin of an animal is treated with an extract of hemlock or oak bark, the result is a substance which does not putrefy, and which gives to a tanned hide the properties of leather.

Keratin and similar substances. - The hair, wool, hoofs, horns, and feathers are made up chiefly of a compound which bears the name keratin. Chemically, it is closely related to the true proteids, we may believe, because when treated with heat or with chemicals like acids and alkalies, the resulting products are nearly similar to those that are secured in the same ways from albumins. Sulfur is a much more prominent constituent of keratin than of the native proteids, the analyses of human hair showing as high as 5 per cent, the average amount found in horn being 3.30 per cent. These keratin bodies belong usually to the epidermis or outer skin of the animal, and are modifications of the exterior tissue to serve certain distinct purposes where rigidity or wearing quality is necessary.

\section{PROTEIN - THE NON-PROTEIDS}

There are certain nitrogen compounds included in the term protein which are non-proteid in character, that is, they possess physical and chemical properties greatly removed from those which characterize albumin and other true proteids. Their office as nutrients is also less comprehensive than that of the albuminoids.

One group of non-proteids which we speak of under the general term amides, is found chiefly in plants. 
They are soluble in water, and consequently are diffusible throughout the plant tissues. It is believed that they are the forms in which the nitrogen compounds of the plant are transferred from one part to another, as, for instance, from the stem to the seed. It has generally been held that amides are more abundant in young plants than in mature. A larger part of the nitrogen of roots and tubers is found in these compounds than in other feeding stuffs, the proportion in grains being the least, and is very small indeed. Such investigations as have been conducted point to the conclusion that amides are not muscle-formers, as is the case with proteids. This is a reason for regarding the protein of coarse foods, roots, and tubers, as of less value than that of the grains and grain products.

The extractives are bodies found in the extract obtained from beef with cold water. After the albumin has been removed from such an extract by boiling, these compounds known as creatin and creatinin chiefly constitute the nitrogenous solids that remain. Their food value is small if anything, for they appear to pass through the body without change. 


\section{CHAPTER VI}

THE COMPOUNDS OF ANIMAL NUTRITION, CONCLUDEDTHE NITROGEN-FREE COMPOUNDS

Much the larger proportion of dry cattle foods consists of non-nitrogenous material. This is especially true of hays and cereal grains, consequently we find that from 75 to 80 per cent of the dry matter stored in a farmer's haymows and grain-bins is made up of substances of this class. While these compounds are not regarded by many as fundamentally so important as the nitrogenous, in quantity they unquestionably occupy the first rank. The activities of plant life are largely devoted to their production, and their use by animal life is correspondingly extensive. They may properly be called the main fuel supply of the animal world. Other nutrients aid in maintaining muscular force and animal heat, to be sure, but these compounds are the principal storehouse of that sunderived energy which furnishes the motive power exhibited in all animal life. They are also important building materials, for they fill a necessary office of this kind in the formation of milk and in the growth and fattening of animals.

The compounds of this class contain only three elements,-carbon, hydrogen and oxygen. They may 
be derived, therefore, wholly from air and water, and they constitute that portion of our cattle foods which is drawn from never-failing and costless sources of supply.

The elementary composition of typical nitrogenfree bodies is given in this connection:

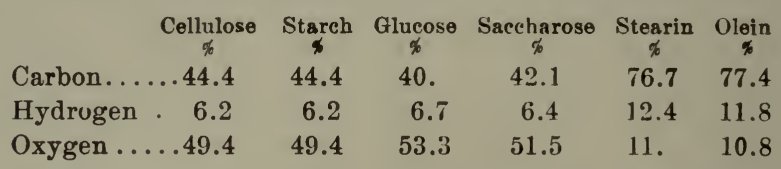

The non-nitrogenous compounds of feeding stuffs are usually divided into three main classes, viz.; crude fiber, nitrogen-free extract and fats or oils. The second class is sometimes spoken of as carbohydrates, because it includes the carbohydrates as its principal members, and the third is known by the chemist as ether-extract, because ether is used to extract the fats or oils from the vegetable substances in which they are contained. The actual fat obtained from hay and other feeding stuffs is always less, however, than the ether-extract.

\section{CRUDE FIBER}

This is the tough or woody portion of plants. It consists largely of cellulose, a familiar example of which in a nearly pure form is the cotton fiber used in making cloth. Crude fiber is separated from asso. ciated compounds by the successive treatment of vegetable substance with weak acids and alkalies, and as so determined is sometimes improperly taken to represent 
the amount of cellulose in a plant. While crude fiber is mainly cellulose, it contains a small proportion of other compounds, and besides, more or less cellulose is dissolved by the acid and alkali treatment, so that the percentages of crude fiber given in fodder tables only approximately measure the cellulose present in feeding stuffs.

All plant tissue is made up of cells, the walls of which are chiefly or wholly cellulose. It is this substance out of which is built the framework of the plant, and which gives toughness and rigidity to certain of its parts. The more of this a feeding stuff contains, the more tenacious it is, other things being equal, and the more difficult of mastication.

The proportion of crude fiber in plants varies greatly with the species. Large plants have more than small ones, as a rule. The dry matter in the trunks and limbs of trees is mostly woody fiber, and the chemical treatment involved in making paper from wood has for its main object the separation of this from other substances. Grass and other small lierbage plants are less rich in fiber, still less existing in such species as potatoes, turnips and beets.

The proportions of cellulose in the different parts of a plant are greatly unlike. It is usually most abundant in the stem, with less in the foliage and least in the fruit. With vegetables like potatoes and turnips, the leaves are much richer in fiber than the tubers or roots, which contain a comparatively small proportion. Of the grains or seeds considerable is present in the outer coatings, while but little is found in the interior. Consid- 
ering feeding stuffs as a whole, we find that hays, and especially straws, are rich in crude fiber, while tubers, roots and the grains contain only small amounts. In certain by-product grain foods, like bran, which is made up mostly of the seed-coatings, fiber is present in fairly large proportions, while in other materials like gluten meal, which are derived from the inner parts of the grain, the percentages are very sinall.

The stage of growth at which a plant is used for fodder purposes has a marked influence upon the proportion of crude fiber. In young, actively growing vegetable tissue, the cell-walls are thin, but as the plant increases in age, these thicken, chiefly through the deposition of cellulose. Pasture grass has less cellulose than hay, and early cut grass less than that which is ripe. In general, the toughness and hardness of mature plants, as compared with young, is due to the increased proportion of woody fiber, although the decrease in the relative amount of water in the tissues and the deposition of other substances have more or less effect.

\section{NITROGEN-FREE EXTRACT}

This name, like protein, is a collective term, being used to designate a group of compounds possessing certain characteristics in common. A great variety of substances is included under this head, many of which are among the most familiar objects of every-day life. Here we find the starches, sugars, gums and vegetable acids, compounds universally used, and which even children recognize by name. Certain of these non-nitrog- 
enous bodies of less importance are not so well known, as, for instance, such uncommon sugars as mannose and galactose, and their mother substances, mannan and galactan.

The manufacture of beers and liquors and many of the ordinary phenomena of cooking operations, are based upon the chemical properties of the starches and sugars. To the presence of these and related bodies are due many of the agreeable flavors and appetizing characteristics of certain foods, as, for instance, the sweetness or acidity of fruits, and flavors produced in grain foods under the influence of heat.

The most prominent and important members of the nitrogen-free extract group are known as carbohydrates, the significance of this term being that these compounds contain carbon united with hydrogen and oxygen in the proportions in which these two elements exist in water.

A common and convenient classification of the carbohydrates, though not strictly rational from the standpoint of chemical constitution, is the following: 1 . The starches, such as corn and potato starch and those bodies similar in elementary composition, including cellulose, inulin, glycogen, the dextrins, pectin and the gums. 2. The sugars, of which there are two main classes, the glucoses and the sucroses, the main sugar of "corn syrup" being a familiar example of the former class, and the ordinary crystallized sugar of commerce the most prominent member of the latter.

The starches.-Starch is a widely distributed and abundant constituent of vegetable tissue. Food plants. 
especially those most used by the human family, contain it in generous proportions, in some seeds as much as 60 or 70 per cent being present. Probably only water and cellulose are more abundant in the vegetable world.

Starch does not exist in solution in the sap, but is found in the interior of plant cells in the form of minute grains, which have a shape, size and structure characteristic of the seed in which they are found. Potato starch grains are large, about $\frac{1}{300}$ of an inch in diameter, and are kidney-shaped, while those of the wheat are smaller, about $\frac{1}{1000}$ of an inch in diameter, and resemble in outline a thick burning-glass. Cornstarch grains are angular, being somewhat six-sided, and those of other seeds show marked and specific characteristics. These differences in size and shape furnish the most important means of detecting adulterations of one ground grain with another, as, for instance, when corn flour is mixed with wheat flour, a practice not unknown at the present time.

Unless modified by some chemical change, starch is not dissolved by water. The starch grains are not affected by cold water, and in hot water at first only swell and burst. Prolonged treatment with hot water causes chemical changes to more soluble substances. For this reason the simple leaching of a fodder material removes no starch; at least not until fermentation occurs. At the same time the treatment of a ground grain with hot water so breaks up the starch grains that they are probably acted upon more promptly by ferments and digestive fluids, though perhaps no more fully, than when not treated. 
It is somewhat customary to refer in a popular way to the nitrogen-free extract of feeding stuffs as synonymous with starch and sugar. Such a comparison conveys an erroneous impression. The nitrogen-free extracts of many feeding stuffs, notably the straws and hays, contain at best. a very small proportion of these carbohydrates, the amount of starch often being inappreciable. It is doubtful whether these coarse fodders usually contain enough to be chemically determined. This has certainly been found to be true in some cases. On the other hand, the dry matter of many seeds, such as rice and the cereal grains, wheat, maize, barley or oats, is largely made up of starch. The same is true of potatoes and other tubers. Johnson quotes the following figures from Dragendorff:

Amount of starch in plants

Per cent

Per cent

Wheat kernel......68.5 Peas .......... 39.2

Rye kernel........67. Beans........... 39.6

Oat kernel........ 52.9 Flaxseed......... 28.4

Barley kernel......65. Potato tubers.......62.5

It appears that in grain plants starch forms most abundantly during the later development of the seed. At the Maine station none could be found in very im. mature field corn cut August 15, while on September 21 the dry matter of the whole plant on which the kernels had matured to the hardening stage contained 15.4 per cent. In general, the stem and leaves of forage plants are poor in starch.

The distribution of starch in seeds is worthy of note. The grain of wheat has been carefully studied 
in this particular, and it is found that this body does not normally exist in the seed-coatings, this tissue consisting largely of mineral matters, proteids, cellulose, and gums. On the contrary, the germ and the interior material deposited around it are rich in starch. To be sure, wheat bran, which is now very largely the outer seed-coats of the grain, has more or less, but this is due to imperfect milling. It is very evident, therefore, that the term nitrogen-free extract, as applied to different cattle foods, stands for greatly unlike mixtures of compounds, for we have largely starch in the cereal grains and mostly other substances in the straws and other coarse fodders. The importance of this fact will appear in considering the digestion and value of food compounds.

Starch is an important commercial article, and for this purpose is mainly obtained from corn and potatoes. It is used as human food, as a source of dextrin and in other ways. By treatment with an acid, cornstarch is converted into the glucose of our markets.

The vegetable gums.-It has become evident, doubtless, during our discussion of nitrogen-free extract, that a considerable portion of this class of compounds consists of something else than the carbohydrates already noticed. For example, at the Maine Experiment Station, the composition of several samples of corn fodder was closely investigated. It was found that the proportions of starch and sugar varied greatly, mostly in accordance with the stage of growth, being much more abundant in the mature plant. Even with flint corn nearly ripe, not over one-half of the 
nitrogen-free extract of the entire plant was found to be starch and sugars. The other half evidently consisted of bodies either not so well known or not known at all.

Among the less familiar compounds which we now recognize as existing quite abundantly in the stem and leaves of many, if not all, fodder plants are the vegetable gums, some of which are designated by the chemist as pentosans. Only a few such substances are definitely known, one of which, araban, is contained in gum arabic, gum tragacanth, cherry gum, beet pulp, and doubtless in various other materials; another being zylan or wood guin, which may be separated in abundance from wood and straw. Stone has examined a large number of agricultural products for these gums, and if present methods of analysis are accurate, he found in the dry matter of such feeding stuffs as hays from several species of grass, corn fodder, sugar beets, rutabagas, wheat-bran and middlings and gluten meal from 6 to over 16 per cent, the highest proportions appearing in timothy hay, corn fodder, and wheat-bran. In mature field-corn fodder he obtained about 16 per cent, thus accounting for about half of the nitrogen-free extract left after subtracting the starch and sugars. Wheat bran contained much more than middlings, and the least was present in gluten meal. These gums are surely much more abundant in the coarse foods than in the grains, a fact which, as we shall learn, is important in comparing the nutritive value of different classes of feeding stuffs. 
The pectin bodies. - Another class of compounds much like the gums, and perhaps related to them chemically, is the pectin bodies. Some of these substances are gelatinous in appearance. The jellying of fruits, such as apples and currants, is made possible by their presence. They exist in greater abundance in unripe fruit than in the ripe, consequently the former is selected for jelly-making. When such fruits are cooked, the pectin which they contain takes up water chemically and is transformed into a gelatinous substance, and the secret of jelly-making is in stopping the cooking process before the chemical transformations have passed beyond a certain point. Mucilages not greatly unlike the gums and pectins exist in certain seeds and roots, the most notable instance being flaxseed.

The sugars. - When considered from the standpoint of efficiency, the sugars are the most valuable of all the carbohydrates, although in quantity they are much less important than the starches, because they are found only in small amounts in the hays and to a scarcely appreciable extent in the grains. Certain distinctively sugar plants, to be mentioned later, are grown agriculturally, which are sometimes used as cattle foods.

Unlike starch, the sugars are found in solution in the sap of growing plants. It is probable that these are the forms in which carbohydrate material is transferred from one part of the plant to another. It is easy to see that some such medium of exchange is necessary. The actual production of new vegetable 
substance takes place in the leaves. When, therefore cell-walls and starch-grains are to be constructed in the stem and fruit, the building material must be carried from the leaves to these parts in forms which will readily pass through intervening membranes. Excepting certain soluble componnds, closely related to starch. the sugars appear to be the only available bodies fitted for this office.

It is very seldom that a plant contains only a single sugar. Generally two or more sugars are found together. This is especially the case in the corn plant, sorghum and the juicy fruits, and the proportions of each depend somewhat upon the stage of growth of the plant.

The most important sugar, commercially considered, is saccharose, which is the ordinary crystallized product of the markets. As a human food it is widely used, and is especially valuable; and its manufacture and sale constitute a prominent industry. This sugar is obtained mostly from two plants, sugar eane and the sugar beet. It also exists abundantly in sorghum and in considerable proportions in ordinary field corn.' The first spring flow of sap in one species of maple tree is richly charged with it, and in a few states large quantities of maple syrup and sugar are manufactured.

Saccharose is not a prominent constituent of the more common cattle foods. While it occurs in meadow grasses, in sweet potatoes and in roots, and perhaps in minute proportions in certain seeds, it is only when the fresh corn plant, sorghum and sugar beets are fed that it constitutes a material part of the ration. In corn 
stover and in silage there is practically none, it having been destroyed by the fermentations that have taken place.

The fruits generally contain saccharose, mixed with other sugars and organic acids, and upon the relative proportions of these compounds depends the character of the fruit as to acidity or sweetness.

A sugar that is intimately related to the first growth which occurs in the germination of seeds is maltose, for it stands as an intermediate product between the store of starch in the seed and the new tissues of the sprout. The solution that the brewer extracts from the malted grains contains this compound as the principal ingredient, and through succeeding fermentations in the beer vats it is broken up into alcohol and other compounds. It sustains an important relation, therefore, to the production of beers and other alcoholic liquors. The glucose syrups found in the markets sometimes contain small quantities of this sugar. It is also found abundantly in the intestinal canal during the digestion of food, being derived from starch and other carbohydrates. Maltose is similar to cane sugar in ultimate composition but not in constitution, though as a nutrient it evidently has an equivalent value. So far as known, however, it does not appear to occur in material quantities in feeding stuffs.

Another important sugar is dextrose or grape sugar, or what is known in the markets as glucose. Excepting in the hands of the chemist it is seldom seen as crystals, although these appear in the "candying" of honey and of raisins. Its commercial forms are molasses and the 
syrups. Dextrose is found in practically the same plants that contain saccharose, such as sorghum, maize and the fruits. So far as known, it is always associated with some other sugar. On account of its difficult crystallization and a lower degree of sweetness, it is less valuable for commercial purposes than cane sugar. That which appears in the market is largely made from starch by the use of an acid, and it is often utilized in adulterating the more costly saccharose. Many seem to regard glucose as a substance deleterious to health, but in consideration of the fact that in digestion, starch and most other sugars are reduced to this compound before entering the circulation of the animal, this view does not seem to be sustained. In fact, there is a lack of evidence to show the ill effect of glucose either upon man or animals.

Still another sugar is levulose or fruit sugar, the composition of which is identical with dextrose but which has a different chemical constitution. It accompanies dextrose and is found in some fruits in considerable quantities. It is as sweet as cane sugar, but does not form erystals with the same readiness.

The acids.-Other substances besides those of a carbohydrate character are included in the nitrogen-free extract. Chief among these are the organic acids, compounds which are found mostly in the fruits, although they appear in certain fermented products, such as silage and sour milk. The most important and well-known of these are acetic acid, found in silage and vinegar, citric acid in lemons, lactic acid in sour milk and silage, malic acid in many fruits, such as currants and apples, and 
oxalic acid in rhubarb. Sometimes these acids are free, that is, not combined with any other compound, and sometimes they are united with lime or some other base, forming a salt. Excepting the fruits, only fermented feeding stuffs contain acids to an appreciable extent. When milk sours, the sugar in it is changed to lactic acid under the influence of a ferment. In silage, various acids develop, the main one being lactic, accompanied by acetic and other acids in much smaller proportions. These are formed chiefly at the expense of the sugars that enter the silo in the corn or other material which is subjected to fermentation.

\section{ANIMAL CARBOHYDRATES}

A study of the composition of the animal body teaches us that, unlike plants, it is very poor in carbohydrate compounds. Only two carbohydrates are of distinctively animal origin, viz; glyeogen or animal starch, and milk sugar.

Glycogen is elosely related to starch, having the same percentage composition. It is a white powder, soluble in water, and may be extracted in very small amounts from the muscles and liver, the latter being the place where it is produced. As we shall see later, it seems to perform a very important office in nourishing the animal body. It was formerly believed that another carbohydrate exists in muscle called inosite, but it is now known that this substance belongs to a different class of compounds.

The only sugar of animal origin which is abundant 
in farm life is that found in milk and which is known in commerce as milk sugar or lactose. The milk of all mammals contains sugar, which appears to be the same compound with every species so far investigated. When fed wholly from the mother, this is the only carbohydrate which young mammals receive in their food. The average proportion of sugar in the milk of domestic animals varies from three to six parts in a hundred, cow's milk containing about five parts. When the cream is removed much the larger part of sugar remains in the skimmed milk, and in cheese-making it is nearly all found in the whey, from which the milk sugar of commerce is obtained. Very soon after milk is drawn, unless it is heated to the point of sterilization, or is treated with some antiseptic, the lactose begins to diminish in quantity, being converted into lactic acid through the action of germ life. Sour milk, therefore, is different from sweet in at least one compound, and this change causes at least a slight modification of food value.

\section{CHEMICAI REIAATIONS AND CHARACTERISTICS OF 'THE CARBOHYDRA'TES}

The various carbohydrates, which have been previously described, are greatly unlike in appearance, taste and other physical qualities, but they are closely related chemically. This is shown not only by what the chemist knows of their constitution, but also by the readiness with which one passes into another, for example, the transformation of starch into dextrose. Under the influence of certain agencies, such as 
heat, ferments and hot acids, certain carbohydrates may be changed to other bodies of the same class. This fact is important in the arts, and no less so in plant and animal nutrition. The movements of these compounds in plants and their uses as nutrients depend largely upon these transformations, as do also certain phenomena in cookery.

Heat is one immediate cause of some of these changes. Starch, when heated, becomes dextrine, a water-soluble, gum-like substance. This occurs in baking corn and wheat bread; so it does in toasting bread, and the bread-crust tea of the sickroom is in part a solution of dextrine. Probably this substance is digested with greater ease than starch, because it is an intermediate stage between starch and glucose, the latter being the final product.

Hot, dilute acids, even the vegetable acids, such as those found in vinegar and in fruits, transform starch, dextrin, gums and pectin bodies into various sugars, of which dextrose is the principal one. Sacharose is changed to dextrose and levulose in the same way. These chemical facts find an application in the manufacture of glucose from cheaper materials, and in cookery where vinegar and acid fruits are used.

These transformations are also brought about by the influence of bodies called ferments. For instance, the carbohydrates in a grain of barley are largely not available for nourishing the new growth that takes place during germination, because, being mostly insoluble, they cannot be transferred from the seed to the point where new tissue is formed. It is so arranged 
that a ferment present in the seed, called diastase, acts upon the starch and converts it into maltose, a sugar. The brewer takes advantage of this fact when he malts or germinates barley, this being nothing more than the same change of starch into sugar, which occurs during germination in the ground. This maltose is utilized by the young plant to form new tissue and by the brewer as a source of alcohol. In the animal body, especially in the mouth and intestines, are found ferments which accomplish essentially the same result. Through their diastatic influence the starch, dextrose, cane sugar and other carbohydrates are transformed, probably by successive stages, finally into glucose (dextrose mainly) in which form the carbohydrate nutrients enter the blood.

The chemical changes so far noted are all in one direction, i. e., the taking up of the elements of water to form new compounds, as, for instance, the transformation of starch to dextrose or cane sugar into invert sugar.

Up to the present time, however, no chemist has discovered a way of reversing this process, and by abstracting the elements of water from the glucoses producing cellulose, starch and cane sugar. That the plant can do this, however, is certainly true. Cell walls and starch grains are undoubtedly made from the sugars under the influence of what we blindly call vital force.

The carbohydrates, especially the sugars, possess such chemical properties as cause them to be easily destroyed and lost from the feeding stuff in which they are contained. If grass or corn fodder is allowed to lie 
in a mass in a green or wet condition, there is very material loss of dry matter, due to the breaking up of the sugars and other carbohydrates into new compounds under the influence of ferments. This action occurs in the silo, where the sugars are used to form considerable quantities of acids besides water and carbon dioxid. Loss from this cause often occurs in the grain bin, where new grain not sufficiently dry is stored. The sugars in canned vegetables or fruits that are not properly heated or sealed soon disappear, either to be lost in gasecus products or to be converted into compounds of an entirely different character. All such fermentations result in a diminished food value. Not only is there an actual disappearance of dry matter from the affected material, but this is brought about at the $\mathrm{ex}$ pense of some of the most valuable food compounds. For this reason the farmer should exercise great care in the storage and preservation of his cattle foods. The dangers of loss from these fermentations are greater than is generally appreciated, for the chemist finds that in drying green or wet foods under conditions more favorable than often pertain to farm practice he is unable to avoid it to a greater or less extent.

\section{FATS OR OILS}

When any finely-ground feeding stuff, either straw or hay, is submitted to the leaching action of ether, chloroform, or certain other liquids, several compounds are taken into solution, the main and important ones being fats or oils. These bodies make up the chief 
portion of such an extract from seeds, while material so derived from hay, straw and other coarse fodders also contains a considerable amount of wax, chlorophyll and other substances. Tables that show the composition of feeding stuffs have a column which is sometimes designated "ether-extract," and sometimes "fats or oils." The former is the more accurate term, because the compounds which it is the intention to describe are often no more than half fats or oils. The real value of the "ether-extract" from different feeding stuffs is partly determined, therefore, by its source. When it is all oil, or nearly so, it is worth much more for use by the animal than when it is made up to quite an extent of other bodies.

The proportions of fat or oil in feeding stuffs vary within wide limits. In general, seeds and their byproducts contain more than the coarse foods, the differences in the percentages of actual oil being greater than is indicated by the ether-extract. Straws naturally have less oil than the hays. But little is found in the dry matter of roots and tubers. Among the cereal grains and other more common farm seeds, corn and oats show the largest amounts, the proportion in dry matter being from five to six in one hundred, while wheat, barley, rye, peas, and rice contain much smaller percentages, wheat having about 2 per cent, and rice sometimes not over one-fifth of 1 per cent. Agricultural seeds that are especially oleaginous are cottonseed, flaxseed, sunflower seeds, and the seeds of many species belonging to the mustard family, such as rape. Peanuts, cocoanuts and palm nuts are also very rich in 
oil. The average percentages in these seeds and nuts are approximately as given below:

Oil in certain seeds

Per cent

Linseed............ 34

Cottonseed............30 30

Sunflower seed........ 32

Rape seed ........... 42

Mustard seed ......... 32

Per cent

Peanuts............ 46

Cocoanuts...........6 67

Palm nuts.......... 49

Poppy seed.......... 41

The oils from all the above are important commercial products, being used in a great variety of ways in human foods and in the arts. In many cases, the refuse from this extraction goes back to the farm as food for the cattle. This is especially true of linseed and cottonseed.

The vegetable and animal fats and oils may, for convenience' sake, be discussed in two divisions, the neutral fats or glycerides and the fatty acids. The neutral fats are combinations of the fatty acids with glycerine. When, for instance, lard is treated at a high temperature with the alkalies, potash and soda, glycerine is set free and an alkali takes its place in a union with the fatty acids. This is the chemical change which occurs in soap-making. There are several of these neutral fats, the ones most prominent and important in agriculture being those abundant in butter and in the body fats of animals; viz., butyrin, caproin, eaprylin, caprin, laurin, myristin, olein, palmatin, and stearin. Butyrin is a combination of butyric acid and glycerine, stearin of stearic acid and glycerine, and so on.

These individual fats possess greatly unlike physical 
properties. At the ordinary temperature of a room some are liquid and some are solid, olein belonging to the former class and palmatin and stearin to the latter. It is a matter of common observation that butter, lard and tallow differ in hardness at a given temperature, and by the use of a thermometer it may easily be discovered that their melting points are not the same. As these animal fats are in all cases chiefly mixtures of olein, palmatin, and stearin, stearin being a solid at ordinary temperatures, and olein a liquid at anything above the freezing point, it is evident that the relative proportions of these compounds will affect the ease of melting and the hardness of the mixtures of which they are a part. Tallow having more stearin than lard and butter and less olein, is consequently much more solid on a hot day.

Milk fat contains not only the three principal fats but also the others mentioned, butyrin, caproin, caprylin, eaprin, laurin and myristin, in small proportions, and these latter tend to give butter certain properties that distinguish it from the other animal fats, which are almost wholly palmatin, olein and stearin. Doubtless the flavor, texture and resistance of butter to the effects of heat are much influenced by the proportions of the numerous fats it contains, but there is much connected with this subject of which we are still ignorant.

Free, fatty acids exist in nature. They are not found in butter, lard and tallow unless these substances have undergone fermentations, or, as we say, have become rancid. The characteristic flavor of strong butter is due to free butyric acid, which, because of fermentations, 
has parted from the glycerine with which it was originally combined in the milk. In plant oils, on the other hand, are found considerable proportions of the free fatty acids, some of which have not been discovered so far in animal fats, either free or uncombined.

Perhaps no one has studied plant oils more thoroughly than Stellwaag, who investigated the ingredients of the ether and benzine extracts from plants. His results show that not only do these extracts include substances which are not fats, but that a considerable proportion of free fatty acids is always present, sometimes in quantities exceeding the neutral fats:

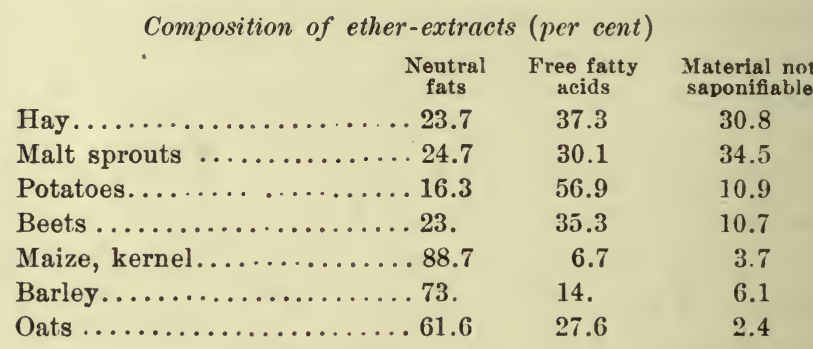

It appears, as before stated, that ether-extract, especially that from coarse fodders, may consist, to a large extent, of materials which should not be classed among the fats. Stellwaag demonstrated that only about 60 per cent of the hay extract which he investigated consisted of oil. On the contrary, the extracts from the grains proved to be nearly all oil. Moreover, the grain oils were made up principally of glycerides, and those from hay, malt sprouts, potatoes and beets consisted largely of free fatty acids. 


\section{CHAPTER VII}

THE COMPOSITION OF THE BODIES OF FARM ANIMALS

THE principal compounds existing in the bodies of our farm animals have been quite fully considered on preceding pages. It now remains for us to learn something of the proportions of these substances that are needed in constructing the carcasses and other tissues of steers, sheep and swine; for it is about these species that we have the most extensive and accurate knowledge as related to chemical composition. Certainly such knowledge is important. The animal is the direct product of food, and before we can consider intelligentiy the functions of food nutrients and the ways in which they are made to fulfil their offices, we must understand what is to be done. So far, then, as it is a matter of construction, what must be accomplished by the use of food in building the body of an animal? 'It has doubtless become evident from foregoing statements that many compounds are common to the vegetable and the animal kingdoms. The chemical constituents in plants and animals are classified in the same way, also; viz., water, ash, or mineral compounds, protein, carbohydrates, and fats. Here the similarity stops, for the proportions of these classes as found in the fat steer and in the stalk of maize are 
entirely unlike, and what is true in this respect of the steer and maize is true of all other animals and plants. The dry matter of the vegetable world consists most largely of fiber, starch and other carbohydrates, while animal tissues contain these compounds in so small a proportion as to be inappreciable in stating the percentage composition. In the average animal dry matter, as it appears in the market, the fats are the leading constituents, and the proportion of protein is more than twice, perhaps three times, that in average vegetable tissue.

In considering the composition of farm animals, we may first divide the body substances into water and dry matter. The dry matter, aside from the contents of the stomach and intestines, and the food ingredients on the way to being used, essentially belongs to three classes of compounds, ash, protein, and fats, which, as is the case with water, are present in greatly varying proportions in different species, and even in the same species according as the animal is young or old, lean or fat. Our knowledge on this subject is largely derived from the investigations of Lawes and Gilbert, at Roth: amsted, England. These investigators carried through the great effort of analyzing the entire bodies of ten animals representing two species at different ages, and three species in different conditions of fatness. At the Maine Experiment Station in this country, the bodies of four steers were analyzed, exclusive of the skin, two steers being younger and not so fat as the other two. From these data a very fair knowledge may be obtained not only of the composition of the bodies of bovines 
sheep, and swine, but also of the extent to which this composition is affected by age and condition:

Composition of farm animals (per cent)

\begin{tabular}{|c|c|c|c|c|}
\hline Species & Water & Ash & Protein & Fat \\
\hline Ox, well-fed............ & 66.2 & 5.9 & 19.2 & 8.7 \\
\hline$x$, half-fat.............. & 59. & 5.2 & 18.3 & 17.5 \\
\hline $\mathrm{Ox}$, fat...$\ldots \ldots \ldots \ldots$ & 49.5 & 4.4 & 15.6 & 30.5 \\
\hline heep, lean... .......... & 67.5 & 4. & 18.3 & 10.2 \\
\hline , well-fed........... & 63.2 & 3.5 & 17.4 & 15.5 \\
\hline , half-fat............ & 58.9 & 3.8 & 16. & 21.3 \\
\hline fat............. & 50.9 & 3.3 & 13.9 & 31.9 \\
\hline , very fat........... & 43. & 3.1 & 12.2 & 41.4 \\
\hline well-fed........... & 57.9 & 2.9 & 15. & 24.2 \\
\hline fat $\ldots \ldots \ldots \ldots$ & 43.9 & 1.9 & 11.9 & 42.3 \\
\hline If $\ldots \ldots \ldots \ldots \ldots$ & 64.6 & 4.8 & 16.5 & 14.1 \\
\hline 7 -months........... & 59.4 & 4.4 & 17.4 & 18.8 \\
\hline 7 -months..... & 57.1 & 5.2 & 17.5 & 20. \\
\hline 4-months $\ldots \ldots$ & 53.1 & 5.1 & 16.6 & 25. \\
\hline teer, 24 -months..... & 53.4 & 5.2 & 16.8 & 24. \\
\hline
\end{tabular}

It is always more or less surprising to the learner to ascertain that the bodies of farm animals of various species and in various conditions are about half water. This is water that is not in any way chemically united with associated compounds, but exists in the blood and tissues in a free state, and may be dried out in the usual manner. Next to water, fat is the most abundant material, protein and ash following in the order named.

Perhaps the most striking fact displayed is the great variation in the proportion of these ingredients according to the age and condition of the animal. For instance, the percentage of water in the fat calf is much 
greater than in the fat $o x$, and this is an illustration of a general truth, that mature animals are less watery than young ones. The amount of water present in the animal body is also influenced to a marked extent by the degree of fatness. The half-fat ox contained over 8 per cent more water than the fat, the store sheep 22 per cent more than the extra fat, and the store pig 14 per cent more than the fat. The explanation of this, as before stated, is not that fat replaces water already in the tissues of the lean animal, but that the increase is much more largely dry matter than was the original body substance. It is obviously true, also, that in fattening an ox or sheep, thus increasing the relative amount of fat, the proportions in the dry substance of ash and protein are decreased. The above statements are explained by the results obtained by Lawes and Gilbert in determining the composition of the increase while animals are fattening:

\begin{tabular}{|c|c|c|c|c|}
\hline & $\underset{\%}{\text { Water }}$ & $\underset{\%}{A s h}$ & $\underset{\%}{\text { Protein }}$ & Fat \\
\hline Lean ox. & 66.2 & 5.9 & 19.2 & 8.7 \\
\hline Lean sheep.............. & 67.5 & 4. & 18.3 & 10.2 \\
\hline Wéll-fed swine $\ldots \ldots \ldots \ldots$. & 579 & 2.9 & 15. & 24.2 \\
\hline Average of lean & 63.9 & 4.3 & 17.5 & 14.3 \\
\hline Av. of increase while fattening & 23.8 & 1.1 & 7.3 & 67.8 \\
\hline
\end{tabular}

This comparison of the composition of lean animals and of the increase when they are fattened is a sufficient explanation of the less watery and fatter condition of the animal when ready for the market. The store animal is nearly two-thirds water and about one-seventh fat, while the increase is less than one-quarter 
water and over two-thirds fat. The percentage of protein in the increase is also very small.

Not only does fattening an animal materially modify the composition, but the proportion of butcher's meat is greatly increased.

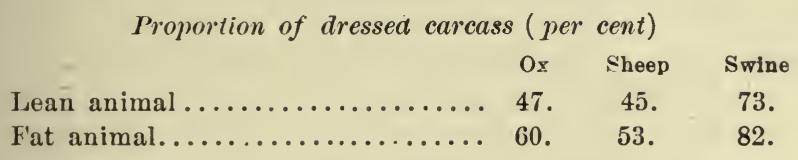

These slaughter tests were made by Lawes and Gilbert, and they explain in part why a fat steer is worth so much more per pound of live weight, even if the quality of the meat is no higher. It may be said, in a general way, that the carcass portion of the animal body varies with bovines and sheep from 50 to 65 per cent of the live weight, according to age and condition. Swine "dress away" not far from one-fifth.

It would be possible to go further in our discussion of the animal body and consider it from the structural or anatomical point of view. It is certainly important to know something of the organs involved in digestion, respiration and assimilation if we would reach a clear understanding of how the food is made available and utilized, but such facts as are deemed necessary concerning these specialized tissues we will take up in their appropriate connections. 


\section{CHAP'TER VIII}

\section{THE DIGESTION OF FOOD}

We have accepted so far without discussion the almost self-evident fact that the food is the immediate source of the energy and substance of the animal body. It now remains for us to consider the way in which the nutrition of an animal is accomplished. The first step in this direction is the digestion of food. It is necessary for food ingredients to be placed in such relations to the animal organism that they are available for use. This involves both condition and location. The various nutrients in the exercise of their several functions must be generally distrikuted in all the interior parts of the animal. It is obvious that hay and grain as such cannot be so distributed, and so their compounds must, in part at least, be brought into a soluble and diffusible condition, in order that they may pass through the membranous lining which separates the blood-vessels and other vascular bodies from the cavity of the alimentary canal.

In discussing physiological relations of food, two terms are employed: viz., digestion and assimilation. Digestion refers to the preparation of food compounds for use, by rendering them soluble and diffusible, changes which are accomplished in what we call the ali- 
mentary canal, a passage that begins with the mouth, includes the stomach and intestines, and ends with the anus. Assimilation signifies the appropriation of $\mathrm{nu}$ trients, after digestion, to the maintenance of energy and to the building of flesh and bones, processes taking place in the tissues, to which the nutritive substances are conveyed by the blood. The two terms are entirely distinct in meaning, although they are confused in popular speech.

In digestion, a feeding stuff undergoes both mechanical and chemical changes. It is masticated, that is, ground into finer particles, after which, in its passage along the alimentary canal, it comes in contact with several juices which profoundly modify it chemically. That portion of it which is rendered diffusible is absorbed by certain vessels that are imbedded in the walls of the stomach and intestines, and is conveyed into the blood. The insoluble part passes on and is rejected by the animal as worthless material, and constitutes the solid excrement or feces. A study of digestion includes, then, a knowledge of mastication, of the sources, nature and functions of the several digestive juices, and a consideration of the various conditions affecting the extent and rapidity of digestive action.

\section{FERMENTS}

The changes involved in rendering food compounds soluble are intimately connected with a class of bodies known as ferments, to which brief reference has already been made in their relations to the preservation of feed- 
ing stuffs; and it seems necessary before proceeding to a consideration of digestion as a process to learn something of the nature and functions of these agents, which are actively and essentially present in the digestive tract.

A ferment may be defined in a general way as something which causes fermentation; in other words, the decomposition of certain vegetable or animal compounds with which it comes in contact under favorable conditions. Ferments are of two kinds, organized and unorganized. Organized ferments are low, microscopic forms of vegetable life, generally single-celled plants. Unorganized ferments are not living organisms, but are simply chemical compounds.

When milk is allowed to remain in a warm room for several hours it becomes sour. An examination of it chemically shows that its sugar has largely or wholly disappeared and has been replaced by an acid. A study of the milk with the microscope, before and after souring, reveals the fact that there has been a marvelous increase in it of single-celled organisms or plants. The growth of this form of life is regarded as the cause of the change of the sugar into lactic acid. We have here the so-called lactic-acid ferment, which may typify the organized ferments known as bacteria. Numerous other fermentations of the same general kind are common to every-day experience. The changes in the cider barrel and the wine cask, the spoiling of canned fruits and vegetables, and the heating of hay and grain are illustrations of what is accomplished by these minute organisms. Bacteria that cause disease, and which multiply in the organs and other tissues of the animal body, may 
also be properly called ferments, because in their growth new compounds are formed which are as truly fermentative by-products as the carbonic acid and alcohol of cider and beer making. As this subject viewed on its pathogenic side is not important to the feeder, we need to study organized ferments only so far as they relate to the preservation of feeding stuffs and to changes in the alimentary canal. We shall be best equipped for controlling ferments and preventing their destructive action if we know what they are, and understand the general conditions under which they thrive. We should also know how, and to what extent, their action occasions harm.

The organized ferments are classed in the vegetable kingdom. As a rule, each individual plant is a single cell, varying in shape and so minute as to be invisible to the unaided sight. It corresponds in its general structure to the cells which make up the tissues of the higher vegetable species, i. e., it consists of a cell wall inside of which are protoplasm and other forms of living matter. These organisms are distributed everywhere, -in the air, in the soil, on surfaces of plants and in the bodies of animals. Whenever the right opportunity offers itself, they are ready to begin to multiply and bring about all the results attendant upon their growth.

The conditions essential to their development are the proper degree of moisture and temperature and the necessary food materials. Thoroughly dry animal and vegetable substances do not ferment. Hay and grain that have been dried to a water content of 10 
per cent will keep a long time without loss from fermentative changes. The heat of a mow of new hay or of a bin of new grain, with its subsequent musty condition, is due to the fermentations that are made possible through the presence of considerable moisture. Thorough drying is a preventive of destructive fermentations.

There is a temperature at which each vegetable ferment thrives best, and there are limits of temperature outside of which the growth of these forms of life does not occur, or is very slight. Numerous species thrive between $75^{\circ}$ and $100^{\circ} \mathrm{F}$. Fermentable materials like fruit and meat at the freezing point or below are not subject to fermentations. The boiling point of water kills most bacteria, and temperatures above $150^{\circ} \mathrm{F}$. retard or entirely prevent their growth.

Like all life, these organisms must have food. Many species find this in acceptable forms in vegetable products. Because they generally contain the sugar, albuminoids, and mineral compounds which nourish bacteria, feeding stuffs are always the prey of ferments under proper conditions of moisture and heat. The prevention of fermentation in cattle foods is desirable because it occasions a loss of nutritive value. This becomes evident when we consider the nature of the chemical changes that occur. For instance, when sugar is broken up through the influence of a bacterium, new compounds are formed which take up free oxygen. This means that combustion occurs, causing the liberation of energy which otherwise would have been available to the animal, if the sugar had been taken 
as food. Many fermentations involve oxidation, all of which are destructive of food value.

Several theories have been advanced to account for the action of the organized ferments. The most plausible seems to be that these little plants use sugar and other compounds as food, deriving energy therefrom, the carbonic acid, alcohol and other new bodies being the by-products of this use. Whatever may be the real explanation of the changes that occur, fermentations due to plant growth are among the most useful agencies with which the farmer deals, and may be the most harmful.

There is another class of ferments which is termed unorganized, and to which the general name enzym is given. These are the ferments especially important in digestion. They are merely chemical compounds which produce a peculiar effect upon certain bodies with which they come in contact. If a thin piece of lean beef be suspended in an extract from the mucous lining of a pig's stomach, to which has becn added a small proportion of hydrochloric acid, the liquid being kept at about $98^{\circ} \mathrm{F}$., the beef will soon begin to soften, afterwards swell to a more or less jelly-like condition and finally dissolve. The same general result would occur with fish, blood fibrin or the coagulated white of an egg. When starch, which is not affected by pure, warm water, is placed in a warm water solution of crushed malt it soon dissolves, leaving a comparatively clear liquid. A chemical examination of these preparations will reveal the fact that the compounds of the meat are present in solution in somewhat modified forms, 
and that the starch has been changed to a sugar or other soluble bodies. In both cases substances insoluble in water have become soluble and diffusible.

The cause of these changes is the presence of typical bodies, one in the pig's stomach and one in the malt, ferments of the enzym class, the former of which renders albuminoids soluble, the latter acting to produce a similar result with the insoluble carbohydrates. This action is different from that of the organized ferments, where oxidation occurs in many cases. The enzyms simply induce the albuminoids and starch to take up the elements of water, which apparently does not greatly diminish their energy value. How this is done cannot be explained in simple terms, if at all. Our knowledge of the manner of the change rests entirely upon theoretical grounds. The digestion of food is almost wholly accomplished through the specific effect of enzym bodies, of which every digestive fluid contains one or more. Examples of these are the pepsin and pancreatin of the drug store that contain enzyms mixed with more or less impurities. The function of each of these ferments we shall consider as we proceed to discuss the various steps of digestion.

\section{THE MOUTH}

The first step in the digestion of fodders and whole grains is to reduce them to a much finer condition. This is done in the mouth, the teeth being the grinding tools.* Sometimes the cutting or grinding is par-

* This is not true of hens, turkeys and other fowls. 
tially or wholly performed for the animal in hay-cutters and grain mills. However this may be accomplished, it is an essential operation for two reasons, (1) it puts the food in condition to be swallowed, and (2) fits it for the prompt and efficient action of the several digestive fluids. Dry whole hay or kernels of grain could hardly be forced down the tube leading to the animal's stomach. It is necessary for these materials to be broken down and moistened in order that they may be swallowed. Even if they could be conveyed to the stomach in their natural condition the process of rendering their constituents soluble would proceed very slowly. Common experience teaches us how much more quickly finely powdered sugar or salt will dissolve than the large erystals or lumps. The more finely any solid is ground, the larger is the surface exposed to the attack of the dissolving liquid, and this is as true of foods as of sugar or salt.

Prompt and rapid solution of food is essential, because if it is too long delayed, uncomfortable and injurious fermentations are likely to set in, and because of imperfect digestion, the final nutritive effect of the ration may be diminished. For these reasons, animals with diseased teeth, or those that have lost teeth, make poor use of their food, and require an unnecessary amount to keep them in condition. These conditions may often be a cause, especially with horses, of disappointing results from an ordinarily sufficient ration.

The teeth of our domestic animals differ somewhat in number and arrangement. Authorities state the following to be the usual number: 


\begin{tabular}{|c|c|c|c|c|}
\hline & Total & Incisors & Canines & Molars \\
\hline Horse & $36-40$ & 12 & 4 & 24 \\
\hline $\mathrm{Ox}$ & 32 & 8 & & 24 \\
\hline Sheep and goat......... & 32 & 8 & & 24 \\
\hline Pig................... & 44 & 12 & 4 & 28 \\
\hline
\end{tabular}

The incisors or front teeth are those which are used for prehension, and by grazing animals for cutting off the grass and other herbages. With the ox, sheep and goat, incisors are found only in the lower jaw. These shut against a tough pad on the upper jaw. They are constantly wearing off, and with old animals may be so worn away as to leave only the roots. Such animals do not graze successfully. With the horse and pig, incisors are found in equal numbers in both jaws.

The molars are the grinding teeth. Those of the horse sometimes need filing on the ontside edges in order to prevent irritation and soreness of the adjacent tissues. A diseased molar may occasion an animal much discomfort and cause imperfect mastication.

During mastication there is poured into the mouth a liquid called the saliva, which has two important functions: (1) it moistens the food, and (2) with several species of animals it causes a chemical change in certain of the constituents of the food.

The saliva has its origin in several secretory glands that are adjacent to the mouth cavity, and from these this liquid is poured into the mouth through ducts that open in the cheek and under the tongue. The chief of these glands are located in the side of the face, below and somewhat back of the jaws and beneath the tongue, and are called the parotid, the submaxillary and the 
sublingual. Other glands of this character are scattered in the cheeks and at the base of the tongue. The anatomy and arrangement of these organs are not essential to our subject. We are chiefly interested in the liquid which they secrete.

The saliva is a transparent and somewhat slimy liquid, and contains generally not less than 99 parts in 100 of water, and one part or less of solid matter. It is alkaline in reaction, because of the presence of compounds of the alkalies. The specific chemical effect exerted by this liquid on the food constituents may be illustrated by subjecting starch to its action. When this is done, the starch gradually disappears as such and is replaced by maltose, the same sugar that we find in barley malt. The chemist has learned that the agent which is active in causing this change is a ferment, to which the name ptyalin has been given, and which is always present in the saliva of man and of some animals. It is classed among the diastatic ferments, because it has an office similar to that of diastase in the germination of seeds; viz., the transformation of the starch into a sugar. This change begins in the mouth and probably continues in the stomach until the food becomes so acid that the ferment ceases to act, for ptyalin is inactive except in an alkaline medium. There is no reason for supposing that any considerable proportion of the starch of a ration is transformed by the saliva, but this solvent action which continues later in the digestive processes certainly begins in the mouth in the manner described. The saliva also moistens the food, which is a most 
important office, for it is a necessary preparation to the act of swallowing. With large ruminants, the quantity of saliva required for this purpose is large, as is evident when we remember that an ox or cow may consume in one day 24 pounds of very dry hay and grain, and that rumination goes on much of the time while the animal is not eating. It is estimated that oxen and horses secrete from 88 to 132 pounds daily, an apparently enormous quantity of liquid for secreting organs no larger than the salivary glands to supply.

\section{THE STOMACH}

When the food leaves the mouth, it passes down the gullet (œesophagus) into the stomach. The only modifications it has suffered up to this point are its reduction to a finer condition and a slight action of the mouth ferment upon the starch, an influence which doubtless continues in the stomach for a larger or shorter period, according to circumstances. After the food is swallowed changes of another kind begin sooner or later, affecting the protein compounds especially.

Before considering gastric digestion from a chemical point of view, we should become acquainted with the widely differing structure of the stomachs of the various farm animals. Those of the ox and horse are greatly unlike. The stomach of the ox, and of all other ruminants, consists of four divisions or sacs, whereas with the horse and pig it is made up of a single sac.

The ruminant stomach is really quite a complicated affair, and the way in which it disposes of the food is 
understood only after a careful study of details. Its four divisions or sacs are the paunch, honeycomb, many-plies and rennet, or what the physiologist has named the rumen, reticulum, omasum and abomasum. With the ox these cavities contain on the average not far from fifty-five gallons, about nine-tenths of this space belonging to the paunch. Fig. 1.

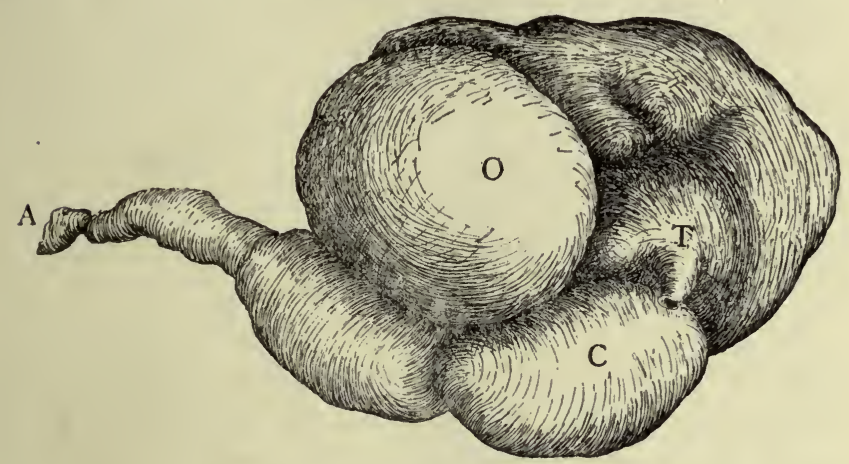

Fig. 1. Stomach of ox.

$\mathrm{T}$, rumen or paunch, showing attachment of oesophagus.

C, reticulum or honeycomb.

$\mathrm{O}$, omasum or many-plies.

A, abomasum or rennet, showing attachment of small intestine.

The food, in its descent from the mouth, passes at first mostly into the paunch through a slit in the gullet. This cavity, as stated, is very large, and it may properly be considered as an immense reservoir for the storage of the bulky materials which the ruminants take as food. As is the ease with the entire digestive canal, the walls of the paunch are composed of three layers of tissue, the middle one being a very thick 
muscular coat, which seems necessary to produce the movement of large masses of food. The inner or mucous layer is covered with numerous leaflike projections, in which the blood-vessels are freely distributed. During its stay in this reservoir, the moist food becomes thoroughly softened and besides undergoes a variety of changes, chiefly those due to the organized ferments combined perhaps with the continued action of the saliva. These fermentations probably are attended by an evolution of gases, the fate of which is not well known. It is suggested that the rapid puffing up of the paunch of a freshly-killed bovine is due to the failure of the blood to take up these gases. Sometimes unnatural and dangerous fermentations set in, induced often by the consumption in the spring of a large quantity of easily fermentable food such as green clover. This causes hoven, and unless the gas pressure is at once relieved by an opening into the paunch the animal dies, often after the bursting of the rumen.

A portion of the food reaches the reticulum or honeycomb, either through the osophagal slit when first swallowed, or through a large opening between the paunch and the honeycomb. The reticulum also communicates with the third stomach by an opening. This is the smallest division of the stomach, and derives its common name from the fact that its interior surface is divided by ridges of the mucous membrane into cells which bear a close resemblance to a honeycomb. These cells, which are several sided and quite deep, appear to be a "catch-all" for the foreign bodies 
which animals are liable to swallow, such as small stones, pins and nails. The contents of this compartment of the stomach are very watery, a condition which is said to aid the return of the food to the mouth, portion by portion, for remastication.

Rumination, which is the re-chewing of food previously swallowed, is peculiar to bovines, sheep and goats. In the case of these species, the mastication of coarse fodder is not completed before it is swallowed the first time, and they have the power of returning to the mouth the material which has become stored in the paunch and honeycomb in order that it may be more finely ground. This is what is termed "chewing the cud." It is an operation which greatly aids digestion by rendering the food mass finer and more susceptible to the action of the digestive fluids. Animals fed on grain alone do not ruminate. They "lose their cud," a condition popularly and erroneously supposed to be fatal to the animal's life.

After remastication, the food does not return wholly to the first and second stomachs, but is mostly carried along in what is known as the osophagal groove to the third stomach, the omasum. The finer portions may even do this when first swallowed. The many-plies (omasum) is a cavity somewhat larger than the honeycomb, which has a most curious interior structure. It is filled with extensions of the mucous membrane in the form of leaves, between which the food passes in thin sheets, an arrangement which seems to have for its purpose the further grinding of the food so that when it finally reaches the fourth and last compart- 
ment it is in a very finely-divided condition and is thoroughly prepared for the action of the juices that are subsequently poured upon it.

It is at the last stage of the journey of the food through this complicated stomach that it is submitted to the true gastric digestion. As a matter of fact, the abomasum or rennet is regarded as the true stomach, the other three sacs being considered as enlargements of the osophagus. In the calf, the rennet is the only part developed, the other divisions not coming into use until the animal takes coarse foods in considerable. quantity. The fourth stomach is larger than either the second or third. It receives directly from the omasum the finely divided food, upon which it pours the gastric juice, a liquid that is secreted in large quantity by glands located in its inner or mucous membrane. This juice, like all the digestive fluids, is mostly water, the proportion being between 98 and 99 parts to less than two parts of solids. The latter consist of ferments, a certain amount of free or uncombined hydrochloric acid and a variety of mineral compounds, prominent among which are calcium and magnesium phosphates and the chlorides of the alkalies, common salt being especially abundant.

Especial interest pertains to the ferments of the gastric juice, one of which, in connection with free hydrochloric acid, causes a most important change in the proteids of the food by reducing albuminoids, such as the gliadin and glutenin of the wheat kernel to soluble forms. We know quite definitely about this action. because it can be very successfully produced in an ar- 
tificially prepared liquid. If the mucous lining of a pig's stomach, after carefully cleaning without washing with water, is warmed for some hours in a very dilute solution of hydrochloric acid, an extract is obtained which has the power of dissolving lean meat, wheat gluten and other proteid substances. The active agent in causing this solution is pepsin, an unorganized ferment or enzym which is present in the gastric fluid of all animals. It changes albuminoids to peptones, bodies so soluble and diffusible that they pass readily into certain small vessels which are distributed in the walls of the alimentary canal and thus become available as nutrients. The other ferment present in the gastrie juice is the one which gives to rennet its value as a means of coagulating the casein of milk in cheesemaking, and is called rennin. The action of this latter body is especially prominent in the stomach of the ealf when fed exclusively on milk, and it is the calf's active stomach, the fourth in the mature animal, which is the source of commercial rennet.

The free hydrochloric acid in the gastric juice is also actively concerned in proteid digestion. It is found that a solution of pepsin has a limited effect in the absence of free acid, for when, during artificial digestion, the supply of this acid is used up it must be renewed or digestion is checked.

The stomach of the horse and pig consists of a single sac, so that digestion with these animals is a much simpler matter mechanically than with ruminants. Chemically, the results are essentially similar, i. e., the protein is in part changed to peptones. The food, after 
being swallowed, is not returned to the mouth, but is very soon brought under the action of the gastric juice

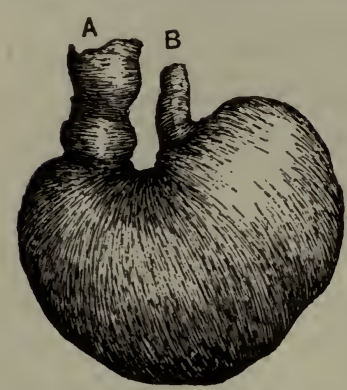

Fig. 2. Stomach of horse. $B$, cesophagal attachment. A, pylorie end of stomach, with beginning of small intestine. without so long-continued preliminary preparation by remastication and trituration. For this reason the horse fails to digest coarse fodders so completely as the ox does. Besides, the stomachs of the horse and pig are too small to admit of so large an ingestion of hay or similar material, as is the case with ruminants of similar size. In all species, however, the chemical result of stomach digestion is essentially the same, i. e., the protein is in part changed to peptones. Fig. 2.

\section{THE INTESTINES}

The most extended portion of the alimentary canal, though not the most capacious in all cases, is the intestines. They consist of a tube differing in size in its various portions, which begins with the stomach and ends with the anus. This tube is not a straight passage between the points named, but presents curves and folds, so that when straightened out it appears surprisingly long. Its average length with the $\mathrm{x}$ is given as 187 feet, sheep 107 feet, horse 98 feet, and hog 77 feet, lengths which are from twelve to twentyseven times that of the body of the animal. The intes- 
tines are divided into large and small, the latter being from three to four times as long as the former.

When the food leaves the stomach, it enters the small intestines. At this point it is only partially digested. The fats are probably so far unchanged and, without doubt, the larger proportion of the proteids and carbohydrates that are susceptible of solution is still in the original condition. Hardly has this partially dissolved material passed into the small intestines before it comes in contact with two new liquids which are poured upon it simultaneously or nearly so; viz., the bile and the pancreatic juice, and the changes which began in the mouth and stomach, together with others which set in for the first time, proceed vigorously.

The bile has its source in the liver. It is a secretion of this organ, and after elaboration it is stored in a small sac attached to the liver which is called the "gall bladder," and from which gall is conveyed to the intestines through a duct opening very near the orifice leading out of the stomach. Bile is a liquid varying when fresh from a golden red color in man to a grass-green or olive-green in certain herbiverous animals. It is slightly alkaline, bitter to the taste and without odor. The specific and characteristic constituents of the bile are two acids, glycocholic and taurocholic, that are combined with sodium and are associated with two coloring matters, bilirubin and biliverdin. Numerous other compounds arè present in very small proportions, such as fats, soaps and mineral compounds, but they appear to have no important. 
relation to digestion. If any ferment is present at all, it is only as a trace, and therefore the bile is incapable of effecting decompositions of the proteids and carbohydrates, such as occur in the mouth and stomach. This is shown by experiments.

Nevertheless, this liquid must be regarded as having a real digestive function, which it exerts in two ways, (1) by preparing the chyme (partially digested food from the stomach) for the action of the pancreatic juice and (2) in acting upon the fats in such a way as to render their absorption possible.

We have learned that pepsin, the stomach ferment, acts upon proteids only in an acid medium. The opposite is true of the ferments which the food meets in the intestines, for these require an alkaline condition. The bile tends to neutralize the acidity of the chyme, and in this, as well as by other chemical changes too complex for discussion here, prepares the way for the pancreatic juice to do its work.

The most important discovery so far made in connection with the bile is the fact that when its entrance into the intestines is prevented the fat of the food largely passes off in the feces. This proves that in some way the liver secretion is essential to the digestion of fats. The ordinary and probably correct explanation of what takes place is that, while bile does not decompose the fats in any way, it is able, in connection with certain influences of the pancreatic juice, to reduce them to an emulsion, i. e., to a condition of suspension in a liquid in very finely divided particles, a form in which they are able to pass into the blood. It is believed 
that the bile has more or less antiseptic influence and so prevents the intestinal contents from undergoing putrefactive fermentation, which would have the effect of greatly increasing the offensive odor of the feces.

The pancreatic juice has a more complex function in digestion than that of any other digestive fluid. It is known to contain at least three distinct ferments, each of which has its own peculiar effect upon each of the three classes of food constituents. This juice reaches the food at practically the same time as the bile. It comes from the pancreas, a gland known to butchers as the "sweet bread," and enters the intestine through a small duct which in some animals is confluent with the bile duct. It is somewhat gluey in character, of alkaline reaction and has a saltish taste.

First of all, the pancreatic juice has, in a marked degree, the power of digesting proteids in an alkaline medium. This power is due to a ferment known as trypsin, which converts proteids to peptones, and corresponds in its function, therefore, to the pepsin of the stomach. Under the influence of this ferment the proteids are also, to some extent, split into simpler bodies.

The transformation of starch into sugar and other soluble bodies, which ceased in the stomach, is again taken up through the influence of a diastatic ferment present in the pancreatic juice, and proceeds vigorously. A third enzym, also present, is one that has the power of splitting the neutral fats into fatty acids and glycerine, a change which appears to have an important relation to the emulsionizing of fats. As before intimated, 
the bile and the pancreatic juice appear to share the function of fat digestion.

As the intestinal contents pass along, they come in contact with a juice secreted by the walls of the intestines, the action of which has been carefully studied. It has been found that this liquid has no action on the proteids or fats, but that it is able to convert starch into soluble bodies, and especially has the peculiar property of transforming into glucose the maltose arising from previous digestion, glucose being the form in which all digested carbohydrates are supposed to enter the circulation. It seems, then, that the intestinal juice supplements the action of the other digestive fluids, so far as carbohydrates are concerned, completing starch digestion and preparing the sugars for absorption, and when we consider that from 80 to 90 per cent of the food of our farm animals consists of carbohydrates the great importance of this office is apparent.

From the time the food enters the stomach until the undigested residue leaves the body the contents of the alimentary canal are subjected to fermentations caused by organized ferments, resulting in the evolution of acids, gases and certain other compounds formed from the proteids, which give to the feces its offensive odor. Just what relation these fermentations have to the digestion of food we are not able to state. There are some reasons for believing that crude fiber (cellulose), during its stay in the first stomach, is the subject of their action, and its digestion may be partly accomplished in this way. Such fermentations become prominent only when, because real digestion does not proceed 
normally, they are given an opportunity to deveıop with unusual activity and cause bloat, colic and offensive odors in the solid excrement.

\section{ABSORPTION OF THE FOOD}

From the time the food enters the stomach, during nearly its entire course along the alimentary canal, there is a constant production of soluble compounds, which progressively disappear into other channels, so that when the anus is reached. only a portion of the original dry matter is found in the residue. In some way, not wholly explainable in all its details, the digested food has been absorbed and received into vessels through which it is distributed to the various parts of the body.

A merely casual observation shows us that the inner surface of the walls of the digestive organs are covered by numerous projections. The anatomist, by a careful study of these, has learned that imbedded in their tissue, especially in the intestines, are the minute branches of two systems of vessels. One set is the lacteals belonging to the so-called lymphatic system and the other set is the capillaries of the blood system. The lymphatic vessels or tubes all lead to a main tube or reservoir, the thoracic duct, which extends along the spinal column and finally enters one of the main blood-vessels. Any material, therefore, taken up by the lacteals ultimately reaches the blood. The capillaries all converge to a larger blood-vessel, known as the portal vein, which enters the liver, carrying with it whatever material the capillaries have absorbed. 
The manner in which the soluble food is absorbed may be explained in part on common physical grounds. When two solutions of different densities, containing diffusible compounds, are separated by a permeable membrane, diffusion through this membrane from the denser to the lighter liquid will always occur. Such a condition as this prevails in the intestines, we may believe. The intestinal solution, the denser one, is separated from a less concentrated liquid, the blood, which is constantly flowing on the other side of a thin dividing membrane. Under these conditions only one thing can occur; viz., the passage into the blood of certain parts of the digested food. It is held that in this way water, soluble mineral salts and sugar pass direstly into the blood-vessels. The peptones are taken up by the capillaries and the fats enter the blood entirely through the lacteals.

In the absorption of peptones, we encounter forces other than those which pertain to the mere diffusion of liquids, the operation of which is still more or less shrouded in mystery. As we have learned, the proteids are largely changed to peptones in the stomach and intestines, but, strange as it may seem, no peptone is found in the blood. At some point in its passage throngh the lining tissues of the digestive tract, it has been regenerated into forms more nearly like those from which it is derived. Moreover, the absorption of fats is regarded as being accomplished through the activity of certain cells or corpuscles, which appear to convey this portion of the food to the lacteals. It seems, then, that the vital forces residing in the living animal cells 
play a part in transferring the nutrients into the blood circulation, and that this absorption can no longer be explained wholly on physical grounds.

FECES

The soluble and insoluble portions of the intestinal contents become separated gradually, and the undissolved part arrives finally at the last stage of its journey along the alimentary canal and is expelled as the solid excrement or feces. This is made up of the undigested food* and a small proportion of other matter, such as residues from the bile and other digestive juices, mucus and more or less of the epithelial cells, which have become detached from the walls of the stomach and intestines. Very small quantities of fermentation products are present also, which give to the feces its offensive odor. The incidental or waste products may properly be considered as belonging to the wear and tear of digestion

\section{THE RELATION OF THE DIFFERENT FEEDING STUFF} COMPOUNDS TO THE DIGESTIVE PROCESSES

Numerous digestion experiments with a large variety of feeding stuffs have abundantly established the fact that these materials differ greatly in their solubility in the digestive juices. This is an important matter, and one which should be well understood, for we must consider both the weight of a ration and its availability in determining its nutritive value. Variations in digestibility are caused primarily by variations in composi-

* See note, p. 125. 
tion. The low digestibility of wheat straw, as compared with that of the wheat kernel, is due to the absence in one of compounds that are abundant in the other. We, therefore, must deal fundamentally with the susceptibility of the various single constituents of plants to the dissolving action of the several digestive ferments.

In this connection, we need to pay little attention to the mineral compounds. They do not undergo fermentative changes in the way that the carbon compounds do, but pass into simple solution either in the water accompanying the food, or in the juices with which they come in contact.

As has been noted, protein is a mixture of nitrogenous compounds, largely albuminoids. The gluten of wheat contains at least five of these bodies, and other seeds as many. What is the relative susceptibility of these single proteids to ferment action either as to rapidity or completeness of change does not appear to be known. Some albuminoids are practically all digested by artificial methods, and probably are in natural digestion. It is a fact, however, that protein is much more completely dissolved from some feeding stuffs than from others. That of milk is all digestible, that of some grains very largely so, while with the fodders quite a large proportion escapes solution. Whether this is due to a differing degree of solubility on the part of the characteristic protein compounds of these feeding stuffs is not quite determined. The fact that highly fibrous materials show the lowest proportion of digestible protein suggests as an explanation that the nitrogen compounds of the coarse fodders are so protected by the 
large amount of fiber present that they escape the full action of the digestive juices. It is certain, anyway, that the protein of young and tender tissues and of the grains is more fully digested than that of the hays and straws.

In the case of the carbohydrates, our knowledge of the relative susceptibility of the individual compounds to enzym action is more definite. First of all, the necessary modification of the sugars, which are already soluble, is slight, and they are wholly digested. In the second place, we have learned in two ways that the starches are wholly transformed to diffusible compounds, first by submitting them in an artificial way to the action of various diastatic ferments, and, second, by discovering a complete absence of starch or its products in the feces of our domestic animals. In no case that has come under the writer's notice has either starch or sugar been found in the solid excrement. We can say, therefore, that under normal conditions the starches, like the sugars, are completely digestible.

Digestibility must be considered, however, from the standpoints both of rapidity and of completeness. As to the former factor, starches from unlike sources exhibit some remarkable differences. Investigations by Stone, who submitted a number of these bodies to the action of several diastatic ferments, show that "this variation reaches such a degree that under precisely the same conditions certain of the starches require eighty times as long as others for complete solution." The potato starches appear to be acted upon much more rapidly than those from the cereal grains. 
Other carbohydrates and related substances, such as the gums and cellulose, do not undergo complete digestion, sometimes half or more of these compounds escaping solution. Stone, after examining twenty feeding stuffs and the fecal residues obtained from them in digestion experiments, found in the feeding stuffs from 6 to 16 per cent of gums, 46 to 77 per cent of which was digested, the average being 58 per cent. Crude fiber proves to be digestible within about the same limits, or 36 to 80 per eent with American fodders. We are much in the dark concerning the manner of digestion of the gums and.crude fiber. To what extent these substances are the subjects of purely fermentative changes, or of merely chemical decompositions, is not known at present, but the fact of a partial digestion is well established whatever may be the causes involved.

The extent of the digestion and absorption of the fats or oils is also not definitely known. If we were to accept the figures given for ether extract in tables of digestion coefficients as applying to the real fats we would believe that their digestibility varies from less than one-third to the total amount. It is unfortunately true that these coefficients mean but very little. The ether extract from the feeding stuffs is only partially fat or oil, as we have seen, and the inaccuracy of a digestion trial is still further aggravated by the presence in the feces of bile residues and other bodies which are soluble in ether, so that the difference between the ether extract in the ration and that in the feces gives us little information as to what has happened to the actual fats. It seems very probable that pure vegetable 
fats and oils are quite completely emulsified and absorbed.

The foregoing statements make it plain that when the general composition of a feeding stuff is known it is possible to predict with a good degree of certainty whether its rate of digestibility is high or low. The larger the proportion of starch and sugar and the smaller the percentage of gums and fiber, the more complete will be the solution. We see this illustrated in the extreme by the difference in digestibility of corn meal and of wheat straw.

NoTE.-Compounds that have been digested and absorbed into the alimentary canal may be excreted in the feces. Bergunan showed that when a compound of phosphoric acid was injected subcutaneously into sheep, the phosphoric acid was excreted in the dung. According to Mendel and Thacher, mineral compounds absorbed from the intestinal tract may afterwards appear in the feces. Recent observations appear to show that phytin, a phos. phorus body, is absorbed, metabolized and its phosphorus subsequently excreted in the feces in inorganic combinations. 


\section{CHAPTER IX}

\section{CONDITIONS INFLUENCING DIGESTION}

THE chemical changes and other phenomena constituting digestion, which have been described as occurring in the alimentary canal, are practically outside the control of the one who feeds the animals. They proceed in accordance with fixed chemical and physiological laws. It is, however, within the power of the feeder to so manipulate the food or vary the conditions under which it is fed that the extent or completeness of digestion is modified, and this must be regarded as an important matter when we remember that only the digested food is useful.

\section{PALATABLENESS}

It is entirely reasonable to believe that a thorough relish for food is conducive to good digestion. The secretion of the digestive juices is not a mechanical process, but is under the control of the nervous system. With man, at least, the enjoyment of eating, even its anticipation, stimulates the secretory power of the salivary glands and those in the mucus lining of the stomach, and it is evident that this holds true with animals. Palatableness is, therefore, an important factor in successful feeding, for it tends to promote a 
state of vigorous activity on the part of the digestive organs. The experienced feeder knows well the value of stimulating the appetite of his animals by means of attractive mixtures. An agreeable flavor or taste adds nothing to the energy or building eapacity of a food, but it does tend to secure a thorough appropriation of the nutrients which enter the alimentary canal. Without doubt, the success of one feeder as compared with the failure of another may sometimes be due, in part, to a superior manner of presenting a ration to the animal's attention and to manipulations that add to the agreeableness of its flavors.

\section{INFLUENCE OF QUANTITY OF RATION}

Early experiments by Wolff, in which he fed larger and smaller rations of the same fodder to the same animals, have been made the authority for the statement that a full ration is as completely digested as a scanty one, provided the former does not pass the normal capacity of the animal. It must be said, however, that the testimony concerning this point is not unanimous. Since Wolff's experiments, Weiske, in feeding oats to rabbits, found the digestibility to be inversely as the quantity of food taken. In experiments with oxen, by G. Kühn, at Möckern, when the grain ration was doubled the digestibility of the malt sprouts used was decreased about nine per cent. Results at the New York Experiment Station from feeding full and half rations to four sheep showed uniformly higher digestion coefficients with the smaller ration, the differ- 
ences being too large and too constant to be considered accidental. Other experiments give varying and conflicting figures. If we assume that the constituents of feeding stuffs have a certain fixed solubility in the digestive fluids, then within reasonable limits the amount of food should have no effect upon the proportions of nutrients digested, but such an assumption cannot safely be made.

Doubtless no single statement concerning this point will be found applicable to all animals and all rations. Certainly, overfeeding may lessen the extent of solution and is never wise, while under-feeding for the sake of securing a maximum digestibility would not be good practice. It is reasonable to suppose, however, that the relation in quantity between the enzyms and the food compounds has an influence, at least, upon the rapidity of digestion; and indeed investigations by Stone very strongly point to such a conclusion, for he found that the rate of ferment action was proportional to the concentration of the ferment solution.

\section{EFFECT OF DRYING FODDERS}

At one time the belief became very firmly fixed in the public mind that curing a fodder causes a material decrease in its digestibility. Because this drying is often carried on under conditions that admit of destructive fermentations or of a loss of the finer parts of the plant, this view is probably correct for particular cases, but if it is accomplished promptly and in a way that precludes fermentation or loss of leaves it is 
doubtful if curing has any material effect upon digestibility.

The point has been the object of six American digestion experiments, Hungarian, timothy, pasture grass, corn fodder, crimson clover and winter veteh being the experimental foods. With four of these slight, but unimportant, differences were observed in favor of the dried material, while the reverse was decidedly true of the crimson clover and the corn fodder. German experiments show in a majority of cases greater digestibility for the green fodders. It seems probable that in general practice, because of greater or less unavoidable fermentation and a loss of the finer parts of the plant, dried fodders have a somewhat lower rate of digestibility than the original green material, a fact not due directly to drying, but to a decrease, either of the more soluble compounds or of the tender tissues.

\section{INFLUENCE OF THE CONDITIONS AND METHODS OF PRESERVING FODDERS}

In comparing the conditions and methods of preserving fodders in their relation to digestibility, we may safely rest upon the general statement that when, for any cause, leaching occurs or fermentations set in, digestibility is depressed. The explanation of this statement is that those compounds of the plant which are entirely soluble in the digestive fluids, notably the sugars, are the ones wholly or partially removed or destroyed by leaching or fermentations, while the more insoluble bodies remain unaffected. When, therefore, hay is cured under adverse conditions, such as long-con- 
tinued rain, digestibility is decreased, and the same effect is inevitable from the changes which occur in a fermenting mass, such as a mow of wet hay, a pile of cornstalks or the contents of a silo. Experimental evidence of the truth of these statements is not wanting. German digestion trials with alfalfa and esparsette, green, carefully dried, cured in the ordinary way, fermented after partial drying and as silage, show a gradually decreasing digestibility from the first condition to the last. A single American experiment, comparing the same fodder both green and as silage, gives testimony in the same direction. On the other hand, field-cured corn fodder, according to nine out of eleven American experiments, is considerably less digestible than silage coming from the same source. Here it is largely a question of the relative loss by fermentation in the two cases, and it is to be expected that the outcome would not be wholly one way.

\section{INFLUENCE OF THE STAGE OF GROWTH OF THE PLANT}

Another generalization, which certainly must hold good with reference to the digestibility of fodder plants, is that any conditions of development which favor a relatively large proportion of the more soluble carbo hydrates; viz., starches and sugars, and secure a minimum of gums and fiber, promote a high rate of digestibility, and reverse conditions produce the opposite result. It is well known that, in general, as the meadow grasses mature the relative proportion of fiber increases and the tissue becomes harder and more resisting. $\mathrm{Nu}$ - 
merous American and European digestion trials unite in testifying almost unanimously to a gradually diminished digestibility as the meadow grasses increase in age. The maturing of maize seems to produce quite the contrary effect. The testimony of experiments conducted at the Connecticut, Maine and Pennsylvania Experiment Stations justifies the statement that the corn plant, cut when the ears are full grown, furnishes not only a larger amount of digestible material, but a larger relative proportion than when cut before the ears have formed; and this is strictly in harmony with our general principle; for the mature plant, on account of the storage of starch in the kernels, has by far a larger proportion of the more digestible carbohydrates.

\section{INFIUUENCE OF METHODS OF PREPARATION OF FOOD}

Much labor and expense have been expended by farmers in giving to feeding stuffs special treatment, such as wetting, steaming, cooking and fermenting, in order to secure a supposed increase in nutritive value, an increase which must come chiefly, if at all, from a more complete digestion. It is plainly noticeable that these methods of feeding have lost in prevalence rather than gained. Practice does not seem to have permanently ratified them, and, so far as digestibility is concerned, this outcome is in accordance with the results of scientific demonstration. The conclusions of German experimenters have been that these special treatments have no favorable influence, their effect being either imperceptible or unfavorable. 
It should occasion no surprise that the mere wetting of a food is without influence upon its solubility in the digestive juices, because it becomes thoroughly moistened during mastication and in the stomach. It is not rational to expect that previous wetting would have the slightest effect unless it induced more complete mastication, which certainly would not be the case with ground grains. The extensive trials by Kühn and others with a hay and bran ration, the bran being fed in several conditions, such as dry, wet, moistened some hours before feeding, treated with boiling water and fermented, gave results adverse to all of the special methods of preparation as either useless or harmful, and no testimony so thorough and convincing has been furnished on the other side.

German and American experiments unite in condemning the cooking of foods already palatable, because this causes a marked depression of the digestibility of the protein, with no compensating advantages. Digestion trials with cooked or steamed hays, silage, lupine seed, cornmeal and wheat bran, and roasted cotton seed, uniformly show their protein to be notably less digestible than that in the original materials, a fact which may explain the lessened productive value of cooked grains which has been observed in certain experiments. It must be conceded, of course, that when cooking feeding stuffs by steaming or otherwise renders them more palatable, and thereby makes possible the consumption of material otherwise wasted, the influence upon digestibility is a minor consideration. 


\section{INFLUENCE OF GRINDING}

Few points are more frequently questioned than the profitableness of grinding grain. There seem to be only two ways in which such preparation ean enhance the nutritive value of a feeding stuff; viz., by diminishing the energy needed for the digestive processes and by increasing the digestibility. While only about a half-dozen experiments bearing upon the digestion side of this question are on record, their evidence is quite emphatic. In three trials with horses, with both corn and oats, grinding caused an increase of digestibility varying from 3.3 to 14 per cent. A single experiment with maize kernels gave a greater digestibility of about 7 per cent from grinding, and with wheat, in one trial, the increase was 10 per cent. In one test of oats with sheep, the unground kernels were as completely utilized as the ground. It is reasonable to expect that with ruminants the danger of imperfect mastication is less than with horses and swine, although whole kernels of grain are often seen in the feces of bovines. The profitableness of grinding grain turns, in part at least, upon the relation of the cost of grinding to the loss of nutritive material from not grinding. If the miller's toll amounts to one-tenth the value of the grain the economy of grinding it may be doubtful, especially with ruminants.

\section{EFFECT OF COMMON SALT}

It is the custom of many feeders to allow their an1mals an unlimited supply of salt, and others furnish it 
in definite and regular quantities. The belief prevails more or less widely that an abundant consumption of salt is beneficial. If this is true, the advantage arises for other reasons than an increased digestibility. The verdict from earlier experiments by Grouven, Hofmeister and Weiske that the addition of salt to the ration does not increase the digestibility has been confirmed by more recent tests by Wolff. Indeed, if we give to the data collected a literal and perfectly justifiable interpretation, salt diminished rather than raised the proportion of digestible nutrients.

INFLUENCE OF FREQUENCY OF FEEDING AND WATERING ANIMALS

Few experiments relative to this point are on record. One by Weiske and others, relative to frequency of feeding, and another by Gabriel and Weiske, in which the effects of the time of watering and of the amount of water were tested, give no indication that the completeness of digestion is materially affected by variations in these details of practice. It seems probable that the nutritive importance of these minor points in managing animals has been much overestimated by some, especially as affecting the utilization of the food.

\section{INFLUENCE OF CERTAIN OTHER CONDITIONS}

It is well known that the composition of fodder crops grown on the same soil may vary somewhat from year to year according as the season is wet or dry, cold 
or warm. Such variations may influence digestibility, though no actual demonstration of this fact appears to be on record. The question is often asked whether the storage of hay for a long period affects its nutritive value. The data from four series of experiments touching on this point indicate that there is a perceptible, though not marked, decrease in digestibility of hay during long-continued storage.

INFLUENCE OF THE COMBINATION OF FOOD NUTRIENTS

Among the apparently important and freely exploited conclusions drawn from investigations in animal nutrition is the statement that the digestibility of food is influenced to a marked degree by the relative proporitions of the several classes of nutrients. It is taught that if more than a certain percentage of starch and sugar, or of feeding stuffs rich in carbohydrates, like potatoes or roots, is added to a basal ration, the digestibility of the latter is decreased, the protein and fiber being especially affected. The conclusions, as stated by Dietrich and Konig, on the basis of a critical study of the data involved are that if pure carbohydrates are used to the extent of more than 10 per cent of the dry substance of a basal ration, or if potatoes and roots are fed equivalent in dry matter to more than 15 per cent, a depression of digestibility occurs, which increases with the amount of carbohydrate material added. A modifying conclusion is, that if the addition of the carbohydrate material is accompanied by correspondingly more protein, the de- 
pression of the digestion coefficients is much lessened or does not occur. Many data are cited in support of these generalizations which are worthy of careful consideration.

It is not unreasonable to suppose that the relative quantity in a ration of the several classes of nutrients may have an influence upon the digestive processes, and we should accept the verdict of previous observations in so far as they will bear critical discussion and further investigation. It should be said in the first place, by way of comment, that the carbohydrate material in the experiments cited has usually been fed in addition to a basal ration, thus increasing the amount of food consumed, and, as we have seen, this may have an influence upon the proportion of total dry matter digested. In this particular, the experiments have not been logical.

In the second place, in these experiments, no allowance has been made for the metabolic nitrogen in the feces, i. e., that not belonging to the true undigested residue. As this appears to be independent of the amount of protein fed and stands more nearly in relation to the total digested nutrients, it follows that the smaller the proportion of protein in the digested food, the larger the error caused by the waste nitrogen products. A careful study of this point in the light of more recent knowledge might modify the conclusion reached as to the depression of protein digestion through feeding starch or starchy foods. In all or nearly all the experiments where this effect is apparently shown the digestible dry matter of the ration 
was largely increased and the protein remained constant or was diminished. The depression of the digestibility of the crude fiber is not easily explained on any other ground than that of the influence of the greater proportion of starch.

What is claimed as the effect of a disproportionate addition to the supply of carbohydrates does not appear to be true of a similar increase in the ration of fat and easily digested protein. Several experiments in which. oils and albuminoids have been added freely to a basal ration did not indicate that such addition had any material effect upon digestibility.

\section{CONDITIONS PERTAINING TO THE ANIMAL: SPECIES, BREED, AGE, AND INDIVIDUALITY}

The conclusion reached by the early experimenters in the field of animal nutrition that the digestive efficiency of the several species of ruminants was practically uniform, has not been set aside by more recent observations. The number of experiments upon which this conclusion was based was large, and their verdict is not likely to be reversed by observations less extensive or less complete.

The following coefficients were obtained from German trials with meadow hay:

Dry substance digested from meadow hay (per cent)

\begin{tabular}{|c|c|c|c|c|}
\hline & Samples & Best & Medium & Poor \\
\hline Sheep. & . 42 & 67 & 61 & 55 \\
\hline Oxen.. & . 10 & 67 & 64 & 56 \\
\hline Horse. & . 18 & 58 & 50 & 46 \\
\hline
\end{tabular}


Nine American experiments have been the means of studying results with large and small ruminants, steers being compared with sheep and cows with goats. In five cases, the large animal digested from 5 to 14 per cent the more, in three cases the excess for the small animal varied between 7 and 17 per cent, and in one case there was little difference. The general effect of such conflicting results is to confirm the older and more numerous observations.

The horse and ruminants differ in digestive capacity to a marked extent. The comparisons which have been made show a uniformly lower digestive efficiency for coarse fodders on the part of the former. It appears that because of less perfect mastication, or for some other reason, the horse dissolves much less of the crude fiber than the steer or sheep, and the effect of this is prominent with hays and other fibrous materials. With the grains, ruminant and equine digestion is not greatly unlike, eight samples of oats with. sheep and twenty-four with the horse showing almost identical digestion of the dry matter. With maize the case is the same. In experiments with beans, the advantage was slightly with the ruminant. So far as we are able to judge, swine digest concentrated food about as do ruminants and the horse. How this is in the case of the fodders we do not know fully, but it is proven that the swine digest crude fiber quite freely:

Past experiments have not revealed any influence of breed upon digestive capacity. There is no reason for supposing that Shorthorn cattle, Southdown sheep and 
Chester White pigs would digest rations differently from Jerseys, Merinoes and Yorkshires.

Young animals seem to digest high quality coarse foods and grains as efficiently as older ones of the same species, which is probably contrary to the popular belief. There is doubtless a variation in the digestive power of individual animals, but the data so far collected do not show this with any degree of definiteness. In those instances where the same four or more steers or sheep have been used in determining the digestibility of several feeding stuffs the highest coefficients were obtained sometimes with one animal and sometimes with another.

\section{DETERMINATION OF DIGESTIBILITY}

If we accept as the undigested food the dry matter of the solid excrement, which is practically in accordance with the fact, we have only to subtract this fecal residue from the dry matter of the ingested food in order to ascertain the amount and proportion digested. All digestion experiments have proceeded on this basis.* Animals have been fed at regular intervals a uniform quantity of carefully analyzed food and the feces have been collected, weighed and analyzed. From the data thus obtained, the digestion coefficients have been calculated. The method and the mathematics of such experiments are so simple that correct results seem very easy to obtain and they do possess an accuracy suffciently approximate to truth to render them useful in practice. As digestion trials are usually conducted, the coefficients of digestibility obtained for the dry matter

\footnotetext{
* See note, p. 125.
} 
and total organic matter represent, we have reason to believe, very nearly the actual digestible matter in the particular material studied. The proportions secured for particular classes of nutrients may be less accurate, for reasons that will appear. We cannot be sure, either, that the digestibility of one hay applies to another produced and cured under totally different conditions. The truth of this latter statement is clearly seen in the effect of the various factors upon digestibility.

The inaccuracies of digestion coefficients are chiefly in those for protein and fats. Let us see how and why this is. The errors in the figures for protein are caused by the presence in the feces of nitrogen compounds which are not a part of the undigested food protein. These are waste compounds which are residues from the bile and other digestive juices, epithelial cells and mucus which are carried along from the walls of the intestines during the passage of the food. Their quantity seems not to be proportional to the protein fed, but appears to be influenced more or less by the amount of food digested. Their source is the "wear and tear" of the digestive apparatus. It follows then that the less protein there is in a ration, the larger the percentage error caused by these metabolic products. In certain experiments with oat straw, the fecal nitrogen has been more than that of the food, although without question much of the straw protein was digested. It has been found, using the best methods known for extracting these waste products, that they cause a much larger error for the protein of the straws than for that of the legume hays. It is probably safe to affirm that at least ten should 
be added to the coefficients of digestibility of the protein of coarse fodders as usually given in the tables that have been compiled.

Errors are caused in determination of the digestibility of fat in much the same way. Certain of the bile residues in the solid excrement are soluble in the ether which is used to extract the fats, and consequently the undigested fat appears to be larger than it really is. 


\section{CHAPTER $\mathrm{X}$}

THE DISTRIBUTION AND USE OF THE DIGESTED FOOD

THE digested food, after absorption, all passes into the blood, either directly or indirectly, and mixes with it. The materials which are to serve the purposes of nutrition are now taken up by a stream of liquid that is in constant motion throughout the minutest divisions of every part of the animal. Flowing in regular channels the blood reaches not only the bones and muscular tissues, but it passes through several special organs and glands where the nutrients it is carrying and certain of its own constituents meet with profound changes. It is here that we discover the manner in which food is applied to use and what are some of the transformations which the proteids; carbohydrates and fats undergo in performing their functions.

In order to follow intelligently this most interesting phase of nutrition, we must know something of the blood and of the organs - the lungs, liver and kidneys - through which it passes.

\section{THE BLOOD}

The blood, when in a fresh state, is apparently colored and opaque, but if a minute portion is ex- 
amined with a microscope, it is seen to be a comparatively clear liquid in which float numerous reddish, disk-like bodies. These bodies, which are known as corpuscles, give to the blood its bright red color. The liquid in which they are suspended is called the plasma.

The corpuscles are not mere masses of unformed matter, but they are minute bodies having a definite form and structure. They make up from 35 to 40 per cent of the blood, and contain over 30 per cent of dry matter. This dry matter consists mostly of hæmoglobin, a compound that is peculiar to the blood and equips it for one of its most important offices. Hæmoglobin, as before stated, is made up of a proteid (globin) and a coloring matter (hæmatin), in the latter of which is combined a definite proportion of iron. The peculiar property of this compound, which renders it so useful a constituent of the blood, is its power of taking up oxygen and holding it in a loose combination until it is needed for use. When thus charged, it is known as oxyhæmoglobin. Because of this function of their most prominent constituent, blood corpuscles become the carriers of oxygen to all parts of the body. There are reasons for believing that they are also chiefly concerned in gathering up one of the waste products of the nutritive changes, viz., carbon dioxid, and conveying it to the points where it may be thrown off from the body.

The plasma is about nine-tenths water, so that it easily holds in solution whatever soluble nutrients are discharged into it from the alimentary canal. Among 
its constituents are found members of all the classes of compounds that are important in this connection,ash, protein, carbohydrates and fats. The proportion of ash is about 1 per cent, three-fourths of it being common salt, and the remainder consisting of phosphoric acid, lime and other important mineral compounds. The solid matter of the plasma is rich in albuminoids, including the fibrinogen which is the mother substance of fibrin and several albumins and globulins. These proteids make up about 80 per cent of the total dry substance of plasma. Sugar and fats are also present, their proportions varying with the extent to which they are being absorbed from the digestion of food. It is evident that the blood is charged with those materials which we recognize as necessary to the construction and maintenance of the animal body.

\section{THE HEART}

In quantity, the blood is from 3 to 4 per cent of the total weight of the live animal. It is contained in the heart and in two sets of vessels, one set called the arteries leading from the heart by various ramifications to all parts of the body, and the other set called the veins, leading from all parts of the body back to the heart. Through these vessels the blood is moving in a constant stream, which we call the circulation. It does not move of itself, but is forced along by a very powerful pump, the heart. This is a highly muscular organ divided into four chambers, which are separated by valves and partitions, the two upper chambers be- 
ing called the right and left auricles, and the two lower the right and left ventricles. The right auricle is above the right ventricle and is separated from it by a valve, and the same is true of the left auricle and ventricle. Out of the left ventricle the blood is pumped into the arteries and after reaching the arterial capillaries throughout the entire body, it passes from these into the smallest divisions of the veins and comes back to the heart along the venous system, en-, tering the right auricle. It is then carried to the lungs by way of the right ventricle and is returned to the left auricle to be sent to the left ventricle, and from there to again start. on its journey through the body. The principal facts pertaining to the blood and its circulation have been reviewed in this simple manner as an aid to the discussing of other considerations somewhat pertinent to our subject.

The nutrients, as prepared for use by digestion, enter the blood on its return flow to the heart, coming into the venous cavity by way of the hepatic (liver) vein and the thoracic duct as previously described. When, therefore, the right side of the heart is reached, a new accession of food material is on its way to sustain the various functions of nutrition.

We are more interested in the object of blood circulation than we are in its mechanism. Somehow the digested food disappears into these constantly moving blood currents, and the only evidence of its effect which comes to us from ordinary observation is the warmth, motion and perhaps growth of the animal that is nourished. 


\section{THE LUNGS}

The first point where important changes occur is the lungs. Here the blood loses the purplish hue which it always has after being used in the body tissues and takes on a bright scarlet, a phenomenon that is more easily understood when we understand the lung structure.

Breathing is a matter of common experience. We all know how air is drawn into the lungs at regular intervals, an equivalent quantity being as regularly forced out. The mechanism of respiration (breathing) we will not discuss at length. It will aid us, however, if we know that the passage which the air follows to and from the lungs, the trachea (windpipe), divides into two branches, one to each lung, and these divide and subdivide until they branch into numerous fine tubes. Each of these tubes ends in an elongated dilation which is made up of air cells opening into a common cavity. These cells are so numerous in the lung tissues that only a very thin wall separates adjoining ones, and in this wall are carried the capillaries or fine divisions of the blood-vessels leading from the heart. This arrangement permits the blood to take up oxygen as it flows along and transfer certain wastes into the lung cavities, and thus be made ready to go back to the body carrying a joint load of digested food and oxygen. Of course the air that passes out of the lungs is less rich in oxygen than when it was taken in, and there have been added to it certain materials which we will notice later. 


\section{'IHE USE OF FOOD}

The revivified blood now passes to all parts of the body and is brought into the most intimate relation with the minutest portion of every tissue. Several things happen in the course of time.

In the first place, the new supply of nutritive substances is used by the living cells in a way we do not wholly understand to rebuild worn-out tissue and to form new growth. With the young animal, much material is appropriated in the latter way. In the case of the milch cow, there is furnished to the udder the nutrients out of which the milk is formed through the special activities of that gland.

Moreover, it is in the tissues that the oxygen which was taken up in the lungs is used to slowly burn a portion of the food. This combustion is believed not to take place by contact of the oxygen and food in the large blood-vessels, but it occurs by progressive steps throughout the minute divisions of the muscles and other parts of the whole body. Notwithstanding this oxidation may be very gradual and occupy much time, its ultimate products are, for the most part, similar to those which result from the rapid combustion of fuel. In the fireplace, starch, sugar, cellulose, fats and similar bodies would be burned to carbonic acid and water, and this is what takes place in the animal to the extent these nutrients are not used for growth.

When the protein is not stored as such but is broken up, the result differs somewhat in the furnace and in the animal because in the latter the oxidation is not 
complete. Here the proteids may be partially burned to carbonic acid and water, but a portion of their substance passes from the body principally in the form of urea and uric acid, which are the prominent constituents of urine. These compounds carry with them a certain proportion of carbon and hydrogen which in ordinary fuel combustion would more fully unite with oxygen. The heat production from protein is therefore less in the animal than in the furnace.

This oxidation in the animal is constant but not uniform. It varies with the exercise the animal is taking and with the amount of food that must be disposed of. The quantity of oxygen needed is therefore variable, and when the demand for it is largely increased the heart pumps faster, more blood passes through the lungs, the breathing is more rapid and the supply of oxygen is in this way augmented.

\section{ELIMINATION OF WASTES}

The various waste products from this combustion and from the breaking up of the proteids within the animal evidently must be disposed of in some manner. If not eliminated from the body, they would cause results of a most serious character, as, for instance, when an accumulation of urea in the body produces uræmic poisoning. The blood therefore not only carries to the tissues the necessary nutrients and oxygen, but it has laid upon it the burden of taking into its currents the waste products of combustion and growth and carrying them to the points where they are thrown off. 
One of the branches of the arterial system of bloodvessels runs to the kidneys, and, by repeatedly rebranching, traverses all their substance. The main function of the kidneys is to secrete the urine, a liquid in which all the waste nitrogen from the digested protein finds its way out of the body in the form of urea and similar bodies. The blood that enters them carries with it the urea and uric acid which have resulted from a breaking down of protein, and in a most wonderful manner these compounds are filtered out so that they are not present in the outgoing blood. An excess of soluble mineral matters such as common salt is also removed by the kidneys, as well as the bile compounds which are absorbed from the alimentary canal.

The carbon dioxid must in some way also be eliminated from the body. This is not accomplished to any extent until the blood containing it reaches the lungs, where it is exchanged for a new supply of oxygen and passes off in the expired air. In the case of man, the air "breathed out" is nearly a hundred times richer in carbonic acid than the air "breathed in."

Water may be regarded from one point of view as a waste, for it is produced in the oxidation of the food, and this passes off from the lungs as vapor, through the skin as sensible or insensible perspiration, and in considerable quantities through the kidneys.

To summarize, it may be said that the blood is constantly undergoing gain and loss. The gain comes from the food (including water and oxygen), and the loss consists of urea, carbonic acid and water given off through various ehannels. 


\section{THE LIVER}

One part of the arterial system of blood-vessels runs to the stomach and intestines and is distributed over their walls in fine divisions. These connect with the capillaries of the portal vein which leads to the liver. During this passage of the blood from one system to the other, part of the digested food is taken up. Now it is very evident that the quantity of material thus absorbed must vary greatly at different times according to the nature and amount of food supply and the activity of the digestive processes. If, therefore, the blood from the alimentary canal was allowed to pass directly into the general circulation, the supply to the tissues of the nutrients, especially the carbohydrates, would be very uneven. Just here comes in a liver function. In that organ there is found a starch-like body known as glycogen, which appears in increased quantity following the abundant absorption of sugar from the intestines. It is believed, because of this and other facts, that the liver acts as a regulator of the carbohydrate supply to the general tissues of the body, storing a temporary excess of the sugar in the form of glveogen and then gradually giving it up to the general circulation as it is needed. 


\section{CHAPTER XI}

\section{THE FUNCTIONS OF THE NUTRIENTS}

THE digestion, absorption and distribution of food are not its use,-they are the preliminaries necessary to use. Not until the nutrients have been converted to available forms and have passed into the blood do they in the slightest degree furnish energy or building material to the animal organism. We have followed to a certain extent the chemical changes which the digested food suffers, but no detailed statements have been made as to the part taken by each class of nutrients in constructing the animal body and in maintaining its complex activities.

Animals use food in two general ways; viz., for constructive purposes, which involve the building or repair of tissue and the formation of milk, and as fuel for supplying different forms of energy, including heat. The tissues which are to be formed are of several kinds, principally the mineral portion of the bone, the nitrogenous tissue of the muscles, tendons, skin, hair, horn and various organs and membranes, and the deposits of fat which are quite generally distributed throughout the body substance.

Energy in the forms in which it is used by the animal organism may appear as muscular activity, such as 
working, walking, breathing, the beating of the heart, the movements of the stomach and intestines, as heat, and as chemical energy necessary for carrying on digestion and other metabolic changes. The animal body is certainly the seat of greatly varied and complex constructive and destructive activities, which are sustained by the matter and potential energy of the food. How this is done we do not fully understand, but we know many facts which are of great scientific and practical importance and which the feeder must consciously or unconsciously recognize if he would not come into conflict with immutable laws.

\section{FUNCTIONS OF THE MINERAL COMPOUNDS OF} THE FOOD

We have learued that mineral compounds are abundant in the animal body. The tissues, the blood, digestive fluids and especially the bony framework contain a variety of these bodies, which are as essential as any other substances to the building and maintenance of the animal organism. Bone formation without phosphoric acid and lime is not possible, and to deprive the digestive juices of the chlorine and soda which they contain would be to destroy their usefulness. Young animals fail to develop if given no mineral food, and mature animals when entirely deprived of even one substance, common salt, become weak, inactive and finally die. Not only must the growing calf have the ash compounds for constructive purposes, but the mature ox must be supplied with 
them in order to sustain the nutritive functions. It is especially true of milch cows, which store combinations of phosphoric acid, lime and potash so abundantly in the milk that they must have an adequate supply of these substances. Nothing is clearer than that these materials must of necessity be furnished in the food. They cannot originate in the animal, neither can carbon compounds take their place.

Nature seems to have made generous provision for the animals' needs along this line. All of our home-raised feeding stuffs, as usually fed, contain in variety and quantity all that is needful of these nutrients except for poultry perhaps. Milk, that is the exclusive food of very young animals, is especially calculated to sustain the rapid boue formation which is taking place. It is only when feeding is one-sided, as in an exclusive corn diet, or when parts of a grain are removed, that we need fear a deficiency of the necessary mineral compounds.

\section{FUNCTIONS OF PROTEIN}

While there are at present many unsolved problems relative to the nutritive offices of protein, there is no reasonable doubt that the vegetable proteids are the only sources of similar substances in the animal body. This is equivalent to a statement that from the proteids are formed the muscles, the connective tissues, the skin, hair, horn, and hoofs, and the major part of the tissues of the secretive and excretive organs; in short, that they are the souree of a large proportion 
of all the working parts of the animal's body. So far, scientific research has not succeeded in demonstrating that an albuminoid is ever synthesized (built up from simple compounds) outside of the plant. It appears that bodies of this class must come to animal life fully elaborated. This is a truth of great significance even in its relation to the nutrition of farm animals. The nitrogenous tissues are those that largely determine the vigor and quality of any animal, and as these are formed rapidly in the early stages of growth, a normal and unrestricted development demands an abundant supply of proteid food. It is also true of mature animals that sufficient protein is not only necessary to health and vigor, but it is essential to production that is satisfactory in quantity and quality.

The functions of protein are not restricted, however, to the use already described. According to existing views, it is utilized in more ways than any other class of nutrients. It was held at one time by prominent scientists that outside the vegetable fats it is the sole source of animal fats, and this view was, not so very long ago, to some extent accepted. Indisputable proof to the contrary is now in our possession, and some investigators even go so far as to deny the possibility of the formation of fat from protein. On this point, opinion is divided. Certainly we must be convinced that nitrogen compounds of the food are, with some species, not the most important source of animal fat, for various investigators, such as Lawes and Gilbert, Soxhlet, and others, have shown upon the basis of searching experiments that sometimes over 
four-fifths of the fat stored by pigs must have had its origin outside the food protein and fat. Besides all this, the common experience of feeders that foods highly non-nitrogenous are often the most efficient. for fattening purposes is good common-sense evidence that fat formation is not greatly dependent upon the protein supply. Nevertheless, the possibility of producing animal fat from protein is not disproved, and there are several considerations which make it seem probable that under certain conditions this does occur.

Protein can unquestionably serve as fuel, or, in other words, as a source of energy. The amount so used depends much upon the animal fed and the character of the ration. In the case of a dog eating an exclusive meat diet or of a fattening animal which receives a ration liberally nitrogenous, probably the greater part of the protein eaten is not stored but is used as fuel. With milch cows or young animals growing vigorously, a much larger proportion escapes oxidation. The fuel value of protein will be discussed later under another head.

\section{FUNCTIONS OF CARBOHYDRATES}

Carbohydrates are usually characterized as the fuel portion of the food, or that part which is burned to produce the various forms of energy. This conception of the function of these bodies is correct in the sense that in the case of ruminants they constitute the larger part of the fuel, although not the whole of it. For instance, in the case of a cow eating daily sixteen 
pounds of digestible organic matter, giving thirty pounds of milk containing 15 per cent of solids, and neither gaining nor losing flesh, not far from five. pounds of this organic matter would be found in the milk and urine, leaving about eleven pounds to be used as fuel, about a pound and a half of which might be derived from the protein and fat, the remainder, or 9.5 pounds, consisting of carbohydrates. If a fattening steer were eating the same amount of the same kind of food and gaining two pounds of live weight daily, the body increase and urine would contain not over 2.5 pounds of dry matter, leaving not less than 13.5 pounds to be oxidized, of which twelve pounds might consist of carbohydrates and fat, mostly the former. It is clear, then, that while other bodies serve as fuel, the carbohydrates furnish much the larger part of that which is needed for this use.

Contrary to views that held for a time, it is now well established that the animal fats may have their source in the carbohydrates; in other words, starch and sugar and related bodies may serve the main purpose in feeding animals for fattening. In many experiments, notably those with. swine, the protein and fat of the food have fallen far short of accounting for the fat in the body increase, sometimes much the greater part of the latter having no possible source other than the carbohydrates. A practical expression of this general conclusion concerning the fat-forming function of carbohydrates is seen in the well-recognized value of corn meal as a 
fattening food, a feeding stuff nearly seven-tenths of which consists of starch and its allies. Recent experiments with milch cows leave scarcely any doubt that milk fat may also be derived from carbohydrates. These more recent views tend to magnify the importance of the carbohydrates as nutrients.

FUNCTIONS OF THE FATS AND OILS

So far as is at present known, the possible uses of the food fats and oils and of the carbohydrates are similar. In other words, both may serve as fuel and both may be a source of animal fat. The differences are that the supply of carbohydrates is much the larger, and the fuel value of a unit weight of fats much the greater. Moreover, it seems possible for a vegetable fat to become deposited in the animal without essential change, whereas fat formation from carbohydrates involves complex chemical transformations.

\section{FOOD AS A SOURCE OF ENERGY}

The living animal, either as a whole or in some of its parts, is constantly in motion. This means that the animal mechanism is ceaselessly performing work. Even if the body is apparently quiet, the heart beats, pumping blood to all parts of the body, the lungs are expanded and contracted, and the stomach and intestines keep up the movements which are essential to digestion. Besides, a living body is the seat of continuous, invisible and complex chemical and physical changes that, if not work in the common meaning of 
the term, are its equivalent. Walking, trotting, pulling, lifting, pumping blood, breathing, masticating, digesting and assimilating food represent, then, a great variety of operations of those living machines which we have named horse, ox, cow and sheep.

Now work requires the expenditure of energy. The projection of a rifle ball through space at the rate of two thousand feet per second is work. The ball does not move of itself, but is propelled by the application of the energy stored in a powerful explosive. Back of every one of our great mechanical operations, such as pumping, grinding and moving railroad trains, will always be found some sort of energy, and what is true of machinery made of wood and iron is equally true of that made of bone and muscle. The fact that the mechanism is alive does not abrogate a single physical law, so that the fundamental principles of energy as applied to machines are as fully applicable to the activities of animal life.

It is safe to go farther, and say that the animal organism does not originate energy. Among the fundamental conceptions upon which all our knowledge of chemical and physical laws rests is this, that energy and matter are indestructible, and, moreover, that the sum total of these in the universe is unchangeable. If, then, the horse expends the muscular energy necessary to draw a load of one ton over ten miles of road, the equivalent of this must have been supplied to his body from some outside source. He could not create it. We know that this is so, and we also know it is conveyed to the animal in the food. 
This is a complex, but a fascinating, field of inquiry; one that is now receiving much attention in our researches after a more intimate understanding of the facts and principles of nutrition. It will be profitable, therefore, for us to gain some conception of the knowledge of this kind, which so far seems to have a practical bearing upon our subject.

It is natural to first ask, What is energy? This is a difficult question to answer in a popular way, and the physicists' definition would hardly serve our purpose. All we can do, perhaps, is to illustrate it by pointing out some of its manifestations. Let us resort to an old illustration. Every farmer's boy has doubtless seen a blacksmith hammer an iron rod until it was red hot. The motion of the hammer-head descending with great velocity was suddenly arrested when it came in contact with the rod. This descent of the hammer-head illustrated one form of active energy; viz., motion of a mass of matter. When the hammer met the iron rod on the anvil, the mass motion ceased. Was the energy therefore lost? Not unless our fundamental conception is wrong, and we find that in this case it is not. The physicist teaches us that the motion of the hammer-head, a mass of matter, was communicated to the smallest particles or molecules of the iron rod, and as the vibrations of the molecule increased in rapidity, the rod grew hotter and hotter. Here we have another illustration of energy; viz., the motion of the molecule or heat.

The iron rod might have been heated in another way,-by plunging it into burning charcoal. And from 
whence would the heat energy come in this case? From the combustion of the carbon. Somehow, when it is deposited in the plant, there becomes stored in this carbon, in a way about which we can only theorize, what perhaps we may call the chemical energy of the atom, which, when combustion occurs, is changed into heat or molecule motion. From these phenomena we learn that not only are there several forms of energy, but that one form is transferable into another.

Perhaps another illustration may still further serve our purpose. A small dynamo is being run by a pair of horses working in a tread power such as is used for threshing grain. The horses are constantly climbing up a moving treadway and thereby communicating motion to machinery. This motion is, by the dynamo, converted into electricity, which, by passing through the carbon film of an incandescent lamp and there meeting resistance, is in part, at least, transformed into heat. We have, then, in a chain, muscular effort, motion of the mass (pulleys, wheels, etc.), electricity and heat, all active energies and all transferable the one into the other. This is a fairly good picture of what goes on with the horse himself, externally and internally, in sustaining life and performing labor for his owner. Back of it all, and this is what interests us, is the animal's food. As a result of years of patient investigation, it has become known that through the combustion of the carbon compounds of vegetable and animal origin, which serve as nutrients, chemical energy may be transformed into those other forms that are manifested in the activities of living 
beings. When we ask from whence comes the energy given up by the plant compounds, we arrive at our last stage of inquiry. Here we enter the domain of plant life, and it is a notable triumph of the human intellect that we are able to declare with certainty that the ceaseless and multiple activities of life on this planet are sustained by an energy which comes to the plant in the sun's rays through almost limitless space.

It is obvious that if the internal and external work performed by the animal is sustained by the food, it is desirable to measure the energy available in different feeding stuffs, provided, of course, that they differ in this respect, as we know they do. In order to measure anything, we must have a standard or unit of measurement. In this case it cannot be a unit of space or of mass, that is, we cannot declare that corn meal contains so many cubic feet or pounds of available energy. Energy has neither dimensions nor weight. If we measure it at all, it must be by units of temperature or of work performed. Units of this kind are applied to the measurement of food energy. The one most commonly in use is the Calorie, this being the energy which in terms of heat is sufficient to raise the temperature of one pound of water $4^{\circ}$ Fahrenheit. Expressed in terms of work, the Calorie is very nearly 1.53 foot tons, or in other words, it is equivalent to the work involved in lifting one ton 1.53 feet. Heat units are expressed in both the large Calorie and the small calorie. When the former is indicated, the word begins with a capital letter. The Calorie represents 1,000 calories. 
The total energy or heat units developed in the combustion of feeding stuffs is determined in an apparatus called a calorimeter. The latest form of this device is one in which the ground hay is burned under pressure in the presence of pure oxygen, and the heat evolved is all used in warming a known weight of water. Data are thus obtained from which it is possible to calculate the Calories in the particular material burned. The energy value of single compounds, such as albumin, starch and sugar, may also be found in the same way, as has been done in a large number of instances. These data show that the heat resulting from the combustion of the compounds of the same class is not the same in all cases. The value in large Calories of one gram (about one-twenty-eighth of an ounce) of the several nutrients is shown in the following table:

Albuminoids, etc.

Cal.

Cal.

Wheat gluten....... 5.99

Egg albumin....... 5.73

Gliadin ........... 5.92

Muscle (pure)....... 5.72

Glutenin........... 5.88

Blood fibrin......... 5.64

Plant fibrin........ 5.94

Peptone .......... 5.30

Serum albumin...... 5.92

Wool.............. 5.51

Milk casein........ 5.86

Yolk of egg....... 5.84

Gelatin ........... 5.27

Carbohydrates Cal.

Asparagin (amide) ... 3.45

Fats

Cal.

Starch ............ 4.18

Of swine.......... 9.38

Cellulose.......... 4.18

Of oxen .......... 9.38

Glucose ........... 3.74

Of sheep......... 9.41

Cane sugar ......... 3.95

Maize oil .......... 9.28

Milk sugar......... 3.95

Olive oil......... 9.47

Maltose........... 3.95

Ether extract of oats... 8.93

Zylose ............ 3.74

Ether extract of barley 9.07 
The heat values of a gram of the dry substance of various cattle foods, which is a mixture of the several nutrients, were found by recent determinations to be the following, expressed in small calories:

cal.

Mixed hay ......... 4494

Alfalfa hay......... 4478

Oat straw..........4480

Sugar beets......... 3931 cal.

Corn meal .......... 4471

Linseed meal ...... 5040

Flaxseed meal.......6935

Rice meal.........4400

These figures mean that when a gram of each of these materials is wholly burned the heat produced is as stated.

Available energy. - We must distinguish, however, between the heat produced when any food substance is wholly oxidized in a calorimeter and the heat or energy which is available when the same material is applied to physiological uses. It never happens that the combustible portion of a ration is entirely burned in the animal.

In the first place, the food of domestic animals is practically never all digested and, as only the digested portion furnishes energy, the available fuel value of a ration must be based primarily, not upon the total quantity of dry matter it represents, but upon the amount which is dissolved and passes into the blood. If all feeding stuffs or rations were digested in the same proportion and with the same ease, their total fuel values might show their relative energy worth, but as digestion coefficients for dry matter vary from less than 50 per cent with the straws to nearly 90 per cent with some of the cereal products, it is evident that the fuel waste in the feces is not uniform. 
In the second place, the digested proteids are never fully burned. A portion of these compounds always passes off in the urine unoxidized, the fuel value of which is lost to the animal. For this reason the available energy of the digested proteids is about one-fourth less than the total.

In the third place, there is, with ruminants and horses at least, an escape from the alimentary canal of unconsumed gases, due to the fermentations which take place during digestion. These gases, mostly methane (marsh gas), have their source in the carbohydrates, and Kellner found them to represent from 10 to 20 per cent of the total energy value of the dry substance digested from various materials. From twenty experiments, upon five different animals, Kühn found the loss in methane to be over one-seventh the energy of the digested crude fiber and nitrogen-free extract.

We are to understand, then, that the available energy of a ration is represented by the fuel value of the dry matter which is digested from it, minus the dry matter of the urine and that lost in gases.

If, however, we wish to know the actual energy gain to the animal from a particular ration, we must go farther than a determination of its available energy.

Net energy. - Within a comparatively short time we have begun to speak of the net energy of foods, and as this is a practical consideration which is likely to be the subject of much future discussion, it is well to notice it in an explanatory way. As we have learned, food is not applied to use until it reaches the blood. 
Between the time when it is taken into the mouth and when it passes into the circulation, it must have work expended on it in the way of mastication, solution and moving it along the digestive tract, and it appears highly probable that the amount of this work per pound of food must vary greatly in different cases. In fact, we know this is so from the result of some masterly investigations conducted by Zuntz in Germany. By means of various devices and methods, a description of which would be out of place here, he measured the oxygen consumption necessary to sustain the mechanical energy of mastication and digestion, and he calculates from his determinations that the following heat units represented the energy used in chewing certain feeding stuffs:

cal.

cal.

1 pound hay............ $76 \quad 1$ pound corn......... $61 / 3$

1 pound oats............21 Green fodder equal to 1

pound of hay....... 47

The differences revealed by these figures are interesting and important. Chewing green food cost in labor only about 62 per cent of the effort required to masticate its equivalent of dry hay, the proportions of labor for hay, oats and corn being in the ratio of 100,27 and $8 \frac{1}{3}$.

This author goes further and calculates that the work of mastication and digestion combined is 48 per cent of the energy value of the digested material from hay and 19.7 per cent of that from oats. He also makes the statement that in general the coarse foods have 20 per cent less net energy value than the 
grains. All these deductions are based upon the excess of oxygen used by the animal when engaged in the work of chewing and digestion, over that used when at rest. It follows from these results that anything in the way of growth or treatment of a fodder which tends to toughen or harden the tissue reduces the net energy value. It has long been believed, though perhaps not proved, that grain foods are superior to coarse foods to an extent not accounted for by the differences in digestibility, and if this is a fact, it is explained in part by the unlike composition but is to some extent undoubtedly due to the greater effort of chewing and digesting the fodders.

If we wish to ascertain the comparative energy worth of two unlike rations, it would obviously be incorrect to multiply the total quantities of protein, carbohydrates and fats in each by the unit heat values in order to ascertain the relative energy gain to the animal body.

To recapitulate, we may define available energy as total energy minus that which is lost in the excreta and in gases which escape, and net energy as available energy minus the cost of digestion and of preparing the food for use. Net energy is the balance of profit to the animal.

\section{ENERGY RELATIONS OF THE SEVERAL NUTRIENTS}

As has been pointed out, the animal body is the field of numerous mechanical activities. What is the relation of the several nutrients to these manifestations of vital energy is an interesting and in some ways an intensely practical matter. For instance, has protein a peculiar function in the maintenance of muscular 
activity which no other nutrients have? The belief prevailed at one time that muscular contraction caused a wasting of the muscle substance which must be replaced by the proteid compounds of the food; in other words, protein alone was believed to sustain the work of the animal body, both internal and external. It would follow from this that the more work is done the more protein is needed. This view is no longer held. The more exact methods of modern research have revealed the fact that an increase of muscular effort, even up to a severe point, increases but little, if any, the nitrogen compounds of the urine, these being the measure of the protein that is destroyed. There has come to light a corresponding fact that the consumption of fuel in the body other than proteids increases proportionately with the increase of work. This means that as animals are ordinarily fed mechanical work is largely sustained through the combustion of carbohydrates and fats, and that while for reasons we do not yet wholly understand a fairly generous amount of protein seems to promote the well-being of a draft animal, the non-nitrogenous nutrients mostly supply the extra energy demanded for the labor.

Heat relations. - The question is very naturally asked, As no energy is lost, into what is the energy of muscular contraction converted, as, for instance, that required for walking, the beating of the heart and the work of the intestines? It is concluded by physiologists that muscular energy used by the animal is partly transformed into external motion and partly into heat, and this certainly is consistent with facts as observed. Vio- 
lent exercise by the animal greatly increases the production of heat. We know this is so because under these conditions an increased amount of blood is thrown to the surface of the body, thereby greatly increasing the loss of heat by radiation; perspiration sets in and with it the consequent evaporation of much more moisture, thus disposing of much heat. The dog, and sometimes other animals, pants and thereby causes a large loss of heat from the expanded surface of the moist tongue. All this occurs without reducing the body temperature below the normal. In fact, nature adopts these various devices, such as increased circulation of the blood and perspiration, in order to regulate the body temperature and prevent its rising above the proper point. The explanation of this greater heat during labor is that the mechanical energy manifested by the muscles is converted to heat, which under circumstances of severe exercise is more than enough to keep the body at its usual temperature and maintain the usual radiation. When it is severely cold, on the other hand, vigorous exercise is sometimes necessary in order to keep sufficiently warm.

The view is held by some that all body heat is a secondary product, that combustion first supports muscular activity which changes to heat, in fact, that no food is burned primarily to keep the animal warm. Convincing proof of this position is still lacking, however. There appears to be no good reason why we should deny the possibility of combustion of food for the specific purpose of warming the body. Certainly an Arctic climate causes a consumption of food which 
in kind and quantity would be impracticable in the tropics, and this too, even if there is no apparent increase of internal or external work. This would seem to indicate the direct oxidation of food for heating purposes. In any case, animal heat is sustained either directly or indirectly by the burning of the nutrients.

Nоте. - Recent investigations indicate that under given conditions there is an air temperature, called the critical temperature, at which metabolism (oxidation) reaches a minimum. If the air temperature falls below this point, thus causing a greater radiation of heat from the body surface, increased oxidation oceurs. If the temperature rises above this point there is no diminution of oxidation but rather a slight increase, hence the conclusion that there is a minimum oxidation necessary to the maintenance of the vital functions which must go on however much the demands for the radiation of heat may be lessened by a rise of the air temperature. It is evident then that at the higher air temperatures there is an excess of oxidation above that which is required for warming the animal, so that some heat must be thrown off as a waste product. Whichever way the air temperature moves from the critical point there is heat regulation, this being chemical for the lower temperatures and physical for the higher.

The critical temperatures for our various farm animals have not been determined, so that we are not yet able to draw therefrom conclusions as to the influence of given temperatures upon production. 


\section{CHAPTER XII}

PHYSIOLOGICAL VALUES OF THE NUTRIENTS

THE preceding discussion of the physiological uses of the various nutrients has dealt largely with them as classes. The special functions and relative values of individual compounds within the same class or of the different classes have not been considered. We know, for instance, that the albuminoids are in a general way flesh-formers, or fat-formers, or heatformers, but we desire still further information as to the relative efficiency of the individual albuminoids for any specific purpose. Are some albuminoids more useful than others in aiding milk secretion? Similar knowledge concerning the non-nitrogenous nutrients is important. How valuable physiologically is cellulose as compared with starch ?

Again, we are convinced that both the carbohydrates and the vegetable fats may be sources of animal fats, but we are bound to inquire what is the relative importance of these groups of compounds as fatformers in the animal body.

It is easy to understand that knowledge of this kind would be valuable. We are coming to know a great deal about the composition of the various cattle foods, and if we could ascertain the exact physiologi- 
cal uses and relative values of even the most prominent individual compounds, we would be able to make somewhat definite comparisons of the different feeding stuffs. It must be confessed that information of this specifie kind is not as complete as one could wish. Its acquirement is very difficult and its present status is in some particulars unsatisfactory. Investigations so far conducted are not only insufficient to final conclusions, but researches by different observers have resulted in a conflict of opinion in some cases.

RELATIVE ENERGY AND PRODUCTION VALUES OF THE NUTRIENTS SINGLY AND AS CLASSES

It is satisfactorily established, as we have seen, that protein, carbohydrates and fats have eertain functions in common, that is, that all three classes are utilized as fuel, and that both carbohydrates and fats, and perhaps protein, may be a source of body fat. The question naturally arises, What is the relative value of these unlike nutrients as a source of energy and as fat-formers? Moreover, as each class is made up of a variety of substances, unlike in physical and chemical characteristics, can we consider the individual compounds within the same class as nutritively equal?

Relative energy values. -As a source of energy, the carbohydrates and their allies are properly regarded as of first importance because of their large relative use as a fuel supply. These bodies, so far as they are digestible, have been considered in formulating rations as of practically equal value. It is well known that 
this is a doubtful assumption. The nitrogen-free extract digested from the fodders is much more largely derived from crude fiber and the gums than that digested from the grains, starch being predominant in the latter, and we are not justified in concluding, except from reliable evidence, that the materials from the two sources are similar and equivalent as nutrients; in fact, some investigators believe the reverse to be true.

If we accept the heat of combustion of the carbohydrates and similar substances when burned in a calorimeter as the measure of their energy value, we have definite figures. The heats of combustion of the compounds found in the nitrogen-free extract have been found to vary from 3.7 to 4.2 Calories per gram. This indicates no great difference in value for the production of heat energy. We are not sure, however, that what is true of simple, rapid combustion is true of physiological use. Certain related facts must be considered. Because of Tappeiner's conclusion that the fermentations to which cellulose is subject, break it up mostly into gases and organic acids which he regarded as largely not useful to the animal, the view has more or less prevailed that digested crude fiber is greatly inferior to starch as a nutrient. More recent investigations throw doubt upon the correctness of this view, and the trend of opinion now seems to be towards regarding cellulose as taking practically the same place in nutrition, apart from ease of digestion, that starch does. It appears that the fermentations in the digestive tract of starch, sugar and other carbo- 
hydrates also give rise to gases which pass off unconsumed, though perhaps not to the same extent as is the case with crude fiber, and several observers declare that digested crude fiber is no less nutritively efficient in a maintenance ration than the more soluble compounds of the nitrogen-free extract.

The question has been raised as to whether the gums (pentosans) which exist so abundantly in many coarse foods and in some grain products, like wheat bran, are not inferior to the other more soluble carbohydrates. It has been observed that the sugars which result from the action of ferments on these bodies have, in some instances, not been oxidized, but have passed off in the urine as such. It appears doubtful whether under normal and usual conditions this occurs to any extent. The gums are constantly present in all rations for farm animals, and we have no reason for believing that the pentose (gum) sugars are constant ingredients of their urine.

The comparative physiological values of individual albuminoids and fats we do not know very much about, other than what we may judge from the determinations of heats of combustion. In experimental work single compounds have been but little studied. The conclusions reached have usually been based upon the results of feeding mixtures of individual albuminoids and fats as they ordinarily exist in plants.

Determinations of the heats of combustion of single and mixed albuminoids and fats from various sources show a variation of from 5.6 to 6 Cal. per gram for the former and from 9.2 to $9.6 \mathrm{Cal}$, for the latter. The 
variation for the same class is seen not to be large, but whether the animal derives energy in similar proportions must be decided by experimental evidence.

In recent years much attention has been given experimentally to the physiological values of the nutrients. Among the most painstaking and extensive investigations of this sort are those conducted at Möckern by Kellner and his associates. This work includes fortyfour metabolism experiments, each of fourteen days' duration, and one hundred and eighty-four respiration experiments, each of twenty-four hours' duration. In order to secure the desired data, there was added to a basal ration gluten, oil, potato starch, extracted straw (mostly cellulose freed from incrusting and accompanying compounds), meadow hay, oat straw, and wellripened wheat straw. From the results obtained, through exact measurements of the ingested food, the excreta and the products of respiration,- thus making it possible to determine the relation of each substance to the maintenance of the animal and to the storage of flesh and fat,- Kellner worked out both the energy and the production values of the experimental materials. While the figures given should not be regarded as final, they have behind them so much careful and severe investigation that they must be accepted as having great weight. They at least correctly record what happened with particular animals.

In presenting these results a distinction is made between available energy value and production or net value. It is the former which interests us at this point, and it is this which is shown in the following figures: 
Total heat value of 1 gram of digested organic matter eal.

Starch....... 4183

Extracted straw. . 4247

Molasses....... 4075

Meadow hay.... 4480

Oat straw...... 4513

Wheat straw .... 4470

Gluten ....... 6148

Peanut oil...... 8821
Per cent of loss in urine and gasesmethane Per cent $10.1 \dagger$ $14 . \dagger$ 10.4 18.7

16.9

25.6

$19.3 \dagger \dagger$
Available heat value for $1 \mathrm{gram}$ digested organic matter eal. 3760 3651 3645 3640 3747 3327 4958 8821
Comparative available heat value when stareh is 100

100 97 97 97 100 88 132 235

†Loss wholly from methane. it Loss wholly in urine.

The available energy is seen in the total energy of the digested organic matter less that which is lost in the urine and from fermentations which produce the unoxidized gases.

These figures show the energy or heat furnished to the animal by the different materials after deducting losses. They also represent the heat production when the substances were fed in a maintenance ration, and as Rubner has demonstrated that the heat lost from the animal that is eating just a maintenance ration is a measure of the animal's use of food, these values show what the different substances were worth for maintenance purposes. It appears that in these investigations the sugars of molasses, extracted cellulose and the material digested from the coarse foods containing much cellulose and gums supplied practically the same available energy to the animal that starch did, wheat straw excepted.

Relative production values of the different nutrients. - - If we calculate the fat-forming value of protein and 
starch on a purely theoretical basis as Henneberg did some years ago, it would appear that 100 parts of body fat can be obtained from 194 parts of albuminoids or 244 parts of starch. The fat factor of albuminoids would be therefore $51.4 \%$ and of starch $41 \%$. The equivalence of food fat in terms of body fat has never been expressed on such a basis, though it is customary to assume that the fat of the food may cause the production of an equal quantity of body fat or milk fat, an assumption which has no foundation whatever.

These theoretical figures are an attempt to show what protein and starch may do when actually used for storage purposes. They cannot be accepted as meaning much in indicating how the food is really used in practice. It is probable that the excess of food over and above maintenance is never all used for production according to the theoretical possibilities based upon chemical rearrangements of compounds. Certainly the production from a given quantity of food varies greatly under unlike conditions. It can scarcely be doubted that the proportion of the available nutrients which are consumed, that is, burned as fuel, increases as the ration increases above what is needed for maintenance, and inversely the proportion of the nutrients stored in the body as flesh and fat is less the greater is the quantity fed in excess of the demands for maintenance. A large excess over maintenance is relatively less efficient than a small one. There comes a point where additional food produces no additional gain, but only additional consumption. The age of the growing animal and the condition 
of a fattening animal also modify the efficiency of the food for production purposes, as does the period of lactation with a cow. With all these variations we have no averages which express with any definiteness the relative practical production value of the different nutrients. Nevertheless this question has been the subject of severe and extended investigation, and some of the results have given valuable information.

Henneberg and Pfeiffer estimate that in experiments with sheep the protein in excess of maintenance caused the production of from 30.7 to 41.1 parts of fat for each 100 parts of protein. It is not shown that the fat came directly from the protein or from the carbohydrates which the excess of protein replaced in other uses. Experiments by Kühn are made the basis of the conclusion that 1 pound of starch supported the storage of .2 pounds of fat.

The most reliable and extensive data as to productive values are those already referred to as having been reached by Kellner and others at Möckern. They are summarized in the following table:

\begin{tabular}{|c|c|c|c|c|c|}
\hline & $\begin{array}{c}\text { Heat } \\
\text { value } \\
\text { gram } \\
\text { organic } \\
\text { matter } \\
\text { cal. }\end{array}$ & $\begin{array}{l}\text { Mainten- } \\
\text { ance value } \\
\text { gram } \\
\text { organic } \\
\text { matter } \\
\text { cal. }\end{array}$ & $\begin{array}{l}\text { Percentage } \\
\text { Mainten- } \\
\text { ance value } \\
\text { applied to } \\
\text { production } \\
\text { Per cent }\end{array}$ & $\begin{array}{c}\text { Productive } \\
\text { value } \\
\text { gram } \\
\text { organic } \\
\text { matter } \\
\text { cal. }\end{array}$ & $\begin{array}{c}\text { Compara- } \\
\text { tive } \\
\text { productive } \\
\text { value } \\
\text { starch } 100\end{array}$ \\
\hline Starch........... & 4183 & 3760 & 58.9 & 2215 & 100 \\
\hline Extracted straw... & 4247 & 3651 & 63.1 & 2304 & 104 \\
\hline Molasses .......... & 4075 & 3645 & 63.6 & 2310 & 104 \\
\hline Meadow hay....... & 4480 & 3640 & 41.5 & 1512 & 68 \\
\hline Oat straw ........ & 4513 & 3747 & 37.6 & 1409 & 64 \\
\hline Wheat straw..... & 4470 & 3327 & 17.8 & 592 & 27 \\
\hline Gluten $\ldots \ldots \ldots$ & 6148 & 4958 & 45.2 & 2241 & 101 \\
\hline Peanut oil........ & 8821 & 8821 & 56.3 & 4966 & 224 \\
\hline
\end{tabular}


The productive value is stated in terms of the available energy less (1) the energy devoted to the work of chewing and digestion, and (2) that which is appropriated to the molecular rearrangement of the digested compounds which are transferred to the body substance.

These being the factors which diminish productive value, it is easy to understand how the usefulness of a nutrient is somewhat determined by its source. When it is contained in a coarse fodder like straw where the work of chewing and digestion is large and where, because of its physical condition, the fodder is slowly acted upon by the digestive fluids and is thus subject for a long time to the action of micro-organisms, the nutrient is less valuable than when supplied to the animal in grain where the work of mastication, digestion and solution is a minimum. Starch, extracted straw and molasses, requiring no energy for mastication and but little for solution, supply digested material which Kellner found to be four times as valuable for production as that coming from ripe wheat straw.

The foregoing figures do not tell us how much a steer would gain daily when fed upon a certain quantity of these nutrients, but they do indicate in a general way what is the relative efficiency of the nutrients when derived from given sources. They give us a scientific explanation of the fact that coarse foods are not adapted to rapid production.

Relative importance of the protein compounds. Much prominence has been given to the fact that protein includes several groups of nitrogen compounds 
quite unlike in character. We know also that these groups exist in cattle foods in unlike proportions. For example, a much larger part of the protein of roots consists of amides than is the case with the grains, the protein of the latter being correspondingly richer in albuminoids. If, therefore, albuminoids and amides differ in function or value, we have established one point of unlikeness between cornmeal and turnips. The testimony so far obtained is quite consistent in one direction, and indicates that the flesh-forming function is confined to the true albuminoids. This means that gelatin, amides (asparagin, etc.), extractives (creatin, etc.), cannot supply real muscle-building material. These non-proteids have nutritive value, however. Experiments with gelatin and asparagin have led to the conclusion that their presence in the ration so protects the albuminoids from consumption that the latter may have their maximum use as fleshand milk-formers. The extractives seem to have a peculiar place among the nutrients. They are not regarded as flesh-formers, or as fuel, but so far as is known they act merely as stimulants of the nervous system.

The albuminoids are the only flesh-formers. There are, however, many albuminoids, and they differ among themselves as raw material out of which to construct the primary tissues of the animal body. Can albumins do what globulins cannot? Are nucleins superior to albumins for special purposes? Not much that is definite can be said on this point: Because the various nitrogenous feeding stuffs are so generally 
interchangeable in the ration, without marked effect upon its efficiency when the protein supply is not diminished, it seems probable that the albuminoids are largely interchangeable in use. On the other hand, certain observed facts throw doubt on this view. For example, well-conducted experiments show that animal protein is superior to vegetable protein as food for ducks, when the two kinds are supplied in equally digestible quantities. It is possible that there are other differences in the effect of the protein from unlike sources which the ordinary methods of observation have not been competent to detect.

One interesting question which has been considered, is whether the special nuclein bodies (albuminoids containing phosphorus) which are found so abundantly in eggs and in milk must be supplied as such in the food, or whether they may be built up in the animal from other albuminoids and phosphates. If we could learn that the food must contain these peculiar albuminoids all ready for use, then we would have a valuable suggestion for feeding cows and poultry. It now seems improbable that this is the case. The sea salmon, which, during its stay up the river, is believed to take no food, undoubtedly produces large masses of eggs from the body substance, and it seems unlikely that so much nuclein as is needed exists in the flesh. If a cow gives thirty pounds of milk daily, nearly or quite a pound of casein must come from somewhere, and there is no evidence that any ordinary ration would contain so large a quantity of phosphorized albuminoids. Hens' eggs are rich in nuclein, beyond 
any amount which the food seems likely to supply. Notwithstanding this indirect evidence, it cannot be safely affirmed that one albuminoid does not possess much greater value for a specific purpose than another, and here is a field in which the investigator may render valuable service.

NoTE.-Extensive experiments recently conducted with milch cows by Jordan, Hart and Patten, showed that in every instance the nucleo-proteids in the rations were equal in quantity to those in the milk and excreta. The experiments gave no evidence of a synthesis of these bodies. 


\section{CHAPTER XIII}

\section{LAWS OF NUTRITION}

THE preceding pages have been devoted to a discussion of the origin of cattle foods, what they are in substance, how their nutrierts are made available and how used. So far no attempt has been made to gather together in a systematic relation what may be called the fundamental principles or laws of nutrition, some of which we have not yet directly stated, but which are inferences from the facts presented. It is desirable to do this, however, before passing to the consideration of the practice of cattle feeding.

1. All energy and building material applied to the maintenance and growth of the animal body come from the food, water and oxygen being included in this term. The animal originates neither force nor matter.

2. Only that portion of the food which is digested, i. e., that which is dissolved by the digestive fluids and rendered soluble and diffusible so that it passes into the blood, is available for any use whatever. This faci is especially important in view of the greatly varying digestibility of different feeding stuffs.

3. The unutilized food and the wastes pass from the body in some direction. The undigested part mainly 
constitutes the solid excrement or feces. The urea and other nitrogenous compounds which are the unoxidized portion of the protein, pass out wholly in the urine. All digested nitrogen not stored is found here. The carbon dioxid is eliminated through the skin and lungs, chiefly the latter, and water is disposed of through the kidneys, skin and lungs.

4. The digested food is used in two general directions, $(a)$ for the production of energy and $(b)$ for constructive purposes.

(a) The food energy is made available through combustion, i. e., the oxidation of the carbon compounds of the food to simpler substances, carbon dioxid and water, thus liberating the energy stored in the plant during its growth. Protein is never fully oxidized, but carbohydrates and fats may be. All the organic nutrients may be oxidized to produce energy, the total heat values of protein, carbohydrates and fats being approximately as $1.5,1,2.4$. This liberated energy finds expression in the animal organism in various ways, as heat, mechanical energy or motion and chemical transformations. The total energy of food is never all available to the animal because of a loss in the excreta and gases. Moreover, the net energy gain seems not to be proportional to the available energy, but is dependent upon the work of digestion, which varies with different cattle foods.

(b) The food compounds are used for constructive purposes, either without changing their general character, as, for instance, the building of muscular tissue from the plant albuminoids, or they may be reorganized into bodies of a very different character, as in the 
formation of animal fats from starch and sugar. Protein is used to construct muscular tissue, in fact, all the nitrogenous parts, and it is perhaps a source of fat. Carbohydrates can only be used constructively for the formation of fat, and the same is true of food fats or oils. Mineral matter is needed for the formation of bone and has important functions in digestion.

5. The matter of the digested food, including water and oxygen, is exactly equal to that stored in the body or in milk, or both, plus that in waste products,-feces, water, carbonic acid and urine solids. Such a balance may not be maintained for any particular day, but will ultimately be found to exist.

6. Under given conditions of species, sex, climate and use, a definite amount of digested organic matter is necessary to maintain a particular animal without gain or loss of body substance. This means simply that tissue wastes must be replaced, and the fuel supply must be kept up.

If the animal receives no food, or less than the amount needed for maintenance purposes, tissue waste and the production of energy do not cease, but go on wholly or in part at the expense of the body substance, and, as it is commonly expressed, the animal "grows thin."

7. Food supplied above a needed maintenance quantity may be utilized for the production of new substances or work or may be eliminated in part and increase the waste. Within limits, both things generally occur. In the proper sense of the term, no production ever occurs without an excess of food above the mainte- 
nance requirement. Milk formation may sometimes go on at the expense of the body substance, but with proper feeding, milk, flesh or muscular work are produced at the expense of food supplied in excess of that needed for maintenance.

8. Regard must be had to the supply of particular nutrients as well as of total food. Even with an animal doing no work and giving no milk a certain amount of protein will be broken up constantly into urea and similar compounds, an amount which will be withdrawn from the body tissues to the extent that it is not supplied by the food. In addition to this, a milch cow, for instance, must have protein for the formation of the nitrogen compounds of the milk, or a steer for the growth of flesh in a quantity proportional to the production, and food must supply it. There is, therefore, a minimum supply of protein, which, in a particular case, is necessary for maintenance and for constructive purposes, less than which ultimately diminishes production to the extent of the deficiency, or else requires the use of body tissue.

9. The different classes of nutrients are to some extent interchangeable in their functions. That is to say, all the organic nutrients may be burned to supply energy. Protein may be so used even to withdrawing it from the purposes to which it is necessary unless the carbohydrates or fats are sufficient to protect it from being consumed as fuel. A proper supply of the nonnitrogenous nutrients is required, therefore, to insure the application of the necessary minimum of food protein to its peculiar uses. 


\section{CHAPTER XIV}

\section{SOURCES OF KNOWLEDGE}

THE foregoing chapters embody many statements of principles and facts which have been made positively and without modification. To quite an extent these are based upon the conclusions of scientific men, that is, conclusions which have been reached after such study of the problems involved as is competent to secure accurate information. In some cases this study has been severe and long continued, having been carried on by the use of methods and apparatus capable of the most precise measurements. Moreover, in the investigations of science an effort has been made to proceed logically, so that the results attained shall not be fallacious. Notwithstanding the fact that a great deal of our knowledge is the result of an earnest and impartial search after truth, under conditions especially favorable to its discovery, many persons are disposed to give more credit to the traditions and conclusions of practice than to the carefully prepared verdicts of science. It may not be out of place, therefore, to present in this connection some of the considerations and methods which have to do with the acquisition of knowledge concerning animal nutrition, for this may aid us to appreciate the value of 
well-established facts and to exercise caution in accepting the verdicts either of science or of practice before they are thoroughly justified.

There are three general ways in which we may be said to have acquired knowledge in regard to feeding animals:

1. The observation of ordinary practice.

2. Practical experiments, so called.

3. Scientific investigation.

\section{CONCLUSIONS OF PRACTICE}

Until within recent years, the practice of cattlefeeding has been entirely governed by the conclusions drawn from ordinary practice. Among the many men engaged in animal husbandry, certain ones possessed of more than average powers of observation and business ability have secured good results with certain feeding stuffs and methods of feeding, and their practice has been accepted by their neighbors with no further demonstration than that these successful farmers sold fat cattle and obtained large returns from the dairy. During the centuries that man has had domestic animals under his care, certain results have appeared to follow from certain systems of feeding or the use of certain foods, and upon these socalled practical observations the feeder has built his ereed.

In these ways there have come to be accepted, sometimes locally and sometimes generally, standards of feeding as to quantity, kind of ration, and times 
of feeding. At the same time, it was necessary only to attend a farmers' convention fifty years ago to become convinced of a great variety of opinions as to the best methods of practice. In fact, opinion was the court of last resort. There were then no known, well-established fundamentals to which appeal could be made as a basis for discussion. While many false notions were entertained, many of the beliefs then prevailing were undoubtedly correct or contained a germ of truth. It is generally safe to assume that when an opinion is widely and persistently held it is not altogether without reason or foundation. It is often the expression, in more or less correct terms, of some important prin. ciple. No one should lightly turn aside from the traditions and convictions of a community in regard to any line of practice. A knowledge of the precepts governing the feeder's art that are the accumulation of experience in the care of animals is to be respected and is, to a great extent, essential to successful practice. It is also true that little substantial progress can be realized in any art if its underlying truths are not. understood, for when this is the case the results of experience under one set of conditions do not serve as a guide under circumstances entirely different.

\section{PRACTICAL FEEDING EXPERIMENTS}

With the advent of modern science and of the efforts to utilize it in agriculture, an attempt has been made to search for important truths more systematically, an effort undertaken chiefly by experiment stations. As 
one means of gaining knowledge, these institutions, and to some extent private farmers, have conducted many so-called practical feeding experiments in order to verify present beliefs, test theories and solve existing problems. The relative value of various feeding stuffs and rations for producing growth and milk and the influence of different fodders and grain foods upon the quality of the product have been the subjects of numerous feeding tests. Much valuable information has been secured in this way, but there has not always been a full recognition, even by experiment stations, of the limitations which should be observed in drawing conclusions from this manner of experimentation.

In order to view this matter more in detail, let us consider experiments in testing rations for growth and milk production. The usual method of procedure with such feeding trials is either to feed two lots of animals on the rations to be compared and note the comparative growth or milk yield, or to feed the same lot on one ration for a time and then change to another ration.

If these tests are made with growing or fattening animals, the increase in live weight is taken as the measure of the relative efficiency of the rations compared. It should be said of these experiments that their apparent verdict is to be accepted with great caution, and definite conclusions are not justified until repeated trials of two rations or of two systems of feeding, made with the use of all possible precautions against error, and under a variety of conditions, give uniform and consistent results in the same direction. 
There are several reasons why this is so, the main one being that the increase in the weight of an animal is an uncertain measure of actual growth. Variations in the contents of the alimentary canal due to the irregularity of fecal discharge and to a lack of uniformity in the water drank may cause temporary variations in the live weight of considerable magnitude. Moreover, the nature of the growth of body substance is revealed neither by the mere weighing of an animal nor by his general appearance. Even if the changes in weight are due to an increase of body tissue, this may be more largely water in one case than in another, so that the real contribution of the food to the dry substance of the body may not be shown. Nor is the eharacter of the solids deposited in the animal discovered by merely weighing him. In fact, by such practical experiments we simply learn that one set of animals has gained more or less pounds of weight than another set, but the why and the how are not explained.

Practically the same considerations pertain to feeding tests for milk production. When the milk flow from one ration is larger than from another, we can easily satisfy ourselves as to the comparative yield of milk solids, which is the real test of such production; but we are not able to decide whether the cow either may not have contributed to the milk secretion from the substance of her own body, or may not have gained in body substance, the extent of such loss or gain being greater, perhaps, with one ration than with another.

Even if these uncertainties did not exist, we have 
the still greater disadvantage of not learning by this means why a particular combination of feeds has superior qualities for causing growth or sustaining milk secretion. The mere data showing that an animal ate so many pounds of food and produced so many pounds of beef or milk are important business facts, but they reveal nothing concerning the uses of the several classes of nutrients and of themselves furnish slight basis for developing a rational system of feeding. We must somehow learn the function of protein, carbohydrates and fats in maintaining the various classes of animals and the real effect of varying the source, quantity and relative proportions of these nutrients before we can draw safe general conclusions.

\section{CHEMICAL AND PHYSIOLOGICAL STUDIES}

As preliminary to more comprehensive and convincing methods of investigating feeding problems, there has been going on during many years a necessary study of the compounds which are found in plants and animals. Much has been learned about the ultimate composition and the constitution of the albuminoids, carbohydrates and fats, their physical and chemical properties, the compounds into which these bodies break under certain conditions, the chemical changes to which they are subject through certain agencies, and their relation to one another. Investigations along these lines have for years occupied the time of some of our ablest scientists, and, while such researches when they were conducted may have seemed to the extreme 
utilitarian to be of little value, we now see how directly they are contributing to human progress and welfare.

To the above information has been added through physiological investigations a knowledge of the ways in which the several food compounds are transformed in digestion and in other metabolic changes, the avenues along which these compounds travel, and the ways in which their products of decomposition are discharged from the animal organism. We have learned how to distinguish between the digested and undigested food, have demonstrated that all the nitrogen of the decomposed proteids passes off in the urine, have measured the combustion of the nutrients ana have learned how to strike a balance between the income and outgo of the animal body. It is now possible to determine with reasonable accuracy just how much substance is retained or lost from the body of the experimental animal while eating a given ration, and what is the nature of the gain or loss. Very recently means have also been devised for measuring the heat given off by a man or an animal in order to ascertain the actual physiological values of different feeding stuffs.

\section{MORE ACCURATE METHODS OF INVESTIGATION}

In applying the principles and facts of chemistry and physiology, the first advance from the ultra-practical feeding experiment in the direction of an accurate history of what occurs when the animal is eating a 
particular ration is the measurement of the digested nutrients and the determination of the gain or loss of nitrogen. This is accomplished, as heretofore stated, by ascertaining the quantity of various compounds eaten and the amount of the same in the feces, the difference being the digested portion. The urine is also collected, and if the nitrogen in it is less or more than that in the digested protein, then the animal is either gaining or losing nitrogenous body substance, unless the measurement is with a milch cow, when the nitrogen in the milk must be taken into account. By an experiment conducted in this way, with careful and continued weighings of the experimental animal, it is possible to secure a probable relation between a unit of digested dry matter and a unit of production. Such a method has been used to determine what is a maintenance ration for animals of several classes, and in those cases where the experiments have been continued for a sufficient length of time and have shown on repetition a reasonable agreement, we are justified in accepting the results as a close approximation to fact. When a ration keeps an animal in nitrogen equilibrium for one or more months and no material gain or loss of weight occurs, we may safely regard it as approximately a maintenance ration under the conditions involved. Experiments of the same kind are equally useful in testing the productive power of various food combinations, and whenever by such continued tests one ration shows no superiority over another, it is safe to assume that no differences exist which would be especially important to the farmer's pocketbook. 


\section{RELATION OF FOOD TO PRODUCTION}

Another class of experiments somewhat more severe in their requirements are those designed to give information as to the relation between the constituents of the food and the growth of the various tissues in the animal body or the formation of milk solids. The experiments conducted by Lawes and Gilbert on the formation of fat with swine may be cited in illustration of the methods used. These were planned so as to learn the amounts of digested protein, carbohydrates and fat consumed by the animal and also the quantities of protein and fat stored in the body during a given period. "In experiment No. 1, two pigs of the same litter, of almost exactly equal weight, and, so far as could be judged of similar character, were selected." One was killed at once and its composition determined, and the other was fed for ten weeks on a fattening ration of known composition and then slaughtered and analyzed. The quantity of protein and fat which the pig's body had gained during the ten weeks as ascertained from the composition and weight of the two pigs was then compared with the food supply of similar compounds. It was assumed that a pound of food fat could produce a pound of body fat and that 51.4 per cent of all the protein not stored in the body as such could be used for fat formation. Even with the most liberal allowances it was found that the protein and fat of the food could not possibly have been the sole source of the new body fat, thus forcing the conclusion that the carbohydrates are fat-formers. 
Practically the same plan has been followed in studying the source of milk fat. Several cows were fed on carefully weighed and analyzed rations extremely poor in fat, and the amount and composition of the feces, urine and milk were ascertained during sixty to ninety days. The fat digested from the food and the theoretical fat equivalent of the decomposed protein as measured by the urine nitrogen were charged up against the milk fat, and a large quantity of the latter could be accounted for only as having had its source in earbohydrates.

Another method of investigating fat formation has been used with dogs. It is well known that when an animal is deprived of food the expenditure of energy by the body is maintained at the expense of body substance. Both muscular tissues and fatty substance are broken down and used in this way, the latter being regarded as furnishing the most natural and available supply of fuel. It was found in the ease of dogs that after a certain number of days of starvation there occurred a sudden and large increase in the waste of nitrogen compounds as shown by the urine excretion, the explanation for this being that the body fat had become exhausted and a demand was at once made upon the proteid tissues for the necessary supply of energy. As soon as this rise of nitrogen waste appeared, then the dog was allowed to eat, and whatever fat was found in the body at the end of the feeding period was regarded as having been formed from the food taken after the starvation period. If, for instance, the ration was wholly protein and fat was found to have become de- 
posited in the body, this was regarded as proof of the formation of fat from protein. Such experiments as these have not always been conclusive, although they are regarded by some scientists as having furnished proof that protein may be a source of fat.

\section{THE RESPIRATION APPARATUS}

After all, the investigations of the kinds described fail to furnish data so accurate and so complete as are necessary for entirely safe conclusions. In every instance, one or more assumptions are involved where definite proof is not furnished. Nothing short of a complete record of the income and outgo of the animal organism during the experimental period is conclusive evidence as to whether there has been a gain or loss of body substance and what is the kind and extent of the growth or waste. The securing of such a record is an expensive and laborious task. It requires not only complete information in regard to the quantity and composition of the food, but also an accurate measurement of the excreta, including the feces, the urine, the respiratory products and the matter given off through the skin. Such measurements are taken by means of a respiration apparatus, a costly and complicated mechanism, a detailed description of which would be of little use to most readers. It is sufficient to state that this apparatus makes possible the collection and analysis of all the excretory products, whether solid or gaseous. The experimental man or animal lives in a closed chamber into which is intro- 
duced food and fresh air and from which is pumped the vitiated air, the water and carbon dioxid of which are absorbed and weighed.

All conclusions drawn from experiments with the respiration apparatus are based largely upon the income and outgo of nitrogen and carbon. As carbon is a constituent of all possible compounds of the animal body except the mineral, it is certain that when the body gains in carbon it gains in organic substance of some kind, and if it loses in carbon there is a waste of organic body substance. The general character of the gain or loss can be determined by the nitrogen balance. If more nitrogen is taken in by the experimental animal than is given off, it is clear that the nitrogen compounds of the body have received an accession. Knowing as we do the proportions of nitrogen and carbon in the various tissues of the animal, we can calculate how much of the gain or loss of carbon belongs in the nitrogenous substance deposited or wasted. If more earbon is gained or lost than can possibly be associated with the nitrogen gained or lost, then there has been a gain or loss of fat, because protein and fat being the main constituents of the animal carcass, any considerable retention of carbon must be in one of these forms. If there has been nitrogen equilibrium, all excess or deficit of carbon belongs to a deposit or waste of fat. By such searching methods as these, it is possible to ascertain with a good degree of accuracy how food is used and what quantity and kind of nutrients are needed in maintaining an animal under given conditions. 


\section{DETERMINATION OF ENERGY VALUES}

We have reached a point in our study of animal nutrition where we realize that food values are to some extent commensurable with energy values and that it is desirable to know the energy product of different compounds and feeding stuffs. Moreover, we cannot possess sufficiently full knowledge concerning the energy needs of the several classes of animals until we have measured energy consumption under the various conditions of work and of production. The mere determination of the income and outgo of the animal body does not necessarily measure energy needs or use. We may go so far as to ascertain that a certain amount of carbon from a certain source was consumed in a given time, but from this alone we do not learn the extent to which this combustion has supported the internal and external work of the body.

Calculation of the energy value of a ration. - Three methods may be adopted for determining the energy expenditure by an animal eating a given ration. The one of these most easily carried out is largely a matter of mathematical calculation. By the use of average digestion coefficients it is possible to ascertain approximately the amounts of digestible protein, carbohydrates and fats contained in any ration which is apparently accomplishing a desired result. We know from previous determinations what are the calorific values of individual compounds such as albumin, starch, sugar, stearin and olein, and these compounds are assumed to represent the energy value of the 
classes of nutrients to which they belong. If, then, we multiply the calculated quantities of digestible protein, carbohydrates and fats by their respective assumed energy factors, we get a number which may be taken as an expression of the available energy of the ration under consideration. This method cannot be regarded as entirely accurate, because the calorific value for protein may not be the same as that for any single albuminoid, and the heat units of the nitrogen-free extract are likely to vary materially from those found for the starches and sugars, while the ether extract is very far from representing the pure fats. At the same time, it is possible in this way to learn the energy value of a ration closely enough, perhaps, for all practical purposes.

Energy value of digested nutrients. - A second method, which is probably a step in the direction of greater accuracy, is to determine by the use of a calorimeter the heat units of the ration and also of the urine and feces. The differences between the food heat units and those found for the excreta are assumed to represent the energy value of that portion of the ration appropriated by the animal. Provided the heat units obtained in calorimeter combustion and physiological combustion are equivalent, this method must be considered as furnishing a reliable energy measurement. However probable this equivalence may seem, it has not been fully demonstrated. We still need more complete experimental proof that the oxidation of the several food compounds in ordinary combustion and in the animal produces identical re- 
sults in the two cases.* Even if this method gives us a correct estimation of the energy equivalent of the food used, it furnishes no definite information as to the manner of use. It does not appear to what extent the digested nutrients have been oxidized with a corresponding radiation of heat or whether there has been a gain or loss of body substance. If there has been a gain of body substance, then the needs of the work horse or milch cow, if these are under consideration, are less than the heat units of the ration, but if there has been a loss of body substance, then the ration is below the required standard for the particular animal under investigation. In a study of energy relations, it is therefore even more necessary to resort to a respiration apparatus of some sort than in determining food balances. We must learn the actual extent of the food combustion which occurs if we would have all the data necessary for measuring energy used, and here we come to the third and most accurate method of determining energy expenditure; viz., experiments with a respiration apparatus.

Measurement of food combustion. - There are two general ways of ascertaining the extent to which food is burned by any living organism. One is to measure the products of combustion and the other is to measure the amount of oxygen used. It is selfevident that no combustion can occur without the use of oxygen, and so if the experimenter is able to learn just how much of this element is taken up in uniting with the carbon and hydrogen of the food, he has a direct and accurate means of measuring actual

\footnotetext{
* This is now regarded as established.
} 
energy production. The older forms of respiration apparatuses simply allowed an estimation of the carbon dioxid and water given off by the animal. How much of the water was formed by the oxidation of the hydrogen of the food and how much was simply evaporated from the store taken in as water, it was impossible to know by direct determination. This could only be calculated. The carbon dioxid was, on the other hand, a direct and accurate measure of the combustion of carbon. Later devices, as, for instance, the one used by Zuntz, allow a direct determination, not. only of the products of combustion, but of the oxygen absorbed by breathing. This method of work has great advantages, as one measurement not only checks the other, but makes it possible to ascertain the actual oxygen consumption during any given period of the experiment, as, for instance, when the animal is at rest, when masticating food, or when performing a given amount of external work. In this way, Zuntz made his masterly demonstrations of the differences in the net values of different foods due to the greater energy cost of masticating and digesting certain ones.

Respiration calorimeter. - None of the older apparatuses, whether allowing the determination of oxygen consumption or not, measured the heat radiation from the animal body, or, in other words, the amount of energy actually evolved from internal combustion. Recently Professors Atwater and Rosa have devised a respiration apparatus which is at the same time a calorimeter. The quantity of heat radiated from a man or other animal confined in this calorimeter is absorbed 
by a known volume of water and is thus determined. This is a great advance towards certainty, because direct measurements of the energy of a ration in use are thus made possible and the necessity for theoretical assumptions is largely removed.

It is already made clear to the reader, doubtless, that the demonstration of facts and principles in the domain of animal nutrition is exceedingly difficult. It should be equally clear that when conclusions are reached in ways which have been briefly described, they are worthy of respect and should have greater weight than the necessarily imperfect observations of common practice. Science often errs in her deductions, but the efforts of her workers are constantly directed towards the elimination of false conclusions, so that unsound theories are not likely to be aceepted for a great length of time. 


\section{PART II-THE PRACTICE OF FEEDING}

\section{CHAPTER XV}

\section{CATTLE FOODS-NATURAL PRODUCTS}

THE number of eattle foods now available for use is very large, and the list appears to be constantly increasing. Not only have several fodder plants been added to those formerly grown, but we have now a great variety of waste products from the manufacture of oils, starch, and human foods that are being placed upon the market as feeding stuffs. At one time farmers produced all their cattle ate, and this was done without going outside a very limited list of forage plants and grains. All this is changed, especially in the older, more thickly-settled portions of the United States, so that considerable knowledge is now needed regarding the composition and specific characters of the numerous kinds of feeding stuffs if they are to be used intelligently.

It will aid in discussing this branch of our subject if we first note the divisions into which the materials used for feeding farm animals are grouped. There is more than one basis upon which it is possible to make these divisions, - botanical relations, the portion of the plant used, whether stem or fruit, and chemical composition. As a matter of fact. all these and other 
distinctions are involved in the classification of the cattle foods in common use at the present time.

The feeding stuffs of vegetable origin are generally divided into four classes: (1) forage crops, consisting of the stem and leaves of herbaceous plants, either in green or air-dry condition, to which is attached in some cases the partially formed or wholly mature seed or grain; (2) roots and tubers, or the thickened underground portions of certain plants; (3) seeds or grains; (4) parts of seeds or grains which are the by-products from the removal of other parts by some manufacturing process. These are the commercial by-product feeding stuffs.

\section{FORAGE CROPS}

The valuable forage plants of the United States belong mostly to two families, the grasses (gramineæ) and the legumes (leguminosæ). June grass, red top, timothy and the cereal grain plants are types of the former; and the clovers, alfalfa (Fig. 3), the vetches, and peas, of the latter. Whether in the pasture or in tilled fields, few plants outside of these divisions contribute materially to the supply of high-class fodders. The most essential difference between the members of these two families of plants when considered as feeding stuffs is the larger proportion of nitrogen compounds in the legumes. It is characteristic of all legumes that their proportion of protein is high as compared with any other forage crops, and for this reason they are greatly prized on dairy farms. The fact that they are regarded as increasing materially the nitrogen supply 
of the farm from sources outside the soil also adds to their value.

Green vs. dried fodders. - Conditions of drying.Nearly all of the herbaceous plants that are grown for consumption by farm animals may be fed either in a green or dry state. Oats, maize, clover, alfalfa, and other species which serve so useful a purpose as soiling crops for summer feeding are also dried that they may be successfully stored for winter feeding, though

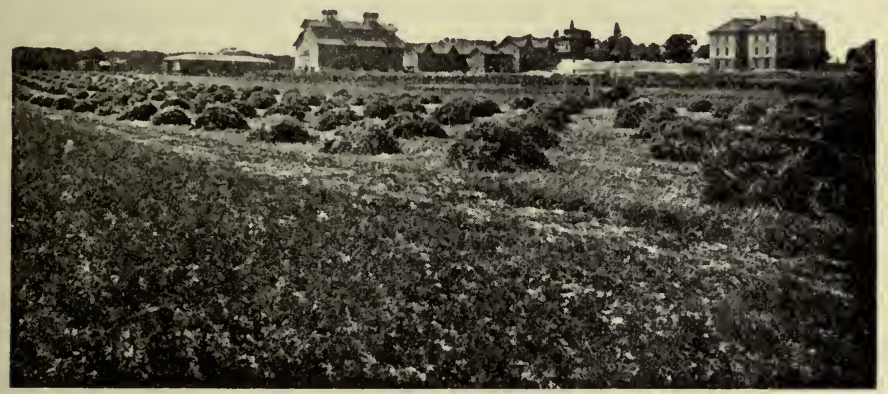

Fig. 3. Crop of alfalfa, New York State Experiment Station.

maize, and, to some extent, other crops, are now preserved in a green condition through the process of ensilage.

The advantages and disadvantages of green as compared with dry fodders have been much discussed, and some of the facts, chemical and otherwise, bearing upon the question are presented in this connection. It is safe to assert that the compounds of a dried fodder. which has suffered no fermentation are practically what they were in the green, freshly-cut material, excepting that nearly all of the water contained in the green 
tissues has evaporated and that in drying there is a possible loss of an imperceptible amount of volatile compounds, whose presence in the plant affects its flavor more or less. It is certain that curing a plant generally diminishes its palatableness and increases its toughness, or its resistance to mastication, although with many crops, as for instance the early-cut native grasses, these changes do not affect nutritive value to a material extent. There is no question but that the mere matter of being green or being dry has very little influence upon the heat which a fodder will develop when burned or upon the extent to which it will sustain growth or milk formation. We must, however, take into account the desirability of the highest state of palatableness.

It is a fact that drying fodders under perfect conditions is often not possible. The long-continued and slow curing of grass in cloudy weather, especially when there is more or less rainfall, is accompanied by fermentations that result in a loss of dry substance more or less extensive, and which involve some of the most valuable compounds, principally the sugars. The tissues of certain plants, maize for instance, are so thick that rapid curing in the field is never possible, and fermentative changes are unavoidable. It is probable that maize fodder and stover are never fielddried without a material loss in food value, for the chemist finds that even when the stalks are finely chopped, drying by artificial heat is necessary to a complete retention of the dry matter. The extent of the loss from curing fodders must be very variable. 
So far as we know, grass, which in "good haying weather" is well stirred during the day and packed into cocks over night so as to avoid the action of heavy dew, suffers practically no deterioration, while dull weather or rain may cause a serious loss. It is doubtful, however, whether night exposure during good weather is sufficiently injurious to justify the expense of cocking partially cured hay. On the other hand, the economy of using hay caps during unfavorable weather is without question. The over-drying of hay before raking into winrows and "bunching" so as to cause a loss of the leaves and the finer parts through brittleness may be as wasteful as under-drying and the consequent fermentation. Over-dried hay does not pack well in the mow and is less palatable. The leguminous hays, such as clover and alfalfa, are especially subject to loss from over-drying before handling. Fodder crops, if dried at all, should be dried to such a per cent of moisture that they will not "heat" to discoloration after being packed in large masses and lose dry matter from the same general causes that operate in field-curing under bad conditions.

The harvesting of forage crops. - The result to be achieved in the growing of forage crops is the production on a given area of the maximum quantity of digestible food materials in a palatable form. The age or period of growth at which a forage crop is harvested is an important factor in this relation and may affect the product in three ways: (1) in the quantity of material harvested, (2) in the composition of the crop, 
and (3) in the palatableness of the resulting fodder. In discussing this question we must recognize the fact, first of all, that in these respects no general conclusion is applicable to all crops. What would be wisest in the management of the meadow grasses might be wasteful in handling the legumes, and especially so in harvesting maize.

The truth of this statement will appear as the facts are displayed.

It is safe to assert that in general the maximum quantity of dry matter is secured when forage crops are allowed to fully mature and ripen. The only exception to the rule is found in the legumes such as the clovers and alfalfa, where at maturity the leaves unavoidably rattle off and are lost, either before or during the process of curing. The fact that growth of dry matter takes place up to the time of full maturity is well illustrated by the results of experiments conducted on the farms of the Pennsylvania State College, the New York Experiment Station, and the University of Maine, in eutting timothy grass, clover, and maize at different stages of growth. These results are summarized in the accompanying tables:

\section{Timothy grass (yield of dry hay per acre)}

$\begin{array}{ccc} & \text { Results in Maine- } \\ \text { av. } 3 \text { years } 1 \text { year } \\ \text { Stage of growth } & 1878-1880 & 1889 \\ \text { lbs. } & \text { lbs. }\end{array}$

$\begin{array}{ll}\text { Nearly in head } \ldots \ldots \ldots \ldots . & 3,720 \\ \text { Full bloom } \ldots \ldots \ldots \ldots & 4,072\end{array}$

Out of bloom or nearly ripe . 4,136

Ripe................. 3,832
Results in Pennsylvania-two farms av. 2 years 1881-1882

lbs.

$$
4,225
$$

2,955

5.086

3,501 
Maize for silage (yield of dry matter per acre)

$\begin{array}{ccc} & \text { New York } & \text { Maine } \\ & 1889 & 1893 \\ \text { Stage of growth } & \text { lbs. } & \text { lbs. }\end{array}$

Tasseled to beginning of ear....... 1,620 3,064

Silked to some roasting ears ....... 3,080 5,211

Watery kernels to full roasting period . 4,640 6,060

Ears glazing $\ldots \ldots \ldots \ldots \ldots \ldots \ldots \ldots, 7,200 \quad 6,681$

Glazed to ripe $\ldots \ldots \ldots \ldots \ldots \ldots \ldots, 7,920 \quad 7,040$

Red clover (yield of dry matter per acre)

Stage of growth

Pennsylvania 1882

lbs.

In full bloom ................... 3,680

Some heads dead ................... 3,428

Heads all dead $\ldots \ldots \ldots \ldots \ldots \ldots \ldots \ldots \ldots \ldots, 3,361$

These data are convincing testimony as to the growth of dry substance in certain forage crops up to and including the period of ripening. Clover is an apparent exception, but is probably not really so because after the heads begin to die there is an actual loss of dry matter from the shedding of the leaves.

It does not follow when a plant increases in its yield of dry matter that its nutritive value has proportionately increased. The end to be sought is the largest possible quantity of available food compounds, and it is entirely possible that changes in texture and in the composition of the dry substance may partially or fully offset the greater yield. With the meadow grasses this undoubtedly happens. The dry matter of mature grass contains a larger proportion of fiber than the immature. The progressive increase of fiber as the plant approaches ripeness is well illustrated by analyses made at the Connecticut Experiment Sta- 
tion of a sample of timothy grass cut at different periods of growth:

\begin{tabular}{cccccc}
\multicolumn{7}{c}{ Composition of dry substance } & (per cent) \\
Stage of growth of timothy & Ash & Protein & $\begin{array}{c}\text { Crude } \\
\text { fiber }\end{array}$ & $\begin{array}{c}\text { Nitrogen- } \\
\text { extract }\end{array}$ & Fats \\
Well headed out .... & 4.7 & 9.6 & 33. & 50.8 & 1.9 \\
In full blossom ...... & 4.3 & 7.1 & 33.3 & 53.3 & 2. \\
When out of blossom . & 4.1 & 7.1 & 33.8 & 53.3 & 1.7 \\
Nearly ripe.......... & 3.6 & 6.8 & 35.4 & 52.2 & 2.
\end{tabular}

These analyses show that the changes are not confined to an increase of fiber. The relative proportions of ash and protein grow less as the plant matures. An examination of the nitrogen-free extract would probably show an accompanying decrease of the soluble carbohydrates.

The combined effect of these changes is to cause the plant to harden in texture and become less palatable. The digestibility is naturally affected. Three American digestion experiments with timothy hay cut in bloom or before show an average digestibility of the organic matter of 61.5 per cent, the average from four experiments with timothy cut when past bloom being 55.4 per cent. Doubtless the increase in dry matter when timothy stands beyond the period of full bloom no more than compensates for the decrease in digestibility. Using the average coefficients of digestibility and the average yields, as given in this connection, the yield of digestible organic matter would be in full bloom, 2,306 pounds, and when out of bloom or nearly ripe, 2,350 pounds. If one considers the decrease in palatableness the advantage is with the earlier cut hay. 
These facts do not pertain to timothy alone. Other meadow grasses are similar in their characteristics of growth. The clovers, and especially alfalfa, deteriorate to a marked degree from the same cause when allowed to ripen too fully before cutting.

It is probable, all factors considered, that if the grasses and clovers which are cut for hay could be harvested when in full bloom a desirable compromise would be effected between quantity and quality. Alfalfa should be cut no later than when the first bloom makes its appearance.

Conditions are quite different with maize. This plant in maturing gains not only in quantity but in quality. In support of this statement data are cited from an experiment conducted at the Maine Experiment Station.

The following is the composition of the dry matter of the corn when cut at several periods of growth:

In 100 parts water-free substance of maize

\begin{tabular}{|c|c|c|c|c|c|}
\hline tage of growth & Protein & $\begin{array}{l}\text { Crude } \\
\text { fiber }\end{array}$ & Sugar & Starch & $\begin{array}{l}\text { nitrogen } \\
\text { free } \\
\text { extract }\end{array}$ \\
\hline are, Aug. 15 & 15. & 26.5 & 11.7 & & 46.6 \\
\hline ars, Aug. 28 .. 6.5 & 11.7 & 23.3 & 20.4 & 2.1 & 55.6 \\
\hline age, Sept. 4 ... 6.2 & 11.4 & 19.7 & 20.6 & 4.9 & 59.7 \\
\hline zing, Sept. 12... 5.6 & 9.6 & 19.3 & 21.1 & 5.3 & 62.5 \\
\hline zed, Sept. 21 & 9.2 & 18.6 & 16.5 & 15.4 & 63.3 \\
\hline
\end{tabular}

Here we see the same decrease in the proportions of ash and protein as occurs with timothy, but, unlike timothy, the maturing of the maize causes a decrease in the percentage of fiber and a material increase in the relative amount of the soluble carbohydrates, sugar and starch, 
These data give us every right to expect that the dry matter of the mature corn plant is more digestible than that of the immature plant, and experimental tests show this to be the case. There follows a summary of American digestive experiments bearing on this point:

Digested from 100 parts organic matter

Corn fodder - Mv. Corn silage
Max. Min.

$\begin{array}{llllllll}\text { Cut before glazing, } 13 \text { experiments .. } & 71.4 & 53.6 & 65.7 & 77.8 & 56.6 & 67.4\end{array}$

$\begin{array}{lllllll}\text { Cut after glazing, } 10 \text { experiments.... } & 74.2 & 61.2 & 70.7 & 80.2 & 65.2 & 73.6\end{array}$

The advantage is seen to be with the mature corn. It is fair to conclude from all these observations that harvesting the corn plant when immature is injudicious from every point of view.

\section{SILAGE}

About twenty-five years ago a new process for preserving crops in a green condition was introduced into the United States; viz., ensilage. This consists in storing green material in receptacles called silos, in masses sufficiently large to insure certain essential conditions. Within a brief period after maize or other green material is packed in a silo, the mass becomes perceptibly warm and in the course of two or three days it reaches its maximum temperature, which is much above the average heat outside. This rise in temperature is due to chemical changes which involve the consumption of more or less oxygen and the production of compounds not previously existing in the fresh material. 
Nature of the changes in the silo.-These changes are very complex. They have been regarded as due to the activity of a variety of ferments, principally those which are believed to cause the formation of alcohol and acetic, lactic and other acids. Whether the oxidations occurring in the silo are wholly induced by ferment action or in part at least are the result of oxidations brought about in other ways is a point over which there has been some recent interesting discussion.

Babcock and Russell have carried on at the University of Wisconsin, able and very suggestive investigations concerning the causes of silage formation. They conclude that the theory that silo changes under normal conditions are due wholly to bacteria "does not rest on a sound experimental basis."

Their data lead them to regard respiratory processes, both direct by the plant cells and intramolecular, as the main causes of the chemical transformations which produce carbon dioxid and the evolution of heat within the ensiled mass. The direct respiration appropriates the oxygen confined in the air spaces of the silo, and the intramolecular respiration uses oxygen combined in the tissues. Both forms of respiration go on only so long as the plant cells remain alive. Concerning bacteria the authors say: "The bacteria, instead of functioning as the essential cause of the changes produced in good silage, are on the contrary only deleterious. It is only where putrefactive changes occur that their influence becomes marked."

Whatever are the inducing causes, the chemist finds, when he keeps a careful record of what takes place in 
the silo, that the silage contains considerably less dry substance than the original fresh material. In some way loss has occurred through the formation of volatile products. An examination of the fresh corn and of the silage shows, moreover, that the latter contains much less sugar than the former, sometimes none at all. In the place of the sugar we find a variety of acids, chiefly acetic and lactic. This is a change similar to the formation of acetic acid in cider and lactic acid in milk, in all cases sugars being the basal compounds. Along with the development of these acids, carbon dioxid and water are formed from the carbon compounds of the ensiled material. In other words, combustion takes place and more or less of dry matter is actually burned up, thus generating heat and eausing rise of temperature of the fermenting mass. The amount of dry matter thus lost is determined partly by the kind of crops and the eare with which the silo is built and filled.

Another important chemical change induced by fermentation is a splitting up of a certain portion of the proteids of the fermenting material into amides, compounds which, as we have learned, have a more limited nutritive function than the proteids. Investigation conducted at the Pennsylvania State College showed that in some cases over half the nitrogen of silage existed in the amide form, this being between two and three times as much as was found in the original fodder. Probably the same change takes place in the fieldcuring of fodder, but no data are available on this point.

All observers agree so far that with normal silage much the larger part of the material lost is sugar. 
Starch seems to resist the usual silo oxidations. In certain experiments a considerable loss of nitrogen is reported. It is hard to understand, though, how this can occur to any large extent unless the conditions in the silo are very bad, so that putrefactive fermentations set in. An extensive loss of nitrogen compounds certainly would indicate very serious and long-continued destructive changes.

The nature of the changes and losses in producing silage have been dwelt upon partly because corn, the principal silo crop, is one of our most important forage crops, perhaps the most so on a dairy farm, and partly in order to illustrate the necessity and value of good management in preserving this crop by the silo method. Moreover, the loss that is incident to the field-curing of maize is practically the same in kind and is fully as large as that-pertaining to silage, so that the facts presented are pertinent to both methods as well as to all circumstances where similar oxidations and fermentations are likely to ensue.

Extent of loss in the silo.-The extent of the loss of dry substance is important. It measures in a general way the difference between the food value of the silage and of the fresh material. The silo combustion reduces the energy or heat value which the fermented fodder will have whenever it is eaten by the animal. The heat lost would warm an animal during a cold day were the combustion to occur within the animal instead of in the silo.* It is desirable, therefore, to know the extent to which dry substance is actually broken up in the preparation of silage. This loss has been measured 
by several investigators, and, as was to be expected, it has been found to depend greatly upon the conditions involved, the figures reached varying from about 2 per cent to nearly 40 per cent of the dry matter of the fresh crop.: In a majority of cases the loss has been over 15 per cent and less than 20 per cent. Professor King, of the Wisconsin Experiment Station, who has given the production of silage much study, concludes upon the basis of his observations that in good practice the necessary reduction of dry matter in making corn silage need not exceed 4 to 8 per cent, and with clover silage from 10 to 18 per cent. The necessary loss is explained as being that which occurs in the interior of the mass where all outside air is excluded and other favorable conditions prevail. Considering the contents of the silo as a whole, it will require careful attention to all details in order to reach Professor King's estimate with the best conditions attainable.

This investigator found that 64.7 tons of silage packed in a silo lined with galvanized iron, thus securing a perfect exclusion of air, lost an average of 6.38 per cent of dry matter. This silo was filled in eight detached layers, and the proportion of loss in these several divisions, as affected by location, is most suggestive:

\begin{tabular}{|c|c|c|c|c|c|}
\hline urface layer... 8,934 & & & 32.53 & & \\
\hline Seventh layer . 8,722 & “" & “. & 23.38 & “ & 6 \\
\hline Sixth layer.....14,661 & ، & “ & 10.25 & “6 & “6 \\
\hline Fifth layer... 48,801 & ، & “6 & 2.10 & “ & ، \\
\hline Fourth layer $\ldots 13,347$ & ، & “ & 7.01 & “6 & “ \\
\hline Third layer.... 7,723 & “ & “ & 2.75 & “ & “6 \\
\hline Second layer...12,689 & “ & “ & 3.53 & “6 & “ \\
\hline Bottom layer...12,619 & “ & ، & 9.47 & “ & “ \\
\hline
\end{tabular}


The mean loss of dry matter in the lower six layers was only 3.66 per cent. These figures show that it is profitable to make the walls of the silo air-tight, even at large expense.

The importance of reducing the loss in the silo to the lowest possible percentage is almost self-evident. As this point is capable of mathematical demonstration, it will be interesting and suggestive to calculate what might take place in a hundred-ton silo. In many of the trials which appear to have been conducted under not unusual conditions, a loss as high as 20 per cent of the dry matter put in the silo has been observed. In a hundred-ton silo filled with corn containing 25 per cent of dry matter, or 50,000 pounds, this would amount to the destruction of 10,000 pounds of dry food substance. As the loss falls chiefly on the sugars or other soluble bodies which are wholly digestible, the available nutrients in the fresh material are diminished by an amount of digestible dry matter, equivalent to what would be required by ten milch cows during two months. If, therefore, by good planning and extra care this waste could be reduced three-fourths or even one-half, the food resources for carrying a herd of cows through the winter would be materially increased, from five to seven and one-half tons of timothy hay being the measure of the saving in a hundred-ton silo.

Ensiling vs. field-curing. - The question is often raised whether ensilage of field-curing is the more wasteful method of preserving a forage crop. Considerable study has been given this matter, and the results secured have been taken as a justification of the 
statement that one method is about as economical as the other, which is correct if we consider only the outcome of certain comparisons. A general survey of the data accumulated shows that on the whole the waste has been the larger in field-curing. Observations made in six states reveal a loss by the old method as low as 18 per cent in only one case, and from 21 per cent to 34 per cent in all others. Possibly under favorable conditions of weather, field-cured corn fodder may lose as little dry matter as silage, though this is doubtful, but in bad weather the waste from the exposed fodder is extensive. The greatest advantage in silo preservation is that conditions can usually be controlled with more satisfactory average results than are possible in field-curing. Other advantages pertain to the silo which are of a business nature and which need not be discussed here, further than to affirm that the cost of a unit of food value is in general diminished by the use of the silo.

Crops for ensilage. - The number of crops that may be successfully ensiled is not large. Maize is the most valuable one for this purpose, and elover is stored in this manner with a fair degree of success. So are peas, especially when mixed with corn. The true grasses and cereal grains outside of corn are not desirable silo crops, first because the silage from them is generally poor in quality, and second because usually they may be successfully and more cheaply stored in an air-dry condition. Any crop with a hollow stalk, giving an enclosed air space, - oats, for instance,-is not adapted to silo conditions, and there is no justification 
tor ensiling any fodder which is susceptible of prompt. and thorough drying in the field, because in such cases there is an unnecessary waste of food substance by fermentation and an unnecessary handling of many tons of water contained in the green material, with no compensating advantages. But any crop used for the production of silage should be managed in the most efficient manner. A few general facts may be discussed in this connection.

Construction of silos. - Silos that are of proper construction and shape have air-tight perpendicular walls and a height considerably in excess of either of the horizontal dimensions. These conditions are essential to the completest possible exclusion of air and to the closest possible packing of the material, with a minimum of exposed upper surface.

Silos may be either round, square or rectangular, provided that in the latter case one horizontal dimension is not too greatly in excess of the other. The shape of a silo which is most economical and efficient is not the same for all conditions, although the round and square forms hold most in proportion to the wall area. Many farmers desire to have the silo in the barn, and generally there the square or rectangular form is more economical of space than a round one. When built outside the barn, the round form, according to the opinion of many, may be used to advantage both as to expense and results. If a square or rectangular silo is built the corners should be cut off inside in order to prevent an access of air and the decay which nccurs at those points when this is not done. Several 
kinds of materials have been used in building silos, wood, brick, and stone, the former material proving to be the most satisfactory.* If the walls are of masonry the inner surface must be cemented not only air-tight but so smoothly as to allow easy and uniform settling of the silage without leaving air spaces. If wood is used, which is certainly to be preferred, the inside construction must meet the same requirements. Lining a wooden silo with iron has been suggested as practical and economical. Economy demands that as a preventive against decay the inner woodwork should at least be treated with some preservative, which may also serve the purpose of obviating excessive swelling and shrinking of the lining boards.

- Filling the silo.-The condition of the crop and the manner of filling a silo determine to a great extent the character of the silage. Obviously it should be so done as to reduce the loss of food compounds to the lowest possible point. Three points are prominently discussed in this connection: (1) the condition of the crops; (2) the preparation of the material, and (3) the rate of filling.

Experience has thoroughly demonstrated that the maturity of a crop influences its value for silage. This is known to be especially true of the corn crop. An immature corn fodder, which always carries a high percentage of water with less of the matured products, such as starch, is always certain to change to very acid silage. On the contrary, mature corn, when properly handled, is converted into a product with the minimum acidity and with an appearance and aroma much

* Satisfactory silos ars now built of wood with a cement lining. 
superior to that from the immature plant. Neither are satisfactory results secured from material that is overdry. It may be stated in general terms that the best results are obtained when the proportion of dry matter falls between 25 per cent and 30 per cent. If corn is harvested for the silo after the kernels have begun to glaze, while the leaves are still green and before they show dryness, other conditions being favorable, it will meet every requirement for good silage.

Whether the material with which a silo is filled shall be put in whole or after eutting or shredding depends to quite an extent upon its degree of coarseness. It is probable that clover, and even the smaller varieties of maize, are often successfully preserved without cutting, but no one professes that this can be done with the coarser varieties of maize. It is generally admitted that, with maize, cutting or shredding it increases the probability of satisfactory preservation, because the finer mechanical condition allows more uniform packing and prompter and more uniform settling. The highest grade of silage with the minimum loss is undoubtedly more surely made from cut or shredded material.

In the early days of silos it was taught that to insure the least possible waste by fermentation, the silo should be filled with the maximum rapidity and then promptly weighted. Following this view was the conclusion on the part of some that very slow filling with no packing other than that given by the weight of the mass, was the proper way to make silage of the highest quality. This method was advocated for producing 
sweet (?) silage. It allowed violent fermentation at first with resulting high temperatures, by which means bacteria were supposed to be killed and subsequent fermentations prevented, a conclusion so far not sustained by scientific observations. At the present time moderately slow and continuous filling, rather than very rapid, is advocated by leading authorities. Two advantages are claimed for this method, one being that more material can be stored in the silo and the other is that silage of a higher quality is produced with a smaller loss of dry matter. The first point must be conceded and the second claim may be true, although in part it lacks proof. It is hard to understand why slow filling, especially if intermittent, should not increase rather than decrease the losses of food compounds. Certainly the less compact the mass the more intense the oxidation and the higher the temperature, the latter condition indicating with certainty the extent of the combustion. This point is illustrated by results reached at the Pennsylvania State College when the chemical changes in two large tubs of sorghum silage were studied, one of which was compactly filled and weighted at once and the other loosely filled and weighted after five days. The temperature rose seventeen degrees higher in the latter than in the former, with a loss of two and one-half times as much organic matter from the loosely filled tub. It follows from the theory of Babcock and Russell, previously noted, that the less the oxygen available in the air spaces and the quicker the plant tissue dies the less will be the combustion or loss of organic matter, These authors suggest as a 
practical application of their theory that the air be excluded from the silo as rapidly as possible and only mature corn be ensiled, because such tissue will die sooner than immature, having less vitality. Their data seem to prove conclusively, also, that the evolution of much heat when a fodder is first ensiled is not essential to the formation of first-class silage. The repeated exposure of a loose upper stratum, which occurs with slow, intermittent filling, must cause extensive loss from portions of the silo. It must be held, in view of the experimental data now at hand, that the more promptly the air is excluded and expelled by the reduction of the contents of the silo to a condition of maximum compactness, the less will be the fermentation losses. The term "sweet silage" means but little as indicating completeness of preservation, for it may even be the result of extensive fermentations, a condition expensively secured. Its significance is entirely different when the sweetness is due to proper maturity of the fodder plant.

\section{THE STRAWS}

When the grain plants which produce seeds valuable for cattle and human foods are threshed, or in some way manipulated to remove the seeds, the other parts of the plant constitute what we call straw in the case of the cereal grains and legumes, and stover in the case of maize. These fodders differ from the same plants, when cut in a less mature condition for hay or fodder, in being more tena- 
cious and less palatable, with a smaller proportion of the more soluble, and therefore more valuable, compounds. The most useful of these materials for feeding purposes are corn stover, oat straw, and the legume straws. These are better relished by farm animals than wheat and barley straws, which are utilized mostly for litter.

\section{ROOTS AND TUBERS}

Certain species of plants, more especially beets, mangel-wurzels, turnips, rutabagas, carrots and potatoes, are agriculturally valuable because of the store of nutrients which they deposit in subterranean branches or in roots. The original purpose of this deposit is, in the case of potatoes and artichokes, to nourish the young plants of the next generation, or, in the case of biennials like beets, to supply the materials for the seed-stalk and seeds of the second year. Potatoes are not grown primarily as food for cattle, but roots have for many years been a standard crop for feeding purposes, especially in the production of mutton and beef. This class of crops has the advantage of furnishing very palatable, succulent food, which may be kept in perfect condition during the entire winter season, an advantage which is not wholly measured by the actual quantity of nutrients supplied by these materials.

The disadvantages of these crops are that they are somewhat expensive to grow and necessitate the handling of large weights of water. A ton of turnips or mangels may furnish even less than 200 pounds of dry substance, to secure which 1,800 pounds of water must 
be lifted several times. The percentage of dry matter in roots and tubers varies in American products, on the average, from 9.1 per cent in mangel-wurzels and turnips to 28.9 per cent in sweet potatoes. Potatoes are more nutritive pound for pound than roots. The dry matter of this class of cattle foods is principally carbohydrate in its character, though the proportion of protein is as large and in some cases larger than in certain grain foods.

Two conditions are essential to the winter storage of roots without deterioration; viz., a low temperature, as near freezing as possible, and abundant ventilation. Large masses of roots unventilated are apt to "heat," and sometimes decay, with a resulting large loss in nutritive value.

\section{GRAINS AND SEEDS}

The conditions which provide for the maintenance of plant life also subserve the interests of the animal kingdom. We have seen that this is true of the store of starch and other compounds in tubers and roots, and it is a fact of much larger significance in the production of seeds, especially those of our cereal grains, including barley, maize, oats, rice, rye and wheat. Other seeds, such as buckwheat, cottonseed, flaxseed, beans and peas, also contribute an important addition to our animal feeding stuffs. In all these species there is deposited in the seed-coats and either around the chit or embryo or in the seed-leaves of the embryo, a store of protein, starch and oil, the purpose of which is to supply materials for growth during 
germination. This deposit of plant compounds represents the highest type of vegetable food, whether we consider concentration, palatableness or nutritive efficiency. Besides, it is in such form that with ordinary precautions it is capable of indefinite preservation, without loss.

It often occurs that when newly-harvested grain is stored in bulk it heats and grows "musty." This condition is due to fermentations that are made possible by the high water content of the fresh grain and which involve a loss of dry substance. It is very desirable that grain shall be thoroughly dried before threshing, and it is generally necessary to secure additional drying after threshing before storing it in large bins.

The agricultural value of the cereal grains is much enhanced by their adaptability to a great range of soil and climatic conditions. They are the American farmer's great reliance for the production of the highest class of cattle foods. Maize, especially, is grown from Maine to Florida and from the Atlantic to the Pacific. These crops are useful, not only for their seeds but as fodder plants. For soiling purposes, as well as a source of dried forage, they are indispensable. 


\section{CHAPTER XVI}

\section{CATTLE FOODS-COMMERCIAL FEEDING STUFES}

THE cereal grains and other seeds are the source of a great variety of by-product feeding stuffs which have a large and widespread use, especially in the dairy sections of the United States. In the preparation of a great variety of human foods and of other materials important in industrial life, certain by-products are obtained which represent particular parts or compounds of the grain or seed. Whenever the methods of manufacture are such as not to injure the palatableness or healthfulness of these waste products, they may be utilized as cattle foods. As a matter of fact, a large proportion of our commercial feeding stuffs is of this general kind and because these materials differ greatly in composition and nutritive value, the purchaser should clearly understand their source and character. Changes in methods and new manufacturing enterprises are constantly modifying the composition of old products and introducing new ones, consequently the facts as they exist at one time may not be applicable for a long period. There is need therefore of constantly keeping informed in regard to the various cattle foods found in the markets, if they are to be economically purchased and wisely used. 
CLASSES OF COMMERCIAL BY-PRODUCT FEEDING STUFFS

For the purposes of description, the various byproduct feeding stuffs may be classified according to their origin. Their sources are mainly as follows:

1. The milling of wheat and other grains.

2. The manufacture of oatmeal and a variety of breakfast foods.

3. The manufacture of beer and other alcoholic drinks.

4. The manufacture of starch and sugars, chiefly from corn.

5. The extraction of oils, chiefly linseed oil and cottonseed oil.

Wheat offals. - No commercial feeding stuffs are regarded with greater favor, or are more widely and largely purchased by American feeders than the byproducts from milling wheat. Wheat-bran and middlings are cattle foods of standard excellence, whether we consider composition, palatableness or their relation to the quality of dairy products. These feeding stuffs consist of particular parts of the wheat kernel, a knowledge of the structure of which aids greatly in understanding what they are and why they possess certain chemical and physical properties.

To ordinary observation the wheat grain appears to be merely a seed, but it is really a seed contained in a tightly-fitting seed-pod. This pod, which is woody and tough, constitutes the outer coating of the kernel. On the seed itself are two more hard and resisting coatings, one of which is double, that serve to protect the 
softer parts. We find, then, that in every wheat kernel there are three coats entirely unlike the rest of the grain, because they consist of hard, thick-walled cells containing but little starch, if any, with a much larger proportion of cellulose or fiber than is found in the inner portion of the kernel. Figs. 4 and 5 .

Just inside the innermost of the three outer coats is a layer of material very rich in protein compounds,

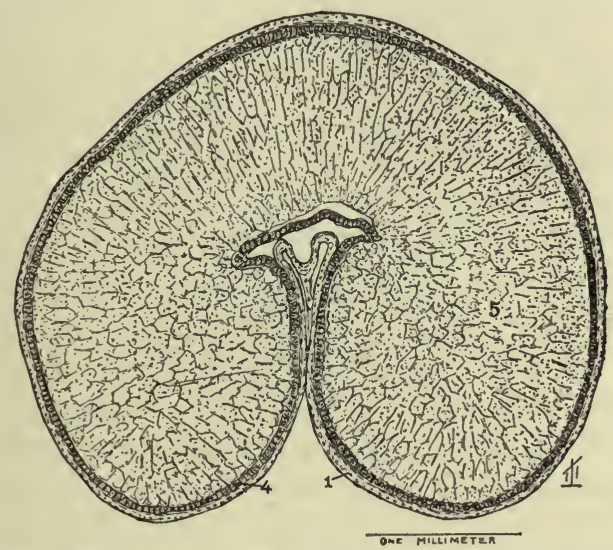

Fig. 4. Section of entire wheat kernel (enlarged 16 diameters).

1, Seed pod and seed coatings. 4, Gluten layer. 5, Mass of starch cells.

which may properly be called the gluten layer. The great bulk of the wheat kernel is made up of cells closely filled with starch grains. This is the soft white portion of the seed and is that which furnishes the flour. All of these parts serve to protect, and, in germination, to nourish the essential portion of the seed, the germ or embryo which lies "at the lower end of the 
rounded back of the kernel." Bessey, in an admirable description of the wheat kernel, tells us that the percentage proportions of its various parts are as follows:

\begin{tabular}{|c|c|c|}
\hline & Per cent & Per cent \\
\hline Coat & 5 & Starch cells..... \\
\hline Gluten layer...... & . $3-4$ & Germ \\
\hline
\end{tabular}

We are now prepared to understand the significance of the statement that in milling wheat the flour of

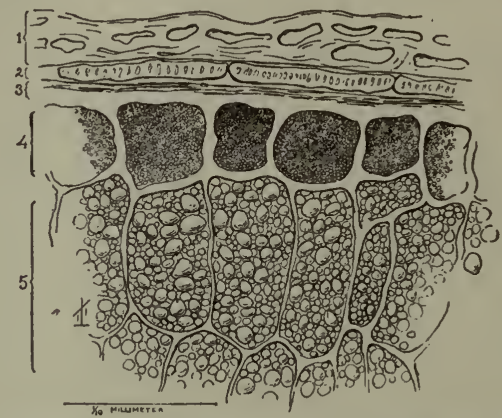

Fig. 5. Partial section of wheat kernel (enlarged 155 diameters).

1. Seed pod.

2. Outer seed coat.
3. Inner seed coat.

4. Gluten cells.

5. Stareh cells.

various grades comes from the starch cells, the other portions passing into the bran, shorts and middlings, which collectively are termed the offal. If only the coatings, gluten layer and germ went to make up the offal it would include only about 14 or 15 per cent of the kernel, the flours taking the remainder, but, as a matter of fact, no milling methods so far used completely separate the starch cells from the enclosing tissue, so that the offal is perhaps never less than 25 per cent 
of the whole grain. In milling tests conducted by the Minnesota Experiment Station, the offal from several lots of wheat, good and bad, varied from 25 per cent to 40 per cent. If four bushels of wheat are consumed per capita by the population of the United States, which is below the estimate, and if only one-quarter of this is converted into offals, the amount of bran and middlings annually consumed by our domestic animals is $2,250,000$ tons, barring the quantity which may be exported.

It is a fact worthy of special comment that because of a somewhat irrational standard of excellence for bread, certain parts of the wheat kernel best adapted to the nourishment of young and growing animals are separated with great care to be used by the brute life of the farm rather than by the farmer and his family. A comparison of the composition of the whole wheat kernel, white flour and the various parts of the offal emphasizes this point. The figures given are taken from the results of an investigation by Snyder, of Minnesota, in which he compared the composition of different grades of wheat with that of the flour and products obtained from them:

Composition of wheat and its milling products (per cent)

\begin{tabular}{|c|c|c|c|c|c|c|c|c|}
\hline & Water & Ash & Total & Gluten & Fiber & $\begin{array}{c}\text { Nitrogen- } \\
\text { free } \\
\text { extract }\end{array}$ & $\begin{array}{l}\text { Starch } \\
\text { and dex } \\
\text { trine }\end{array}$ & Fat \\
\hline Wheat kernel.. & 10.2 & 1.8 & 13.7 & 13.5 & 3.2 & 69. & 64.9 & 0 \\
\hline Wheat flour.... & 10.6 & .4 & 11.2 & 11. & & 77.3 & 70.4 & .5 \\
\hline Wheat germ ... & 10.4 & 2.7 & 15.7 & 15.3 & & 67.7 & & 5 \\
\hline Wheat shorts .. & 10.1 & 3.1 & 13.1 & 12.9 & 5.4 & 65.3 & & 0 \\
\hline Wheat bran.... & 10.4 & 5.9 & 15.4 & 14.8 & 10.2 & 52.9 & & 5. \\
\hline
\end{tabular}


The greater richness of the coatings of the kernel in mineral matter, protein, fiber, and oil is made plain by this comparison. There is four times as large a percentage of mineral matter and of oil in the whole wheat as in the flour, nearly one-third more protein and considerably less starch. On the other hand, the bran is not less than ten times richer in mineral compounds and oil than the flour, one-third richer in protein, with correspondingly less starch. "Graham" flour, which contains more or less of those parts which pass into the offal in milling white flour, does not differ so much from the whole kernel. Middlings differ from bran in containing less of the hard, tough coatings and more of the finer parts of the kernels, and this feeding stuff varies from the coarser kinds to the fancy middlings, according to the proportion of starchy material present. Red Dog flour is counted among the offals from milling wheat, and it represents the dividing line between the middlings and the high-grade flour.

There is a belief more or less prevalent that bran from the old milling processes which contained more of the starchy part of the kernel than is now the case, was more valuable than roller process bran is. It is probable that a greater proportion of starch increases the digestibility of bran, and in this sense the old process bran was superior to the roller process product; but, on the other hand, the latter is more nitrogenous than the former and is therefore more effcient as a protein supplement to home-raised foods.

Residues from breakfast foods. - In the manufacture of breakfast foods, the use of which has become so 
prevalent, certain by-products are obtained which are now found in the market as cattle foods. The preparation of oatmeal and similar materials involves the selection of the finest oat-grains, i. e., those having the largest kernels, from which the hulls are removed. These hulls and the smaller oat-grains, and perhaps bran, constitute by-products which, after being finely ground, are sold as oat-feed and in various mixtures.

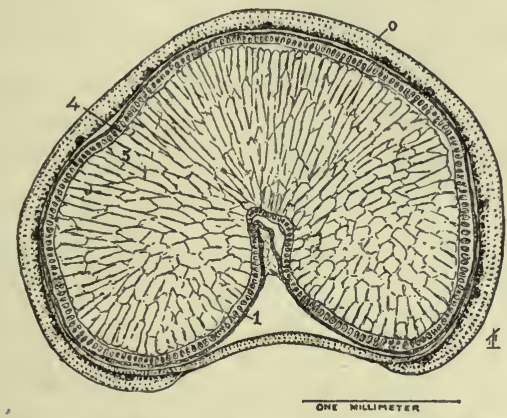

Fig. 6. Section of entire oat grain (enlarged 16 diameters).
0. Hull.
1. Seed coat.
4. Gluten layer.
5. Mass of starch cells.

As the sale of oat hulls as such, or in a fraudulent way when mixed with other substances, is likely to occasion a financial loss to feeders, it is desirable to clearly understand the situation. We shall accomplish this by a study of the relation of the oat hulls to the kernel in quantity and composition. Figs. 6 and 7.

It is common knowledge that the oat-grain consists of a hull and kernel, which are easily separated. The former is fibrous and tough, and the latter soft with very little fiber. The hull forms a considerable portion of the grain. In 1894, the Ohio Experiment 
Station made a study of numerous varieties of oats. It was found that with sixty-nine varieties the hulls constituted from 24.6 per cent to 35.2 per cent of the whole grain, the average being 30 per cent. It did not appear, contrary to the general opinion, that the proportion of hull was larger with light oats than with heavy, although observations elsewhere have sustained the popular view. At the Mustiala Agricultural College twenty-eight samples of Finnish oats and twenty samples from five other counties gave from 28 to 32 per cent of hulls. Wiley states that the average proportion of hull to kernel is as three to seven, which varies with the locality in which the oats are grown. The figures in the next table show the composition of the dry matter of whole oats, oat hulls and the hulled kernel:

\begin{tabular}{|c|c|c|c|c|}
\hline & $\underset{\%}{\operatorname{Ash}}$ & $\underset{\%}{\text { Protein }}$ & $\underset{\%}{\text { Fiber }}$ & $\begin{array}{c}\text { Nitrogen- } \\
\text { free } \\
\text { extract } \\
\%\end{array}$ \\
\hline Whole oats, 30 samples..... & 3.4 & 13.2 & 10.8 & 67. \\
\hline Hulls, New Jersey........... & 7.2 & 3.5 & 32. & 56.3 \\
\hline Hulls, Vermont........... & 6.9 & 4.4 & 29.5 & 57.2 \\
\hline Hulls, Wisconsin........... & 7.8 & 2.3 & 50.1 & 39. \\
\hline Hulled kernels, 179 analyses. & 2.3 & 15.4 & 1.5 & 72.1 \\
\hline
\end{tabular}

The inferiority of the hulls as compared with the whole grain or with the hulled kernels is very apparent, because of their smaller proportion of protein and oil and their much larger percentage of fiber. If hulls are purchased at all the price should be on a par with that at which the coarsest and cheapest grades of fodders are sold, and the surprisingly prevalent dishonest adulteration of ground whole grains with oat 
hulls should in some way be prevented by official inspection. Farmers will do well to carefully inquire into the character of the so-called oat feeds and mixed feeds offered to them. These articles are often oat hulls, poor oats and other refuse mixed with corn or with by-products of another class and are distinctly inferior to the whole grains. Such low grade mixtures a re not wisely purchased at prices nearly equal to those ruling for whole cereal grains of any kind.

Other grains besides oats are used as the source of specially prepared human food. Barley feed, a by-product from the manufacture of pearled barley, like oat feed consists of the hulls and portions of the grain and contains more fiber and less starch than the origi-

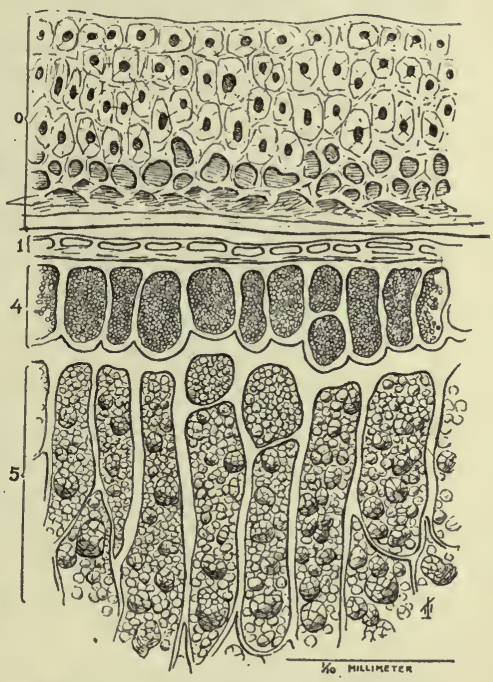

Fig. 7. Partial section of oat grain (enlarged 170 diameters).
0. Hull.
1. Seed coat.
4. Gluten cells.
5. Starch cells. nal grain, its value being proportionately less. Hominy is made from corn and consists of the hard portions of the kernel, leaving as a residue the hull, germ, and part of the starch cells, which collectively are sold as hominy feed or chop. This differs from the whole kernel but little in composition and is practically as digestible. 
Brewers' by-products. - Sugar in some form is at present essential to the production of alcoholic beverages, a cheap supply of which is obtained by converting the starch of certain cereal grains into maltose, which afterward passes into fermentable sugars. This result is accomplished by placing barley and other grains under such conditions of moisture and temperature that they germinate. We have already seen that during germination the starch of a seed is converted into maltose through the action of a diastatic ferment, and the maltster arrests this germination at a point which gives the maximum quantity of sugar. The malted grains are subsequently dried and the sprouts after removal appear in our markets in an air-dry condition, eonstituting one of our valuable nitrogenous feeding stuffs. The malted grains are then crushed, the sugar is extracted from them, and the residue is known in commerce as brewer's grains, a by-product feeding stuff fairly rich in protein. The high proportion of protein is due to the fact that the starch has been partially used up, leaving the other constituents behind in a more concentrated form. These grains are mostly dried and may then be shipped to distant markets in a perfectly sound and healthful condition.

Residues from starch and glucose manufacture. Within a comparatively recent time the gluten meals and feeds have assumed an important place among our commercial feeding stuffs. These materials and others bearing related names vary within wide limits in texture and composition, and concerning their qualities and value there has existed among the farmers 
much confusion of thought. Even the best informed have not always been promptly cognizant of new products of this class or of changes in the composition of older ones, so rapidly have new methods of manufacture developed.

The gluten meals, gluten feeds, corn bran, and the like are residues obtained in the manufacture of starch and glucose from the maize kernel. This kernel, like

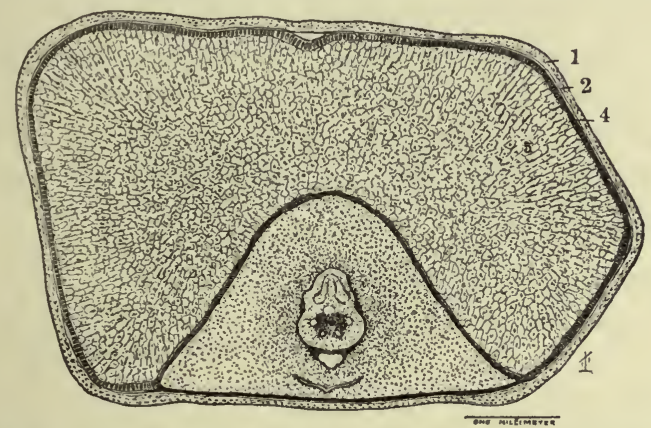

Fig. 8. Section of entire maize kernel (enlarged 10 diamèters).

1. Outer layer of husk or skin. 2. Inner layer of skin. 4. Gluten layer.

5. Mass of starch cells.

that of wheat, is not homogeneous in structure and composition, a condition which makes it possible, through mechanical or chemical operations, to secure a variety of by-products greatly unlike in texture and in their proportions of nutrients.

All this is made plain through a consideration of the structure of the maize kernel. This seed is in some respects similar to that of wheat. We have first an outside husk or skin made up of two distinct layers, one less than we find in wheat. This skin is rich in 
fiber, scarcely any being found in the other portions of the kernel. Next on the inside is a layer of cells rich in gluten. The body of the kernel surrounding the germ or embryo consists of closely compacted starch cells, though some of this interior tissue on the sides of the kernel next to the walls is flinty. We may properly speak of the maize kernel, then, as consisting of four parts, - the husk, the gluten layer, the germ, and the starchy and hard part. Figs. 8 and 9. At the New Jersey Experiment Station 100 grains of the maize kernels were separated as nearly as possible into the skin, germ, and main or starchy and hard portions. These parts were analyzed, and below are given the results:

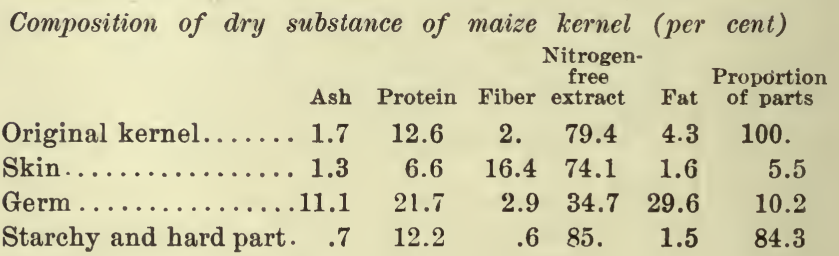

These figures are essentially similar to those obtained by other investigators, including Salisbury, Atwater, and Balland.

The separation of starch cells from other parts of the kernel is now accomplished mechanically. Either before or after soaking in warm water, the maize kernels are crushed into a coarse powder. The various parts separate in water by gravity, the hulls floating on the surface and the germs sinking to the bottom. The starch and harder portions of the kernel remain 
in suspension in the water, which is conducted slowly through long troughs, where the starch settles to the bottom and the more glutinous portions float off and are recovered.

It is now easy to see how these various byproducts may differ widely. When made up largely of the hulls or bran they are characterized by a relatively

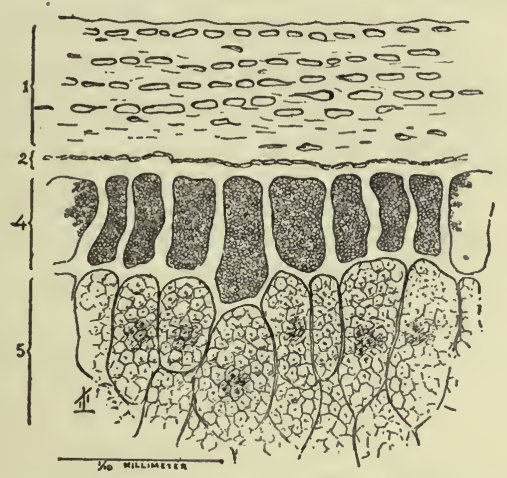

Fig. 9. Partial section of maize kernel (enlarged 170 diameters).

1. Outer layer of skin. 2. Inner layer of skin. 4. Gluten cell. 5. Starch cells.

high proportion of fiber with comparatively low percentages of protein and fat. The presence of the germs increases the relative amount of protein somewhat and of the fat very greatly. The fine glutinous part, that is finally separated from the starch, when unmixed with other materials is distinguished by its high content of protein.

As found in the market, the principal brands are "sugar corn" or "starch" feed, made up mostly of hulls and germs; gluten meal, that comes from the flinty portion of the kernel, and gluten feed, which is now a 
mixture of hulls and the gluten part. When unmixed with other parts of the kernel, the hulls are also known as corn bran and the germ portion from which the oil has been pressed is called, when ground, germ oil meal. The corn bran contains the least protein and the gluten meal the most, while the gluten feed and germ oil meal occupy a position between these. It should be remarked that the commercial names for gluten products are not always a safe guide in their purchase.

Residues from the manufacture of beet sugar.-An industry apparently now on the increase in the United States, the manufacture of beet sugar, is offering to farmers two waste products, sugar beet pulp and sugar beet molasses. The former is the extracted beet tissue from which all the sugars and more or less of other soluble compounds have been removed. This pulp as it leaves the factory has been found to contain an average of scarcely 10 per cent of solids. One ton of pulp supplies, then, not over two hundred pounds of total dry substance, or perhaps one hundred and sixty pounds of digestible dry substance. This means that it would require six tons of pulp to supply as much of digestible nutrients as one ton of good hay. The solids of the pulp must be regarded as inferior to those of the beets before extraction, because consisting more largely of fiber and gums whose productive value is below that of sugar. Experiments at Cornell University indicated that the pulp is worth about one-half as much as corn silage, which would be approximately the relation of digestible matter in the two materials.

Sugar beet pulp is, however, a useful, succulent 
food, and may be fed to advantage in quantities from seventy-five to one hundred pounds daily to full-grown animals, provided it can be purchased at a price proportional to its value.

The pulp is not adapted to transportation for long distances because of the heavy expense of freight and handling, but is most available for consumption near the factories.* It may be preserved in pits or silos.

The molasses is generally four-fifths or more dry substance and contains from 40 to 50 per cent of sugar, which is all digestible and which gives to this product its only value for feeding purposes.

This material has been fed successfully to bovines and swine. When given as an addition to coarse foods and home-raised grains it obviously should be combined with some nitrogenous feeding stuff like gluten meal or the oil meals.

The oil meals in general. - Materials of this class may properly be regarded as among the standard feeding stuffs. Because of their uniformity in quality and composition, their general usefulness in compounding rations and their value in maintaining soil fertility, their use has had the sanction of scientific men and of successful practice. The oil meals are so called because they are the residues left after the extraction of the oil from certain seeds and nuts, among which are cottonseed, flaxseed, hemp and poppy seed, rape seed, sesame seed, sunflower seed, cocoanuts, palm nuts, peanuts, and walnuts. Of the residues from these sources, those from cottonseed and flaxseed are most common in the United States; in fact, no *The dried pulp is now on the market. 
other oil meals have become important in our cattle feeding. A description therefore of the production of cottonseed meal and linseed meal will not only cover the points of practical interest to American feeders, but will serve to illustrate the main facts that pertain to the manipulation of these oil seeds.

It may be stated in a general way that two methods are used for removing vegetable oils from seeds, expressing by pressure and extraction with a solvent, both of which are now in use. In using the first method, it was formerly the custom to express the oil from the cold crushed seed, but now the seed is more generałly submitted to heat, either by boiling or steaming, afterwards applying the pressure to the warm material. More oil is obtained by the latter process. The second or extraction method involves the use of a solvent, generally a light naphtha, which leaves less oil behind than either cold or warm pressure. Before extraction the crushed seed is heated just as when pressure is used.

Cottonseed meal.-The cottonseed as gathered from the plant consists on the exterior of a mass of long white fibers that are attached to the outer coat or hull, inside of all of which is the kernel or meat. The seed is first delinted by running it through a gin, which removes the lint or cotton of commerce. After this operation there is still attached to the seed a soft down, which is subsequently removed and which constitutes what is known as "linters," a short lint that is used in making cotton batting. The remaining portion is that from which cottonseed oil and certain by-product feeding stuffs are produced. 
The first process in the manufacture of the oil is to remove the hull from the inside meat. This is done by a sheller, which breaks the seed-coat and forces it from the kernel. These seed-coats, which constitute from 45 to 50 per cent of the delinted seeds, are known in commerce as cottonseed hulls, and are used to some extent as a feeding stuff. They are characterized by a very low proportion of protein and a very high content of fiber. Twenty-two analyses show a range of protein from 1.6 per cent to 4.4 per cent, and of fiber from 35.7 to 66.9 per cent. Such material as this belongs with the very lowest grade of coarse fodder, as both composition and experience demonstrate. The hulless kernels make up from 50 to 55 per cent of the delinted seed, and from those the oil is obtained. These meats are first cooked twenty or thirty minutes in large, steam-jacketed kettles in order to drive off the water and render the oil more fluid, and then after being formed into cakes in wire eloths, they are submitted to a pressure of 3,000 to 4,000 pounds to the square inch. This removes at least four-fifths of the oil and leaves the cakes very solid, which after drying are cracked and then ground into a fine meal, known in commerce as cottonseed meal. Formerly a ton of ginned seed yielded the following quantities of the different parts:

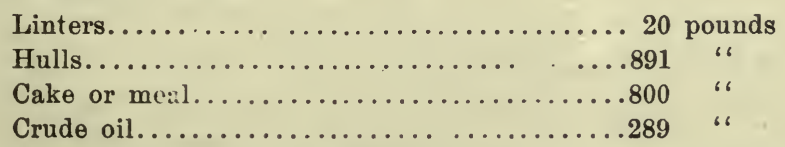

Since the above estimate was prepared the manuiac, 
turing process has been so improved that from forty to forty-five gallons of oil are now obtained from a ton of seed, giving a correspondingly smaller amount of cake. Chemists are well aware that cottonseed meal at the present time is less rich in oil than was the case a few years ago.

When we learn that no less than $1,500,000$ tons of cottonseed are worked annually at oil mills, which involves the production of about 600,000 tons of meal, we realize the importance of this by-product feeding stuff, and the future possibilities are seen in the fact that only about one-third of the seed now grown finds its way to the oil mills. The composition of the cotton oil by-products may properly be stated in this connection:

\begin{tabular}{|c|c|c|c|c|c|}
\hline $\begin{array}{c}\text { Water } \\
\%\end{array}$ & $\begin{array}{c}\text { Ash } \\
\%\end{array}$ & $\begin{array}{c}\text { Protein } \\
\%\end{array}$ & $\begin{array}{c}\text { Fiber } \\
\%\end{array}$ & $\begin{array}{c}\text { Nitrogen- } \\
\text { free } \\
\text { extract } \\
\%\end{array}$ & $\begin{array}{c}\mathrm{F} \text { at } \\
\%\end{array}$ \\
\hline Cottonseed .......9.9 9.9 & 4.7 & 19.4 & 22.6 & 24. & 19.4 \\
\hline Cottonseed hulls...11.4 & 2.7 & 4.2 & 45.3 & 34.2 & 2.2 \\
\hline Cottonseed kernels. 6.9 & 6.9 & 30.3 & 4.8 & 21.4 & 29.6 \\
\hline Cottonseed cake... 8.6 & 7. & 44.1 & 4.9 & 21.2 & 14.2 \\
\hline
\end{tabular}

These figures represent the composition of the several materials when the separations are fairly complete. Cottonseed products are sometimes sold, however, in a more or less mixed condition. There has been found in the market undecorticated cottonseed meal, or the meal with all the hulls ground in without removal from the seed. Practically all the meal found in the markets now is the decorticated, or that free from hull. This should be light yellow in color and have a slightly nutty flavor, It should show few or no black 
specks, because the presence of these indicate either accidental or intentional adulteration with hulls. Cottonseed feed, which appears to have found only a limited use, is a finely-ground mixture of cottonseed hulls and cottonseed meal, and its value is usually much less than that of the pure meal.

Linseed meal (oil meal).-The original source of this feeding stuff is the flax plant. This plant serves a very useful purpose in producing a valuable fiber, an oil which now seems indispensable as a constituent of paint and a high class stock food. Flaxseed, of which the annual production in this country averages about twelve million tons, contains a very high percentage of oil, ranging in the analyses so far made from 22 to 40 per cent. The average is variously stated by different compilers at from 33 to 37 per cent, and the mean of these two numbers is probably fairly correct. On this basis a bushel of flaxseed, weighing fifty-six pounds, contains nineteen and one-half pounds of oil and thirty-six and one-half pounds of other substances.

Linseed oil is obtained from the seed by both the pressure and extraction methods. The oldest method was to subject the cold crushed seeds to a heavy pressure, which expressed from 70 to 80 per cent of the oil, leaving a cake containing from 10 to 15 per cent. Later the warm pressure process was introduced, which consists of moistening the crushed seed, heating it to from $160^{\circ}$ to $180^{\circ} \mathrm{Fahr}$, and submitting it to a pressure of $2,000^{\circ}$ to 3,000 pounds per square inch. This improvement increased the output of oil from a given 
quantity of seed, the amount expressed being about 90 per cent of the whole, leaving a cake containing from 6 to 7 per cent. The latest and most effective process is the extraction of the oil by a light naphtha. The seed is crushed and heated as in the warm pressure method, and the oil is then extracted by repeated leachings with naphtha until the residue when dry contains only about 3 per cent of oil. The naphtha is thoroughly driven from this residue with steam so that the resulting meal is entirely free from odor and is as palatable as the residue from the pressure process.

The terms "old process" and "new process" are now applied to linseed meal, the former referring to that made by the cold and warm pressure processes and the latter to the residue from naphtha extraction. The composition differences between the two is seen in the following average of several analyses of each kind which were made by Woll :

\begin{tabular}{cccccc} 
& & \multicolumn{4}{c}{$\begin{array}{c}\text { Nitrogen- } \\
\text { free }\end{array}$} \\
$\begin{array}{c}\text { Water } \\
\%\end{array}$ & $\begin{array}{c}\text { Ash } \\
\%\end{array}$ & $\begin{array}{c}\text { Protein } \\
\%\end{array}$ & $\begin{array}{c}\text { Fiber } \\
\text { extract }\end{array}$ & $\begin{array}{c}\text { Fat } \\
\%\end{array}$ \\
9.4 & 5.4 & 35.6 & 7.1 & 35. & 7.5 \\
9.2 & 5.4 & 366 & 8.6 & 37. & 3.2
\end{tabular}

These averages show 1 per cent more protein and 3 per cent less fat in the new process meal.

The old process samples analyzed by Woll were doubtless from the warm pressure methods and do not fairly represent the linseed which was found in the markets when it first eame into general use. Four hundred and twenty-eight analyses of old process cake compiled by Dietrich and König, which were made previous to 1888 , show an average of only 28.6 per cent 
of protein and 10.6 per cent of fat. An average by the same authors of $\mathbf{1 7 9}$ analyses of the meal shows 30 per cent of protein and 9.9 per cent of oil, those samples taken previous to 1880 being poorer in protein and richer in fat than those analyzed after that date. The average of twelve samples of linseed cake made prior to 1883 and compiled by Jenkins, gives 29.7 per cent of protein and 11.2 per cent of fat. There is no question but that the meal now found in the markets is considerably richer in protein and poorer in fat than that with which American farmers were first acquainted.

The relative values of the old and new process meals are much discussed. Many farmers are prejudiced in favor of the former, possibly because anything which has been treated chemically is regarded with suspicion when considered as a food. No good evidence exists, however, that new process meal is less palatable or less healthful than the old process product, nor has practice demonstrated that in a general way it is less nutritious.

A very useful inquiry by Woll into the characteristics of the two kinds of meal showed certain differences which are interesting in this connection. Two points were studied: the digestibility and the property of swelling to a mucilaginous condition when stirred up with water. Experiments with animals both in Germany and in this country have shown a quite uniformly lower coefficient of digestibility for the protein of the new process, than for the old process, meal. Woll tested this matter by artificial digestion with a 
solution of pepsin, and his results verified those secured with animals, the protein of the old process samples proving to be 10 per cent the more soluble. This difference is believed to be caused by the additional cooking with steam which attends the driving out of the naphtha from the new process meal, for it seems to be well proven that the digestibility of vegetable protein is diminished by cooking. American experiments do not indicate a lower digestibility of total dry matter for the new process meal, which is contrary to the verdict of German digestion trials.

The property of swelling to a mucilaginous condition is one well known to pertain to flaxseed. This is due to mucilage cells found in the seed-coat. When this mucilaginous matter has once been swollen, it will not repeat the process after drying. Woll's tests showed that the old process meal responded to the swelling test, but not the new process, a result due probably to the steam cooking of the latter. This may serve as a means of determining the method used in manufacturing a given lot of meal, but probably has no special significance as to feeding value, unless it indicates the new process meal to be less useful in making a porridge for feeding calves

\section{CHEMICAL DISTINCTIONS IN CATTLE FOODS}

The classes of eattle foods as arranged in the previous discussion have had reference to several factors, chiefly those relating to origin and texture. Chemical facts have not been considered in these divisions. There 
are, however, certain chemical differences among the various groups of feeding stuffs, a knowledge of which is helpful in selecting materials for compounding rations.

Coarse foods vs. grains and grain products. - In comparing hays, straws, and other fodders with grains and grain products there are points of chemical unlikeness which bear an important relation to problems of nutrition. In the first place, the nitrogen compounds differ. In the grains we find the nitrogen combined mostly in the form of albuminoids, while in the fodders a proportion of it, and sometimes quite a large one, exists in amides. This is a point in favor of the grains, for, as we have seen, the nutritive function of amides is probably more limited than that of albuminoids. Again, the non-nitrogenous material of the grains is in general superior to that of the herbaceous cattle foods. In the former, especially in the cereal grains, there is but little fiber and the nitrogenfree extract is made up largely of starch and other bodies, whose net value in nourishing an animal is quite surely greater than that of fiber and gums found in such abundance in the hays and other fodders. The work of digesting fiber and gums is greater than with sugar or starch, and of the digested material from the former we cannot affirm an equal value with that coming from the more easily soluble carbohydrates. In short, the terms protein and nitrogen-free extract do not signify the same compounds or the same values when applied to different feeding stuffs.

Classification according to the proportions of $n u$ trients.-The relative proportion of nitrogenous and 
non-nitrogenous compounds in feeding stuffs is greatly varied. There is no fixed proportion in the same species, even, but it varies to some extent with the season, period of cutting, and other conditions. At the same time, there are differences of composition between several groups of feeding stuffs that are constant within not very wide limits, and which it is important to recognize.

There are a few terms that are popularly used to differentiate feeding stuffs which are misleading. For instance, corn meal is often spoken of as "carbonaceous" in contrast to cottonseed meal, which is called "nitrogenous." It may be seen by reference to preceding data that there is a higher proportion of carbon. in albuminoids than in starch or sugars. Cottonseed meal is more carbonaceous than corn meal, rather than less so. Such a distinction is therefore absurd.

"Heat forming" is another term often applied to foods rich in carbohydrates, while the more highly nitrogenous materials are characterized as "muscle forming," a distinction apparently based upon the facts that carbohydrates are usually largely burned in the animal body, and that albuminoids are the only source of the muscle compounds. But, as a matter of fact, the potential heat value of the digestible part of an oil meal is certainly as great as that of digestible corn meal. Under certain conditions one feeding stuff is no more fully used than the other for tissue-forming purposes, and both may be wholly utilized in the production of some form of energy, ultimately heat, the potential value of the oil meal being no less in this respect than that of the corn meal. 
The satisfactory division of feeding stuffs into as few as two classes, according to their composition, is not possible by the use of any terms whatever. Such a division is necessarily based upon the relation in quantity of the protein to the non-nitrogenous part, and there is an almost uniform gradation of foods in protein content from those containing the least to those most highly nitrogenous. Any division into groups with reference to the percentage amount of protein must be entirely arbitrary and should take account of at least four classes of materials, otherwise the extremes of each division are too widely apart. Probably no more convenient and rational classification of grains and grain products can be suggested than the one proposed by Lindsey:

Class I. Thirty to 45 per cent protein, 30 to 45 per cent carbohydrates. The oil meals and gluten meals, the latter of which are represented by the Chicago, King, Cream, and Hammond.

Class II. Twenty to 30 per cent of protein, 60 to 70 per cent carbohydrates. Gluten feeds, including the Buffalo, Golden, Diamond, Davenport, Climax, Joliet, and Standard as now made, Atlas meal, dried brewer's grains, malt sprouts, buckwheat middlings, and beans and peas.

Class III. Fourteen to 20 per cent protein, 70 to 75 per cent carbohydrates. Wheat brans and middlings, rye bran, mixed feeds or any mixtures of oat feed reinforced by more highly nitrogenous material. 
Class IV. Eight to 14 per cent protein, 75 to 85 per cent carbohydrates. Barley, corn, oats, rye, wheat, cerealine, hominy, oat feeds, corn and oat chop, and corn bran. The hays and other fodders properly belong with Class IV.

By reference to these groups it is possible to ascertain about what place a particular feeding stuff will take in making up a ration, for instance, to what extent it will serve as a protein amendment to a mixture of materials composed largely of carbohydrates.

\section{FOODS OF ANIMAL ORIGIN}

The principal materials of animal origin that are used in feeding domestic animals are milk, dairy byproducts and offals from slaughter-houses. They are mostly characterized by their large relative proportion of protein and their high rate of digestibility. The net nutritive value of their solid matter is very high, because it is practically all utilized and a minimum amount of energy is required for its mastication and digestion. Practice has long recognized the peculiar efficiency of feeding stuffs of this class, which is due to the directly available forms of the nutrients.

Milk.-Whole milk has a greatly varying food value according to its proportion of solid matter. Its composition is determined by several factors. The milks of different species of domestic animals are greatly unlike both in their proportions of total solids and in the relation in quantity of the different constituents.

The table of composition of the milk of several 
species, including human milk, given herewith, is taken mostly from figures given in Richmond's Dairy Chemistry :

Composition of the milk of mammals (per cent)

\begin{tabular}{|c|c|c|c|c|c|c|}
\hline Species & Dry matter & r Ash & Casein & Albumin & Sugar & 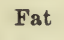 \\
\hline itch. & & .73 & 6.10 & 5.05 & 3.09 & $-\pi$ \\
\hline$\ldots \ldots 7$ & & .97 & & & & \\
\hline or & & 1.05 & \multicolumn{2}{|c|}{7.23} & .13 & \\
\hline Goat......886.0 & 10.80 & .76 & 3.49 & .86 & 22 & \\
\hline $\operatorname{Cow}^{*} \ldots$ & & .70 & \multicolumn{2}{|c|}{3.20} & 0 & \\
\hline Woman.....888.20 & 11.80 & .20 & 1. & .50 & 6.80 & \\
\hline 89.80 & 10.20 & .30 & \multicolumn{2}{|c|}{1.84} & 6.89 & \\
\hline
\end{tabular}

The milks are arranged in the order of their richness, the dry matter present varying from 24.54 per cent to 10.20 per cent. Those containing a high proportion of total solids, particularly those from the bitch and the ewe, are especially rich in proteids.and fat, the percentages of sugar being less than half those in the poorer milks. It is noteworthy that the proportions of proteids and fats in the milk decrease, and the percentage of sugar increases, as the total solids diminish. Two-thirds of the solids of mare's milk is sugar, the proportion of this constituent in the dry matter of a ewe's milk being only about one-eighth.

If we assume that the milk of each species is best adapted to its own progeny, it follows that when the young of other species is fed the milk of the cow, as is so often done, this milk should be modified so far as possible to simulate that provided under natural conditions, When, for instance, cow's milk is fed to 
a colt, it should be diluted and have its content of milk sugar increased; or when lambs are given cow's milk it may well be made richer, by the addition of cream, perhaps. The milk of the cow varies with the breed, the individual and the period of lactation, and in its use for feeding purposes these variations should be considered. While we have little or no data on the subject, it is probable that the same causes operate in affecting the milk of all species.

Dairy by-products. - These by-products are three in number, skim-milk both from the gravity and the separator processes, buttermilk, and whey. Their average composition, as taken from compilations by several authors, is as follows:

$$
\begin{array}{r}
\text { Composition of dairy offals (per cent) } \\
\text { Water solal Ash Casein album }
\end{array}
$$

Casein and

Sugar Fat

Skim-milk, general average, Cooke...90.25

Skim-milk, gravity, Fleischman......89.85

9.75

.80

3.50

$5.15 \quad .30$

10.15

.77

4.03

$4.60 \quad .75$

$9.50 \quad .78$

3.57

$4.95 \quad .10$

Buttermilk, Cooke.................99.50

Buttermilk, Vieth.................90.39

Whey, Cooke.

9.50

.70

3.

$5.30 * \quad .50$

9.61

.75

3.60

$4.06 \dagger .50$

7.03

.60

.93

5. .50

Whey, Van Slyke...............93.07

6.93

$.60 \ddagger \quad .83$

$5.16 \quad .34$

Skim-milk and buttermilk are not greatly unlike in richness in solid matter or in general composition. In case the skim-milk is sweet, buttermilk differs from it because in the latter the sugar has changed partially or wholly to lactic acid. Whey is considerably poorer in solids than the other dairy by-products and also differs from them in the proportions of the several constituents.

* Probably includes the lactic acid. $\quad$ .80 per cent lactic also present. $\ddagger$ Assumed. 
Skim-milk is the residue left after removing the cream. It differs in composition according to the composition of the original whole milk and the thoroughness of the creaming. The percentage of solids which it contains is proportional in a general way to the richness of the whole milk. At one time a contrary notion prevailed and the skimmed milk of the butter breeds, especially the Jersey and the Guernsey cows, was popularly supposed to be of inferior quality. Numerous analyses have been made of this by-product from several breeds, and the succeeding figures give the proportion of solids and fat in skimmed milk from the gravity process:

\begin{tabular}{|c|c|c|c|}
\hline & $\begin{array}{c}\text { Solids in } \\
\text { whole milk } \\
\%\end{array}$ & $\begin{array}{l}\text { Skimmed } \\
\text { Total } \\
\text { solids } \\
\quad \%\end{array}$ & $\begin{array}{r}\text { milk } \\
\text { Fat } \\
\%\end{array}$ \\
\hline Holstein. & 12.22 & 9.50 & .52 \\
\hline Ayrshire................. & 12.98 & $10.40^{\prime}$ & .85 \\
\hline Jersey................... & 15.24 & 10.50 & .37 \\
\hline
\end{tabular}

These figures show most clearly that the Jersey product is more valuable than that from Holstein cows, volume for volume.

Skim-milk is also affected by the manner or thoroughness with which the cream is removed. The more perfectly the fat is taken out the less the percentage of solids left behind and the less their unit value as a source of energy. For these reasons gravity process skimmed milk is often more valuable for feeding than that from the separator, though under the best conditions of skimming in both cases the difference is small.

Buttermilk, which is the residue after extracting 
butter from eream, varies in composition from such causes as the composition of the cream and the perfectness of the churning. The more fat is left in it the more it is worth for feeding purposes. Its feeding value is but little less than that of skim-milk.

Whey solids are mostly sugar. In good cheesemaking practice, whey retains scarcely any of the casein and fat of the milk. It therefore takes a place in the ration quite different from that of skim-milk, as it is essentially a carbohydrate food.

The dairy offals are peculiarly valuable as food for young animals and swine. It is safe to say that for calves and pigs no other sufficiently inexpensive materials can fully take their place in their relation to health and vigor.

Slaughter-house and other animal refuses. - The offals from slaughter-houses and from fish, which have a somewhat limited use in feeding domestic animals, are meat scraps, meat meal, dried blood, and dried and ground fish. The accompanying analyses display their composition, which is subject to great variations:

Composition of slaughter-house and other refuses (per cent)

$\begin{array}{lrrrr} & \text { Water } & \text { Ash } & \text { Protein } & \text { Fat } \\ \text { Animal meal, N. Y. station.. } & 2.2 & 38.7 & 37.5 & 13.2 \\ \text { Meat meal, German analysis.. } & 10.7 & 4.1 & 71.2 & 13.7 \\ \text { Fish scrap, German analysis. } & 13.9 & 31.3 & 48.4 & 6.4 \\ \text { Dried blood, Henry.......... } & 8.5 & 4.7 & 84.4 & 25\end{array}$

The meat and fish offals vary greatly according to proportion of bone which they contain. The percentage of protein is always large, nevertheless. Dried 
blood is much less rich in mineral matter and fat than other slaughter-house offals are generally, and the proportion of protein is correspondingly larger. All these materials are excellent poultry foods when used as a part of the ration. They may be fed to swine also as an amendment to cereal grains when dairy by-products are not available. 


\section{CHAPTER XVII}

\section{THE PRODUCTION OF CATTLE FOODS}

THE farmer, in deciding what forage and grain crops he shall grow, should take into consideration several factors, of which the following are the main ones: (1) the adaptability of the various crops to the soil and climate; (2) the adaptability of the various crops to the kind of business which is to be followed, whether dairying, stock-growing or sheep husbandry; (3) the capacity of the various crops for the production of digestible food; (4) the protein supply; (5) the maintenance of fertility.

1. Concerning the adaptability of crops to the great variation of soil and climate in this country, it is not possible to treat extensively in this connection without going too fully into questions of agricultural botany. There are, however, a few general facts worthy of mention. In the first place, few farmers have accurate information concerning the species of grasses which are growing on their farms. Only occasionally is one found who carefully observes what species are most prosperous under his conditions. This is equivalent to the statement that but little attention is given to the matter of the adaptability of forage plants to the environment under which they must be grown. While 
it may be said that nature carries on for the farmer more or less of a selective process, it must be remembered that the rotation of crops, involving of necessity an artificial selection of species, interferes with this process. The old practice of maintaining mowing fields for ten to twenty years without breaking the sod might allow the grasses most congenial to the soil and climate to establish themselves, but successful farming on this basis is now scarcely possible. It is essential, therefore, especially in dealing with meadows and pastures, to know what members of the grass family or other forage plants find the environment congenial.

It is commonly remarked, with much reason, that more is to be gained by the proper selection and proper care of the forage crops which have maintained successful, though perhaps unrecognized, existence among us for years, than by seeking for better results from some introduced species. No cultivated plant possesses qualities that will defend the farmer against the evil effects of poor or ill-directed culture, and when intelligent, thorough methods prevail, many of the familiar species will do for us all we can reasonably expect. Occasionally an introduced species may serve a useful purpose, as is true of alfalfa, but in general a more economical production of cattle foods will be reached most surely through an improvement of methods in growing what we already have.

2. It is obvious that the home production of feeding stuffs must be adapted to the kind of stock kept. A herd of good dairy cows can hardly be most successfully managed on the old basis of exclusive pastur- 
ing in the summer and exclusive dry food in the winter. To attain the best results the pasture must be amended by soiling crops, at least during late summer and early autumn, and a succulent food is a decided improvement to a winter ration. On the other hand, the successful growing of steers, sheep or horses requires in many localities only a good pasture and plenty of dried fodder and grain, although some succulent foods are desirable with any class of animals. Every feeder, no matter what his line of business, should have at command quite a variety of fodders.

3 . The productive capacity of the different crops used as cattle foods is greatly unlike. A satisfactory crop of maize or alfalfa contains greatly more dry matter per acre than one of oats, peas, or any of the usual meadow grasses, and in order that land may yield a maximum supply of feeding stuffs it is necessary to step outside grass and grain farming, where long rotations are practiced and where a major part of the farm is kept in meadow grasses and only small areas are devoted to cultivated crops. Rapid rotation and the use of the more grossly feeding crops are necessary to a vigorous development of the resources of any land for the maintenance of animal husbandry.

Other things being equal, the most desirable crop is the one producing the largest amount of digestible dry matter. This will not be the same crop for all localities. In one section it may be maize, in another alfalfa, or in another roots. The selection must be determined by circumstances, and no rule of general 
application is possible. Of course, other things outside of quantity of production are not generally equal. The cost of production varies so that the largest yielding crop is not necessarily the most economical. This is a local matter also, concerning which no safe general statement can be made. It would be convenient if some correct, universal standards of production and cost could be formulated for the guidance of farmers, but both growth and cost are much modified by locality and other circumstances, and data are not available, and doubtless never will be, from which useful averages may be obtained.

The most that it is possible to show is the relative productive capacity of different crops when the yield is what is regarded as highly satisfactory in favorable localities under good culture. This is done in the accompanying table. Attention is again called to the fact that judgment should be based upon the amount of digestible dry matter produced:

\begin{tabular}{|c|c|c|c|c|c|}
\hline f & $\begin{array}{c}\text { Yleld } \\
\text { per acre } \\
\text { fresh ma- } \\
\text { terial }\end{array}$ & $\begin{array}{c}\text { Dry } \\
\text { matter }\end{array}$ & $\begin{array}{c}\text { Dry } \\
\text { matter } \\
\text { per } \\
\text { acre }\end{array}$ & $\begin{array}{l}\text { Dry } \\
\text { mat- } \\
\text { ter } \\
\text { digesti- } \\
\text { ble }\end{array}$ & $\begin{array}{c}\text { Digestible } \\
\text { dry } \\
\text { matter } \\
\text { per } \\
\text { acre }\end{array}$ \\
\hline & lbs. & $\%$ & lbs. & ж & lbs. \\
\hline Alfalfa ... & 35,000 & 25 & 8,750 & 69 & 5,162 \\
\hline Maize, whole plant........... & 30,000 & 25 & 7,500 & 61 & 5,025 \\
\hline Red clover, about $3 \frac{1}{2}$ tons new hay.. & 18,000 & 30 & 5,400 & 57 & 3,070 \\
\hline Oats and peas...................... & - 20,000 & 16.2 & 3,240 & 65 & 2,106 \\
\hline Timothy, about $23 / 4$ tons new hay.... & 11,500 & 38.4 & 4,416 & 57 & 2,517 \\
\hline Hungarian grass.................. & 19,000 & 25 & 4,750 & 67 & 3,182 \\
\hline 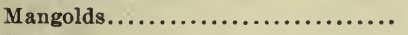 & 60,000 & 10 & 6,000 & 88 & 5,200 \\
\hline Sugar beets.................... & 32,000 & 20 & 6,400 & 88 & 5,632 \\
\hline Potatoes... & 18,000 & 25 & 4,500 & 85 & 3,825 \\
\hline
\end{tabular}

The estimates here given may not coincide with the views of all as to what constitutes a fair crop, but 
from the data shown, any one can easily make a calculation on the basis of his own estimate.

The foregoing figures emphasize the relative high productivity of alfalfa, maize and roots, as compared with certain cereal grains and the meadow grasses. The former crops fill an important place in intensive stock husbandry. Probably no species of forage plants are known that are more economical sources of high class cattle food than alfalfa and maize. While no more productive than mangolds and sugar beets when these are at their best, the former cost much less in labor.

Crops of such large productive capacity are especially adapted to dairymen located on limited areas of high-priced land. They occupy a place in intensive culture which will become more and more important as grazing and long rotations are replaced by soiling and stable feeding during the entire year.

4. The protein supply of the farm may be augmented by the growth of leguminous crops, such as peas, beans, alfalfa and the clovers. In so far as climate and soil permit the economical production of this class of fodders, there will be a correspondingly less necessity for the purchase of nitrogenous feeding stuffs.

5. The leguminous crops are regarded as sustaining an important relation to fertility in acting as nitrogengatherers, and for this reason they are believed to be a valuable adjunct of any system of farming. Just what proportion of the nitrogen in a crop of clover, for instance, comes from outside the soil is not known, however, either for particular conditions or as to the average. 


\section{SOILING CROPS}

The production of green crops as an amendment to the pasture, or as a substitute for it, is a practice essential to the highest success in dairying on many farms, and is to some extent desirable in other branches of stock husbandry.

There are few pastures, perhaps none, that afford grazing in August and September of such a quality as to maintain a satisfactory flow of milk. In many instances, moreover, farmers owning a limited area of high-priced tillable land wish to keep the maximum number of animals per acre, and to do this they must cultivate soiling crops for stable feeding.

It is no longer a debatable question, whether or not soiling is profitable under most conditions. Unlimited testimony can be furnished showing the great gain from every point of view of even partial soiling as an amendment to the pasture. Whether soiling should be substituted entirely for grazing is a business matter which should be decided according to the conditions involved.

New England farmers owning upland rocky pastures in which grow native grasses of the highest quality for any class of animals could not wisely dis(ard them. Such land generally absorbs but little eapital, and the labor of supplying food by this method is reduced to a minimum. The case is different with high-priced, easily tilled land located near good markets. These conditions call for intensive farming, and grazing animals on permanent pastures is not a part 
of intensive practice. Under such circumstances the wisdom of a soiling system is clearly indicated.

In the first place, much more food is produced per unit of area by soiling than by pasturage. Armsby found that two soiling crops in one season, for instance, rye followed by corn, yielded five times as much digestible organic matter as pasture sod, when the whole growth on the latter was plucked without waste, the quantities being, respectively, 5,845 pounds and 1,125 pounds. It is variously estimated from observations in practice, that three to five times as many animals can be supported on a given area by soiling as by grazing.

Again, grazing is wasteful because of the imperfect consumption of the growth that is made. Much grass is tramped down and much is fouled with dung and urine. These facts are well understood. Other advantages besides economy of land and material pertain to soiling, such as saving of fences, comfort of the animals and an increased supply of manure, but these factors do not require discussion in this connection.

Outside of considerations previously noted, productiveness especially, the dairy farmer in selecting soiling crops must have regard chiefly to the number of animals to be fed, the time when the crops will be needed, and the number of days required for their development. If soiling is adopted in order to amend the pasture during the late summer and early fall a limited number of crops will meet the demand. Three sowings of peas and oats in late May and early June and two plantings of corn, one at the usual time and 
one two weeks later, would furnish a supply of green food when it is most likely to be needed. If it is a question of selecting crops for a system of complete soiling, nothing more suggestive can be offered as to species and succession than schemes prepared by Phelps for Connecticut, and by Voorhees for New Jersey :

\section{Connecticut scheme}

Species of crop Time of seeding.

Winter rye.............. Sept. 1

Winter wheat.......... Sept. 5-10

Clover.............. July 20-30

Grass (from meadows)....

Oats and peas........... April 10

Oats and peas........... April 20

Oats and peas............ April 30

Hungarian............. June 1

Clover, rowen ...........

Soy beans ............. May 25

Cow peas............. June 5-10

Rowen grass (meadows)...

Barley and peas......... Aug. 5-10

New Jersey scheme Species of erop Time of seeding

Winter rye............ Sept.

Winter wheat.......... Sept.

Crimson elover.......... Sept.

Oats and peas............ April 1

Oats and peas.......... April 10

Mixed grasses.......... Sept.

Oats and peas.......... May 10

Cow peas............ May 20

Corn . ............ June 1

Japanese millet ......... June 20
Approximate time of feeding

May 10-20

May 20-June 5

June 5-15

June 15-25

June 25-July 10

July 10-20

July 20-Aug. 1

Aug. 1-10

Aug. 10-20

Aug. 20-Sept. 5

Sept. 5-20

Sept. 20-30

Oct. 1-30

Approximate time of feeding

May 1-10

May 10-20

May 20-June 1

June 1-10

June 10-20

June 20-30

July 1-10

July 10-20

July 20-Aug. 1

Aug. 1-10 
New Jersey scheme-continued

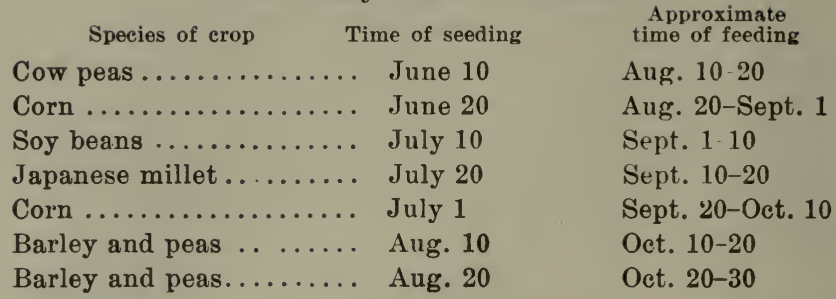

The schemes are not practicable for all sections of the United States. In the southern and western states more especially, they would need modification to suit local conditions.

Alfalfa is not included in either of the foregoing lists. For all sections where this plant can be grown successfully it takes first rank as a soiling crop. In portions of New York, for instance, in favorable seasons it can be cut continuously from about the middle of May until late in September, and no other crop is more thoroughly relished by horses and cattle. It is valuable for horses, even when they are doing hard work.

The area devoted to soiling crops must be determined by the number of animals and the productiveness of the land which is to be used. Voorhees states that seven acres devoted to the succession of crops which he recommends will supply twenty-five cows from May 1 to November 1 . This estimate would hold only when two and three crops are grown on the same land in a single season, which requires a generous use of manure or of commercial fertilizers, or of both. The following are suggestions of possible rotations: 
$\left\{\begin{array}{l}\text { Winter rye, or crimson clover } \\ \text { Oats and peas } \\ \text { Soy beans }\end{array}\right.$

Cats and peas

$\{$ Japanese millet

(Barley and peas

$\left\{\begin{array}{l}\text { Winter rye, or winter wheat } \\ \text { Corn }\end{array}\right.$ $\left\{\begin{array}{l}\text { Winter wheat } \\ \text { Cow peas } \\ \text { Japanese millet }\end{array}\right.$

$\left\{\begin{array}{l}\text { Oats and peas } \\ \text { Cow peas } \\ \text { Barley and peas }\end{array}\right.$

$\left\{\begin{array}{l}\text { Crimson clover } \\ \text { Corn }\end{array}\right.$

Some writers estimate the needed area of soiling crops on the basis of one-quarter to one-half a square rod per day for each full-grown animal, the smaller unit applying to corn and the larger to oats and peas, and similar crops. All this must be a matter of judgment based upon the eircumstances involved. 


\section{CHAPTER XVIII}

\section{THE VALUATION OF FEEDING STUFFS}

IT seems to be very generally supposed that it is possible to state fixed relative money values for feeding stuffs, and that by comparing these with market prices the relation of value to cost may be ascertained. Such a state of knowledge is certainly much to be desired, for it would be of great practical use to feeders. For various reasons, however, it is not yet attained, and there is little present prospect that it will be. The establishment of such relative values for cattle foods, as a whole and for general use, is a much more complex matter than many suppose it to be, for. it touches on one side some of the most profound problems of physiological chemistry, concerning which we have only partial knowledge.

The problem of assigning values to the classes of nutrients in feeding stuffs may be approached from two directions; viz., from the commercial side and from the physiological side. In the first case, the effort would be to calculate on the basis of the prices of standard commercial feeds, what is the actual pound cost of each of the classes of nutrients, and thus have a means of ascertaining whether a particular feed is selling for less or more than the existing market con- 
ditions warrant. In the second case, the attempt would be to determine the relative physiological importance of digestible protein, carbohydrates, and fats, and this being done, the relative agricultural values of feeding stuffs would be established on the basis of their composition and digestibility, thus providing purchasers with a guide for selecting the materials costing the least in proportion to their value.

\section{COMMERCIAL VALUES}

Experiment stations have for many years published relative commercial valuations of the various brands of fertilizers that are in the market. Why are we not able to follow the same course with cattle foods? Simply because of existing conditions. The dry matter of attle foods is made up of ash, protein, carbohydrates, and fats. We practically ignore the ash and base the value of a given food upon the other three classes of compounds, which are the same in number as the three useful ingredients of mixed fertilizers. Now if we could find in the market a cattle food supplying only a single ingredient, as is the case with fertilizers, we could from its composition and market price determine the cost of this ingredient. As a rule, however, these classes of nutrients must be bought in a mixed condition. All commercial cattle foods, except, perhaps, one waste product from sugar production, are mixtures in varying proportions of protein, carbohydrates, and fats. When we buy one we buy all three. Protein, starch, sugar or oils as found in commerce have 
become, through the necessary processes of separation, too costly to be considered for cattle-feeding purposes, and their prices in these forms are not a proper basis of calculation. If, therefore, a farmer pays $\$ 15$ for a ton of wheat bran, what proportion of this sum shall he assign to the 320 pounds of protein, the 1,240 pounds of carbohydrates, or the 84 pounds of fats?

Commercially considered our problem is complex, and no simple process will solve it. If we were to determine what is the cost of one pound of dry matter through the simple division of the price of a ton of feed by the pounds of dry matter which it contains, and then declare that all forms of dry matter have equal cost, we would get as many prices for protein and starch as there are commercial feeds, with no distinction as to the money value of these nutrients. Such a method would be absurd. It would be a bare assumption to declare that all the compounds of a food should have equal market cost.

An attempt was made in Germany, and to some extent in this country, to calculate by the "method of least squares" what should be considered the cost of protein, carbohydrates, and fats as based upon the ton prices of a variety of feeding stuffs. Valuations so derived appeared to find favor for a time, and some of our experiment stations, following the lead of German chemists, published pound prices for the three classes of nutrients, and calculated what commercial cattle foods should cost when valued on a common basis, It was soon found, however, that, mathemati- 
cally as well as practically, most absurd results were obtained.

In the first place, it is already demonstrated that the money valuations are often greatly influenced by the choice of feeds which shall enter into the calculation. Penny, in New Jersey, using cottonseed meal, bran, middlings, cobmeal, corn meal, and oats, obtained certain values for protein, carbohydrates, and fats. Hills shows that if Penny had left out the cobmeal the value for fat would be only half that found, and the value of the protein and carbohydrates would be a quarter more. Woll obtained certain pound prices with a list of common feeds, but Hills shows again that if Woll had left out rye bran these prices would be greatly changed. It appears that varying individual judgments as to the list of feeds which shall determine values may cause absurd differences in the calculated market cost of the nutrients, and introducing into the list or withdrawing from it a comparatively unimportant feeding stuff may lower or raise the price of one nutrient even one-half.

A still more serious difficulty arises from the fact that often when an apparently typical and proper list of feeds is used from which to calculate prices, the use of the method of least squares results in giving a negative value to one of the nutrients. In several cases of this kind the fat was shown to be worth less than nothing, a most absurd conclusion. This mathematical method is, therefore, not available for the valuation of feeding stuffs, and so far no mathematician has offered one that is. 


\section{PHYSIOLOGICAL VALUES}

We are left now to inquire whether we may not use physiological values, in other words the work which a nutrient will perform in the animal body, as a starting point from which to calculate relative values. If, for instance, it could be demonstrated that protein has a fixed physiological value twice, and fats three times, that of carbohydrates, it would then be a very simple matter to ascertain what proportion of the cost of a ton of cottonseed meal should be applied to each class of nutrients. To illustrate, a ton of average cottonseed meal contains about 590 pounds of carbohydrates, 860 pounds of protein, and 260 pounds of fat. If these ingredients are assumed to have a ratio of value of 1,2 , and 3 , then the whole would be equivalent to 3,090 units of carbohydrates, the cost of one unit of which would be .8 cent, when we pay $\$ 25$ per ton for the cottonseed meal. On this basis it would be necessary to assign to the protein a cost of 1.6 cents per pound, and to the fats 2.4 cents. If our premise were correct we could calculate the cost of the nutrients in any one of the feeding stuffs, and could either ascertain which was the cheapest source of each in gredient, or by averaging could establish a basis for a general valuation. Unfortunately no such a premise can be correctly formulated. We are not yet wise enough to establish fixed relative physiological values for the three classes of nutrients.

It may be asked, do we not know the heat value of a unit of each of the nutrients, of protein, of starch, 
and of fat? We probably do. These values have been found with apparent accuracy. Why, then, may we not establish the relative value of the nutrients on the basis of their potential energy, which is measured by the heat they produce upon combustion? Simply because foods have another function beside furnishing motive power to the animal and keeping him warm. They act as building material. The protein and fat of milk and of the body tissues are derived from the food compounds, and the actual relative value of these compounds for constructive purposes is not yet known. No one has yet succeeded in actually determining the relative money value of protein, carbohydrates and vegetable fats as fat producers, and we have no data that allow a definite conclusion concerning the comparative money worth of the muscleforming function of protein as against the fat-forming function of starch. There is no promising prospect, at present, of being able to compare foods on the basis of their physiological importance as a means of determining what should be the relative market cost.

\section{SELECTION OF FEEDING STUFFS}

What useful knowledge is available to the stockfeeder as a means of guiding him to an economical selection? In the first place, the feeder may know the composition of feeding stuffs. If he cares to be intelligent in his business he will know that some feeds carry more nitrogenous matter than others; he will be aware that all the cereal grains contribute to 
the ration much the same compounds in much the same proportions, and he will understand the variations of composition among the waste products that are in the market as commercial feeds. He will learn how the coarse foods differ among themselves and from the grains. Practice and observation will teach him that some feeds are better adapted than others to a certain class of animals, even though of essentially the same composition. In his efforts to compound rations he will not only have regard for this adaptation, but he will keep in mind what practice and science have taught concerning the mixtures necessary to secure an efficient combination of nutrients for the work to be done.

After all this is understood, there may be several feeds which are essentially alike in composition and nutritive function but which have different prices, and there still remains the problem of selecting the most economical. If a feeder wishes for carbohydrates, from what source should he purchase them? If he needs protein should he select gluten meal, one of the oil meals, or some other of the nitrogenous byproducts? It is clear that the best he can do is to select the feeds that supply the largest quantity of available nutrients for the least money. If all the feeding stuffs were digested in equal proportions there would be no need of considering digestibility, but this is not the case. Large differences in digestibility exist. From 86 to 88 per cent of the dry matter of the cereal grains, oats excepted, is dissolved by the digestive juices, while the solubility of wheat bran, brewer's 
grains, and oat feeds is on the average only about 62 per cent. Oats are nearly one-fourth less digestible than corn, barley or rye. The refuse products known as the oil meals are less digestible than the gluten feeds and meals, due, doubtless, to the hulls contained in the former. These facts are important and affect the nutritive value of commercial feeds very materially.

Farmers should base their judgment of the value of feeding stuffs primarily upon the proportions of digestible dry matter which they contain. This method will probably allow the closest approximation to relative values of any. It is certainly more accurate than a comparison of the proportions of total dry matter. A hundred pounds of corn contains even less dry matter than the same weight of oat feed, but the digestible material of the former is over 30 per cent in excess of that in the latter. It is to be remembered, however, that comparisons of this kind can only be instituted between feeding stuffs of the same class. The relative values of oil meal and corn meal cannot be ascertained in this way, neither can those of timothy hay and corn meal. We should not pay for oil meal and corn meal on the basis of the quantities of. digestible nutrients which they furnish, because the nutrients are not identical in the two cases. Digestible material, which is 40 per cent protein, cannot be measured by digestible material, which is only 10 per cent protein. Neither can we so compare timothy hay and corn meal, for while the proportions of protein and non-protein compounds may not be so very different in the two, the nitrogen-free compounds are 
greatly unlike and may have unlike physiological values, as we have seen.

The following table shows the digestible material in 100 pounds of various feeding stuffs, as calculated from average composition and digestibility. In the case of hays the water content is assumed to be uniform; viz., 12.5 per cent, while the percentages given for the grains are the averages found by analysis:

\section{Class I-Dried grass plants}

Corn fodder, dent ..........

Corn fodder, flint..........

Corn fodder, sweet........

Corn stover...............

Hungarian hay............

Oat straw................

Orchard grass hay..........

Red top hay..............

Timothy, all .............

Timothy, in bloom or before. Timothy, after bloom.......

Class II-Dried legumes

Alfalfa..................

Clover, alsike .............

Clover, red...............

Clover, white ............

Class III-Cereal grains

Barley..................

Corn meal..............

Corn and cob meal ........

Oats....................

Oat feed .................

Rye meal...............

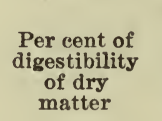

64

68

67

57

65

50

57

60

53

61

53

59

58

57

67

86

88

79

70

62

87

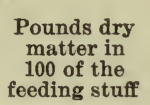

$60^{*}$

$60^{*}$

$60^{*}$

$60^{*}$

87.5

90

87.5

87.5

87.5

87.5

87.5

87.5

87.5

87.5

87.5

89

85

85

89

92

88
Pounds digestible dry matter in 100 of feeding stuff

38.4

40.8

40.2

34.2

56.9

45

49.9

52.5

46.4

53.4

46.4

51.6

50.8

49.9

58.6

76.5

74.8

67.1

62.3

57

76.5 
Class IV-Nitrogenous feeds 16-30 per cent protein

Brewer's grains ...........

Gluten feed.............

Malt sprouts............

Wheat bran ............

Wheat middlings ..........

Pea meal. ...............

Class V-Nitrogenous feeds 30-45 per cent protein

Gluten meal.............

Linseed meal, O. P........

Linseed meal, N. P........

Cottonseed meal...........

\section{Per cent of digestibility of dry matter}

62

86

67

62

75

87

90

79

80

74

\section{Pounds dry matter in \\ 100 of the \\ feeding stuff}

57

79.1

60.3

54.5

66

78.3

It is fully recognized that these figures cannot be taken as absolute relative values. Feeding stuffs bearing the same name are not always exactly similar in composition or in equally good condition. Variations in the moisture content occur, especially with the coarse fodder's. Even after allowing for all these factors, results will not follow exactly the quantities of digestible matter supplied, because there seems to be a greater adaptability of some feeds to the needs of a particular species. Nevertheless we are forced to conclude that food materials of the same class must furnish energy and building material in proportion to what is digested from them.

\section{OTHER STANDARDS OF VALUATION}

Certain writers and speakers base the value of nitrogenous feeding stuffs, from bran up, entirely on the 
protein content, and they divide the price by the pounds of protein in a ton in order to determine the relative economy of purchasing this or that material, and the feeding stuff in which the protein cost is the least when so reckoned is regarded as the economical one to purchase. This method seems to be absurd, for it is an assumption that the nutritive value of the carbohydrates and fat in commercial foods may be ignored. The argument is that the farm furnishes carbohydrates in abundance, and that commercial products should merely serve the purpose of reinforcing the protein supply. If the earbohydrates of the farm have no selling value then this argument has some force, but this is ordinarily not the case. When starch and similar compounds must be purchased as a necessary accompaniment of protein, thus causing a surplus of carbohydrate food, certainly hay, oats, corn, barley, or some other home product may be sold to relieve this surplus.

Many practical feeding experiments have been conducted for the purpose of comparing the different grain products as foods for the various classes of animals. Useful facts have been reached in this way, especially as to the greater adaptability of some materials than others for a particular species. But experiments of this kind cannot be relied upon to fix relative values of feeding stuffs for milk production, beef production or for any other purpose. This is so, first of all, because the errors of such tests are so large that we cannot regard their apparent outcome as establishing constants. Again, the problems involved are too complex and the 
effect of a given ration too dependent upon variable conditions, to allow logical conclusions from such experimental data. The difficulties of the situation will be made clear to any one by a careful study of the whole mass of data resulting from feeding tests. Differences appear, some of which are consistently in one direction, especially in comparing nitrogenous with carbohydrate foods, but as between materials of the same class their comparative values as indicated by different experiments are greatly variable, even contradictory. Any one who endeavors to reach fixed and universal valuations on an experimental basis of this kind will find himself involved in hopeless confusion.

Once in a while some one talks wildly about leaving food valuation to the "old cow." It is sometimes considered a telling argument against the chemist's wisdom to declare that he and the old cow do not agree. Certainly the cow knows better than the chemist what she likes to eat, and it is little use to offer her foods she does not relish. Even a chemist knows that. If, however, a dozen commercial feeding stuffs were spread around on a barn floor it would be much safer to trust an agricultural chemist, especially one experienced in stock feeding, to select a ration than any cow ever grown, - Holstein, Ayrshire, Jersey, longhorned, dishorned, or what not. The cow would probably get at the corn meal and stay with it until well on the way to a fatal case of indigestibility. Her judgment is just about as good as that of a child with a highly cultivated "sweet tooth." 


\section{CHAPTER XIX}

\section{THE SELECTION AND COMPOUNDING OF RATIONS}

THERE are several factors that must be considered in selecting an efficient and economical ration,-factors which relate to both science and practice. It is generally desirable that a food mixture shall be "balanced," but this gives no assurance that a ration can be fed under particular conditions with satisfactory results. Intelligent observation in the barn or stable really takes the first place in formulating a method of feeding, which is supplemented to a valuable extent by the scientific insight of the chemist and physiologist. A ration may be chemically right and practically wrong, but, at the same time, it is worth much to the feeder to be assured that the-nutrients which he supplies to his animals will meet their physiological needs. Moreover, commercial relations such as the prices of feeds must be considered, and this is a business question and not a scientific matter.

1. A successful ration must be palatable. An agreeable flavor is not a source of energy or of building material, but it tends to stimulate the digestive and assimilative functions of the animal to their highest efficiency, and is a requisite for the consumption of the necessary quantity of food. Common experience 
teaches that when cows or animals of any other class do not like their food, they "do not do well." Persons sometimes claim that they have contracted dyspepsia by eating food which is not relished, even food that is nutritious and well cooked, and which would be entirely satisfactory to other individuals. The situation is still worse when the food is undesirable both as to texture and flavor. We have reason to believe that animals are susceptible to the same influences as man, though perhaps not to the same extent. An animal is more than a machine, and is possessed of a nervous organism, the existence of which should never be ignored.

One way of stimulating an animal's appetite is to feed a variety of materials. Continuous feeding on a single coarse food and one grain is not conducive to the best results. The various available fodders and grains should be so combined as to allow the feeding of all of them throughout the season and avoid the exclusive use of one or two kinds for any extended period of time. The skilful feeder, then, will not fail to make the ration as palatable as possible, and will always consider the idiosyncrasies of appetite of each animal.

2. The ration must be adapted to the species. This is obvious as relates to quantity, but is equally true of the kinds of materials. For instance, both poultry and swine generally eat cottonseed meal with reluctance and with danger to health. Wheat bran is less desirable for swine than for other species. The horse and the hog are not adapted to rough fodder as are 
the ruminants. It is useless, however, to mention at this point other instances of this character, or to comment on their importance, further than to emphasize the foolishness of trying to bring all species of animals to a common basis in the supply of feeding stuffs.

3. The physiological requirements of the animal must be considered. A ration of maximum physiological efficiency and economy must contain the several nutrients in such quantities and proportions as will meet the needs of the particular animal fed, without waste. This statement is based upon facts given elsewhere in this volume relative to the demands of the animal body and the functions of the nutrients.

It remains now for us to consider how to compound such rations as are desired, or those that are adapted in kind and quantity to the requirements which they are to meet. Obviously, the first essential for doing this is the adoption of standards to which rations should conform, for if we do not have these there is no possibility of concluding whether one food mixture is better or worse than another for a particular purpose.

Such standards have been proposed, which we knew first as German feeding standards. As found in the tables published by German authors, they are the result of numerous and elaborate studies of the balance of loss or gain to the animal organism when rations of various kinds were fed to animals at rest, at work, and when producing meat, wool or milk, in desirable quantities. They relate entirely to physiological demands without reference to the cost of the 
rations or to the profits which may result from their use.

These standards take account of two main factors: (1) the quantity of available nutrients, and (2) the relative proportions of the classes of nutrients. Quantity is an essential consideration, for it is obvious that enough energy and building material must be supplied to do a given work. It is also obvious that quantity must be a variable factor according as the animal is large or small, doing hard or light work, giving much or little milk, or fattening rapidly or slowly.

Account must be made of the proportions of the nutrients, because protein, for instance, has peculiar functions which other nutrients cannot exercise, and less than a certain minimum of the proteids would limit production by just the amount of the deficiency. In order for the protein to serve its maximum usefulness its energy should not be encroached upon to fill a place equally well or better taken by earbohydrates; consequently, the proportion of carbohydrates must also be considered.

The relative proportion of the nutrients of a ration we speak of as the nutritive ratio. By this term is meant the relation in quantity of the digestible protein to all the other digestible organic matter reckoned in terms of carbohydrates. If we multiply the quantity of fat by 2.4 we get its carbohydrate equivalent, and if we add this product to the quantity of digestible carbohydrates present we have the carbohydrate value of the digestible matter other than the protein. This sum divided by the number representing the pro- 
tein gives the nutritive ratio. For instance, in a ration mentioned later there are .94 pound protein, 9.65 pounds carbohydrates, and .49 pound fat. $(.49 \times 2.4$ $+9.65) \div .94=11.5$. $1: 11.5$ is therefore the nutritive ratio of the ration.

A nutritive ratio may be designated as "narrow," "wide," or "medium." These terms do not represent exact limits, to which there is universal agreement. A narrow ratio is one where the proportion of protein is relatively large, not less perhaps than 1:5.5. A wide ratio is one where the carbohydrates are very greatly predominant, or in larger proportion perhaps than 1:8.0. Anything between 1:5.5 and 1:8.0 may properly be spoken of as a medium ratio.

For the purpose of illustration a few feeding standards are given in this connection. These are selected from standards proposed by Wolff, as modified by Lehmann. (See full table in appendix.) They refer in all instances to animals weighing 1,000 pounds:

For 1,000 pounds live weight daily

\begin{tabular}{|c|c|c|c|c|c|}
\hline $\begin{array}{l}\text { Dry } \\
\text { sub- } \\
\text { stance }\end{array}$ & $\begin{array}{c}\text { Diges- } \\
\text { tible } \\
\text { pro- } \\
\text { tein }\end{array}$ & $\begin{array}{l}\text { Diges- } \\
\text { tible } \\
\text { carbohy } \\
\text { drates }\end{array}$ & $\begin{array}{l}\text { Diges- } \\
\text { tible } \\
\text { fat }\end{array}$ & $\begin{array}{l}\text { diges- } \\
\text { tible } \\
\text { organic } \\
\text { matter }\end{array}$ & $\begin{array}{l}\text { Nutri- } \\
\text { tive } \\
\text { ratio }\end{array}$ \\
\hline lbs. & lbs. & lbs. & lbs. & lbs. & \\
\hline
\end{tabular}

$\begin{array}{lllllll}\text { Cow, yield milk, 22 lbs... } & 29 & 2.5 & 13 & .5 & 16 & 1: 5.7 \\ \text { Fattening steer, 1st per... } & 30 & 2.5 & 15 & .5 & 18 & 1: 6.5 \\ \text { Horse, medium work..... } & 24 & 2 & 11 & .6 & 13.6 & 1: 6.2\end{array}$

These and other standards will be discussed later when we come to consider the feeding of the various farm animals. Our present purpose is simply to make clear the steps necessary to bringing the quantity and 
composition of the ration into conformity with the standard selected.

As a means of showing the steps involved in calculating what a ration is, and how to improve it if necessary, we will assume that it is desired to learn whether a food mixture which a milch cow is eating is what it should be, and if it is not, how to make it so. The standard ration for a 1,000-pound cow, giving twenty-two pounds of average milk, expressed in terms of water-free nutrients, has been given in the preceding table.

The first point which requires our attention is that this standard is mainly expressed in terms of waterfree digestible nutrients. This means that we must take into account the composition and digestibility of the particular feeding stuffs which enter into a ration if we would discover what it really is supplying of available food compounds. It is evident that usually feeders cannot have their cattle foods analyzed, and so they must resort to the tables of averages of composition and digestibility, which are, or may be, in the hands of every farmer. But what figures shall be selected for use? As we have learned, feeding stuffs, especially fodders, differ within quite wide limits in what they contain and in what the animal will dissolve from them, according to the stage of growth and conditions of curing, etc., and an average percentage of protein or an average coefficient of digestibility is likely to differ widely from the actual facts as pertaining to a particular material. All that can be done is to select as nearly as possible the figures which 
have been found for feeding stuffs in the condition of those which are to be fed. If the hay is from mature grass use the composition percentages and digestion coefficients given for such hay; if the silage is from mature corn, pursue a similar course in this case, and so on. Difficulty will be met in always finding suitable figures, because without question there has been a failure to properly classify tables of composition and digestibility on the basis of the character of the materials.

The assumed ration which we wish to find out about consists of
Late cut timothy hay. . 10
Hominy chops....... 2
Corn silage....... 25
Winter wheat bran... 3

The averages for composition and digestibility, which are as likely as any to represent these and other materials, are the following:

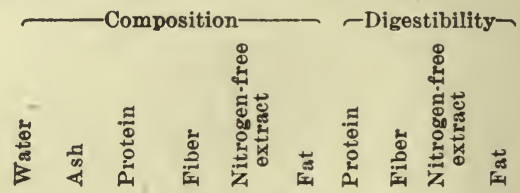

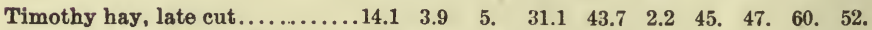

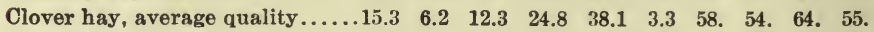

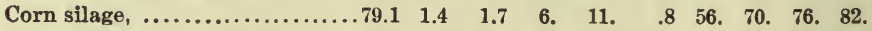

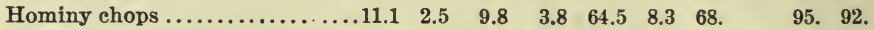

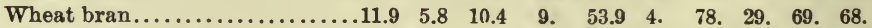

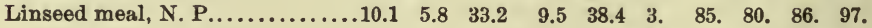

The first step in the calculation is to find out what percentages of digestible material the components of our proposed ration contain, and we shall obtain these 
by multiplying the percentages of composition by the coefficients of digestibility and dividing the product by 100 ; that is, if timothy hay contains five per cent of protein, 45 per cent of which is digestible; then fortyfive hundredths of five will be the percentage of digestible protein in the hay. In this way the following figures were obtained. The percentage of digestible carbohydrates represents the sum of the quantities digested from both the crude fiber and the nitrogenfree extract. Tables are now published which show percentages of digestible ingredients, and which will render this calculation largely unnecessary:

$\begin{array}{lcccc} & \begin{array}{c}\text { Digestible } \\ \text { protein } \\ \%\end{array} & \begin{array}{c}\text { Digestible } \\ \text { carbohy- } \\ \text { drates } \\ \%\end{array} & \begin{array}{c}\text { Digestible } \\ \text { fat } \\ \%\end{array} & \begin{array}{c}\text { Total } \\ \text { digestible } \\ \text { organic } \\ \text { nutrients }\end{array} \\ \text { Timothy hay, late cut ...... } & 2.3 & 40.8 & 1.1 & 44.1 \\ \text { Clover hay, average quality } & 7.1 & 37.8 & 1.8 & 46.7 \\ \text { Corn silage, average quality. } & .9 & 12.6 & .6 & 14.1 \\ \text { Hominy chops.............. } & 6.7 & 61.3 & 7.6 & 75.6 \\ \text { Wheat bran................ } 12 . & 39.8 & 2.7 & 54.5 \\ \text { Linseed meal ............. } & 28.2 & 40.6 & 2.9 & 71.7\end{array}$

The second step is to calculate the pounds of digestible nutrients in the quantities of the several feeding stuffs to be used. It is clear, for instance, that ten pounds of hay will contain ten one-hundredths of the amounts in one hundred pounds, so we simply need to multiply the percentage of digestible protein and so on by ten and divide by one hundred in order to learn what ten pounds of hay will furnish to the animal. If we make this computation for each constituent of each feeding stuff, we reach the figures of the following table 


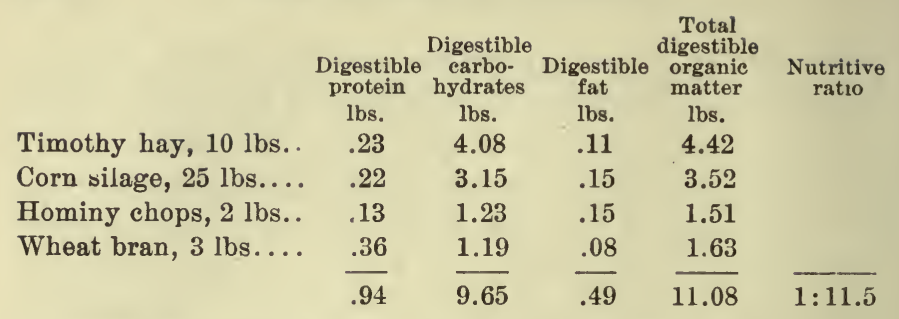

Several authors have published tables showing the amounts of digestible nutrients in given quantities of our feeding stuffs, which still further shorten the work that the feeder must do in computing rations.

.When we come to compare this ration with the standard ration we find it is seriously defective in two particulars; it contains much too little digestible organic matter and the nutritive ratio is too wide.

In order to correct these faults we must add digestif ble organic matter which contains a much larger proportion of protein than is found in any of the materials so far selected, and we must seek such a supply in part at least among the highly nitrogenous feeding stuffs like the oil meals and gluten meals. It is easy for one with experience to see also that all the necessary additional organic matter cannot be secured from a highly nitrogenous food without increasing the protein supply unnecessarily. In order to avoid this, the amount of silage may be raised ten pounds and still not feed an excessive quantity. If clover hay is available it would also be well to substitute five pounds of it for five pounds of the timothy. If, then, we add to the ration three pounds of linseed meal we shall approximate more nearly to our standard. 


\begin{tabular}{|c|c|c|c|c|c|}
\hline 1 & Protein & $\begin{array}{c}\text { Carbohy. } \\
\text { drates }\end{array}$ & Fat & $\begin{array}{c}\text { Total } \\
\text { digestible } \\
\text { organic } \\
\text { matter }\end{array}$ & $\begin{array}{c}\text { Nutritive } \\
\text { ratio }\end{array}$ \\
\hline Timothy hay, 5 lbs....... & $\begin{array}{l}\text { lbs. } \\
.11\end{array}$ & $\begin{array}{l}\text { lbs. } \\
2.04\end{array}$ & $\begin{array}{l}\text { lbs. } \\
.06\end{array}$ & $\begin{array}{l}\text { lbs. } \\
2.21\end{array}$ & \\
\hline Clover hay, 5 lbs. ......... & .35 & 1.89 & .09 & 2.33 & \\
\hline Corn silage, 35 lbs........ & .31 & 4.41 & .21 & 4.93 & \\
\hline Hominy chops, 2 lbs..... & .13 & 1.23 & .15 & 1.51 & \\
\hline Wheat bran, 3 lbs........ & .36 & 1.19 & .08 & 1.63 & \\
\hline Linseed meal, N. P., 3 lbs.. & .85 & 1.22 & .09 & 2.16 & \\
\hline & 2.11 & 11.98 & .68 & 14.77 & $1: 6.4$ \\
\hline
\end{tabular}

This ration is still below the standard in quantity, but as the relation of the nutrients is approximately what is called for, it is only necessary to increase the quantities of each component about one-fifteenth in order to furnish the animal sixteen pounds of digestible organic matter. It is, however, a good ration for cows of the smaller breeds weighing from 800 to 900 pounds.

There are several points to be considered in this connection. First of all, the standard rations are the quantities to be fed per day and per 1,000 pounds live weight. This is ordinarily taken to mean that if a 1,000 -pound cow requires 16 pounds of digestible nutrients an 800 -pound cow should be supplied with only four-fifths as much, or 12.8 pounds, or that a 1,200-pound horse needs 50 per cent more food than one weighing 800 pounds. Unfortunately this simple mathematical way of calculating rations does not meet the plain requirements of practice. The needs of a producing or working animal are not directly proportional to its size, although it is more nearly so with working animals than with those fed for production. It is certain that an exact adjustment of a ration to the 
weight of the animal would produce absurd conditions, especially in the case of cows where production and not the size of the animal is the main factor.

However, we cannot ignore the size of the animal in determining the quantity of the ration. Concerning this Armsby says: "The function of the maintenance ration is essentially to supply heat to the body to replace the constant loss that takes place.* Now, Henneberg has long ago shown that, in round numbers, over 90 per cent of this heat is removed by radiation and evaporation. Consequently, we should expect the demands of the organism for heat (i. e., for maintenance), to be proportional to its surface (including lung surface), rather than to its weight, and the more recent researches of Rubner have confirmed this theoretical conclusion." For the purposes of calculation it is assumed that animals are geometrically similar figures and therefore that their surfaces are proportional to the cube root of the square of their weights. Several steers having weights from $1,0<0$ pounds up to 1,700 pounds would need on this basis amounts of digestible food for maintenance proportional to figures given in the table below :

$\begin{array}{cc}\begin{array}{c}\text { Weight of the animal } \\ \text { approximately }\end{array} & \begin{array}{c}\text { Proportion of food per } \\ 1,000 \text { lbs. live weight }\end{array} \\ 1,000 \text { lbs. } & 100 \\ 1,100 \text { 66 } & 96 \\ 1,200 \text { "6 } & 93 \\ 1,300 \text { "6 } & 90 \\ 1,400 \text { "6 } & 88 \\ 1,500 \text { "6 } & 86 \\ 1,600 \text { "6 } & 84 \\ 1,700 \text { "6 } & 82 \\ \text { * The note on p. } 169 \text { should be read in this connecticn. }\end{array}$


For adjusting a maintenance ration to the weight of a steer or horse this method seems to have a plausible basis, but it is evidently less applicable to dairy cows or rapidly growing or fattening animals, for in these eases size is not so largely a controlling factor.

Again, is there a fixed quantity and proportion of protein from which it is unwise to deviate? If we are trying to supply the needs of a cow giving twenty five pounds of milk or of a steer gaining two pounds of body substance daily, there is without question a minimum quantity of food protein absolutely necessary in each case, but what these minima are has not yet been closely determined. These necessary quantities are undoubtedly not exactly the same for all individuals, although they are not likely to differ widely between single animals of the same class and productive capacity. It is safe to assert that the protein standards are those which it is practicable to feed and which unquestionably meet the demands of intensive production, but we are not sure that when other conditions are right 10 per cent more or 10 per cent less than the specified quantities would influence efficiency either way; in other words, we have no proof in those cases where 2.5 pounds of protein is the standard for a milch cow that 2.75 pounds would not induce larger production or that 2.25 pounds would not meet all requirements when the earbohydrates are present in sufficient quantity.

All this is equivalent to saying that we cannot fix exact nutritive ratios. There is, of course, a minimum food energy which is essential for sustaining a 
particular animal, and the non-nitrogenous nutrients should be present in sufficient quantity to protect the protein that it may be applied to its peculiar uses rather than be consumed for heat production. It is more than probable, though, that the nutritive ratio may vary considerably from the German standards without causing any appreciable influence upon growth, work or milk yield.

We have good reasons for believing, however, that when the supply of food meets the requirements of the animal as to quantity, the nutritive ratios given in the feeding standards provide fully for the needs of animals under all conditions. The significant fact is that in practice it is possible to depart so widely from these ratios as to greatly diminish the efficiency of the ration for specific purposes, and this is the justification of standards which may only approximate to the best, but which serve admirably as a guide in avoiding serious errors. The foregoing - statements do not mean that the feeding formulas so far published are the result of guess-work and rest upon no basis of exact observations, for this is not true. It is simply intended to point out the fact that we cannot now set exact limits to the formulas of nutrition.

4. The rations should be compounded with reference to the quality of the product. Our knowledge of the influence of foods upon the quality of meat products is indefinite, but that food has an influence upon the flavor of milk and upon the chemical and physical properties of butter, seems to be fairly well established. 


\section{Business Considerations in Selecting Rations 293}

5. Rations should be compounded with reference to the home supply of feeding stuffs and to market prices. Economy often demands that the materials in hand shall be used even if the ration is not ideal. Again, there are several protein foods which may be used, and it is often only a question of price in determining which should be purchased. Notwithstanding the claims of manufacturers, there is no one feeding stuff essential to the health of animals or to the highest quality of the product, so that the feeder may often consider the matter of cost and select the cheapest source of protein without in any way impairing the ration.

Those who have carefully followed the preceding statements must have become convinced that the selection of a ration which shall be the best possible from a business standpoint is not a simple matter. We must always distinguish between the combination that is most efficient physiologically or productively and the one that is the source of largest profit. It is often the case-perhaps generally - that a food mixture which induces a high rate of production is the most profitable one to use, but this occurs only when business conditions make it possible. Many seem to think that if a ration is "balanced" it necessarily meets all the requirements for the maximum profit, but this is an erroneous view.

For instance, a farmer somewhat remote from the markets may have on hand an abundant supply of hay and home-raised grains of such a character that it is impossible to compound them so as to conform 
to the accepted feeding standard for milch cows. If the prices of dairy products are low, and those of protein feeding stuffs are high, it is entirely possible for the farmer to secure more profit from his cows with an "unbalanced" ration than with one which has the standard nutritive ratio.

The western stockman can generally afford to waste corn on fattening steers rather than use it with greater physiological economy by mixing it with purchased grains. The cost of the latter would soon offset the profits otherwise possible. All this is equivalent to saying that practical considerations often justify a wide departure from the standard rations. Hills states the case well when he says:

"The study of the requirements of the individual animal and the adapting of food to its needs is to be preferred to placing the herd, as a whole, upon any inflexible ration. The capacity of an animal to receive, its ability to produce, the effects of the sundry feeds upon the health and condition of the animal, upon its appetite and taste, upon the quality of the product, the money values of feed and the profits to be derived from their use, are important considerations which do not enter into the make-up of the physiological standard, but which are vital factors in the feeder's problem. Clearly the physiological standards may supplement, and in some measure guide, judgment, but cannot take its place." 


\section{CHAPTER XX}

\section{MAINTENANCE RATIONS}

A MAINTENANCE ration is one supplying the needs of an animal without production of any kind and with no loss of body substance. To be more specific, when an ox doing no work excretes just the quantities of nitrogen and carbon that are contained in the food consumed, he is said to be eating a maintenance ration. The work done by the animal at rest is largely needed in the following directions: the chewing of food and its movement along the intestinal tract; the muscular action of the heart in causing blood circulation; and the metabolic activity of the cells in causing the chemical transformation of the nutrients. Some work is also done in moving the body. The demands upon the food for maintenance purposes are therefore entirely for the production of muscular energy and heat.*

Nine-tenths or more of a maintenance ration may consist of carbohydrates which, because the income and outgo are balanced, are used solely as fuel. Only a very small amount of protein is necessarily destroyed by a resting animal, although a minimum food supply is absolutely essential if the nitrogenous tissues of the body are to be kept from wasting. If an animal is not eating protein, urea will continue to appear in

\footnotetext{
* See note, p. 169.
} 
the urine and in time protein starvation will cause death.

Any ration fed for production may be looked upon as made up of two parts, that which is needed to maintain the animal and that which may be applied to growth or the formation of milk solids. It is possible, of course, for the production of milk or wool to occur when the cow or sheep is fed what is really only a maintenance ration, but the materials for production under these circumstances are furnished at the expense of the body substance. With what is regarded as liberal feeding, from one-third to one-half of a production ration is needed for maintenance purposes. It seems fitting, then, to speak of a maintenance ration as a tundamental quantity, a knowledge of which is important to both science and practice. It is clear that no rational understanding of the uses of food can be had unless we know what amount is required simply for maintenance, and the feeder is certainly helped to a more intelligent compounding of rations if he has some means of judging how large an excess he is supplying for production purposes. Occasionally, too, it is desired to provide horses and other animals when not at work with just enough food to keep them in a uniform condition without gain or loss.

No ration is more easily provided from the ordinary farm supply than is that for maintenance, for two reasons: (1) because the quantity of available nutrients which must be eaten is so small that this ration may be wholly or mostly made up of bulky materials such as corn fodder and hay; (2) because investigation has 
demonstrated that mere maintenance demands a comparatively small amount of protein and so this ration may have a wide nutritive ratio such as pertains to the nutrients of the more common farm products.

\section{MAINTENANCE FOOD FOR BOVINES}

Experiments having for their object a determination of the daily quantity of nutrients necessary to simply maintain animals of this class were conducted by Henneberg and Stohman with oxen as long ago as 1858. A number of rations were fed and the conclusions which were reached were based upon the amount of food digested, the gain or loss of nitrogenous tissue by the animals and their weights and general appearance. The average daily quantities of digestible nutrients which appeared to be sufficient to maintain a 1,000-pound ox without growth or loss was approximately 8.2 pounds, of which .53 pound was protein, the whole having an energy or heat value of not far from 15,000 Calories. Because of the high temperature of the stalls used in the above-named experiments, Wolff estimated later that for winter feeding the standard should be 8.9 pounds of digestible nutrients, of which .7 pound should be protein, the energy value being approximately 16,000 Calories, and even until now Wolff's figures are published as the standard maintenance ration.

It is certainly time that this standard should be revised. The earlier experiments on which it was based furnished data insufficient for accurate conclusions, for the only means of judging whether the 
animals were gaining or losing body substance were the changes in live weight, which cannot be regarded as conclusive evidence. Some of the earlier feeding experiments conducted in the United States, especially those of Sanborn and Caldwell, indicated that a ration based on Wolff's standard was capable of causing a material growth of steers, and the accuracy of Wolff's figures was called into question. Later observations of a more exact character have shown quite conclusively that a 1,000-pound steer may be maintained without loss of body substances on considerably less than 8.9 pounds, or even 8 pounds, of digestible nutrients per day.

Elaborate experiments by Kühn from the years 1882 to 1890 , afterwards discussed by Kellner, were regarded by the latter as justifying the conclusion that the minimum quantity of digestible organic matter which will maintain a 1,000 -pound mature ox at rest is 7.3 pounds, .7 of a pound of which should be protein. Later Armsby, in presenting the results of experiments of his own in connection with a critical review of Kühn's work, concludes that "we may place the average maintenance of a steer weighing $500 \mathrm{kgs}$. $(1,100$ pounds $)$ and receiving only a mainly coarse fodder at 13,000 Calories of available energy." As Armsby found one gram of digestible matter from timothy hay to be equal to 3.62 Calories of available energy, 13,000 Calories would equal 7.92 pounds of digestible matter from this source. This would be the same as 7.4 pounds for a 1,000-pound animal. (See method of calculation in Chapter XIX.) 
Still later, Kellner, basing his figures upon extensive researches by himself and associates, which are the most elaborate so far made, gives us the following as the minimum quantities which will satisfy the maintenance needs of mature animals of different weights:

$\begin{array}{cc}\begin{array}{c}\text { Approximate weight } \\ \text { of animal } \\ \text { lbs. }\end{array} & \begin{array}{c}\text { Energy } \\ \text { Cal. }\end{array} \\ 1,000 & 10,740 \\ 1,100 & 11,520 \\ 1,200 & 12,280 \\ 1,300 & 13,010 \\ 1,400 & 13,720 \\ 1,500 & 14,420\end{array}$

\begin{tabular}{|c|}
\hline $\begin{array}{l}\text { Digestible } \\
\text { organie substance from } \\
\text { average meadow hay }\end{array}$ \\
\hline lbs. \\
\hline 6.75 \\
\hline 7.22 \\
\hline 7.72 \\
\hline 8.18 \\
\hline 8.62 \\
\hline 9.06 \\
\hline
\end{tabular}

The necessary quantity of available nutrients may be larger if only very ripe, coarse food is fed, than if the ration is part grain, because of the somewhat less available energy from the digested part of the former. In order to express a maintenance ration for bovines in terms of hay and grain, there are given in this connection several mixtures, which, on the basis of average composition and digestibility, will furnish quite closely the necessary digestible matter, using Armsby's conclusions as the basis for calculation :

\section{To maintain a 1,000-pound animal}
$1\left\{\begin{array}{r}12 \text { lbs. average timothy hay. } \\ 3 \text { lbs. wheat bran. }\end{array}\right.$
$3\left\{\begin{array}{l}23 \text { lbs. mature corn silage. } \\ 5 \text { lbs. timothy hay. } \\ 3 \text { lbs. wheat bran. }\end{array}\right.$
$\overline{2}\left\{\begin{array}{l}8 \mathrm{lbs} . \text { corn stover. } \\ 6 \mathrm{lbs} . \text { clover hay. } \\ 3 \mathrm{lbs} . \text { corn and cob meal. }\end{array}\right.$
$4\left\{\begin{array}{l}5 \text { lbs. timothy hay. } \\ 5 \text { lbs. elover hay. } \\ 4 \text { lbs. corn and cob meal. }\end{array}\right.$

5. $15 \frac{1}{2}$ lbs. good mixed hay. 
These combinations are merely illustrative. Many others furnishing an equivalent quantity of available nutrients may be used. Doubtless these various mixtures wili not show equal efficiency. Ration No. 3 would probably be more satisfactory than No. 5 , because of greater palatableness. All such facts as the proportion of grain in the mixture, the stage of growth of the fodder, whether early or late cut, immature or mature, the amount of moisture present, as in stover, and the completeness of preservation, will have an influence upon the nutritive effect of a ration, and these factors must be considered according to the best judgment of the feeder. It is possible, without question, to maintain an animal on one fodder alone, such as hay, but for several obvious reasons it is better to feed a mixture.

The maintenance rations heretofore stated apply to a 1,000-pound animal. For animals weighing more or less the quantity should be increased or diminished, but not in just the ratio in which the animal varies in weight. For information on this point the reader should refer to what is given in the chapter on compounding rations.

\section{MAINTENANCE FOOD FOR HORSES}

The general facts which have been presented in relation to the function and character of a maintenance ration are as applicable to horses as to bovines. It is true, however, that rations simply sufficient for maintenance purposes have a very limited application 
with horses, because in nearly all cases they are at least used for occasional driving or light work, and even if merely "boarded," regular exercise is necessary to their welfare.

If recent conclusions are sound, a horse needs somewhat less digestible food for mere maintenance than a steer of equal weight. Zuntz, who has so thoroughly studied the nutrition of the horse, concludes, after a critical survey of the results of other men in connection with the elaborate data from his own extended investigations, that a 1,000-pound horse can be maintained on 6.4 pounds of nutrients, provided the total ration contains not more than three pounds of crude fiber. This means that the nutrients should come from a mixture of hay and grain if this minimum quantity is to be sufficient. Were only hay to be fed the necessary nutrients would probably exceed the amount named.

Grandeau in his experiments found that three horses, whose mean weight was 852 pounds, were maintained for fourteen months on $\mathbf{1 7 . 6}$ pounds of hay per day, from which the three animals digested an average of 6.06 pounds of organic matter. Using the method of computation already described, this is equal to 6.75 pounds of digestible nutrients for a 1,000-pound horse, a result not greatly different from that of Zuntz.

The latest conclusion of Wolff was that a 1,100 pound horse should have for maintenance at rest 7.26 pounds of digestible organic matter daily, exclusive of the digested crude fiber, which would be the same as 
6.78 pounds of fiber-free nutrients for a 1,000 -pound horse. As Wolff regarded the fiber as useless to a horse, either for maintenance or for production of work, the last figures represent his estimate of the maintenance needs of a horse at rest.

It is proper to remark that Wolff's views as to the nutritive value of crude fiber are not generally accepted.

In calculating rations for horses, the coefficient of digestibility obtained in experiments with this class of animals should be used, coarse fodders, as stated previously, not being so efficiently digested by horses as by bovines or sheep. For this reason, the gross weight of the maintenance food for horses may be as great as that for ruminants, though the actual nutrients needed are less. Accepting 6.6 pounds of digestible organic matter as the daily requirements of a resting horse, the following rations would maintain a 1,000-pound animal for one day:

$1\left\{\begin{array}{c}16 \frac{1}{2} \text { lbs. medium quality } \\ \text { mixed hay. }\end{array}\right.$

$2\left\{\begin{array}{r}10 \text { lbs. timothy hay. } \\ 5 \text { lbs. oats. }\end{array}\right.$

$3\left\{\begin{array}{r}10 \text { lbs. timothy hay. } \\ 4 \text { lbs. cracked corn. }\end{array}\right.$

$5\left\{\begin{array}{c}12 \mathrm{lbs} . \text { mixed hay. } \\ 3 \frac{1}{2} \mathrm{lbs} . \text { bran, or } \\ 3 \mathrm{lbs} . \text { oats, or } \\ 2 \frac{1}{2} \mathrm{lbs} . \text { cracked corn. }\end{array}\right.$

$4\left\{\begin{array}{c}10 \text { lbs. medium mixed hay. } \\ 43 / 4 \text { lbs. wheat bran. }\end{array}\right.$

$6\left\{\begin{array}{l}10 \mathrm{lbs} . \text { timothy. } \\ 10 \mathrm{lbs} . \text { carrots. } \\ 2 \frac{1}{2} \mathrm{lbs} . \text { corn. }\end{array}\right.$

$7\left\{\begin{array}{c}10 \mathrm{lbs} . \text { mixed hay. } \\ 10 \mathrm{lbs} . \text { carrots. } \\ 23 / 4 \mathrm{lbs} . \text { ats. }\end{array}\right.$

$8\left\{\begin{array}{c}10 \text { lbs. mixed hay. } \\ 8 \text { lbs. carrots. } \\ 3 \frac{1}{2} \text { lbs. bran, }\end{array}\right.$ 
These rations serve as examples and also indicate how with ten pounds or twelve pounds of hay the several grains mentioned may be combined to give a maintenance ration. It is not wise to feed a horse on hay alone, even when doing no work. Ten to twelve pounds of hay are enough coarse fodder, which may be supplemented to advantage by both roots and grain. 


\section{CHAPTER XXI}

\section{MILK PRODUCTION}

MiLK, like all other animal products, is derived from the food. Its secretion stands almost unrivaled as an example of the rapid, extensive and continuous transformation of the food into animal compounds. In no other instance, except perhaps in the case of the earliest growth of animals, is so large a proportion of the digested nutrients utilized in building new material or is there so intimate a relation between the extent and kind of the feeding and the extent and character of the resulting product. For these and other reasons, the successful feeding of milch cows requires, perhaps, greater expertness and a wider knowledge of facts than any other department of animal husbandry. This will appear more fully as we continue to develop this subject.

It is not proposed in this connection to enter into an elaborate discussion of the chemistry and secretion of milk, for this is presented elsewhere in the series of which this volume is a part. It is essential to present purposes, however, that we call to mind certain facts which are pertinent to a consideration of the food relations of milk formation.

Milk is a fluid that is secreted by all mammals in a gland which with the cow is called the udder. It con- 
tains water and solids, the latter being made up of mineral compounds, proteids, fats and sugar. The average composition of normal cow's milk, excluding samples of unusual character, according to a compilation by Van Slyke of 5,552 American analyses is as follows:

$\begin{array}{cccccc}\text { Total solids } & \text { Ash } & \text { Proteids } & \text { Fats } & \text { Sugar } & \text { Water } \\ \% & \% & \% & \% & \% & \% \\ 12.9 & .7 & 3.2 & 3.9 & 5.1 & 87.1\end{array}$

'The variations in the composition of cows' milk are large, the proportion of water ranging under perfectly normal conditions from 84 to 89 per cent, with ocrasional analyses entirely outside these limits. The chief known causes of such variations are breed, individuality, period of lactation, and nervous disturbances. There are material daily fluctuations as well, for which no reasons can now be assigned. These changes are mostly in the proportions of water and total solids, for the composition of the solids, that is, the relative proportion of proteids, butter fats and sugar, is remarkably constant with the same animal. The effect of breed in cows is illustrated by averages obtained in breed tests at three experiment stations:

\begin{tabular}{|c|c|c|c|}
\hline & $\begin{array}{c}\text { Holstein } \\
\%\end{array}$ & $\begin{array}{c}\text { Ayrshire } \\
\%\end{array}$ & $\begin{array}{c}\text { Jersey } \\
\%\end{array}$ \\
\hline Total solids ...... & 12.2 & 12.9 & 15. \\
\hline Fat $\ldots \ldots \ldots \ldots \ldots \ldots$ & 3.4 & 3.6 & 5.3 \\
\hline Solids not fat............... & 8.8 & 9.3 & 9.7 \\
\hline
\end{tabular}

These variations and those due to other causes are important in considering the relation of milk forma- 
tion to nutrition, because the food expense of milk is determined, other things being equal, not by the volume but by the milk solids elaborated, for which reason the draft upon the supply of nutrients, water excepted, is greater for the secretion of 100 quarts of Jersey milk than for the same quantity of Holstein milk. In studying the economy of milk production, therefore, we should consider the relation of food to milk solids and not to milk volume.

\section{MILK SECRETION ${ }^{\circ}$}

There is no milk in an animal's food, that is to say, hay and grain contain no casein, butter fat or milk sugar. They do contain nutrients, which, when subjected to the vital processes of the animal, are ultimately transformed into the constituents of milk. The mammary gland is not a sieve through which certain compounds in the blood are strained into the udder cavities, but it is a specialized tissue in which wonderful and extensive chemical changes occur. Here, for the first time, we find casein, the mixture of compounds known as butter fat, and a sugar unlike any that is found in plants, or in any other part of the animal organism. Vegetable fats contain glycerides similar to some of those found in milk, to be sure, but not in the same number or proportions. One fact, moreover, which dairymen have been slow to recognize in all its significance, is that the udder of each individual cow is a law unto itself in the characteristics of the milk which it secretes, and is not subject in any large de- 
gree to control through feeding or other treatment that is not actual abuse.

The manner of milk secretion is something of which we know but little, and this is, perhaps, not immediately important to the dairyman. The food source of the constituents of milk is, on the other hand, a matter of great practical interest, and here we have information more or less definite.

Sources of milk solids.-The previous discussion of the functions of nutrients must have made it clear that the proteids of the milk can have only one source; viz., the proteids of the food, a unanimous conclusion which rests upon experimental evidence as well as upon the universally accepted truth that the animal organism does not have the power to construct proteids from simpler compounds. It now seems quite certain that the proteids are the only constituents of milk which must have their origin exclusively in the food proteids, for we have apparently sound reasons for believing that milk sugar and butter fat are constructed, in part at least, from carbohydrates. In an investigation at the New York Agricultural Experiment Station as to the food sources of milk fat, two cows, both of which gained materially in live weight during experiments continuing two months or over, produced respectively nineteen pounds and forty pounds more of butter-fat than could be accounted for from the food fat and available proteids. The amount of digestible food fat supplied was relatively insignificant and the secretion of milk fat seemed to be related in no direct way to the protein exchange. These observations led 
straight to the conclusion that earbohydrates are milk fat formers. The extent to which food fat assists in the production of milk fat is not yet determined. It cannot be safely asserted that the ingested fats do not pass directly into the milk, but it seems quite evident that the larger part of the glycerides of milk have their origin in the animal. We are not sure. either, whether protein is ever a source of milk fat, but that it is a necessary source now seems quite improbable.

The rate of formation of milk solids. - A cow yielding 6,000 pounds of average milk per year is not regarded as an unusual animal. This means, however, the annual production of not less than 780 pounds of milk-solids, an amount at least double the dry matter in the body of a cow weighing 900 pounds. When we consider that this manufacture of new material is carried on not only during a single year, but through the entire adult life of the animal, we begin to realize how extensive are the demands upon the food supply. Still more striking is the case of high grade cows yielding annually over half a ton of milk solids, and when we remember the performance of Clothilde, whose 26,000 pounds of milk produced in one year certainly contained more than 2,500 pounds of solid matter, we must regard the cow as possessing wonderful powers of transmutation. Her capacity for the rapid and economical production of human food of the highest quality is not equaled by an other animal.

No facts could more forcibly illustrate the necessity of liberal and proper rations for the milch cow. 


\section{THE AMOUNT AND CHARACTER OF THE RATION FOR MILK PRODUCTION}

This ration is used in various directions. It must supply the raw materials for milk formation, provide for the growth of the fœetus, sustain the effort of milk secretion and maintain the usual and necessary functions of the animal body. The nature and extent of these uses are in part quite definitely understood. First of all, the kind and quantity of milk solids may be estimated for any given case. The daily production of thirty pounds of average milk, a performance reasonably to be expected in a good herd, involves the elaboration of 3.87 pounds of milk solids. For mere maintenance it is fair to assume that the food requirements of the cow and steer would not be greatly unlike, disregarding the demand for energy utilized in milk secretion, and for the material used in the growth of the young. On this basis the milk solids and the mere maintenance of the cow call for about 11.25 pounds of dry matter daily, a quantity utterly insufficient, as experience teaches, to maintain a cow giving thirty pounds of average milk. We are led to the reasonable conclusion that outside the building of milk solids, a large expenditure of food energy is required to sustain the nerve force, metabolic cell activity and warming of the extra water and food, which are necessarily involved in milk secretion. This view is sustained by the results of investigation. In unpublished experiments by the writer with two cows in full flow of milk, which made only a slight gain in body weight, 
the available energy of the rations and of the milk was determined. The figures reached were approximately as follows :

Cow $10 \quad$ Cow 12

wt. 775 lbs. wt. $1,200 \mathrm{lbs}$.

Cal.

Cal.

Available energy of ration $\ldots \ldots \ldots .27,120$

31,300

Energy of milk solids

$\begin{array}{rr}\frac{8,450}{18,670} & \frac{10,200}{21,100} \\ \frac{10,100}{8,570} & \frac{13,700}{7,400}\end{array}$

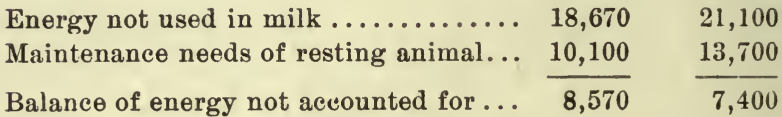

This energy not accounted for, amounting with the two cows to more than one-fourth the total available energy of the rations, may properly be charged to the work of milk formation. Science and practice agree in naming 15.5 to 16.5 pounds of digestible organic matter as approximately the proper daily amount of digestible nutrients for economical milk production with a good cow of average size, much less than which is not to be considered as generous feeding. The necessary supply of nutrients will vary somewhat according to the size of the cow, but the gradation of quantity should by no means be directly proportional to live weight. Productivity independent of size is a controlling factor. In general small cows eat proportionately more food than larger ones.

The question now arises, What proportion of this quantity should be protein? The actual amount of proteids in our thirty pounds of average milk is about one pound. If .60 pound is needed daily for mere maintenance as in the case of the steer, we can see where 1.6 pounds of protein must be used, a quantity 
which is now regarded as too small when both food economy and the efficiency of the ration are considered. With this amount of protein in sixteen pounds of total digestible matter, the nutritive ratio of the ration would be about 1:9.5. A ration with as wide a ratio as this is regarded by the great majority of careful experimenters, and most intelligent dairymen, as less efficient than one richer in protein. While it is not possible to point out just how more protein is used, there is no question but that a larger quantity promotes the flow of milk. Few instances are on record where, in carefully conducted experiment station work, other conditions being the same, a moderate ration with a nutritive ratio of $1: 5.5$ to $1: 6.5$ has not proved to be more efficient than one equivalent in quantity but with a ratio materially wider. The observations of Atwater and Woods among the dairy herds of Connecticut, where the owners were induced to narrow the rations they were found to be using, gave emphatic testimony as to the desirability of a larger proportion of protein than is ordinarily supplied in a home-grown ration. This added protein may not be needed for construction uses, but its presence certainly in some way induces an increased milk secretion. The chemical changes involved in milk formation are obscure and complex, and it may be that this extra protein somehow enters into these transformations. One view which appears to be rational is that the presence of a generous amount of circulatory protein stimulates the cells of the body to great metabolic activity, thus promoting the secretion of milk solids. 
According to the majority of testimony available, a cow of average size and good capacity should receive at least 2.25 pounds of protein daily during the full flow of milk, the ration to have a nutritive ratio not wider than 1:6.5. The nutritive ratio of young pasture grass, perhaps as efficient a milk-producing food as we have, is even 'narrower than this, a fact which doubtless explains in part the large flow of milk from abundant June pasturage, and which offers a suggestion for the compounding of winter rations.

While the importance of nitrogenous feeding stuffs to a dairy herd is conceded, there is a tendency with certain writers to distort the relation of protein to milk production. Their utterances give the impression that in feeding milch cows protein is about the only factor to be considered. This view is typified by the assertion that "a cow gives milk only in proportion to the protein that she receives," a remark which might be made with equal accuracy about carbohydrates. It is true that even if carbohydrates are supplied in abundance, a depression of the protein below a certain limit will diminish the milk flow. It is also true that when sufficient protein is fed, a reduction of the carbohydrates below the necessary quantity will cut down the milk yield. An adequate supply of easily digestible carbohydrates is no less important physiologically than keeping up the necessary proportion of protein, though the former may be accomplished more easily than the latter because of the usual character of home-raised crops.

The following are illustrative examples of well-com- 
pounded rations for cows of moderate size and fairly large productive eapacity:
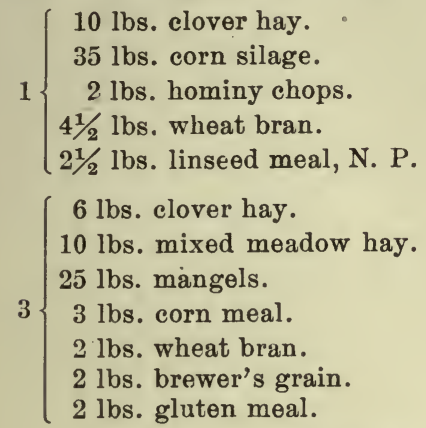
( 10 lbs. mixed meadow hry 40 lbs. corn silage.
$2\{4$ lbs. wheat middlings.
3 lbs. malt sprouts.
1 lb. gluten meal.
$10 \mathrm{lbs}$. corn stover.
5 lbs. alfalfa hay.
25 lbs. sugar beets.
$3 \mathrm{lbs}$. corn and cob meal.
3 lbs. buckw't middlings.
$1 \frac{1}{2} \mathrm{lbs}$. cottonseed meal.

$$
5\left\{\begin{array}{l}
12 \text { lbs. clover or alfalfa hay. } \\
30 \text { lbs. corn silage. } \\
4 \text { lbs. ground oats. } \\
3 \text { lbs. ground peas. } \\
2 \text { lbs. brewer's grains. }
\end{array}\right.
$$

These rations may be criticised on the ground that they are too small to sustain heavy milk production. This would be a just criticism for cows of large capacity that are furnishing high-priced milk.

- It is the writer's opinion that under ordinary conditions few cows under 1,000 pounds in weight will render larger profit from heavier rations.

The sources of protein for mille production.-The dairyman has constantly to face the fact that from the usual list of home-grown feeding stuffs it is difficult to make up a ration throughout an entire season with a nutritive ratio much narrower than $1: 8$, and a proportion of protein even as high as this requires a gener- 
ous admixture of clover in. the hay, and the use of more or less oats or peas in the grain ration. It should not be forgotten that the plants used for forage crops are generally not harvested until they are approaching maturity, and as the later growth of most plants is largely due to the formation of nonnitrogenous compounds, the hay and other fodders stored for winter feeding are comparatively poor in nitrogen compounds. On those farms where the hay crop comes largely from the true grasses, like timothy and red-top, and where the corn crop is a prominent. feature, a home-raised milk ration having a maximum efficiency per unit of dry matter consumed is not possible. On the other hand, where alfalfa and clovers constitute a good proportion of the hay, and where generous areas of peas and oats are grown, a ration compounded from home resources may have a high milk-producing efficiency.

It must be confessed, however, that most dairy farms are lacking in a proper home-raised supply of the more nitrogenous feeding stuffs, and as nearly all dairymen depend to some extent upon purchased grain, it is a quite prevalent custom for them to seek those by sproducts that will strengthen the protein side of the ration, a course which they have been led to adopt through the teachings of science. It is unquestionably true that farmers should be more independent of the markets, and they certainly may be if an intensive system of cultivating well-selected crops is adopted; but so long as more or less grain will certainly be purchased, it is wise to consider the matter of select- 
ing commercial protein feeds for dairy cows. Those from which it is possible to choose are the oil meals, the gluten meals and feeds, brewers' grains, malt sprouts, peas and buckwheat middlings. The offals from the milling of wheat, while somewhat more nitrogenous than the cereal grains, cannot be considered as an abundant source of protein, although they are excellent components of a milk ration.

Notwithstanding the claims which trade interests may make to the contrary, no one of the above-mentioned feeding stuffs is alone essential to the economical production of the best of milk. There is no single food or any one combination of foods that is always best for dairy cows. Apart from certain considerations which will be discussed later, a selection of the source of commercial protein is a matter of availability and of relative market cost. For instance, when gluten meal costs $\$ 20$ per ton few buyers can afford to pay $\$ 27$ for linseed meal to feed in any considerable quantity. If prices were reversed, oil meal should be selected. Both oil meals and gluten products may be ignored if ground peas, buckwheat middlings or the brewers' residues are available at more favorable prices. It is simply necessary that the grain ration shall contain protein in sufficient quantity and proportion, and shall be made up of a variety of materials, better not less than three kinds, all of which should be palatable and exert no deleterious influence upon the milk or its products. There are few grain products that cannot be used successfully in grain mixtures, even though they are undesirable when fed alone. 
THE RELATION OF FOOD TO THE COMPOSITION AND QUALITY OF MILK

There is a widely prevailing opinion among the farming public that the character of milk is intimately related to the kind and quantity of food from which it is produced, i. e., that a dairyman who is possessed of sufficient knowledge may, by variations in the rations, cause material changes in the composition of the milk of his herd. This is equivalent to believ- . ing that thin milk or rich milk, milk rich in fats and poor in casein or the reverse, may be obtained at the will of the feeder. Such a view in its extreme form is very far from the truth. While below a certain limit for each cow the quantity of milk is mostly determined by the ration, other factors, such as breed, individuality and period of lactation are much more potent than the food in fixing its composition.

In discussing this topic, it must be confessed first of all that the experiments touching its several phases have not furnished information satisfactorily definite and conclusive in all respects. The testimony arrived at is more or less confusing and contradictory. There are several directions in which it has been necessary to look for the effect of food upon milk: (1) Effect upon composition: (a) in changing the proportion of water and total solid matter; $(b)$ in changing the relative proportions of proteids, fat and sugar; $(c)$ in changing the constituents of the fat. (2) Effect upon flavor.

1. (a) Effect of food upon the composition of milk.In discussing the effect of food upon the proportion 
of total solids, the question is, Can the richness of milk be modified by changes in the ration? For instance, is the milk from a very generous food supply richer than that from a moderate or scanty ration, or will a highly nitrogenous ration cause a secretion of milk with a higher percentage of solids than a ration poor in protein? It would probably be generally conceded that if variations in milk are caused in these ways, they are small as compared to those due to breed characteristics or to individuality. Can we bring about variations sufficiently large to be important? This question has been much discussed and much investigated from the work of Kühn in 1868 down to the present day. Many experiments have been conducted for long periods and short periods in which very moderate rations have been compared with very large ones, highly nitrogenous foods with those of a low protein content, dry with green or succulent materials, and grains of the same class with one another, and, in a great majority of cases, the verdict has been that "no consistent relation appears to exist between the quantity or character of the ration and the composition of the milk." The writer has examined the results of nearly all the important experiments of this character of which he could find a record, and in but few cases could he discover that there was a material increase or decrease in the proportion of milk solids which bore a logical relation to variations in the ration. In some cases, a temporary change appeared in the milk immediately after a violent change in the ration, but in most instances of this kind, there was very 
soon a return to the animal's normal product. In a small proportion of experiments, the milk appeared to sustain a permanent though not extensive modification. The weight of testimony bears out the statement that the quality of milk cannot be changed at will by the farmer, but is largely determined by causes not under his control, such as breed and individuality, although feeding and treatment, especially the latter, have more or less influence upon the character of the milk secreted. It is possible, even probable, that continuous feeding either very poorly or very highly may bring about in time a permanent change in a cow's milk, but to-day no one is wise enough to point out a way of definitely controlling this product through the food.

(b) In the discussions relative to feeding dairy cows, another point has received much attention; viz., the effect of foods upon the proportions of the constituents which make up the dry matter of milk. A popular notion has prevailed that it is possible to "feed fat into milk," having its origin in part, perhaps, in misconceptions as to the manner of milk formation. If the mammary gland served simply to capture the unchanged constituents of the food, then it might be reasonable to expect the milk to partake of the character of the digested nutrients and be "fat" or "lean" according to the proportions of proteids and fats supplied to the animal. When, however, we consider that this gland has the function of transforming the raw material of the food into a milk which is characteristic of the breed or of the individual in accordance with somewhat fixed constitutional limitations, and that from 
the same food the Jersey cow will make Jersey milk and the Holstein cow Holstein milk, that a cow which starts in life giving thin milk is never transformed into a producer of rich milk, we can easily understand the general failure to find a recipe for feeding fat into milk. Experimenters who have added large quantities of fat or oil to a ration have in all but a very few instances failed to permanently or even temporarily increase the percentage of fat in the milk solids; and, on the other hand, rations rich in protein do not appear to cause a larger relative amount of proteids in the milk dry substance than rations with a wide nutritive ratio. As a matter of fact, after years of investigation and intelligent observation, we are not able to affirm that the proportion of fat to other milk solids is in any way related to the feeding of the cow, and if apparent exceptions to the general experience have been noticed, no one has discovered any general method or law whereby the exception may be made the rule. In view of our present knowledge, certainly no more absurd view prevails to-day than the belief that the composition of the milk solids is subject to the will of the man who feeds the cow.*

(c) It should not be inferred from the previous statements that none of the compounds of the food enter the milk as such, or that the qualities of the milk are in no way influenced by the character of the ration. Such conclusions would not be consistent with the outcome of numerous investigations. While it has become quite evident that the composition of butter, and therefore its qualities, such as hardness and melting

- See note. p. 323. 
point, are sometimes materially modified by the cow's food, information along this line is in a state of confusion and inadequacy, and it is not now possible to state with any definiteness just what influence the various feeding stuffs have upon the chemical and physical properties of butter. Experimenters are fairly unanimous, however, in concluding that the liberal feeding with cottonseed or cottonseed meal has the effect of raising the melting point of butter and of diminishing the percentage of the volatile fatty acids. On the other hand, when gluten meal rich in oil has been introduced into the ration in generous proportion, the butter has been found to melt at a lower point, and appeared softer. Certain chemical reactions indicate that this decrease in the melting point has been accompanied in some cases at least by an increase in olein, a fat which is a prominent constituent of olive oil, and is liquid at ordinary temperatures. One set. of experiments, where gluten meal with different proportions of oil was used, appears to warrant the conclusion that the softening of the butter from feeding this material is not marked when its percentage of fat is small, as is the case with some brands of gluten meal at the present time. The conclusion which has been reached as a result of some experiments, that gluten meal causes softer butter than corn meal, the fats and other compounds in the two feeds being similar in kind, is wholly irrational unless we conclude that the larger quantity of fat fed in the former is the cause of its specific influence. In a few cases where various oils were fed in liberal quantity the butter is re- 
ported to have varied in ways corresponding to the composition of the oils, a result not at all improbable.

In looking over the record of investigations along this line it is found that food rich in sugar and other soluble carbohydrates is credited with producing soft butter, potatoes are charged with the same effect, and even cooked or sour foods are said to have a peculiar influence. Some writers go so far as to present lists of feeding stuffs in the order in which they increase the volatile fatty acids, but such definite representations must at present be taken "with a grain of salt." In most instances, no relation is established between the effect observed and the market value of the butter. In fact, it is distinctly asserted by one or two experimenters that there is no clear relation between the melting point and hardness. It seems quite probable that when the ration includes a variety of grain foods, practically the entire list of feeding stuffs may ${ }^{\circ}$ be utilized under proper conditions without damaging the market value of the butter for local consumption.

2. Effect of food upon the flavors of milk and its products. - It is not possible with our present knowledge to establish a relation between the flavors of dairy products and the presence of definite compounds. Whatever causes flavor in milk or butter is generally present in such minute quantities that even if the nature of the substance was known the determination of its amount would be beyond the skill of the chemist. Milk satisfactory to the critical taste and smell may be so simply because bad flavors are absent, or there may be present the positive influence of some constituent of the ration. 
It is probably safe to assert that compounds in the food may pass into the milk as such, and the superiority of June butter, if such exists, may be due to the almost imponderable volatile odors which are derived from the young grasses. Nothing is more certain than that the deleterious odors of certain foods and those that pertain to the stable are often absorbed by milk, as, for instance, when cabbage, turnips and onions are fed.

It is generally believed that odors or flavors from the foods which affect milk in so marked a manner may enter it in two ways, by transference through the animal and by absorption from the air of the stable. Unfortunately, however, the various views which are accepted regarding this matter are not based upon satisfactory experimental evidence. Some farmers declare in most positive terms that they can feed turnips to their cows with no harm to the quality of the butter, while others assert that this cannot be done. It is claimed that the time of feeding, whether just before or just after milking, has a marked influence upon the extent to which turnips and similar materials impart a flavor to the milk. Concerning all these points, we have but little evidence other than the somewhat loose observations of practice.

The results of a few quite recent experiments are worthy of mention in this connection. King and Farrington, of the Wisconsin Experiment Station, declare that their experiments show beyond question that when silage is fed before cows are milked a sweetish flavor is imparted to the milk, and that such a flavor is not detected when the silage is fed after milking. These 
experimenters also placed milk within a silo exposed to the air for an hour, and silo air was forced through the contents of some cans. In seven out of twenty tests no silage odor could be detected, and it was less in any case than when silage was fed before milking.

Canadian experiments, on the effect of feeding turnips, seemed to warrant the conclusion that the mere presence of a strong turnip flavor in the stable did not affect the milk, and that when the turnips were fed in small quantity (one peck) daily no flavor was imparted, but that when one bushel or more was given the flavor appeared whether the turnips were fed before milking or after. On the other hand, in a Norwegian experiment as high as 2.8 bushels of turnips were fed to cows daily, and no turnip taste could be detected in the milk. The cows were fed in one place and milked in another, and so the experimenter concluded that when this taste is observed it is due to absorption by the milk after it is drawn. That warm milk may absorb odors is shown by Russell. These observations illustrate fairly the somewhat inclusive condition of the testimony on the points in question.

Note.-Physiological disturbances may result from feeding a ration so selected or treated that it is greatly deficient in certain nutrients. In recent experiments by Jordan, Hart and Patten, the deficiency of phosphorus compounds in the rations of milch cows appeared to cause, among other effects, a marked diminution of the proportion of fats in the milk solids. By-product feeding stuffs similarly deficient might cause a similar result. 


\section{CHAPTER XXII}

\section{FEEDING GROWING ANIMALS}

A DISCUSSION of rations for growing animals relates in large part to the uses of food for constructive purposes. The formation of bone and soft tissue proceeds rapidly in the young organism, the nutrition of which must be adapted in kind and quantity to large demands in this direction. This is true of all young domestic animals. The actual daily increase in live weight of a well-nourished calf may be as great as that of a mature steer when liberally fed. It is not unusual for the former to gain two pounds a day in weight, and 1.5 pounds is less than would be satisfactory. It is possible to calculate approximately what this growth would require of actual dry matter. The only analysis of a calf's body which is available is that made by Lawes and Gilbert, from which it appears that the entire animal when fat has approximately the following composition :

$\begin{array}{cccc}\text { Water } & \text { Ash } & \text { Protein } & \text { Fat } \\ \% & \% & \% & \% \\ 64.6 & 4.8 & 16.5 & 14.1\end{array}$

A gain of 1.5 to 2 pounds live weight means a storage of not less than .24 to .33 of a pound of dry protein in the animal's body, and the laying on, when the animal 
is fed for fattening, of .21 to .28 of a pound of actual fat. Here, then, is an actual daily increase of dry body substance of .45 to .61 of a pound, which may be equal to one-fifth or more of the total dry substance of the ration.

More definite information is furnished by the somewhat limited studies which have been made of the metabolism of the calf. As long ago as 1878 Soxhlet studied the income and outgo of three young calves fed on whole milk. One pound of milk solids, practically all digestible, produced one pound increase of live weight, which was equivalent to a storage of at least one-third pound of body dry substance, a food efficiency for growth practically ten times that exhibited with animals somewhat mature. Nearly 70 per cent of the protein of the food was fixed in the bodies of these calves, and only a small proportion was broken down, conditions quite the reverse of those which pertain to the use of food by well-grown steers. Seventytwo per cent of the phosphoric acid and 97 per cent of the lime were retained for the purposes of growth. Later experiments with calves fed on rations in whole or in part composed of skim-milk, show a deposit of from 26 to 43 per cent of the protein. These results illustrate the vigor with which a young animal assimilates food for growth, and explain the greater profits from feeding young animals as compared with feeding those more or less mature.

During recent years there has been much discussion and many experiments touching the influence of food upon the development of the animal body. Several 
experimenters, notably Sanborn and Henry, in this country, have compared the growth of swine on rations presenting extreme differences, as, for instance, middlings and blood against corn meal alone, or shorts and bran against potatoes, tallow and corn meal. As would be expected, the development of the two lots of pigs was in these cases greatly unlike. Those fed on the nitrogenous rations contained more blood than the other; their organs, 'such as the kidneys and liver, were much larger in proportion to the weight of the body, the bones were stronger and the proportion of muscle in the carcass was much greater. These differences were very marked. It should not be forgotten, however, that these were extreme and somewhat unusual rations. It is doubtful whether there are generally sufficient differences in the food combinations of ordinary practice to occasion such marked differences of body structure.

At the Cornell University Experiment Station lambs fed on oil meal and bran made a much more satisfactory gain than a lot the grain ration of which was corn meal alone, but the photographs of the carcasses do not show a larger proportionate growth of muscular tissue from the nitrogenous foods.

An elaborate study of the influence of the ration upon the composition of the carcass was made at the Maine Experiment Station, where two lots of steers were fed from calfhood on rations widely unlike in their nutritive ratio. The grain food of one lot was oil meal, wheat bran and corn meal, and of the other lot corn meal, mixed with a minimum proportion of 
wheat bran, the nutritive ratios being respectively $1: 5.2$ and 1:9.7. One animal from each lot was killed at the end of seventeen months of feeding and the others at the end of twenty-seven months, the entire bodies of the four steers, exclusive of the skins, being analyzed. It was found that the composition of the several animals did not differ materially. The amount of growth was at first more rapid with the more nitrogenous ration, but the kind of growth appeared to have been controlled by the somewhat fixed constitutional habits of the breed. Nevertheless, the evidence of all wellconducted experiments and of all experience is unanimous in emphasizing the necessity of supplying in the food of young animals an abundance of those nutrients which are needed for the building of bone and muscle. A satisfactory development of the organism at maturity is insured only when the early growth is liberal and uniform, and is such as to produce strong bone and a vigorous muscular system. More than this, there is induced by proper nourishment a lively temperament or energy of body that may be called vital force, which chemical analysis eannot search out or measure, but which gives the chief value to eertain classes of animals and is desirable in all. It is believed that this condition of strong vitality is promoted by a liberal supply of the proteids in the food.

In considering the feeding of young animals, we recognize the mother's milk as in general supplying the necessary nutrients in the best forms and proportions. It is true in the case of cows that the very rich milk of the butter breeds when generously fed 
often causes a serious disturbance of the calf's digestive organs, but the fact remains that casein, milk fat and milk sugar are adapted through Nature's design to the digestive processes and the nutrition of young animals. Moreover, milk is rich in the mineral compounds needed for bone formation. When, therefore, it becomes necessary or desirable to substitute other food for the mother's milk, it is essential not to act counter to physiological necessities and conditions.

One fact of importance is that the very young animal is somewhat undeveloped in its eapacity to digest the starchy grains and similar substances, the secretions necessary for this purpose not yet being abundant. It follows, then, that the first substitute for whole milk should not consist largely of the insoluble carbohydrates, like porridge from any of the cereals. Again, the young animal's stomach is at first unfitted for receiving and utilizing bulky, fibrous food. Some time must elapse before the calf or colt can be expected to obtain much nourishment from grass, hay or like materials.

\section{THE FEEDING OF CALVES}

The most successful way of feeding calves to secure rapid growth, especially to produce veal of the highest quality, is to supply them with the mother's milk up to the limit of their capacity. Where they are to be raised for stock purposes, satisfactory growth may be maintained with the use of substitutes for whole milk, which is fortunate, because with the exception of the western plains, where cows are cheaply kept simply 
for breeding purposes, or where a breeder is selling his increase at fancy prices, the feeding of whole milk is not warranted by the value of the resulting animal.

For this reason, most dairymen, particularly those who sell milk as such, kill the calves at the age of a few days, excepting perhaps during that portion of the year when veal sells at a very high price. On the other hand, many dairymen who have a supply of skimmed milk, successfully feed this to growing calves, when it is desired to raise heifers or even steers. Experience has shown that it is entirely practical to do this, and it is certainly economical, for experiments have demonstrated that as prices average, the cost of a pound of growth so produced is about one-third what it would be if whole milk were fed.

As a guide in providing a substitute for whole milk, it may be stated that a vigorous calf should very early be made to eat daily not less than three pounds of highly digestible matter with a nutritive ratio at first not wider than that of whole milk solids. The exclusive feeding of skimmed milk for any length of time is not to be recommended. Experience shows that for young calves it should be so combined with other materials that a mixture is obtained which, so far as possible, resembles whole milk in its nutritive ratio. After the fat is removed from the milk, the nonnitrogenous compounds are probably not present in sufficient proportion to protect the protein from waste as fuel. No feeding stuff appears to be a more efficient amendment of skimmed milk for the earliest feeding than flaxseed meal cooked into a porridge. 
The explanation of this is the high percentage of oil in this meal, its low content of starch, and its high rate of digestibility. Besides, it appears to promote a healthy condition of the organs of digestion. Oil meal may be used in its stead, but it is less desirable at first.

The calf should be allowed whole milk for a few days, not necessarily more than a week, when it may be gradually changed over to skimmed milk and flaxseed meal. An admirable mixture is prepared by cooking the flaxseed meal in water in the proportion of one to six by volume, and adding a small amount of this (the equivalent of three or four tablespoonfuls of the dry meal at first) to eighteen or twenty pounds of warm skimmed milk, which may serve as a day's ration. The quantity of meal should be gradually increased up to one pound a day inside of a few weeks. In six or eight weeks the calf should be allowed access to dry oatmeal, or oatmeal and wheat middlings, or the oatmeal and middlings may be boiled with the flaxseed meal and mixed with the milk. After ninety days the flaxseed meal may be dropped for the sake of economy. The calf will soon appreciate a wisp of early cut hay, some coarse food becoming a necessity before many months pass. This method of feeding has repeatedly produced rapid growth and fine animals. For heifers it is probably to be preferred to whole milk feeding, as it is fully as conducive to the vigorous development of the muscular system and is less likely, perhaps, to promote a tendency to lay on body fat. 
Hay tea is sometimes used as a milk substitute, but it is a poor one. Only a small proportion of the nutrients of hay is soluble, and the water extract is a dilute and comparatively innutritious food for a growing animal, the use of which can be justified only in the absence of milk in any form, and which, when used, must be very liberally fortified by grain feeds.

\section{THE FEEDING OF LAMBS}

The first growth of lambs is chiefly from the mother's milk, and we have little occasion to consider substitutes for this food. The fact first in order and most important in this connection is that well-fed mothers are absolutely essential to rapid growth. NA lamb must be fed through its dam. Nothing is more pitiable than the sight of a pair of hungry twin lambs making an effort to satisfy their insistent demands for growth with the milk furnished by a small, lean, under-fed mother. It is a repetition of the cruel command to "make bricks without straw." As a matter of fact, the treatment of the ewe before the birth of her young should be such as to prepare her for the strain of supplying a generous flow of milk.

Ewes that are suckling lambs, while fed from the barn, should be supplied with good clover or alfalfa hay, or hay from fine mixed grasses. Pea and bean straws are excellent coarse feeds for sheep. Timothy hay is an abomination as sheep food, especially under these conditions. The grain ration should not be less than three-fourths of a pound daily, made up in part 
of one or more of the highly nitrogenous feeding stuffs. It is also desirable to feed a small proportion of some succulent food. What is needed is a milk-producing ration, and the discussion of feeding cows for milk production in a preceding chapter is in part pertinent to ewes. Corn, oats, wheat bran or middlings, beans, peas, gluten and oil meals are all useful in making up such a ration. With safe feeding one pound daily of a mixture of oil or gluten meal, one part, wheat bran, two parts, and corn meal, two parts, combined with two or three pounds of roots or silage and what coarse feed the appetite will bear, is a good milk ration, and will bring the ewes through the strain of suckling lambs in good condition. If it is desired to produce the most rapid growth of the lambs, they should also have access from nearly the first to a grain mixture. Experiments indicate that this mixture is most economical, especially if the lambs are to be fed later for the market, when containing a generous proportion of corn meal, to which may be added, among other materials, ground oats, wheat bran, gluten feed or meal, or oil meal, reference being had to the ruling market prices. In an experiment at the Maine Experiment Station lambs suckled by grain-fed mothers and with access to grain themselves made 75 per cent or more gain in live weight than those did that received no grain and which were suckled by mothers that ate a limited grain ration. Five and three-fourths pounds of grain produced one pound of growth. At the Wisconsin Experiment Station, as an average of three trials, lambs fed grain before weaning gained in ten to twelve weeks 
seven and a half pounds more each than those not so fed. Four pounds of grain produced one pound of live weight.

Liberal feeding means more economical growth, a higher quality of product and the earliest possible market. The foregoing discussion is applicable to the raising of early lambs. If, however, they are dropped during the grazing season, where the ewes have abundant pasturage, the question of feeding is simplified, for no ration is more promotive of abundant milk secretion than young grass; besides, the low price at which late lambs are usually sold does not encourage extensive grain feeding. When lambs are grown for breeding stock their early grain rations should be lighter, and may properly consist more largely of oats and bran, with a smaller proportion of corn.

\section{FEEDING COLTS}

The value of a horse for either draft or road purposes is greatly dependent upon those physical qualities which secure vigor and endurance. A horse is not regarded as desirable that is devoid of "nerve" and that cannot sustain, if necessary, the strain of hard, or even severe, work; and breeders seek to produce animals having these characteristics. Two main factors are involved in the proper physical development of the colt: food and exercise. The latter is a part of the general management to which the horse breeder must give detailed attention and will not be discussed in this connection. The technics with which the 
horseman should be familiar must be learned through experience and by consulting special literature.

It is proper to state that our knowledge concerning the feeding of colts consists largely of the conclusions derived from experience of practical men. Very little experimental attention has been given to this subject by investigators. During the twenty-five years that experiment stations have existed in the United States only two stations have reported experiments along this line, and these were not extensive; but notwithstanding the lack of direct data from scientific sonrces there are well proven and safe facts to which we can refer.

Feeding the dam.-The proper feeding of the young foal is accomplished first through the proper feeding of the dam. The mare with a colt at her side should be regarded as a milch animal, making demands upon the food for generous milk production similar to those made by the milch cow. This is equivalent to the statement that when suckling her foal the dam should be given foods that stimulate milk secretion. If she is allowed the run of a good pasture both mother and colt will usually thrive satisfactorily. Young pasture grass is as efficient with the mare as with the cow. If, on the other hand, the feeding is from the stable, either wholly or to amend an insufficient or inferior food supply from grazing, then the grain ration should be made to include such feeding stuffs as barley, oats, wheat, wheat bran, wheat middlings, peas, and even a small proportion of linseed meal. Whenever soiling crops are grown these may be fed, especially alfalfa. In case the legume fodders are available, either green 
or dried, the necessity for protein in the grain is not so great and corn may form a larger proportion of the ration.

A good grain mixture for ordinary conditions would be cracked corn two parts, wheat bran seven parts and linseed meal one part; or ground oats four parts, wheat middlings five parts and linseed meal one part.

Feeding the colt.-Before the colt is weaned, with good management, he will learn to eat grain, which is very likely to be the same mixture as that eaten by the dam. If desired, an enclosure may be built, into which the colt and not the mother can pass, where a special grain food may be provided. This brings us to the consideration of what shall be the grain ration of the colt, both before and after weaning.

The opinion is generally held that oats are superior to all other feeding stuffs as horse food, particularly for the development of those qualities of temperament and muscle which are regarded as so desirable, especially in a carriage horse. It is recognized, of course, that oats are comparatively costly, but it is claimed that the superior results, whether in the kind of development of the colt or in the quality of service of the mature animal, justify their use. An opinion so universally entertained is not wisely ignored. It has been shown many times, however, that popular views have been wholly or in part erroneous, or, at least, have been based upon wrong premises; and in this particular case certain statements are currently accepted as facts which have no well-established basis.

Reference is frequently made to the tonic effect of 
oats, and there appears to be a popular notion abroad that this grain contains a peculiar compound which acts as a nerve stimulant and imparts "life" to the horse.

No chemical facts to support this view can be cited. To be sure, it was announced in 1883 that Sanson had discovered in oats a characteristic alkaloid having a stimulating effect upon the motor nerves of the horse, but subsequent elaborate investigations by Wrampelmyer failed to verify Sanson's conclusions. Notwithstanding the fact that the oat kernel has been the subject of very careful chemical studies, no chemist has yet discovered that it contains any compounds so characteristically unlike those of other grains as to account for an unusual influence upon the nervous system, or for a superior development of the muscles.

There does not appear to be on record testimony of a more convincing character concerning the stimulative influence of oats than opinions, partly traditional and partly the result of not very exact practical observations. While it is certainly not easy to present a definite and satisfactory explanation of the existence of these opinions, it may be suggested that the "life," or nervous condition, of a horse is a resultant of several factors or influences. These are the quantity of digestible food supplied, the proportion of protein in the ration, the condition of the digestive tract, care, exercise, and all the many small influences which affect health. In those instances where feeding oats has seemed to improve the performance of the horse, even if this has actually occurred, we have no assurance 
that in changing the ration the amount and proportions of the nutrients digested have remained the same. It is probable that usually comparisons have been made between oats and corn, and whenever this has been done it is not necessary to refer the better effect of the former to the existence of compounds having tonic properties. The well-known differences in the general composition of the two grains will in part account for the more satisfactory condition of the animal when the oats are fed. With the liberal feeding of corn there is a tendency towards the laying on of fat, and a greater likelihood of imperfect digestion, because of the high proportion of carbohydrates and the liability of undesirable fermentations. It seems entirely probable that if thorough comparison could be made between oats and the best grain mixtures which could be suggested in the light of present knowledge, the oats would not maintain so great a superiority over other feeds for growing colts as is now generally attributed to them. The few experiments which have been made indicate that for producing rapid growth oats were inferior to either a mixture of peas and middlings, or to a mixture of middlings, gluten meal and linseed meal; but these observations were not carried far enough to determine the relative effect upon the quality of the animal.

Whatever may be the whole truth in this matter, doubtless all necessary conditions for producing growth and quality in colts would be met by a ration of which oats form a part. The following mixtures are suggested as illustrative of good ones: 
Mixture 1

Oats ............4 parts

Bran or middlings ..4 parts

Peas...........2 parts
Mixture 2

Corn ...........2 parts

Oats...........4 parts

Bran............3 parts

Oil meal .......... part

These mixtures are generally less expensive than oats alone, and in kind fully meet the demands for growth of both bone and muscle.

Henry gives as a fair allowance of grain for a colt, measured in oats, the following quantities: Up to one year of age, two to three pounds; from one to two years, four to five pounds; from two to three years, seven to eight pounds. In using the other grain feeds suggested, which mostly have a higher rate of digestibility than oats, no larger quantities would be necessary. Skim milk may be fed to colts in limited amounts with good results, as experiments show. Feeding it in quantities sufficient to force rapid growth is to be deplored.

It is generally conceded that the colt-should be allowed to eat a reasonable proportion of coarse feed as a means of properly developing the digestive tract. It is entirely possible to supply concentrated grains too freely, to the exclusion of more bulky materials, and in that way fail to secure a desirable distension of the alimentary canal. This does not mean that the colt should be allowed to gorge himself with hay or other coarse material, as an unfortunate extreme in this direction is easily reached. 


\section{CHAPTER XXIII}

FEEDING ANIMALS FOR THE PRODUCTION OF MEAT

THE production of beef was at one time a source of income to nearly all farms. In earlier days the New England farmer annually sent to the market à few fat steers or oxen. At the present time the beef consumed in the United States and that exported comes very largely from the wide grazing areas of the west, where the cost of feed and the necessary amount of labor are at a minimum. The reasons for this change are not hard to find. The food cost of beef-making is relatively large as compared with dairy products, and in the east the growth of home markets for milk and cream has made it possible for farmers to turn their high cost feeding stuff into products having a higher proportionate market price than beef. Moreover, certain eastern lands have, with enlarging markets, been occupied to good advantage with fruit and vegetables. Doubtless the time will come, after the wide areas of the west are more densely peopled, when beef production will receive more attention in the eastern states. Some farmers find it profitable there even now. It is certain that it involves good judgment, skill and the art of feeding to the highest degree, especially if it is to secure fair returns against western competition, 
The breeding or selection of animals of the most profitable type that will supply the market with a highgrade product, and stable feeding, so as to produce rapid and continuous increase without disease or disaster of any kind, require experience and an intelligent application of all the factors involved.

THE NATURE AND EXTENT OF THE GROWTH IN BEEF PRODUCTION

Feeding steers or oxen for the market may be carried on with young animals that are still making some growth of bone and muscle, or with those so mature that additional weight comes almost wholly from a deposition of fat in the tissues already formed. This is the difference between feeding a two-year-old and a fiveyear-old steer. In either case the predominating constituent of the increase is fat. This fact is established by the investigation of Lawes and Gilbert and by one experiment in this country. Dr. Gilbert in his lectures summarizing the Rothamsted work gives the following figures:

Composition of increase when steers are fattening

$\begin{array}{llccc} & \% & \% & \% & \% \\ \text { Oxen fattened very young......... } & 32-37 & 21 / 4 & 10 & 50-55 \\ \text { Matured animals, final period } \ldots . . & 25-30 & 11 / 2 & 7-8 & 60-65\end{array}$

A merican results with well-fed steers, growth from 17 mos. to 27 mos. of age .............

These figures may be regarded as reliable, and they show most conclusively that in beef production the 
constructive use of the food is largely in the direction of fat-forming.

The extent of the actual production which occurs can be closely estimated for any given case. It is considered satisfactory if the rate of increase-during a reasonably long period of fattening is $2 \mathrm{lbs}$. live weight per day. This means the actual addition to the dry substance of the body of from 1.3 to $1.5 \mathrm{lbs}$. Sometimes during short periods with excessive feeding the daily gain may be $3 \mathrm{lbs}$. live weight, and generally after animals are well fattened, during the finishing period, it may be as low as $1 \mathrm{lb}$. or less. The actual daily growth of new material may vary then, aside from the water, from .6 to $2.25 \mathrm{lbs}$. per day. Actual fat formation may thus range from .4 to $1.8 \mathrm{lbs}$. per day. The proteid content of the increase, on the other hand, probably does not exceed $.3 \mathrm{lb}$. daily in any instance, and with mature animals it is very insignificant.

The food needs of the fattening steer. - In view of the foregoing facts and of the prevailing views as to the fat-forming function of carbohydrates, we can but conclude that the non-protein part of the ration may be the source of the chief part of the body substance laid on by a fattening steer. The amount of protein necessary for constructive work seems to be very small - with mature animals it is practically nothing. Our theoretical point of view as to the nutrients which will serve the purposes of a fattening animal is therefore quite different from what it was when eminent authorities regarded protein as the main source of body fat. It would seem, looking at the matter merely from the 
standpoint of the demands for growth, that in feeding fairly mature animals, for beef production a ration may be efficient with a wide nutritive ratio, much wider than what is recommended in the German standards.

It is recognized, though, that we cannot decide upon a ration merely upon the basis of the raw materials that are needed for constructive purposes. The influence of a particular feed or of a variety of feeds upon the appetite and upon what we speak of as general condition, as well as upon the quality of the product, and the necessity of avoiding so large a preponderance of carbohydrates as to cause a possible depression of digestibility are all points which must be considered in determining the value of a ration. We should remember also that the stimulating effect of the food upon the vital functions is a factor in successful feeding. So, after all, we must appeal to experience, scientific and practical, for information as to what rations are efficient for fattening purposes.

The German standard rations for fattening bovines which are at present recommended eall for 18 to 18.4 lbs. of digestible organic matter daily for each 1,000 lbs. of live weight, with a ratio of $1: 5.4$ to $1: 6.5$, requiring from 2.5 to $3 \mathrm{lbs}$. of digestible protein. If protein was regarded as taking a prominent part in fat-building and in. sustaining muscular activity, as was once held, this standard might seem rational, but in view of more recent scientific conclusions concerning the functions of nutrients it is not easy to understand why a fattening steer requires more protein than a milch cow or even as much. 
It is gratifying to discover that feeding experiments with fattening oxen, conducted under the improved methods of research, give results not inconsistent with the facts to which attention has been called. Kellner very ably discusses a large number of such experiments, made by himself and associates with the aid of the respiration apparatus, and he emphatically declares that the nutritive ratio of a fattening ration may vary from $1: 4$ to $1: 10$ without affecting the increase of body substance from a unit of digestible food material, provided, however, that the nutrients supplied above maintenance needs shall come from the more easily digestible feeding stuffs. He cites, in the support of his conclusion, the outcome of nineteen previous experiments by Wolff, in which rations varying in nutritive ratio from $1: 4$ to $1: 9.5$ showed no material differences in the efficiency of a unit of digestible matter. It seems, then, that scientists are coming to agree that a wide nutritive ratio is not inconsistent with most successful feeding of fattening steers, especially those that are mature. If the animals are so young as to be making material growth, then it is conceded that there is more reason for avoiding a very wide ratio.

Among the practical feeding experiments conducted in the United States, there are several instances where the wide ratio rations have been found equal to the more nitrogenous. On the other hand, and perhaps in a majority of experiments, the rations containing the largest proportion of protein have caused the most rapid growth. In 1893 the writer made a careful study 
of many previous experiments, and found that the addition of some highly nitrogenous feeding stuff to corn meal, or other home-raised grain, in most instances increased the productive power of the ration. This fact stands in apparent conflict with the more scientific conclusions to which reference has been made. The probable explanation of this discrepancy is that the rations richest in protein have generally contained the greater variety of feeding stuffs, have been more palatable, more stimulating to the appetite, and, in general, have caused a more vigorous exercise of the animal's functions. The proportion of protein has probably been a minor factor. If as great a variety of as palatable and as easily digestible materials can be fed without the use of highly nitrogenous feeding stuffs as with them, the result will doubtless be just as favorable. This means that a mixture of home-raised grains may form as efficient a ration for fairly mature fattening steers as when the oil meals or gluten meals are introduced. Palatableness, variety and ease of digestion are the main points to be secured, and these factors have been somewhat overshadowed by the effort to secure merely a definite relation of protein to carbohydrates.

It need not be feared that when mixed cereal grains are fed as the major part of the ration, there will be a materially lower rate of digestibility than when a protein food is introduced. There is still something to be said, however, in favor of adding to a fattening ration a small proportion of an oil meal, or of some material of similar character, for palatableness is thus 
promoted, and observations show, in many instances, that an appearance of greater thrift and vigor is thus induced, which is probably due to the stimulating effect of the greater amount of circulatory protein upon the metabolic processes of the animal. With young steers making some growth of bone and muscle, a small quantity of a protein food is of unquestioned advantage.

The German standard for fattening cattle is open to criticism as to the quantity of nutrients recommended for $1,000 \mathrm{lbs}$. of live weight. In order to supply 18.4 lbs. of digestible organic matter it would be necessary to feed, for instance, $8 \mathrm{lbs}$. of hay and $21.5 \mathrm{lbs}$. of an ordinary mixture of corn meal, bran and oil meal. While it may be possible to induce young steers weighing from 600 to $800 \mathrm{lbs}$. to eat at this rate for a short time, so large a ration is seldom, if ever, so profitable as a smaller one, even if it could be fed with safety. If an attempt was made, however, to apply this formula to mature steers weighing from 1,300 to $1,500 \mathrm{lbs}$. the situation would become absurd, because the ration would then be from 10.5 to $12 \mathrm{lbs}$. of hay and from 25 to $32 \mathrm{lbs}$. of mixed grains for a single animal. An appeal to concrete examples of steer feeding will clearly show the excessive requirements of the German standard for fattening cattle. In 1891 to 1893 the Kansas Agricultural Experiment Station conducted feeding experiments with three-year-old steers, and as these are good examples of practical management, the data from them will serve to illustrate the point under discussion. These data are stated in a tabular form: 


\begin{tabular}{|c|c|c|}
\hline Number of animals . & $\begin{array}{c}\text { 1st Expt. } \\
5\end{array}$ & $\begin{array}{c}2 d \text { Expt. } \\
3\end{array}$ \\
\hline Days fed............................... & 182 & 129 \\
\hline Weight per animal, average for period........... & 1,412 & 1,237 \\
\hline Hay eaten per day $\ldots \ldots \ldots \ldots \ldots \ldots \ldots \ldots \ldots \ldots$ & $7.8^{\prime \prime}$ & $6.7 “$ \\
\hline 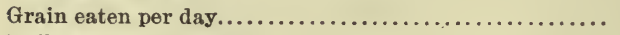 & $23.9 "$ & 23. “ \\
\hline 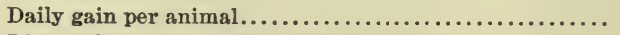 & $2.39 “$ & $2.4 “$ \\
\hline Digestible organic matter daily per animal ............ & $19.5 “$ & 19. “ \\
\hline Digestible organic matter per 1,000 lbs. live weight..... & $13.8 “$ & $15.3 “$ \\
\hline
\end{tabular}

In 1895-6 the Iowa Agricultural College fed steer calves for fourteen months, during ten of which a record was kept of all the food consumed. During the second period the steers were fattened for market. This particular experiment is cited because the animals were young and all the conditions were favorable to the maximum consumption of food in proportion to live weight:

1st period 2d period

Number of animals............................. 5

Days fed.................................... $120 \quad 181$

Age of steers at beginning........................ to $10 \mathrm{mos} .16$ to $17 \mathrm{mos}$.

Weight per animal, average for period ............. $766 \mathrm{lbs} . \quad 1,197 \mathrm{lbs}$.

Coarse food eaten daily (partly roots and green fodder). 11 " 12.8 "

Grain eaten daily (partly snapped corn) .............. $\quad 9$ " $\quad 19.5$ "

Daily gain per animal ........................... 2.04 lbs. $2.11 \mathrm{lbs}$.

Gain per $1,000 \mathrm{lbs}$. live weight...................... $\quad 2.66$ "

Digestible organic matter daily per animal.......... " 10.4

Digestible organic matter daily per 1,000 lbs. live weight. 13 . " 11.8 "

The largest amount of digestible nutrients fed daily per animal at any time during this experiment was about $\mathbf{1 7 . 5} \mathrm{lbs}$., after the animals had reached an average weight of $1,200 \mathrm{lbs}$. or over. This would be approximately $14.5 \mathrm{lbs}$. digestible organic matter per 1,000 pounds live weight.

These two experiments are instances of successful feeding where the increase was rapid and very satis- 
factory, and where the quantity of digestible nutrients supplied daily was greatly below $18 \mathrm{lbs}$. per 1,000 lbs. live weight.

Many other feeding trials might be cited in illustration of the unpractical character of the German standard, when accepted without modification.

The writer is led to conclude, from observation and a study of the results of experiments, that under proper conditions 8 to $10 \mathrm{lbs}$. of dry coarse food and 15 to $18 \mathrm{lbs}$. of grain is all that can generally be fed with greatest profit to a steer actually weighing 1,000 lbs., and may be even more than is utilized by the animal to the best advantage. Such a ration would supply about $16 \mathrm{lbs}$. of digestible organic matter. If considerably smaller steers are fed the ratio of food to weight may be increased, but if the animals are several hundred pounds heavier the ratio must be materially diminished. It is safe to accept as a general principle the rule that the larger the animal the less the proportion of food to weight. The fixing of the quantity of a fattening ration directly in proportion to the size of the animal is a simple and quite convenient rule, but is utterly impracticable, and is so recognized at present in the standards for growing animals and should be in all estimates and proportions.

\section{THE SELECTION OF A FATTENING RATION}

Two conditions already mentioned that are of the highest importance should not be forgotten; viz., that the ration should be palatable and be composed of a 
variety of easily digestible materials. Rough fodder in any quantity is not adapted to fattening bovines. With this exception, the whole list of high-class cattle foods may be regarded as available, and the selection will properly depend largely upon prices and the local supply. In the zorthern states, hays from the fine grasses and the legumes, silage, roots, cereal grain mixtures and such by-product feeding stuffs as offer digestible nutrients at the least cost will all appeal to the experienced feeder. In the south, cottonseed byproducts may, with economy, enter largely into the ration. In the west, the fodders peculiar to that region will be utilized, corn being the chief, and sometimes the only, grain that can be fed with economy. The following may be regarded as good types of mixtures for the full feeding of fattening steers weighing approximately 1,000 lbs. each at the beginning of the feeding period. They will supply-about $16 \mathrm{lbs}$. of digestible organic matter if their components are of average quality and composition:
$1\left\{\begin{array}{c}5 \text { lbs. elover hay. } \\ 16 \text { lbs. corn silage. } \\ 13 \text { lbs. corn meal. } \\ 3 \text { lbs. wheat bran. }\end{array}\right.$
$4\left\{\begin{array}{c}8 \text { lbs. alfalfa hay. } \\ 12 \text { lbs. corn meal. } \\ 5 \text { lbs. ground oats. }\end{array}\right.$
$2\left\{\begin{array}{l}10 \text { lbs. corn stover. } \\ 20 \text { lbs. mangels. } \\ 14.5 \text { lbs. corn meal. } \\ 22 \text { lbs. cottonseed meal. }\end{array}\right.$
$\left\{\begin{array}{c}5 \text { lbs. elover hay. } \\ 50 \text { lbs. beet pulp. } \\ 11 \text { lbs. cot }\end{array}\right.$
$5\{11$ lbs. corn meal.
(2 lbs. cottonseed meal.
$3\left\{\begin{array}{c}8 \text { lbs. mixed hay. } \\ 12.5 \text { lbs. corn meal. } \\ 3 \text { lbs. wheat bran. } \\ 2 \text { lbs.oil meal or gluten f'd. }\end{array}\right.$
$6\left\{\begin{array}{l}8 \mathrm{lbs} . \text { eorn stover. } \\ 12.5 \mathrm{lbs} \text {. corn meal. } \\ 20 \text { lbs. brewer's grains, wet. }\end{array}\right.$ 

2 lbs. oat straw.
75 lbs. beet pulp.
$10 \mathrm{lbs}$. beet molasses.
4 lbs. gluten meal.

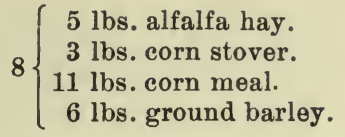

$$
9\left\{\begin{array}{l}
5 \text { lbs. mixed timothy and clover. } \\
30 \mathrm{lbs} . \text { silage. } \\
13 \mathrm{lbs} \text {. oats and peas. }
\end{array}\right.
$$

The above rations are well up to the quantity limit for the profitable feeding of animals weighing approximately 1,000 lbs. They are simply illustrative, however, both in kind and in quantity. Many mixtures equally efficient may be used, and the quantity of the ration must vary not only with the age and size of the animal but with individuals, according to appetite and capacity. Any feeder of experience will understand, of course, that such rations will be eaten with safety to the animal only after a period of preliminary feeding, during which there has been a gradual increase in the quantity of food offered.

\section{MUTTON PRODUCTION}

Attention has been called to the fact that beef production in the United States has gravitated to the extreme west. This is also true of the production of mutton, though not to the same extent. Flocks of sheep are still kept on many farms of the eastern and middle-west states, and the growth of early lambs and the fattening of maturer animals to supply the demands of the local markets is found to be most profitable by those farmers who possess the knowledge and skill requisite for this branch of stock husbandry. 
Sheep occupy a peculiar place on the farm in that they will accommodate themselves to pasturage that is not adapted to cows and horses, and will utilize some kinds of rough fodder not readily eaten by other farm animals without submitting it to somewhat expensive methods of preparation. If it were not for the discouragement which sheep husbandry has received from the depredations of dogs, sometimes real and sometimes greatly overestimated or even imagined, the production of wool and mutton would greatly increase on the hill farms of this country, with undoubted profit to eastern agriculture especially, where soil fertility needs strengthening in every possible way.

THE NATURE AND EXTENT OF THE GROWTH IN FATTENING SHEEP

The character of the animal that is fattened for mutton varies within wider extremes than in steer feeding. This is due chiefly to the greater range in maturity of the former, from the two months' lamb to the mature wether. There are corresponding differences in the nature of the increase while fattening, according as the animal is young and making growth of all parts of the body or is simply storing fat in the mature organism. The character of the body substance stored probably is also influenced by the stage in the fattening period, whether at the beginning when the animal is thin or near the end when a fat sheep is becoming fatter. The only definite data which can be presented relative to the composition of the increase of fattening 
sheep are based upon the analyses by Lawes \& Gilbert of animals in various states of fatness. These investigators analyzed a "store" sheep, a "fat" sheep and a "very fat" sheep, and from the figures thus obtained are calculated the increase in two stages of fattening:

Composition of increase of fattening sheep

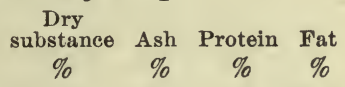

Increase from "store" to "fat" condition $\begin{array}{lllll}78 . & 2.12 & 7.16 & 68.8\end{array}$ Increase from "fat" to "very fat" condition.81.8 $3.12 \quad 7.75 \quad 70.9$

A comparison with the increase of fattening oxen shows that the sheep stores the larger proportion of fat in the dry substance laid on.

Sheep liberally fed give a larger increase per 1,000 lbs. live weight than steers. With animals weighing from 75 to $150 \mathrm{lbs}$. each the daily gain with good management may range from .2 to .5 lb. per head, or from 2 to $5 \mathrm{lbs}$. per $1,000 \mathrm{lbs}$., live weight, the increase varying according to age, conditions and liberality of feeding. Lambs will sometimes greatly exceed the above maximum. If we base our estimates upon what will occur with the maturer animals, a number of lambs or sheep weighing $1,000 \mathrm{lbs}$, perhaps seven, perhaps twice as many, will store daily .15 to $.40 \mathrm{lb}$. of protein and from 1.4 to $3.5 \mathrm{lbs}$. of fat.

\section{FOOD NEEDS OF FATTENING SHEEP}

After long-continued and careful experiments in feeding a fattening ration to mature sheep, whose composition was investigated at various stages of 
fatness, Henneberg concludes that the very sinall amount of muscle tissue laid on by such animals may be ignored. Pfeiffer reached the same conclusicn from experiments with the same class of animals. This view would not hold with lambs during their increase from weaning time to $100 \mathrm{lbs}$. in weight, for in this period there must be a material and continuons storage of nitrogenous tissue.

As is the case with steers, the demand for protein storage is seen to be small with mature fattening sheep, the constructive use of the ration being largely directed to fat formation. The more recent views of the function of the nutrients allow us to believe that, as with bovines, carbohydrates and perhaps fats play a leading part in supplying raw materials for the carcass increase. There is one point of difference between steers and sheep, however: viz., the growth of wool with the latter, that requires the use of more or less food protein.

The German standard for fattening sheep is 18.5 to $18.6 \mathrm{lbs}$. of total digestible organic matter per 1,000 lbs. live weight, 3 to $3.5 \mathrm{lbs}$. of which shall be protein, thus giving a nutritive ratio ranging from $1: 4.5$ to 1:5.4. There is little doubt that this standard calls for an unnecessarily large proportion of protein. - Neither scientific facts nor the observations of practice justify the conclusion that sheep will fatten faster when protein is so liberally supplied than when properly compounded rations with a wider nutritive ratio are fed. Doubtless more regard should be paid to the protein supply with sheep than with steers, but it is difficult to adduce a single argument for insisting upon so 
narrow a nutritive ratio with any species of fattening animal, unless it becomes incidental to an economical purchase of feeding stuffs. We may safely conclude that the resources of the farm are sufficient to supply enough protein for a ration of an efficient character for the class of animals under consideration, though we should give due recognition to the fact that, with fattening lambs especially, the protein feeding stuffs may be most efficiently utilized.

The quantity of nutrients prescribed by the published standard for fattening is practically the same per unit of weight as that given for fattening bovines. This runs contrary to common observation and the results of experiments. The standard for steers has been characterized as excessive, but this fault eannot be charged to the one for sheep, for, if anything, it is below the demands of practice. Even mature sheep about average size will consume $18.5 \mathrm{lbs}$. of digestible nutrients per 1,000 lbs. live weight, but this ratio does not meet the requirements for the prevalent intensive feeding of lambs and yearlings weighing from 75 to 125 lbs. each. It is easily demonstrable not only that sheep will utilize a proportionately larger quantity of food than bovines, but that they will make a relatively greater increase. The results of two experiments in fattening wether lambs, reported from the Iowa Agricultural College in 1896 and 1897, when compared with the outcome of steer-feeding trials, serve admirably to illustrate the correctness of this statement. The lambs were divided among seven mutton breeds. Sixty-nine were fed 90 days and 64 others were fed 107 days. 
The main facts derived from these feeding trials are as follows:

Number of animals ..................... 133

Average days fed.................... $\quad 98.2$

Total average weight of animals ...........16,400 lbs.

Average weight single animal............ 123 "

Dry matter consumed....................51,000 "،

Digestible organic matter consumed..........34,500 “

Dry matter eaten daily per 1,000 lbs. live wt. . 31.8 “

Digestible organic matter eaten daily per 1,000

lbs. live weight .................... 21.5 “

Daily gain per $1,000 \mathrm{lbs}$. live weight ........ $3.73 \mathrm{lbs}$.

Daily gain per animal................... $\quad .467$ “

The food consumption in this instance of the successful fattening of lambs is considerably in excess of the German standard; and the amount of food consumed is not unusual, though it is stated that in the latter stages of the experiments the animals were crowded to their full capacity.

If a comparison is made of this experiment with the steer feeding experiments previously eited it becomes clearly evident that the published feeding standards are not consistent in calling for practically the same quantity of nutrients for the same live weight of the two species. Sheep will consume at least onequarter more food than steers and lay on flesh proportionately faster. Moreover, sheep appear to make a larger gain in live weight than steers for each unit of nutrients consumed. It may be that the testimony of the experiments cited relative to the points under discussion is not a correct expression of the average conditions, but the differences shown are too marked 
to be accounted for by any unusual conditions pertaining to these feeding trials, and therefore indicate what may generally be expected in practice.

\section{THE SELECTION OF A RATION FOR SHEEP}

The range of feeding stuffs from which a sheep ration may be selected is wide and includes practically all home-raised fodders and grains and the whole list of by-products. It cannot be said, though, that all materials are equally desirable as sheep food. Of the fodders, those from the legumes are especially to be sought, even pea and bean straws, and among the grains corn stands preëminent as the basis of a fattening ration. Probably no feeding stuffs are more favored for mixing with corn than oats, bran and linseed meal, probably because none are more successfully used. Barley, peas, beans, gluten feed, gluten meal and cottonseed-meal have also been successfully fed to sheep. A mixed grain ration is unquestionably to be preferred to any single grain or by-product, because with the mixture greater palatableness is insured, it is possible to maintain the consumption of a larger ration, and the danger to health of heavy feeding is less. The selection of the components of the grain mixture should be governed somewhat by market prices. A supply of silage or roots is much to be desired as a part of a sheep-fattening ration, especially when heavy grain rations are to be fed during a long period, although successful feeding during a limited time is entirely possible without these.

A succulent food 
promotes appetite and health, however, and is usually economical and sometimes necessary.

Rations made up in definite quantities will not be presented in this connection. The quantity of nutrients which it is desirable to supply is so variable according to the age and maturity of the animals to be fattened that a feeding standard is applicable to only one set of conditions not long maintained and therefore it must be freely and frequently modified according to the judgment of the feeder. It is, nevertheless, possible to offer practical suggestion as to the proportions of grains in the mixtures that will be found acceptable and as to the kinds and quantities of coarse foods ordinarily utilized.

In the Iowa experiments cited in this connection the grains used were corn, oats, bran and linseed meal. In the last of these trials the grain ration for fifteen days at first was made up of corn, oats and bran in the proportions 2,2 and 1 . When the feeding was well established the grains were oats, corn, bran and oil meal, the relation in quantity being $8,8,2$ and 1 respectively. Each animal ate about 1 pound of roots daily and about two-thirds as much hay as grain. The lambs were fed up to the full ration very gradually, several weeks being occupied in doing this. For such preparatory feeding bran and oats are especially useful. When these tests began, each animal ate from one and a half to two pounds of grain daily, which quantity was increased later to three pounds with the largest eaters, some individuals not taking over two. The conduct of these feeding trials typifies good prac- 
tice, both as to materials and management, and may serve as a guide in handling other similar feeding stuffs.

It is undoubtedly possible to feed sheep with equal success without the use of purchased grains, especially on farms where clover or alfalfa, roots, corn, oats, or oats and peas are produced. We are not justified by experimental results in concluding that bran and oil meal or any other by-product feeds are essential to the highest success in fattening sheep, although these feeding stuffs are very useful for this purpose. A mixed grain ration is always better than any single grain fed alone.

Instances are on record of a successful combination of green forage crops with grain in fattening sheep. The legume fodders and rape may be fed profitably in the green state with the usual grain mixtures, care being taken to avoid indigestion from excessive eating of the green material.

Grain in connection with ordinary pasturage is a successful method of fattening sheep or lambs for the fall market.

\section{PORK PRODUCTION}

The feeding of swine is a matter of almost universal interest to farmers. Even in the older portions of the east a few animals of this class are kept on nearly every farm. Swine are well adapted to the disposal of certain wastes, particularly those from the table and the dairy. They are especially useful as a means of profitably converting dairy by-products into a marketable form, and, moreover, during the past 
twenty-five years pork production has offered more encouraging inducements to the home consumption of grain than has beef production.

Within recent years there has been a great change in the methods of pig feeding and in the character of the animal when placed upon the market. This is emphatically true of the eastern and middle states, where pork is grown wholly for local consumption. Formerly good feeders were not supposed to slaughter a pig under three hundred pounds carcass weight, and many animals dressed four hundred pounds when taken to the market, this size being secured only after a feeding period of twelve to eighteen months. Pork of this character was regarded as well adapted to packing. At the present time the demand of the local markets is for small carcasses weighing not over one hundred and fifty pounds, and supplying the maximum proportion of lean cuts. This change is in the direction of greater profits for the farmer, as he has learned, because the food expenditure required for the production of small carcasses is much less per unit of weight than under the old system, when the feeding was continued during a longer period. Pigs properly fed are now wisely turned off at the age of a few months, excepting, perhaps, in those localities where a slow early growth is cheaply secured on pasturage.

CHARACTER OF THE GROWTH IN PORK PRODUCTION

The modern hog is emphatically a fat-producing organism, having a capacity in this particular greatly 
surpassing any other species of domestic animal. The dry matter of the carcasses of individual animals has been found to consist of over 80 per cent of fat, even after the leaf-lard was removed, and the average proportion in the dry substance of eight dressed pigs, representing six breeds, was found by Wiley to be 78 per cent.

The statement of the composition of a Berkshire pig and of a Duroc-Jersey will be found interesting in this connection :

Composition of the entire dressed animal, head, leaf-lard and kidneys removed. Wiley.

\begin{tabular}{|c|c|c|c|c|c|c|}
\hline & $\begin{array}{l}\text { Weight } \\
\text { carcass } \\
\text { lbs. }\end{array}$ & $\begin{array}{l}\text { Water } \\
\%\end{array}$ & $\begin{array}{c}\text { Dry } \\
\text { substance } \\
\%\end{array}$ & Ash & $\begin{array}{l}\text { Protein } \\
\%\end{array}$ & $\begin{array}{c}\text { Fat } \\
\%\end{array}$ \\
\hline Berkshire............ & 129 & 43.1 & 56.9 & 2.6 & 13. & 40.5 \\
\hline Duroc-Jersey......... & 149 & 30.6 & 69.4 & 1.8 & 9. & 57.7 \\
\hline $\begin{array}{l}\text { Fat pig, entire animal } \\
\text { (Lawes \& Gilbert).. }\end{array}$ & & 43.9 & 56.1 & 1.9 & 11.9 & 2.3 \\
\hline
\end{tabular}

It appears that there was stored in the part of the animal analyzed by Wiley only 13 pounds of protein with the Duroc-Jersey and about 17 pounds with the Berkshire, the quantities of fat being 52 pounds and 86 pounds, respectively. The figures for the entire animal, as analyzed by Lawes and Gilbert, are at the rate of 23.8 pounds protein and 84.6 pounds fat, in a pig weighing 200 pounds.

These proportions bring out sharply the character of the growth with swine. It is to be noted that in no other species, very fat sheep possibly excepted, does the body consist so largely of dry matter, which means that the increase of a unit of live weight in- 
volves the storage of more food substance than with other domestic animals. The data at our command warrant the statement, in a general way, that when a pig gains $1.5 \mathrm{lbs}$. daily in live weight he stores not less than $.84 \mathrm{lb}$. of dry substance, of which $.18 \mathrm{lb}$. is protein and $.63 \mathrm{lb}$. is fat, these figures representing the average growth during the life of the animal.

Lawes and Gilbert estimate that the increase of pigs while fattening has the following composition:

$\begin{array}{ccccc}\text { Water } & \text { Dry substance } & \text { Ash } & \text { Protein } & \text { Fat } \\ 22 \% & 78 \% & .10 \% & 6.4 \% & 71.5 \%\end{array}$

According to these figures the protein storage, with $1.5 \mathrm{lbs}$. daily gain, would be only $.10 \mathrm{lb}$. and the fat $1.07 \mathrm{lbs}$.

FOOD REQUIREMENTS FOR PORK PRODUCTION

Feeding the dam.-Under a system of intensive production pigs go to market so young that we may properly discuss their feeding from birth. We deal first with the mother as a milch animal. According to observations by Henry, in an inquiry as to the yield and composition of sow's milk, it seems probable that in proportion to their weight small sows yield as large a quantity of milk solids daily as a good cow. The average daily production of milk solids per animal appeared to be about one pound. This would be four pounds for four sows, which is the equivalent of the solids in over thirty pounds of cow's milk of average quality. It follows, therefore, that the demands upon 
the food for milk formation are proportionally as heavy with swine as with cows, and consequently the ration should be one that will stimulate and sustain abundant milk secretion. Such feeding is not only necessary, but economical, for independent experiments indicate that the food cost of the growth of pigs before weaning is no greater than it is after weaning.

Skimmed milk or buttermilk combined with a mixture of wheat middlings and any of the ground cereal grains, barley, oats or corn, cannot be improved upon as food for milch sows. The feeding should be liberal, quite up to the limits of capacity, and even then the dam suckling a large litter of young will grow thin.

Feeding pigs for the market.-If we merely consider the nature of the body substance of swine in its relation to the constructive functions of the nutrients, it would not be unreasonable to believe that rations with a wide nutritive ratio are adapted to the needs of this class of animals for growth. In a certain sense, practice ratifies this view. Thousands of fat hogs have been the product of almost exclusive corn feeding, especially during the later stages of growth. There is no doubt but that large size and an excessively fat condition may be secured through a liberal supply of carbohydrate material, but such one-sided nutrition is not now regarded as being adapted to the physiological requirements of the pig or as producing pork which meets the existing demands of the market.

It is doubtful if any other species of domestic animal has been the subject of so much abuse through improper feeding, combined with an unhealthful en- 
vironment, as has the pig. We now regard the abnormal masses of porcine fat which have heretofore appeared in our markets as not only an exhibition of physical monstrosities, but as not serving the health interests of the human family.

The primary object in feeding pigs should be, as with all domestic animals, the securing of a normal and vigorous physiological development, i. e., an organism with a strong bony structure and with such a growth of muscular tissue as shall insure full exercise of all the vital functions. The view seems to have prevailed, in a practical way at least, that pigs can be fed on anything, live and sleep anywhere and still not suffer ill effects, as.would be the case with the other farm animals. This has been unfortunate, because probably no other domestic species is so susceptible to abnormal development through improper feeding as are swine. It is true, at least, that no other species has shown so marked a response to changes in the character of the rations, through modifications of the bony structure and through variations in the proportions of muscle and fat tissue.

Notable proof of the plasticity of the pig's organism was supplied by the experiments of Sanborn and Henry in comparing rations extremely nitrogenous with those extremely carbohydrate in character. Pigs fed liberally on blood, milk and shorts combined with more or less corn meal, made growth more rapidly, had stronger bones, larger organs and more muscular tissue than those fed on corn meal or a mixture of corn meal with other highly non-nitrogenous materials, 
such as potatoes and tallow. The latter combination was deficient both in protein and in bone-forming compounds. Such marked differences are not usually seen, because rations are not generally so extremely one-sided. These experiments teach the lesson, though, that as much eare should be exercised in choosing the pig's ration as the cow's.

Experimental observations demonstrate that the pig's ration should be selected with reference to supplying an abundance of bone-making material and a reasonably large proportion of protein. Evidence is not wanting that the feeding of wood ashes and ground bone to growing pigs promotes both a normal development of the bony framework and a more liberal consumption of food. Animals that are grazing may not need to have the ration so supplemented, but it is wise and even necessary with those confined in pens.

In selecting foods for the production of small pork where the development of all forms of tissue is taking place, first rank must be given to the dairy wastes. As a means of promoting rapid growth and a condition of health and vigor, and also as a supplement to cereal grain products, skim-milk and buttermilk are not excelled, and perhaps not equaled, by any other feeding stuffs. In order to secure the maximum result from a given quantity of dairy wastes, they should be fed in eombination with grain products. When this is done, and the proportions of skim-milk or buttermilk and grain are what they should be, it appears to require less digestible food substance for a pound of growth than when grain is fed alone or when the 
liquid food is largely eaten. In other words, dairy wastes are not only efficient in themselves in producing growth, but in proper combination they cause a saving of the grain products necessary to secure a given ratio of gain. Henry states, on the basis of eight feeding trials involving the use of ninety pigs, that $462 \mathrm{lbs}$. of skimmed milk effected a saving of $100 \mathrm{lbs}$. of corn meal. This means that $46.2 \mathrm{lbs}$. of digestible milk solids, when combined with corn meal, saved, approximately, $76 \mathrm{lbs}$. of digestible corn meal substance.

Henry's experiments were arranged so as to gain information as to the most desirable proportion of milk and meal, and from his data the writer has calculated the quantity of digestible nutrients required in each combination for one pound of growth:

Digestible matter required for $1 \mathrm{lb}$. of gain

Combination

lbs.

Mixed grains alone $\ldots \ldots \ldots \ldots \ldots \ldots \ldots . . .6$

$1 \mathrm{lb}$. corn meal to $1-3 \mathrm{lbs}$. skim-milk ....... 3 .

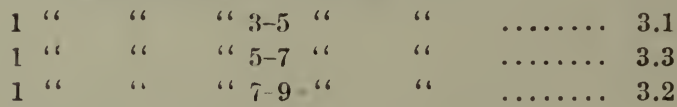

These results show the greatest food efficiency with the minimum proportion of skim-milk. Other experiments, notably those by Linfield and Robertson, give similar testimony. With the former, in seven experiments, a milk and grain ration produced $1 \mathrm{lb}$. of gain for each $2.58 \mathrm{lbs}$. of digestible matter, the requirement with milk alone being $2.85 \mathrm{lbs}$. and with grain alone $3.19 \mathrm{lbs}$. When $2 \mathrm{lbs}$. of skim-milk was fed with $1 \mathrm{lb}$. of grain, $100 \mathrm{lbs}$. of the milk replaced $31 \mathrm{lbs}$. 
of grain, but when the milk and grain were as 4 to $1,100 \mathrm{lbs}$. of milk only replaced $24 \mathrm{lbs}$. of grain.

Doubtless with pigs in the earliest stages of growth after weaning, the proportion of milk to grain may well be larger than in the more mature periods, and in any case the ratio will naturally depend somewhat on the relative supply of the milk and grains.

In the absence of dairy wastes, meat meal, dried blood and fish scraps may be used to supplement the grain products or a mixture of the more nitrogenous feeding stuffs with corn and barley will be found greatly superior to the corn or barley alone. Milk is more efficient with young pigs than the grain feeds rich in protein, but in the maturer periods the digestible matter of certain of the latter seems to have a value not greatly, if any, below that of skim-milk solids.

The protein feeds adapted to pigs are gluten meal, gluten feed, buckwheat middlings, brewer's wastes, peas and middlings. The oil meals, excepting in small quantities, affect the health of swine unfavorably, and wheat bran is inferior to middlings.

Of the carbohydrate foods, oats, barley, wheat, rice products, and especially corn, are all useful. Although the excessive corn feeding of swine is to be deplored, this grain is second in value to no other in the pig's ration, and only needs to be reinforced with more nitrogenous feeds in order to find a safe and profitable use. In the later stages of growth or fattening it may well form the major part of the ration. Probably no combination has been found more satisfactory for all around use than skim-milk, 
wheat middlings and corn meal, the latter constituting the larger proportion of the grain food.

At the present time much attention is given to forage crops for swine. Clover, alfalfa, rape, sorghum, rye and ordinary pasturage have all been found to be adapted to hogs. When fed with grain, economical and satisfactory production is secured. When fed alone the growth is so slow as to be unsatisfactory. In two experiments at the Wisconsin Experiment Station, one acre of rape, when combined with grain, proved to be equal to $2,767 \mathrm{lbs}$. of corn and shorts. Other observations show beyond question that such feeding is practicable and under some conditions profitable. Better results seem to follow when the pigs are allowed to graze than when the fodder crop is cut and fed to animals confined in pens. 


\section{CHAPTER XXIV}

\section{FEEDING WORKING ANIMALS}

THE working animals now in use in the United States are chiefly horses and mules. Oxen were once employed extensively for farm labor and in lumbering, but these are rarely seen under the yoke at the present time, except in remote rural districts. It will be proper, therefore, to treat in this connection chiefly of horses that are used for draft and road purposes.

The horse a machine.-In feeding a working animal the essential product of the food is energy to be used in drawing, walking or trotting. The latent food energy is made available, as heretofore stated, by the oxidation of the several nutrients into the ordinary products of combustion, and the units of heat or work or other forms of kinetic energy evolved are directly proportional to the quantity of digested food which suffers combustion, just as the possible work of a steam engine under given conditions is proportional to the fuel consumption in the boiler. The establishment of fundamental relations between food and work requires on the one hand an understanding of the energy values of food, and on the other hand at least a general conception of the amount of work performed. The energy values of food have been considered and 
it now remains for us to ascertain what is known concerning energy consumption by a laboring animal.

The work performed by a horse.-The labor performed by a draft or road animal, exclusive of the energy required for maintenance, may be regarded as consisting of two components; viz., the effort of moving the load and that of moving the animal's body. If a horse weighing $1,000 \mathrm{lbs}$. draws one mile a wagon which, with its load, weighs $1,500 \mathrm{lbs}$, $2,500 \mathrm{lbs}$. of matter have been moved through the distance traveled. In other words, a horse moves himself and his load, whether the load is drawn on a wagon or is loaded on his back.

The exact expenditure of energy involved in both of these components cannot be measured directly. The work of drawing a load may be determined by the use of a dynamometer, but it can only be estimated so far as the body of the horse is concerned. If the latter factor could be calculated on the basis of simply projecting a mass of matter through the space traveled it would be a comparatively simple problem. There is a vertical motion of the horse's body to be accounted for, as well as a horizontal, and the reduction of both to units of work is a difficult matter. If this conld be done, our present knowledge of the food energy necessary for the performance of a unit of mechanical labor would allow quite definite calculations of the daily food needs of horses of different classes. As a matter of fact, the actual work accomplished by laboring animals has been to quite an extent a matter of estimation, and still is. 
Chardin, a French army veterinarian, estimates that the average daily work performed is about 2,580 foot tons. Lavalard calculates that the total ordinary work of an army horse equals 8,500 foot tons. As stated by Armsby, the ordinary day's work of a horse is estimated at 1,500,000 kilogram meters, or 5,425 foot tons, this evidently meaning the mechanical labor outside the motion of the body. With the knowledge we now possess it is possible to estimate approximately the actual work performed in a given case.

It would be a good day's labor if a 1,000-lb. horse travels twenty miles over a smooth, level, dirt road hauling a wagon with a load of $2,000 \mathrm{lbs}$. The draft of the loaded wagon would be not far from $100 \mathrm{lbs}$. A simple calculation shows that the mere moving of such a load the distance of one mile would be equivalent to 264 foot tons. The energy expenditure in walking a given distance has been measured by Zuntz, who ascertained the difference in oxygen consumption of a horse when at rest and when traveling at a walk over a level road. According to these measurements, it appears that a 1,000-lb. horse in walking one mile at the rate of two to three miles per hour would expend a total energy of 473 foot tons, 44.4 per cent or 201 foot tons of which belong to the effort of walking over and above the energy needed for mere maintenance. In the case assumed, a horse would perform a total labor in walking and drawing twenty miles equivalent to lifting 9,300 tons through a space of one foot. This estimate is presented merely as an approximation of the work done under given conditions. 
These figures are, perhaps, less important to the owner of work or driving horses than is a knowledge of the influence of speed upon the labor expended in a unit of time. "According to Marcey, the work accomplished in a given time is proportionate to the square of the velocity. His coefficients were 3.42 for walking or pacing, 16 for trotting, 28.62 for cantering, and 68.39 for a full gallop." This general fact would be applicable to horses under all conditions of labor. Moreover, it is clearly demonstrated by two investigators that the food energy required for a unit of work increases with the speed. In other words, a horse that trots 20 miles a day must have more food than when he walks the 20 miles. In the same way draft animals require food somewhat in proportion to the pace with which they travel over a given distance. Grandeau has shown that a horse was kept in condition with $19.4 \mathrm{lbs}$. of hay when he walked $12 \frac{1}{2}$ miles, but $24 \mathrm{lbs}$. was insufficient when he trotted the same distance. Zuntz measured the oxygen used per meter kilogram when a loaded horse traveled at different velocities. When the pace was three miles per hour, with a load of $275 \mathrm{lbs}$., the energy required was equal to 4,600 calories for each kilogram meter of horse, which increased to 7,753 calories when the speed reached $6 \frac{1}{3}$ to $7 \frac{1}{2}$ miles per hour. The food needed per unit of work increased nearly 70 per cent in increasing the speed from 3 miles to 7 miles. Zuntz shows that if a horse exerts himself to the utmost the use of oxygen rises at a rapid rate, and that the food consumed per unit of work is nearly one-half more than with ordinary 
draft. It appears to be a rule that as the intensity of exertion of the horse increases the food cost of a given amount of labor performed increases. Men of experience recognize this fact in a general way when they insist on favoring their animals to the slowest pace that is consistent with the conditions involved.

The food requirements of a working horse. - There are two general ways of ascertaining the food needs of a working horse, by practical experiments in which the rations are varied until a conclusion is reached as to what will support an animal under given conditions, and by determining through scientific investigations the amount of work performed in various ways and the relation of a unit of food to a unit of work. It would not be far from the truth to state, however, that the feeding standards which are offered to us through investigations made by Boussingault, Wolff, LeClere, Grandeau, Hoffmeister, Lavalard, Zuntz, Kellner, and others, are the outgrowth of both practical observations and scientific research, a most desirable combination. In a large number of instances the kind and quantities of digestible food consumed daily by working horses have been determined, and in many cases the accompanying wastes and gain and loss of the animal body have been measured.

The standard rations now found in German tables are the result of such observations. According to these standards a 1,000-pound horse requires $11.4 \mathrm{lbs}$. of digestible food daily when doing moderate work, $13.6 \mathrm{lbs}$. for average work, and $16.6 \mathrm{lbs}$. for heavy work. With a basal ration of $10 \mathrm{lbs}$. of hay the grain 
needed to furnish these quantities of digestible nutrients, when consisting of a mixture in equal parts of corn and oats would be approximately $11.5 \mathrm{lbs} ., 15$ lbs., and 2) lbs. for the three conditions of labor. Lavalard, who made observations covering a period of a number of years for 32,000 omnibus, army, and draft horses, has reached the conclusion that "a horse performing ordinary work requires 115 grams of digestible protein and 1,100 grams of digestible carbohydrates per 100 kilograms live weight." This is at the rate of $1.215 \mathrm{lbs}$. of digestible uutrients per $100 \mathrm{lbs}$. of live weight. This observer bases the ration upon the weight of the animal, but practically concedes that "somewhat larger amounts of protein and carbohydrates are considered necessary with small horses," a conclusion which is entirely consistent with observation and related facts. Lavalard's formula would furnish a 1,000-pound horse, doing ordinary work, with $12.1 \mathrm{lbs}$. of digestible nutrients daily, a quantity not inconsistent with the German standard.

It seems to the writer that the results of the masterly and extensive metabolism investigations which Zuntz has carried on with a horse under various conditions may properly be cited in this connection. This investigator determined the oxygen consumption, which is equivalent to ascertaining the food use, by a horse at rest, when walking on a smooth level without load, and when performing both light and heavy work. First of all, it appears from his observations that 31.6 per cent, or about one-third, of the total food energy can be converted into useful work. This is much less 
than the coefficient of useful work found by Wolff, whose conclusions Zuntz regards as erroneous. But even if Zuntz's figures are none too low, it is evident that the animal machine uses fuel with much greater economy than a steam engine where the coefficient of usefulness might not be over 10 per cent. The figures he reached show further that the total expenditure of energy by a horse weighing 1,000 pounds in walking one mile equaled 453 foot tons, which would be furnished by $164 \mathrm{lb}$. of digestible food. As 44.4 per cent of this, or 201 foot tons, was due to the effort of walking over and above the needs for maintenance, the extra digestible food needed per mile of walking was $.07216 \mathrm{lb}$.

Zuntz also found that when a horse increases the external mechanical labor performed such increase costs $.001155 \mathrm{lb}$. digestible dry matter for each foot ton of work. On this basis the 264 foot tons of energy which is needed for pulling one mile a load with a draft of $100 \mathrm{lbs}$. would be furnished by .3049 lb. of food matter. The total food expenditure, therefore, for walking and a draft of $100 \mathrm{lbs}$. over a smooth, level road for one mile, would be $.377 \mathrm{lb}$. digestible nutrients, and for twenty miles $7.54 \mathrm{lbs}$. If we add to this the $6.4 \mathrm{lbs}$. needed for mere maintenance, we have $13.94 \mathrm{lbs}$. digestible matter as the proper ration for a horse doing the work stated for a distance of 20 miles. These figures are certainly not inconsistent with the standard reached by other methods for a horse doing average work. Such a calculation is at least useful in showing the direct relation of food expenditure to 
work performed, and the necessity of feeding a laboring animal somewhat proportionately to what he does. It should be borne in mind constantly that when the intensity of effort of the horse increases, even if only the same work is performed in a shorter time, the food needs per unit of work are greater. If a driver in making the regular number of trips to the railroad station needlessly hurries his horse, or if a drayman whips his team into a fast walk and then lets it stand idle, more food must be consumed than if the slowest possible gait was allowed.

Source of the ration for working horses. - In treating of this matter we must, in the first place, consider the digestive apparatus or storage capacity of the horse. It is certainly not adapted to the consumption of large quantities of coarse food, as is the case with ruminants. If a horse at severe labor needed $17.7 \mathrm{lbs}$. of digestible dry matter per day, he could get it from hay only by eating over $40 \mathrm{lbs}$. - a most absurd requirement. It is especially necessary, therefore, with hard-working animals, that the larger part of their nutriment come from the concentrated feeding stuffs. Ten to $12 \mathrm{lbs}$. of hay is all a draft horse should consume in one day. Working horses on the farm generally eat too much coarse fodder.

The net values of feeding stuffs are also important in this connection. It has been shown that the net energy value of a unit of digestible matter from dry hay is less than with that from the grains, and consequently when it is necessary to supply an animal with a large amount of energy for external mechanical uses, 
requiring high feeding, we must resort to the grains in order to construct a ration of maximum efficiency.

Concerning the nutritive ratio or proportion of protein, in a ration designed for working horses, there is a variety of recommendations. The German standards call for ratios from 1:7 to $1: 6$, according to the severity of labor, the daily weight of protein for a 1,000 -pound horse to be from 1.5 to $2.5 \mathrm{lbs}$. This is greatly more protein than is recommended by Lavalard, who, on the basis of extensive experience, declares that $1.15 \mathrm{lbs}$. of protein daily is sufficient for ordinary work, this to be increased to $1.35 \mathrm{lbs}$. when the labor becomes more severe. There is one fundamental fact that is pertinent to a discussion of this point, which is that the nonnitrogenous constituents of the ration are largely the source of muscular power. As stated before, it was formerly thought that muscular effort was sustained at the expense of muscular tissue, but when it was found that no more urea was excreted by men climbing a mountain than when they were much less active, this view was abandoned. Later researches have clearly shown that when work increases the excretion of carbon dioxid increases in like proportion, without any important rise in the protein exchange. In other words, the carbohydrates and fats are largely the fuel that supplies energy for mechanical purposes. Common experience ratifies this conclusion of science. How many horses and oxen have successfully endured severe labor on meadow hay, oats and corn, sometimes the grain being largely the latter!

It is the judgment of the writer that a ration prop- 
erly compounded from ordinary farm products, such as silage, roots, meadow hay, legume hays and the cereal grains, will generally contain protein in sufficient proportion, and will seldom need reinforcing with the nitrogenous feeding stuffs. It is probably true, however, that when working animals are called upon to endure a severe strain material advantage is gained from introducing into the ration a small quantity of some nitrogenous feeding stuff, such as beans or oil meal.

One of the opinions regarding the feeding of horses which has widely prevailed and which is still held by many is that oats in liberal proportions are essential to the successful maintenance of road and work horses, especially the former. It has been believed, as has been stated, that this grain imparts to the horse greater nervous activity or life than any other feeding stuff, and when it was announced that "avenine," an alkaloid, had been extracted from oats, this was quickly accepted as an explanation of their peculiar effect. We have given up the avenine and seem likely to modify our views in other ways, for it is becoming increasingly evident that other grains may be substituted for oats with no detriment to the horse and with a material saving to his owner. Barley, brewer's grains, maize, maize cake, wheat, wheat bran, wheat middlings, have been extensively and safely fed in the place of oats, wholly or in part, by experiment stations and in practice by omnibus and horse-car companies. In this way the cost of maintaining horse labor is materially decreased, for usually oats are comparatively much more expensive than other grains and the by-products in pro- 
portion to their feeding value. Unless prices change, a farmer can generally afford to sell a part of the oats he raises and buy other grains, and he can do this with confidence that he will be able to maintain his road and working horses in proper flesh, and good health and spirit, on the cheaper materials.

As a suggestion to feeders concerning the ways in which several feeding stuffs may be combined so as to furnish practically the same quantity of digestible organic matter, the following rations are presented as meeting the needs of a horse weighing 1,000 lbs. and doing moderate work:

$\left\{\begin{array}{l}10 \mathrm{lbs} \text {. timothy or mixed hay. } \\ 11 \frac{1}{2} \text { lbs. oats. }\end{array}\right.$

$\left\{\begin{array}{l}10 \text { lbs. hay. } \\ 5 \text { lbs. corn. } \\ 4 \frac{1}{2} \text { lbs. barley. }\end{array}\right.$

$\{10$ lbs. hay.

$\left\{10 \frac{1}{2} \mathrm{lbs}\right.$. oats and corn, equal parts by weight.

$\left\{\begin{array}{l}10 \mathrm{lbs} . \text { hay. } \\ 10^{1 / 2} \text { lbs. oats and barley, } \\ \text { equal parts by weight. }\end{array}\right.$

$\left\{\begin{array}{l}10 \text { lbs. hay. } \\ 8 \text { lbs. oats. } \\ 4 \text { lbs. brewer's grains. }\end{array}\right.$

$\left\{\begin{array}{r}10 \text { lbs. hay. } \\ 5 \text { lbs. corn }\end{array}\right.$

$6 \frac{1}{2} \mathrm{lbs}$. wheat bran.

$\left\{\begin{array}{l}10 \text { lbs. hay. } \\ 5 \text { lbs. corn. } \\ 6 \text { lbs. brewer's grains. }\end{array}\right.$

$\left\{\begin{array}{l}10 \text { lbs. hay. } \\ 41 / 2 \text { lbs. barley. } \\ 4 \text { lbs. wheat bran. } \\ 3 \text { lbs. brewer's grains. }\end{array}\right.$

$\int 10$ lbs. hay.

$\{8$ lbs. oats.

( 4 lbs. wheat bran.

$\left\{\begin{array}{l}10 \mathrm{lbs} . \text { hay. } \\ 3 \frac{1}{2} \mathrm{lbs} . \text { corn. } \\ 4 \mathrm{lbs} . \text { wheat bran. } \\ 4 \mathrm{lbs} . \text { brewer's grains. }\end{array}\right.$

Silage, roots and other green materials may often be substituted for a minor part of the hay with advantage to the animal's appetite and health. 
No definite rations are suggested for more severe labor. The amount of food must simply be increased with the amount of work performed. Any increase should apply to the grain and not to the hay, the proportions of the several feeding stuffs in the grain ration to remain the same in the larger quantity. It, is well understood, of course, that a ration should increase proportionately faster than the amount of work done, and that an old animal generally demands higher feeding than does a young one. The condition of the road, the intensity of the effort and other circumstances also modify the needs of the working horse, so that the feeder is always called upon to exercise the trained judgment which comes from experience. No working animal can be fed successfully by mechanical rules. 


\section{CHAPTER XXV}

\section{THE FEEDING OF POULTRY}

BY William P. WHEELER

ONE pronounced characteristic of birds is an intense vitality. Their life is never sluggish. The growth of the young and the transformation of food into eggs are exceedingly rapid. The temperature is high, running with certain species from a little above $100^{\circ} \mathrm{F}$. to $112^{\circ}$ or more. The energy expended in this direction is proportionately great, and material for its supply is in urgent demand; for a vigorous animal is the seat of rapid metabolic ehange. The large appetite is an indication of the extensive needs. The very active digestive apparatus must be in good order and supplied with efficient food.

The domestic fowls may be classed with the majority of birds as omnivorous. While seed-eaters like the common fowl are able to subsist for long periods on grain alone, as can also the goose by grazing, the natural food of most young birds is largely animal. Many wild birds which feed almost entirely on seeds supply their rapidly-growing young with an abundance of animal food.

Kinds of foods.-It is a common experience that better success follows the use of several foods com- 
bined rather than a few, and it seems to be a fact that some variety is essential. While in practice a combination must be employed for best results which are partly due to the usually greater palatability and other indirect effects on the general health, it is not because of a greater nutritive value of the constituents from different sources that the different foods are needed. The important consideration seems to be the proportion of constituents. In experiments made at the New York Agricultural Experiment Station, the better results from rations containing animal food were found to be largely due to the greater amount of mineral matter, chiefly phosphate of lime, in the animal food used. When rations of grains naturally lacking in ash content were supplemented by bone ash, their efficiency was increased without addition of other food. For chicks during the periods of most rapid growth the rations of vegetable origin supplemented by material rich in phosphate of lime were equal or even superior to rations supplying large quantities of animal protein and fat. For laying hens the time during which such rations were equally efficient was limited to a few months. Rations containing animal food were much superior for ducklings, although the addition of bone ash to rations of grain and other vegetable food notably increased their efficiency.

Although it is possible, for some purposes, to compound effective rations from grain alone when the deficiency of ash is made good, it is better in practice to use some animal food. A variety of grain food supplying enough nitrogenous matter is not always to 
be found, and animal foods, when rich in protein as most of them are, prove of great service; for with them can be freely fed some of the cheaper, starchy foods, typical among which is the palatable and remarkably efficient Indian corn. For fattening mature fowls animal food is not so important except when its use improves the palatability of the ration. This last is a matter always to be considered.

Succulent vegetable foods are eagerly eaten by domestic fowls. Aside from the beneficial effect on the health of the birds, it is important to use such foods so far as possible, for the nutriment they supply is cheaply obtained. With most rations the more nitrogenous fodders, such as clover, alfalfa, and very immature grasses, are best. These foods also contain more of the needed lime than do grains. It must be remembered, however, that fowls are not fitted to depend largely on such bulky materials while production is rapid. The goose is better adapted than most birds to live by grazing, but the liberal use of the more concentrated grain and animal foods has been found necessary except during the idle season.

At the time of greatest egg production the choice of bulky foods should preferably be confined to those of the most tender and succulent nature. Certain experiments also indicate that a ration which contains any considerable proportion of dry or woody coarse fodder, although finely ground, is not suited to young chicks, and that only the more succulent kinds of bulky foods, like the first shoots of grasses and clovers, should be fed in the fresh condition. After the birds 
approach maturity and growth is slower, so that a much larger proportion of the food is used for maintenance, and during colder weather, when the heat from the extra energy required for digestion is useful, more of the coarse foods can be fed without apparent disadvantage.

Incidental effects of the food.-Another reason, sometimes a very important one, for using such foods as young clover, fresh or dried, is the effect on the color of the egg-yolk. Eggs from hens which are fed only certain grain and animal substances generally have yolks of a pale yellow, color. This is often objected to by those who have a preference for eggs with darker orange-colored yolks. The liberal feeding of fresh or dried young clover, alfalfa or grass will generally insure the deeper coloration. The cause for this frequent lack of what may be considered the normal yellow color of the egg-yolk is not well known, but the occurrence of the pale color can be generally prevented by attention to the food.

At the New York Experiment Station pens of hens which were fed alike except that no hay or green food was given to one while three others had different amounts, apportioned by geometrical ratio, of clover hay alternated with green alfalfa, produced eggs showing marked differences in color. The orange-yellow shade of the yolk corresponded directly in intensity with the proportion of hay or green fodder in the ration. The greenish color of the white also varied, but not so regularly. Eggs from each lot were very uniform in appearance, 
The differences in flavor and other qualities which are probably caused by the food cannot be satisfactorily explained at present. They are, however, slight with normal rations. In general the color of the shell is determined by the breeding or by the individual characteristics of the fowl.

Digestive apparatus. - The process of digestion with birds is essentially similar to that with mammals, although there are important differences in the apparatus by which it is accomplished. It is necessary to know something of the general arrangement and working of the digestive canal when attempting to establish proper methods of feeding, and for a better selection and combination of suitable foods.

Although some extinct species of birds were well supplied with teeth, existing forms have the mouth armed only with a horny beak. The common fowls must swallow grains whole, but are able to tear some food into small fragments, which they particularly do when feeding the young. Ducks, and geese more especially, have the mouth supplied with laminæ, which serve to cut soft herbage.

In birds the salivary glands are small and the limited amount of saliva probably has little effect on the food.

- The cesophagus is of great caliber and very expansible. It is dilated in the cervical portion in ducks and geese. In gallinaceous birds, instead of this dilatation there is attached to, and forming practically a part of, the œesophagus, the reservoir called the crop. The food is temporarily retained in the crop, but is 
changed very little other than being softened by the water swallowed with it, the small amount of mucus and the inconsequential amount of saliva. The high temperature doubtless assists this softening effect, and fermentation also progresses rapidly when food is retained long in the erop from injury or by overloading with coarse material.

The divided crop of pigeons secretes, with both sexes, for several days after the young are hatched, a thick milky fluid which serves to feed the young birds. With other domestic birds the crop serves for little more than a temporary retaining reservoir.

The stomach, which is a single organ in some birds, is represented by two reservoirs in domestic fowls. The first, through which the food passes after leaving the crop, is the glandular stomach, the succentric ventricle or proventriculus, and the second, closely connected, is the gizzard or muscular stomach. The first, from its structure, has been considered the true stomach, but it is now believed that gastric juice is secreted in the gizzard. The food does not accumulate in the first stomach, but in passing through carries along such juices as are there secreted.

The gizzard is a powerful grinding apparatus. There is a strong lining which is capable of resisting great pressure and the action of the sharp sand and pebbles. In this organ the grains and seeds, with other materials, are more finely ground than by the mastication of many other animals.

The intestines are long in domestic fowls. While serving the same purpose as in mammals and having 


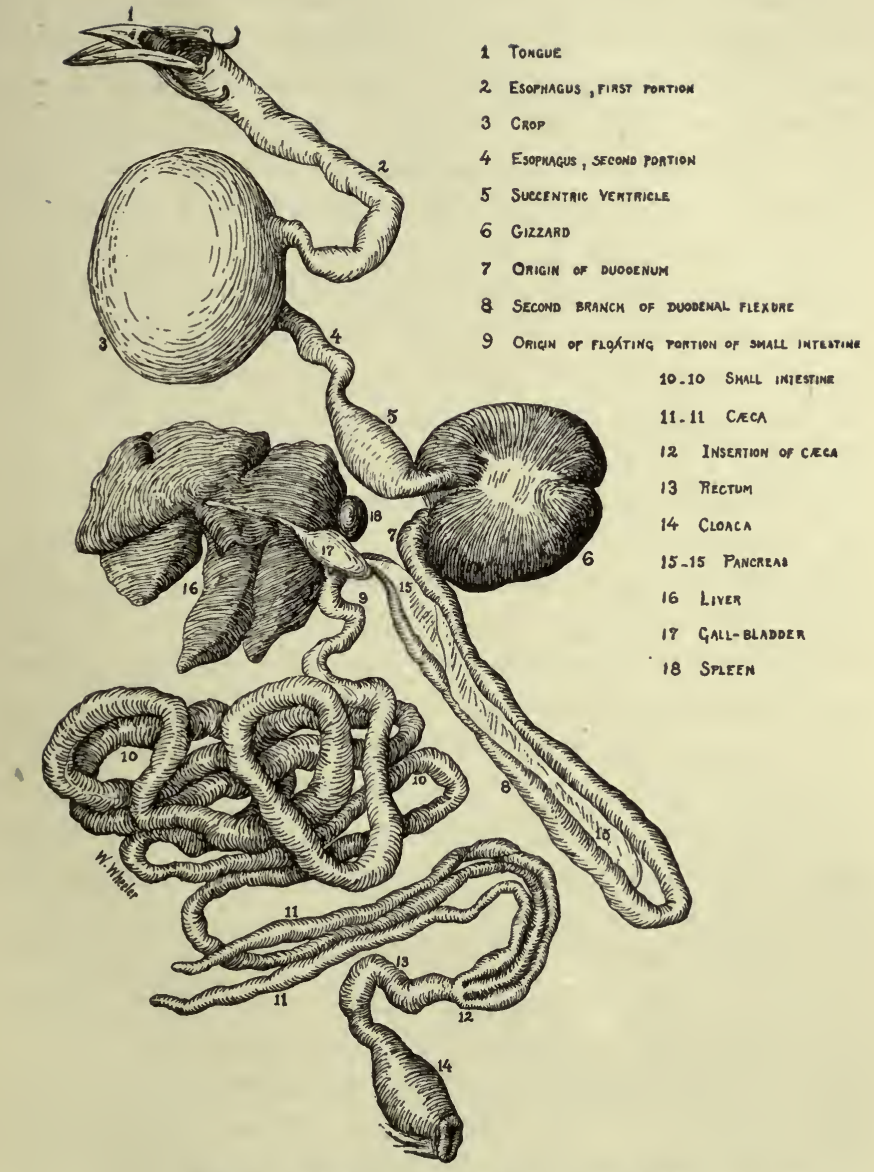

Fig. 10. Digestive apparatus of common fowl. 
a general resemblance to the mammalian form, they do not clearly show the same divisions. The diameter is about the same throughout. The cæca, each of which is closed at one end and opens into the intestines at the other, seem to be important and essential modifications of that canal. Each cæcum is from six to seven inches long in mature fowls. Not far from the openings of the cæca the intestine ends in a dilatation, the cloaca, into which the genito-urinary passages also open. It is because of the mixing here of the undigested residues of the food with the secretions from the kidneys and with some other products of metabolism, that an accurate estimation of the digestibility of food by birds is so difficult. No satisfactorily accurate methods for separating some of the nitrogenous residues from different organs seem yet to be perfected.

Into the intestine shortly after it leaves the gizzard two dncts from the liver and two from the pancreas enter, discharging the bile and pancreatic juices. The liver, as usual, is a large organ. The pancreas also is very largely developed, and extends for several inches along the duodenal loop of the intestines, reaching in the common fowl a length of over five inches.

Altogether the structure of the digestive apparatus of birds indicates extreme efficiency and the capacity for rapid work. A study of it suggests, also, as does that of any complicated and delicately adjusted apparatus, that it should not be overloaded nor violently disturbed when running at high pressure. It may be said to run at high pressure while the extremely rapid growth of young birds occurs, and during the extended 
laying season, for the resulting products call for an uninterrupted supply of food and the transformation of all material that is available. Chickens of two pounds weight at ten weeks of age show a gain over the weight of the first week of nearly 1,700 per cent. Ducklings five pounds in weight at nine weeks show a gain during about eight weeks of 3,900 per cent. Such rates of growth are not very unusual for young fowls under favorable conditions.

CONSTITUENTS OF THE BODY

Whether the production of meat or of eggs is the prime object, the young fowl must first be grown. It is desirable, then, to consider what constituents make up the body of the animal, for all must be derived from the food. Many slight variations in composition exist, of course, but there is always a certain approximation to the normal full-grown animal.

In the whole body of the common fowl, unless especially fattened, not far from one-half of the dry matter is protein and about 8 per cent ash. This of itself would suggest that a slow growth must follow the use of foods containing small amounts of nitrogenous and mineral matter.

Analyses made, mostly by Jenter, at the New York Experiment Station, give as the average composition of the body of a Leghorn hen, typical of the laying breeds, 55.8 per cent of water, 21.6 per cent of protein, 3.8 per cent of ash, and 17 per cent of fat. This is not the composition of the edible portion alone nor of 
the carcass as found in the market, but that of the whole body, bones, blood, feathers, and all the viscera. The different parts of the body were all separately analyzed. Separate analyses of four individual hens each gave a close approximation to the average. The composition of the body of a Leghorn pullet in full laying was little different from the average for the hens, being 55.4 per cent of water, 21.2 per cent of protein, 3.4 per cent of ash, and 18 per cent of fat.

The body of a mature eapon (Plymouth Rock) contained 41.6 per cent of water, 19.4 per cent of protein, 3.7 per cent of ash, and 33.9 per cent of fat. If the extra amount of fat were removed the composition would be very similar to that of the other fowls. In younger and immature birds the percentage of fat is very much less than in older birds.

The egg, which, aside from the shell, is potentially a chick, shows in the general proportions of the constituents a striking resemblance to the body of the grown bird. Of the dry matter of eggs analyzed, aside from the shell, 49.8 per cent on the average was protein, 3.5 per cent ash, and 38.6 per cent fat. Of the dry matter of the bodies of hens 48.9 per cent was protein, 8.6 per cent ash, and 38.5 per cent fat.

Of the total dry matter in the entire egg 35.6 per cent is ash, 25.9 per cent fat, and about 33.3 per cent protein, or 38.5 per cent if estimated by difference. The fresh egg with a good firm shell consists of about 11.4 per cent shell, 65.7 per cent of water, 8.9 per cent of fat, 11.4 per cent of protein by factor, or 13.2 per cent by difference, and .8 per cent of ash con- 
stituents aside from the shell. Of this ash 53.7 per cent is phosphoric acid. Over .2 per cent of the edible portion of the egg is phosphorus. This eomposition is the average from twenty-four analyses by Thompson, and eighteen by Wheeler, representing over 400 eggs from hens of several breeds under different rations. None of the analyses differed much from the average.

Necessity for considering the water. - In the products which have been mentioned, as in most animal products sought by feeding, there is always a large amount of water. In every dozen eggs there is a pint of water. Aside from that necessary for constructive use there is required for the activities of the living animal a free supply. Particular mention is made of the necessity for water, because its great importance is sometimes overlooked, for an especially provided supply is not necessary under some circumstances. Instances occur when the lack of water is the cause of ill success.

The organic and mineral nutrients in food.-Mention of the characteristics and composition of the different nutrients of the food and a discussion of their functions will be found elsewhere in this volume. The facts apply to the feeding of poultry as well as to that of other animals.

It appears from present knowledge that protein derived from animal sources is more efficient for certain uses, particularly the feeding of ducklings, than that derived from vegetable foods. Previous mention has been made of experiments at the New York Experiment Station, the results of which accord with this assumption. The rations which contained animal 
food proved much more efficient than those of vegetable origin, the latter having, according to the ordinary methods of estimation, the same nutritive value as the former.

It seems probable that the ash constituents have sometimes not been sufficiently considered in feeding. While the importance of the mineral nutrients can be largely overlooked without serious practical disadvantage when feeding some animals for certain purposes, it must be given consideration when feeding domestic fowls. While in milk, for instance, about 5 per cent of the dry matter is ash, in eggs over 35 per cent of the dry matter is represented by the mineral constituents.

The shell of the egg, which represents about 11 per cent of the fresh egg, consists almost entirely of carbonate of lime. Most grain foods which naturally constitute the bulk of ordinary rations contain little mineral matter and the amount of lime is notably low. For simply supplying the deficiency of material for the egg shell, carbonate of lime in the form of oyster shell can be used. This was shown in experiments at the New York Experiment Station made with laying hens after they were closely confined on a clean floor for over three weeks. It was then found that about nine-tenths of the lime in the egg shell was unaccounted for in the food aside from the oyster shells which were fed.

While less than 10 per cent of the body of a fowl is mineral matter, it consists largely of phosphate of lime and exceeds in proportion that of many foods. 
The bony framework is also rapidly formed in the growing bird, so that mineral matter is in imperative demand. The results of many trials made at the New York Experiment Station are clearly in accord with this assumed need. As has been previously mentioned, the addition of phosphate of lime from several sources to rations for young fowls has noticeably increased their efficiency.

Common salt in considerable quantity is a necessity to the living animal. Some foods contain a probably sufficient amount, but in others the proportion is very small. In order to make sure of an excess and to avoid any possible deficiency it is well to add salt regularly to the food, especially when it also increases the palatability of the ration. About five ounces in every $100 \mathrm{lbs}$. of food has been found a safe proportion. Fowls regularly accustomed to salt are not likely to eat an injurious quantity of very salty material when it is accidentally within their reach. Pigeons are very fond of salt and a liberal allowance is generally considered necessary to insure health in the loft.

Fowls at liberty are generally able to find grit enough in the form of sharp pebbles and sand to facilitate the grinding which occurs in the gizzard. When they are confined or do not have extended range, sharp and hard grit of some kind should always be freely supplied. Clean, sharp sand is useful for the very young birds, and is quite generally considered an essential part of all mixtures fed to ducklings. Good results accompany its free use. 
THE STUDY OF RATIONS AND DEDUCTION OF STANDARDS

In studying and comparing different rations, it is not possible to consider all the combinations that can be made of the many foods. It is only practicable to consider foods with reference to their varying proportions of constituents. The only portion of these constituents of nutritive value is that which can be digested. Therefore, in compounding rations, we are guided primarily by the amount of the digestible nutrients supplied by the food; and feeding standards are for convenience limited to a statement of the assumed requirements in terms of digestible protein, ash, carbohydrates and fat. The bulk of the ration supplying these nutrients must also, of course, fall within certain limits. In the absence of enough specific data calculations must be based on the coefficients of digestibility observed for other animals. These afford safe enough approximations for present use, for the feeding standards must be largely provisional.

Growth and egg production can only be sustained by the food in excess of that required to support life, although egg production can temporarily occur at the partial expense of the body. The amount of food, then, required for simple maintenance puts a limit on one side to an efficient and profitable ration. In the other direction, it is only limited by the capabilities of the individual animal. So the highest possibilities depend altogether on the intelligent judgment, and careful, daily attention of the experienced feeder. In a general way only averages can be considered. 
Maintenance rations. - A number of feeding trials made at the New York Experiment Station supply information relative to the amount of food required for simple maintenance. The amount varies, as might be expected, with the size of the animal. The larger fowls required more food, but much less for each pound of live weight. These feeding trials did not cover any molting period and egg production was, for the time, suspended. From the data secured maintenance rations have been deduced which correspond very closely to those actually fed for quite extended periods during which practically no change in live weight occurred. The data were from an aggregate of fifty-two capons, averaging by different lots from 9 to $12 \mathrm{lbs}$. in weight, for 158 days' feeding, and from sixty hens ranging from 3 to $7 \mathrm{lbs}$. in weight for 150 days' feeding.

The rations are stated in the following tabulated form :

\section{Maintenance Rations}

Digestible nutrients per day for each 100 pounds live weight

$\begin{array}{rrrrrrr}\begin{array}{c}\text { Total dry } \\ \text { matter } \\ \text { lbs. }\end{array} & \begin{array}{c}\text { Ash } \\ \text { lbs. }\end{array} & \begin{array}{c}\text { Protein } \\ \text { lbs. }\end{array} & \begin{array}{c}\text { Carbohy- } \\ \text { drates } \\ \text { lbs. }\end{array} & \begin{array}{c}\text { Fat } \\ \text { lbs. }\end{array} & \begin{array}{c}\text { Fuel } \\ \text { value } \\ \text { Cal. }\end{array} & \begin{array}{c}\text { Nutritive } \\ \text { ratio }\end{array} \\ \text { Capons of } 9 \text { to } 12 \mathrm{lbs} \text {. wt...2.30 } & .06 & .30 & 1.74 & .20 & 4,600 & 1: 7.5 \\ \text { Hens of } 5 \text { to } 7 \mathrm{lbs} \text {. weight..2.70 } & .10 & .40 & 2.00 & .20 & 5,300 & 1: 6.2 \\ \text { Hens of } 3 \text { to } 5 \text { lbs. weight...3.90 } & .15 & .50 & 2.95 & .30 & 7.680 & 1: 7.4\end{array}$

Rations for laying hens.-Hens in full laying seem to require rations which have a larger relative content of protein and ash, and which show an increase in fuel value of from 15 to 40 per cent, according to size, over those required for maintenance. The following standards approximate the requirements : 


\section{Rations for Hens in Full Laying}

Digestible nutrients per day for each 100 pounds live weight

$\begin{array}{ccccccc}\begin{array}{c}\text { Total dry } \\ \text { matter }\end{array} & \begin{array}{c}\text { Ash } \\ \text { lbs. }\end{array} & \begin{array}{c}\text { Protein } \\ \text { lbs. }\end{array} & \begin{array}{c}\text { Carbohy- } \\ \text { drates }\end{array} & \begin{array}{c}\text { Fat } \\ \text { lbs. }\end{array} & \begin{array}{c}\text { Fuel } \\ \text { value }\end{array} & \begin{array}{c}\text { Nutritive } \\ \text { ratio }\end{array} \\ \text { Cal. } & \\ \text { ht..3.30 } & .20 & .65 & 2.25 & .20 & 6,240 & 1: 4.2 \\ \text { ht..5.50 } & .30 & 1.00 & 3.75 & .35 & 10,300 & 1: 4.6\end{array}$

These standards are not absolute and inflexible rules, for such would not be justified by a thousand times the number of available data. They supply a definite starting point, and are not supposed to obviate the use of judgment. Because it is found convenient, on account of different requirements and capabilities, to divide hens into two groups, it should not be presumed that a hen just under five pounds in weight must always have one ration or a hen just over five pounds must always have the other.

A ration which corresponds to the standard given for maintenance for hens of the larger size could be composed of one pound of cracked corn, one pound of corn meal, one-half pound each of ground oats, wheat middlings, and clover hay, one-fourth pound of fresh bone and two ounces of meat scraps.

The following stated ration is given as an illustration of one which would supply the nutrients called for in the standard for laying hens of the larger size: One pound of cracked corn, three-fourths pound of wheat, three-fourths pound of corn meal, one-half pound each of wheat middlings, buckwheat middlings, and animal meal, two-thirds of a pound of fresh bone, and threefourths of a pound of young green alfalfa.

Rations for young birds. - The requirements of the 
rapidly-growing young fowl are so constantly changing that a satisfactory average ration for any extended period cannot be easily formulated. In the following statement of rations for chicks they are averaged for periods of two weeks at different ages during the time of most rapid growth. The ration for the last period will suffice for several weeks longer, although the amount required per 100 pounds live weight will gradually diminish up to maturity. For fattening nearly mature fowls a ration with a wider nutritive ratio of about $1: 8$ can be liberally fed for limited periods.

The duck grows faster than the common fowl, and more food is required during an equal time. Rations for ducklings differing somewhat from those for chicks are given separately.

\section{RATIONS FOR CHICKS}

Digestible nutrients per day for each 100 pounds live weight

\begin{tabular}{|c|c|c|c|c|c|c|c|}
\hline & $\begin{array}{l}\text { Total dry } \\
\text { matter }\end{array}$ & Ash & $\begin{array}{l}\text { Pro- } \\
\text { tein }\end{array}$ & $\begin{array}{c}\text { Carbohy- } \\
\text { drates }\end{array}$ & Fat & $\begin{array}{l}\text { Fuel } \\
\text { value }\end{array}$ & $\begin{array}{c}\text { Nutritive } \\
\text { ratio }\end{array}$ \\
\hline & lbs. & lbs. & lbs. & lbs. & lbs. & Cal. & \\
\hline For the first 2 weeks....... & 10.1 & .5 & 2.0 & 7.2 & .4 & 18,800 & $1: 4.1$ \\
\hline From 2 to 4 weeks of age... & 9.6 & .7 & 2.2 & 6.2 & .5 & 17.730 & $1: 3.4$ \\
\hline From 4 to 6 weeks of age... & 8.6 & .6 & 2.0 . & 5.6 & .4 & 15,640 & $1: 3.3$ \\
\hline From 6 to 8 weeks of age... & 7.4 & .5 & 1.6 & 4.9 & .4 & 13,780 & $1: 3.7$ \\
\hline From 8 to 10 weeks of age.. & 6.4 & .5 & 1.2 & 4.4 & .3 & 11,680 & $1: 4.3$ \\
\hline From 10 to 12 weeks of age. & 5.4 & .4 & 1.0 & 3.7 & .3 & 10,000 & $1: 4.4$ \\
\hline
\end{tabular}

RATIONS For DUCKLINGS

Digestible nutrients per day for each 100 pounds live weight

\begin{tabular}{|c|c|c|c|c|c|c|c|}
\hline & $\begin{array}{l}\text { Total dry } \\
\text { matter }\end{array}$ & Ash & $\begin{array}{l}\text { Pro- } \\
\text { tein }\end{array}$ & $\begin{array}{c}\text { Carbohy } \\
\text { drates }\end{array}$ & Fat & $\begin{array}{c}\text { Fuel } \\
\text { value }\end{array}$ & $\begin{array}{l}\text { Nutritive } \\
\text { ratio }\end{array}$ \\
\hline For the first 2 weeks. & $\begin{array}{l}\text { Ibs. } \\
172\end{array}$ & $\begin{array}{l}\text { Ibs. } \\
1.6\end{array}$ & $\begin{array}{c}\text { lbs. } \\
4.0\end{array}$ & $\begin{array}{l}\text { lbs. } \\
11.2\end{array}$ & $\begin{array}{r}\text { lbs. } \\
1.4\end{array}$ & $\begin{array}{c}\text { Cal. } \\
34,180\end{array}$ & $1: 3.7$ \\
\hline From 2 to 4 weeks of age... & 17.0 & 1.5 & 4.1 & 10.1 & 1.3 & 31,900 & $1: 3.2$ \\
\hline From 4 to 6 weeks of age... & 11.2 & .8 & 2.7 & 7.0 & .7 & 21,000 & $1: 3.3$ \\
\hline From 6 to 8 weeks of age... & 8.0 & .6 & 1.7 & 5.2 & .5 & 14,940 & $1: 3.8$ \\
\hline From 8 to 10 weeks of age.. & 7.0 & .5 & 1.4 & 4.7 & .4 & 13,030 & $1: 4.1$ \\
\hline From 10 to 15 weeks of age. & 4.6 & .3 & .9 & 3.2 & .2 & 8,470 & $1: 4.1$ \\
\hline
\end{tabular}


As an example of a day's ration which would correspond to the requirements of the standard given for young chicks during the second week the following is stated: Four pounds of cracked wheat, two pounds of granulated oat meal, three pounds of corn meal, onehalf pound each of wheat middlings, buckwheat middlings, ground oats and old process linseed meal, two and one-fourth pounds of animal meal and two and three-fourths pounds of young green alfalfa. This would feed from eight hundred to a thousand chicks of this age.

Another ration in accord with the standard given for ducklings about three weeks old might be constituted as follows: Eight pounds corn meal, three pounds wheat middlings, two pounds ground barley, two pounds of old process linseed meal, six pounds of animal meal, two pounds of fresh bone and three pounds of young green alfalfa. This and other specimen rations are given under the assumption that free supplies of sharp grit, as 'well as water, are also provided.

A consideration of the adaptability of the different foods, aside from their composition, and of the apparent requirements of the young at different periods suggests a ration somewhat wider in nutritive ratio for the first few days than for some weeks afterward.

In providing a ration, it may be possible to devise one in accord with the formal standard which will be decidedly inefficient at times if the chemical composition and coefficients of digestibility are alone considered. The adaptability of foods that are palatable must be considered. The difference in the energy required to 
digest various foods which can supply equal proportions of digestible matter may be also at certain times an important factor.

A large number of the ordinary grains seem practically interchangeable and many grain by-products can be freely substituted for different whole grains or for each other and all combined as desired. But some foods, such as cottonseed meal, do not seem suited to common fowls, even in very small quantities. Linseed meal can be fed more freely, but the unground flaxseed is less satisfactory. It is probable that oats, whole or ground, which appear so valuable sometimes, should not be freely used at other times. About thirty per cent of the entire grain is hull. To obtain the available material from this requires an expenditure of energy that can be better applied during periods of rapid transformation, especially during the first few weeks of the young bird's growth. The products of the oat kernel, however, from which the hull has been separated are in the unquestioned class of foods. The same observation applies to buckwheat, some kinds of pea meal and to certain other foods less commonly used, containing a large proportion of crude fiber. Reference to this point has been made before under the topic of coarse and bulky foods.

Primary consideration has naturally been given to those domestic fowls upon which we depend for the great bulk of eggs and meat. Other kinds are of considerable importance in certain localities, or often to the fancier, but concerning them not enough is recorded to establish separate feeding standards. It 
is probable that their requirements will be found to correspond fairly well with those of either the duck or of the common fowl. The general food of the turkey is similar to that of the common fowl, but it should be less artificial, and conditions of general feeding more nearly resembling those which exist in a wild state are required.

Unsatisfactory as is our present knowledge of the fundamental laws which underlie the science of nutrition applied to man and other animals, there are nevertheless volumes of carefully collected data that make it possible to ascribe fairly narrow limits to their operations. Compared with mammals, however, the class of birds has received very little consideration. There have been a few careful studies made, but for lack of enough information our feeding must be guided by the rules applying in common to all animals. Undoubtedly the accepted laws of nutrition observed for other animals are applicable in a general way to domestic fowls, and it is safe to apply in the light of the specific data we have any general principles of feeding that have already been established. This has been done in formulating the feeding standards which are here presented, and all available data of a reliable character have been considered. There have not been enough, however, to justify narrow limitations, and the suggested standards should not be considered fiul and unchangeable. They simply represent the averages of rations which under careful management and like conditions have given better results than various other rations with which they 


\section{Modifications of the Standard Important 399}

have been contrasted. Slight modifications were made in accord somewhat with the habits of the different fowls and with a consideration of the character of the products desired. It is important that the feeder, while following such standards in a general way, should give enough consideration to the subject to make modifications suited to the species and breed and to his particular conditions of market and farm. 


\section{CHAPTER XXVI}

\section{THE RELATION OF FOOD TO PRODUCTION}

ONE of the questions much discussed by farmers, and which has an important bearing upon the economics of animal husbandry, is the food cost of the various animal products. To illustrate, a herd of cows consumes a certain quantity of food and produces a certain weight of milk, milk solids, cheese or butter, according to the terms in which we state the production. If the same food is fed to a lot of steers a certain increase in their live weight is secured. There is in each case a relation of quantity between the food and the product. The food cost, that is, the food consumption, involved in growing a pound of beef, is quite unlike the food requirements for producing a pound of pork, a pound of veal or a pound of eggs. If we consider merely food expenditure, that branch of animal husbandry is most economical of raw materials in which the largest proportion of the food dry substance is converted into some new, useful product, or, differently stated, where the food units bear the lowest ratio to a unit of product.

In presenting the matter it is necessary to first define our units. What shall we accept as a food unit? Certainly it cannot be a pound of food as eaten. One 
farmer feeds his cows silage or roots, and grain, with but little hay, while another fattens steers on dry food alone. A comparison of production in the two instances on the basis of the gross weight of food consumed would be absurd, because with the cows the dry matter is largely diluted with water. It would be equally absurd to accept the dry matter in the ration as a standard. In instituting a comparison between bovines and swine we must remember that the former consume materials much less digestible than do the latter, and so a unit weight of food does not represent the same weight of available nutrients with the two classes of animals.

We should, so far as possible, reduce rations to their units of nutritive value, and so the digestible dry matter is now the nearest approach we can make to a basis for comparing rations with each other or with the production which they sustain. It follows, then, that if we wish to show the comparative economy of production in dairy farming and in beef farming, food alone considered, we should express this relation on one side in terms of digestible dry food substance.

What shall we consider as a unit of production? We may answer this question from two standpoints. We may measure production by the quantity of the commercial article which the farmer places on the market; or by the actual contribution which any given production makes to the food resources of the human family. More specifically stated, we may determine the relation of a unit of digestible food substance to the live animal, beef, pork, milk, cheese, 
butter or eggs resulting from its use, and calculate the ratio of any one of these to the actual nutrients consumed, or we may ascertain the ratio of food consumption to the edible dry substance in the various animal products. The latter is the important ratio to consider if we are seeking to learn how we can most efficiently apply farm crops to the sustenance of the human family.

This study of food economics requires a knowledge of several factors. In the first place, we must have the information coming from feeding experiments, where a careful record has been kept of the kind and amount of food consumed and of the weight of the resulting growth, milk, eggs, or what not. This information must be supplemented by a knowledge of the digestibility of feeding stuffs, of the ratio between the live animal or other gross product and the commercial products and of the composition and proportion of edible material supplied by the commercial article. For instance, we find it takes, on the average, $7.40 \mathrm{lbs}$. of digestible organic substance in the ration to produce one pound of growth in a steer, and we have learned by slaughter tests that the average per cent of carcass for 97 animals was 61.4 , and by the butchers' and chemists' analyses, that the carcass contains an average of 33.2 per cent of edible dry matter. From these data it is easy to calculate that $12 \mathrm{lbs}$. of digestible food are needed for the growth of one pound of carcass or $36.3 \mathrm{lbs}$. for the growth of one pound of edible beef solids.

The following tables give the data upon which is 
based the productive. power of food when utilized by the various classes of animals. Data of this kind are practically our only means of studying the economics of producing those human foods which are most costly in proportion to their nutritive value, a study which is very important wherever it becomes necessary to economize energy. It shows the coefficients of efficiency of various species of animals in maintaining the human species. The sources of all these figures are not given, for they are so numerous as to make this difficult:

\section{Production by Farm animals}

Proportions of carcass and edible substance

\begin{tabular}{|c|c|c|c|}
\hline $\begin{array}{c}\text { Number } \\
\text { of } \\
\text { animals }\end{array}$ & $\begin{array}{l}\text { Carcass } \\
\text { in per cent } \\
\text { of live } \\
\text { weight }\end{array}$ & $\begin{array}{l}\text { Per cent* } \\
\text { of edible } \\
\text { dry matter } \\
\text { in carcass }\end{array}$ & $\begin{array}{l}\text { Per cent of } \\
\text { edible dry } \\
\text { matter in live } \\
\text { animal }\end{array}$ \\
\hline Steers, general average $\quad 97$ & 61.4 & 33.2 & 20.4 \\
\hline Steers, Iowa.......... & 64. & 33.2 & 21.2 \\
\hline Steors, Kansas........ & 61.4 & 33.2 & 20.4 \\
\hline Steers, Maine†........ & 57.7 & 32.3 & 18.6 \\
\hline Sheep............. & 50.7 & 37.4 & 19. \\
\hline Lambs ............ 44 & 50.7 & 33.7 & 17.1 \\
\hline Lambs, Iowa ......... 133 & 54. & 33.7 & 18.2 \\
\hline Swine, general average 97 & 81.2 & 62.7 & 50.9 \\
\hline Pigs, Iowa.......... 56 & 77.9 & 62.7 & 48.8 \\
\hline Calves............. 23 & 57.2 & 22.2 & 12.7 \\
\hline Fowl, large........ 12 & 80.8 & 27. & 21.8 \\
\hline Fowl, small.......... & 78. & 27. & 21.1 \\
\hline Chickens, broilers..... 107 & $82.1 \ddagger$ & 14.7 & 12.1 \\
\hline Eggs ............ 348 & $88.8 \|$ & 26.3 & $23.3^{* *}$ \\
\hline \multicolumn{2}{|c|}{$\begin{array}{l}\text { * From Bull. 28, Office of Experiment Stations. } \\
\text { † Grown from calfhood, entire bodies analyzed. } \\
\text { † Not drawn. } \\
\text { \& Number of samples. } \\
\text { I Per cent after removing shells. } \\
\text { ** In eggs with shells. }\end{array}$} & \multicolumn{2}{|c|}{ Revised edition. } \\
\hline
\end{tabular}


Relation of food to product

Diges- Diges- Diges-

tible org. tible org. tible org. substance substance substance

Number
of Number
experi- of
ments animals
produc-

ing $1 \mathrm{lb}$. increase live wt.

lbs. produc. ing $11 \mathrm{~b}$. increase carcass

lbs.

roducing

$1 \mathrm{lb}$. in.

crease edible sol.

lbs.

Milk, average......... 61

391

.72

5.55

Milk, New York*........ 113† 30

Steers, average......... $32 \quad 242$

Steers, Ia., growth 9 to $24 \mathrm{~m}$. $1 \quad 5^{\circ}$

.63

4.85

7.40

12.

36.3

Steers, Kansas, 3 years old. 118

5.97

9.33

28.1

8.08

13.16

39.6

Steers, Maine.......... 1

Sheep and lambs, average. .

$11 \quad 122$

6.65

11.5

35.7

Lambs, Iowa, growth while

fattening............

Swine, $\ddagger$ average ........ 277 $\quad 1,385$

133

7.20

14.2

37.9

Pigs, Iowa ............ 1

Calves, average......... 3

56

5.63

10.43

30.9

3.29

4.

6.4

3.03

3.89

6.2

30

1.57 ?

2.70

12.3

5.10

6.30

23.4

Fowl, small, to 5 or $6 \mathrm{mos}$.

Chickens, broilers, 12 wks.\| 15

5.10

6.50

24.2

$3.48^{* *}$

4.20

28.8

Eggs\|.............. 14

$139 \dagger \dagger 4.56 \ddagger \quad 5.10 \quad 19.6$

The figures of the foregoing tables can be regarded as being trustworthy for average conditions. They are obtained from the recorded data of experiment stations, and involve a large number of observations with dairy cows and with growirg and fattening animals.

In most cases the amount of digestible matter in

* Extending over seven years.

+ Short periods.

$\ddagger$ Deduced from compilation by Dr. Armsby for U.S. Dept. of Agriculture.

\& Dry matter, mostly from milk, practically all digestible.

I Unpublished data from experiments at the New York Agri. Expt. Station.

**4.35 lbs. dry matter, assumed to be 80 per cent digestible.

H Egg product, 100 eggs per year.

$\$ \$ 85.70$ lbs dry matter, assumed to be 80 per cent digestible. 
the ration is calculated from the average coefficients of digestibility.

The facts brought out by this study of the relation of food to product are emphatic and suggestive. In order to display them as clearly as possible there are shown in the next table the quantities of the various commercial animal products, and of human food in animal forms, which ean be produced by the use of a quantity of cattle food containing $100 \mathrm{lbs}$. of digestible organic matter:

Relation of food to product

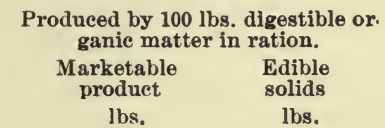

Milk, general average............ 139.

18.

Milk, New York experiments ........ 158.7

20.6

Cheese, green................. 14.8

9.4

Butter

Steers, general average, live weight... 13.5

Steers, Iowa, live weight.......... 16.8

Steers, Kansas, live weight......... 12.4

Steers, Maine, live weight ......... 15.

Steers, general average, carcass ..... 8.3

Steers, Iowa, carcass............ 10.7

Steers, Kansas, earcass ........... 7.6

Steers, Maine, carcass ........... 8.7

2.84

Sheep and lambs, general average,

live weight............... 13.9

Lambs, Iowa, live weight ........ 17.8

Sheep and lambs, general average, carcass................... 7 .

Lambs, Iowa, carcass .......... 9.6

Swine, general average, live weight... 30.4

Swine, Iowa, live weight ......... 33. 
Relation of food to product - continued

Produced by 100 lbs. digestible organic matter in ration.

Marketable product

lbs.

Edible

solids

Swine, general average, carcass..... 25.

lbs.

15.6

Pigs, Iowa, earcass ............ 25.7

16.1

Calves, live weight............. $\quad 63.7$

Calves, carcass................ $\quad 36.5$

Fowl, large, live weight ......... 19.6

Fowl, small, live weight......... 19.6

Fowl, dressed carcass, average...... $\quad 15.6$

Broilers, live weight........... $\quad 28.7$

Broilers, dressed carcass.......... $\quad 23.8$

Eggs.

19.6

It may properly be said of the foregoing figures that they are only averages and that the relation of food to production varies with different animals of the same class and with the conditions involved. While this is true, the relations shown in the preceding calculations represent differences too wide to be explained on any other ground than that the various animal products have greatly unlike food cost.

The most noticeable fact brought out by this comparison is the low relative food cost of milk and other dairy products. The growth of a pound of edible beef solids requires a food expenditure nearly seven times as great as is necessary for the elaboration of a pound of milk solids. On the other hand, swine are fed with nearly as great economy as are milch cows. In fact, when proper allowance is made for the period of growth of the cow and for the annual periods when she is giving no milk, she seems to have 
no advantage over the pig except in kind of product. Next in the order of economical use of food comes the calf, when fed largely on milk. Poultry products stand next in line. Sheep and lambs do not differ materially from steers, meat products of these two classes requiring the largest proportional food consumption of any form of growth here considered. The order of food efficiency as related to the several animal products is therefore as follows: milk, pork, veal, poultry and eggs, mutton and beef. The common claims that the food cost of a pound of butter is no greater than that of a pound of dressed carcass is not borne out by these average figures.

It is suggestive, at least, to notice that the food factor is inversely as the labor factor in these various lines of production. For instance, labor is a large factor of the cost of a pound of any dairy product, and a small factor in the cost of beef or mutton, while the reverse is emphatically true of the food cost. 


\section{CHAPTER XXVII}

\section{GENERAL MANAGEMENT}

THERE are many considerations pertaining to the feeding and management of live stock that have a more or less common application to all classes of animals and which may be discussed conveniently under one head. They are partly of a business character and to quite an extent lie outside the chemical and physiological principles of nutrition. Some of those questions are matters of much importance, but many of them which relate, for instance, to times and methods of feeding are given a prominence in current discussions out of proportion to their real influence in determining success. "It should be understood, too, that many of the details of practice are not limitable by fixed rules but must be variable according to the conditions involved. Tact and judgment are demanded of the farmer who wisely adjusts his practice to business principles.

General management properly includes, among other considerations, the following topics:

(1) The selection of animals; (2) -manipulation of the ration and manner of feeding; (3) the intensity of feeding; (4) environment and treatment of the animal. 


\section{SELECTION OF ANIMALS}

The object to be sought in feeding animals is the conversion of a unit of food into the largest possible quantity of the product best adapted to the producer's commercial opportunities, and here the limitations of the animal are often the limitation of the farmer's profits. Within each species varietal and individual differences determine the rate of production and also whether the food shall be transformed into poor milk or rich milk, inferior beef and mutton or superior meat products, fine wool or coarse, trotters or draft horses, and small eggs or large ones.

The selection of animals should have reference to three general factors, which largely fix the rate and character of production,- -viz., breed, individuality and age.

The selection of cows. - The breed and individuality of the cow largely determine the quality of her product and the quantity of production from a unit of food. Neither heavy feeding nor skill in compounding rations can be made the means of causing her to overstep her constitutional limitations.

The selection of cows simply with reference to breed is a question of adaptability. If the production of milk at the minimum food cost per unit of volume is the result most desired, the dairy breeds characterized by milk with a low proportion of solids should be chosen, but if the object is to merely secure butter-fat with the lowest possible food expenditure, the so-called butter breeds are in general to be preferred. 
When the chief consideration is the manufacture of milk solids most economically, we must deal not so much with breeds as with individuals. In fact, with all breeds and with animals of no breed, individual eapacity is the consideration fundamental to profitable feeding. Some Holsteins will return both more milk and more butter for a unit of food cost than will some Jerseys, and the reverse is equally true. There is no magic in heredity which overcomes lack of capacity either for the breeder or for the dairyman.

The "general-purpose" cow has been much discussed in recent years. While her specifications have never been fully and clearly set forth, it is supposed that she is an animal reasonably profitable along both beef and milk lines. It is doubtful whether such a cow, even if she exists, is one adapted to general utility. There are few localities where milk is not more profitable than beef or beef more profitable than milk, and whichever is the more profitable should be produced by an animal of specialized capacity. Any extra value which the calves' and the cow's carcass may have when flesh-forming tendencies are prominent, will generally come far short of compensating for a merely mediocre milk yield in those localities where there is a market for milk and its products; and the stockman who is endeavoring to put on the market beef animals of the highest quality cannot afford to compromise with dairy qualities. Milk formation and flesh formation are antagonistic, and not correlated, functions, both of which do not operate intensely in the same individual. At present we have no breed or fixed type of animals 
that can be regarded as presenting and perpetuating "general-purpose" qualities. Such a type, if found at all, must be sought among individuals.

The selection of animals for meat production. - It is generally conceded that the selection of breeds of the beef and mutton types is essential to the highest success in the production of meat. This is. true with steers, not because those from the dairy breeds will make very much slower growth than Shorthorns or Herefords, for this does not seem to be the fact, but because the quality of the product is higher with the latter, that is, the proportion of valuable parts is greater and the distribution of fat and lean tissue is more desirable, in the distinctly beef animal.

A choice from the beef and mutton types and from the various breeds of swine may safely be left to personal preference. Many experiments have been conducted with a view of determining the relative capacity of growth of the prominent breeds of bovines, sheep, and swine, and the testimony so far adduced is of a negative character and does not point to any one breed of any species as clearly superior to all others. It is well understood, however, that within every breed individual variations are important and that from a "bunch" of steers it is possible to select some animals superior to the others in their capacity to make profitable use of food.

A most important factor in this connection is the relation of age to the profits of meat production. Nothing has been more fully established by experimental evidence than that the younger the animals 
the larger the ratio of increase to body weight and the greater the increase for each unit of food consumed.

Some of the more striking evidence on these points is presented in the following figures:

Results with steers from five breeds slaughtered at the Smithfield

(England) Fat-Stock Show (from Henry's compilation)

\begin{tabular}{lcc}
\multicolumn{1}{c}{ Age } & Number animals & Daily gain \\
One year old & 77 & $2.00 \mathrm{lbs}$ \\
Two years old & 89 & 1.76 " \\
Three years old & 54 & 1.58 “"
\end{tabular}

Steers at American Fat-Stock Show (Stewart's compilation)

$\begin{array}{rcc}\text { Age } & \text { Number animals } & \text { Daily gain } \\ 297 \text { days } & 30 & 2.6 \text { lbs. } \\ 612 \text { “" } & 152 & 2.2 \text { “" } \\ 943 \text { “ } & 145 & 1.7 \text { “ } \\ 1,283 \text { “ } & 133 & 1.5 \text { “" }\end{array}$

American experiments with pigs (Henry's compilation)

Weight of pigs Number feeding trials Food for $100 \mathrm{lbs}$. gain $38 \mathrm{lbs}$.

41

78 “ 100

$293 \mathrm{lbs}$.

128 “

- 119

174 “

107

227 “

72

271 "

46

320 "

19

400 “
437 “
482
498 “
511 “
535 “

Results of Danish experiments with pigs

Weight of pigs

35 to $75 \mathrm{lbs}$.

75 to 115 : ،

115 to 135 "

155 to 195 “"

195 to 235 “"

235 to 275 "

275 to 315 “"

\section{Number experiments}

3

10

13

15

14

11

3
Food for $100 \mathrm{lbs}$. gain $376 \mathrm{lbs}$.

435 "

466 "

513 “

540 .6

614 “"

639 “ 
Testimony of this character is abundant, and the lesson for practice is that animals should be fed for market at the earliest age that is consistent with other conditions.

\section{MANIPULA'TION OF THE RATION}

A great deal of experiment and discussion has been devoted to the economy of various methods of treating cattle foods, such as cutting, grinding, wetting and cooking. The economy of these operations requires no extended comment. It is a simple and safe rule that any fodder or grain that in its natural condition is palatable, is wholly eaten and is thoroughly masticated, should be fed without the unnecessary expense which these manipulations would cause. Grinding any material that is not otherwise thoroughly masticated doubtless increases the efficiency of the food, but when the grinding costs as much as 10 per cent of the market price of the grain it is doubtful if any advantage accrues. Cutting, unless for the purpose of mixing, has the sole advantage of saving the animal a little work.

Wetting and cooking render certain foods more tender and more palatable, and when this secures the consumption of materials otherwise wasted these operations may become economical. On the contrary, similar treatment of grain foods already much liked by the animal is, according to the majority of testimony, an occasion of loss rather than of gain.

Practice differs as to the number of portions into which the daily ration shall be divided. Some herds 
are fed three times a day and some twice. While it would be possible to feed too many times, or too much at any one time, it seems more than probable that if animals are fed regularly the ration may be as efficient when divided into two portions as when there are three feeding periods. The adaptation of any system to the requirements of farm work is a matter of more importance, probably, than any influences proceeding from the number of feeding periods. The warming of the water consumed has been introduced to some extent with dairy herds. Certainly it is bad practice to force cows to drink ice-cold water, but it is also bad practice to warm the water above the point of palatableness. The likes and dislikes of animals must be considered, and to ignore them, even to save the small food expense necessary for warming the ingested water, is not advisable.

\section{QUANTITY OF THE RATION}

Great stress is usually laid upon the fact that it is only the food that is supplied above maintenance needs which is productive. This truth, indiscriminately accepted, has led, the writer believes, to feeding so excessively as to injure the health of the animals and diminish profits. The largest production is not always the most profitable. Abundant testimony can be eited in support of the statement that very heavy rations yield smaller returns per unit of food consumed than more moderate ones. It is possible, also, to adopt an unprofitable extreme in the direction of 
light feeding. Heavy rations are sometimes warranted by the low cost of feeds and the high price of the resulting product, a condition which has not existed for the past ten years. In the writer's judgment milk is more economically produced by cows not unusual in character or size when the grain ration, wisely compounded, ranges between 8 and 12 pounds daily, according to the weight and capacity of the animal, than when more is fed, provided the coarse foods are supplied in the ordinary proportion. It is especially important with breeding animals, where the physical condition of the dam should be kept at its best, that the indigestion and high physical tension induced by extreme rations should be avoided.

\section{ENVIRONMENT AND TREATMENT OF ANIMALS}

The quarters in which animals live should be comfortable, that is, they should be neither too warm nor too cold and should be well ventilated. These conditions are essential to health and the most profitable production. The stable temperature in winter should be held above $45^{\circ} \mathrm{F}$. as a minimum, and may well be kept below $60^{\circ}$. A constant exchange of air should be secured without ereating cold drafts, and the "King" system of ventilation seems to be worthy of commendation.

All domestic animals, whether the milch cow or the fattening steer, should have a reasonable amount of exercise under comfortable conditions. Little sympathy should be shown towards the modern fad of 
tying cows by their heads in one spot for five or six months, under the plea that exercise is work and work costs food. The statement had better be in accordance with the experience of all time, that exercise is health and vigor and that food is well used in maintaining these. The cow is more than a machine; she is a sentient being, susceptible to many of the influences which are essential to the physical welfare of the human species. Let no one take this opinion as an excuse: for the cruel and wasteful exposure of farm animals to inclement weather, which is so often observed, for this is simply a violation of the laws of kindness and economy in the other direction.

A sympathetic relation should be established between the animal and the herdsman. Close observers declare that such a relation promotes greater thrift and larger production, especially with dairy cows. These animals, possessed of the instincts and affections of motherhood, respond to fondling through its influence upon their nervous organization.

Moreover, the economic relation is not the only one man sustains to the animal world. Farm animals are man's companions and friends, for which he may entertain even sentiments of affection. The daily life of the farm-house is full of pleasant experiences that belong to the care of, and association with, the grateful creatures whose wants must be supplied,- the motherly cow, the faithful horse or the noisy, cackling fowl. No farmer has reached his best estate who does not find in the animal life about him an enjoyable companionship of which he need not be ashamed. and without a sense 
of which he is not prepared to fulfil his obligations to the creatures dependent upon him.

While it is the purpose of this volume to deal with the facts and principles of science and practice, it is not improper to briefly urge the need of the cultivation of right sentiment concerning kindness in the care of animals, for we really do not fully appreciate the unkindness shown by man toward the inferior species under his control. In no way has he more clearly demonstrated" that he partakes of the brute nature than in his treatment of the brute. As a master he has been guilty of cruelty which it is humiliating to contemplate, a cruelty not as swift in its operation as that of the beast of prey, but which is greatly more shocking and is wholly at variance with the exalted characteristics that we attribute to humanity. The half-sheltered animals that have endured our 'cold northern winters, the spavined, wind-broken wrecks of our livery stables, whose infirmities secure for them no relief from hard service, the daily exhibitions on our city streets of the patient draft horse with raw flesh under the collar and smarting under blows from unfeeling, eursing drivers, and especially the deliberately brutal practices of the race-track, where amid the plaudits of a throng of men and women who would claim to have kind hearts, noble animals, by unjustifiable "scoring" and in the subsequent race, are often forced to the last limits of endurance, are all evidences of an utterly selfish indifference to the suffering of living creatures that zan neither utter a complaint nor avenge their wrongs. A certain proportion of humanity appears to regard the animal 
as a mere unfeeling machine out of which pleasure and gain are to be forced even to the pound of flesh, and not as sentient beings capable of the keenest physical pain and with rights that should be respected. The constant occurrence of the ill-treatment of animals is perhaps the cause of the complaisance with which it is regarded, but it is no excuse for such thoughtless indifference. Society notes and punishes flagrant cases of abuse, but the average human conscience is not yet sufficiently tender toward man's treatment of his faithful servants. 


\section{APPENDIX}

COMPOSITION AND DIGESTION TABLES

1. Average composition of American feeding stuffs (pp. 419-427).

2. Average coefficients of digestion (pp. 427-435).

3. Feeding standards (pp. 435-438).

4. Fertilizing constituents of American feeding stuffs (pp. 439-443).

\section{AVERAGE COMPOSITION OF AMERICAN} FEEDING STUFFS

The figures in the following table have been taken from Bulletin No. 11, Office of Experiment Stations; Farmers' Bulletin No. 22, U. S. Department of Agriculture; Henry's Feeds and Feeding, Bulletin No. 81, Vermont Agricultural Experiment Station, and Bulletin No. 166, New York State Agricultural Experiment Station.

The percentages given represent averages from which there are material variations. These variations are mostly due to differences in the water content, the influence of locality and of the stage of growth and the changes brought about by the methods and conditions of curing. They are not so large and important with the grains as with the fodders. 


\section{Composition of Feeding Stuffs}

Green Fodder

$\begin{array}{ccccccc}\text { Water } & \text { Ash } & \text { Protein } & \text { Fiber } & \begin{array}{c}\text { Nitrogen- } \\ \text { free ex- } \\ \text { tract }\end{array} & \begin{array}{c}\text { No. of } \\ \text { Fat } \\ \text { analy- } \\ \text { ses }\end{array} \\ \% & \% & \% & \% & \% & \% & \end{array}$

Corn fodder-*

$\begin{array}{llllllll}\text { Flint varieties . . } & 79.8 & 1.1 & 2 . & 4.3 & 12.1 & .7 & 40\end{array}$

Flint varieties eut after kernels had

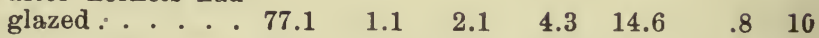

$\begin{array}{llllllll}\text { Dent varieties . . . } 79 . & 1.2 & 1.7 & 5.6 & 12 . & .5 & 63\end{array}$

Dent varieties cut after kernels had

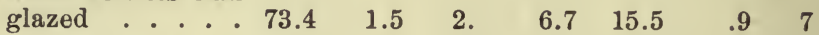
$\begin{array}{lllllllll}\text { Sweet varieties } & \ldots & 79.1 & 1.3 & 1.9 & 4.4 & 12.8 & .5 & 21\end{array}$

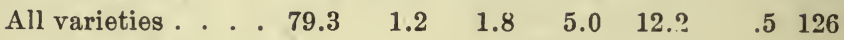
Leaves and husks,

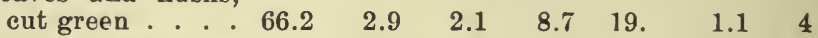
Stripped stalks, cut green . . . 76.1

Sorghum fodder . . . 79.4

$\begin{array}{rrrrrr}.7 & .5 & 7.3 & 14.9 & .5 & 4\end{array}$

$\begin{array}{llllll}1.1 & 1.3 & 6.1 & 11.6 & .5 & 11\end{array}$

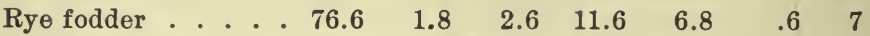

$\begin{array}{llllllll}\text { Barley fodder . . . . 79. } & 1.8 & 2.7 & 7.9 & 8 . & .6 & 1\end{array}$

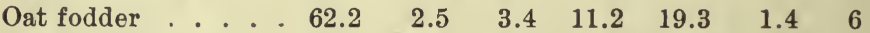

$\begin{array}{llllllllll}\text { Pasture grass . . . . } 80 . & \text { 2. } & 3.5 & 4 . & 9.7 & .8 & \text {. }\end{array}$

Redtop, $\dagger$ in bloom . . $\begin{array}{lllllll}65.3 & 2.3 & 2.8 & 11 . & 17.7 & .9 & 5\end{array}$

Tall o at grass, $\ddagger$ in

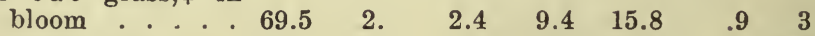

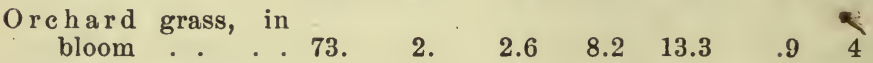

Meadow fescue, in

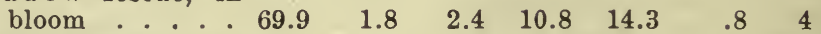

Italian rye grass, com -

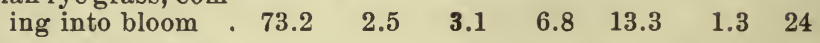

Timothy, 8 at different

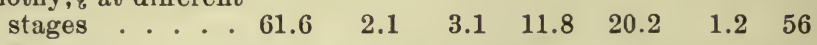

* Corn fodder is the entire plant, usually a thickly planted erop. Corn stover is what is left after the ears are harvested.

† Herd's grass of Pennsylvania.

$\ddagger$ Meadow Oat Grass.

Herd's grass of New England and New York. 


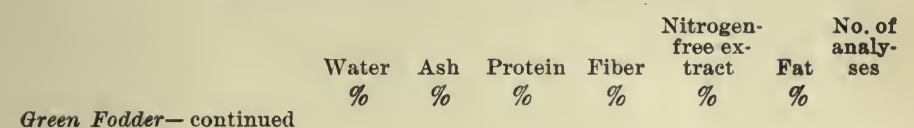

Kentucky blue grass, *

$\begin{array}{ccccccrr}\text { at different stages } & 65.1 & 2.8 & 4.1 & 9.1 & 17.6 & 1.3 & 18 \\ \text { ungarian grass . . . } & 71.1 & 1.7 & 3.1 & 9.2 & 14.2 & .7 & 14 \\ \text { panese millet . . . . } & 75 . & 1.5 & 2.1 & 7.8 & 13.1 & .5 & 12\end{array}$

Red clover, at differ-

$\begin{array}{llllllll}\text { ent stages . . . } & 70.8 & 2.1 & 4.4 & 8.1 & 13.5 & 1.1 & 43\end{array}$

Alsike clover, $\dagger$ in

$\begin{array}{llllllll}\text { bloom ... . } & 74.8 & 2 . & 3.9 & 7.4 & 11 . & .9 & 4\end{array}$

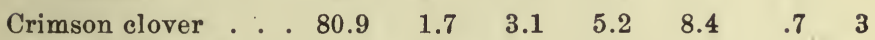

Alfalfa, $\ddagger$ at different

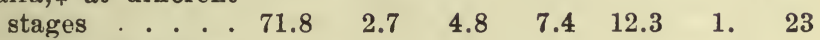

Serradella, at differ-

$$
\begin{array}{llllllll}
\text { ent stages ... . } & 79.5 & 3.2 & 2.7 & 5.4 & 8.6 & .7 & 9
\end{array}
$$

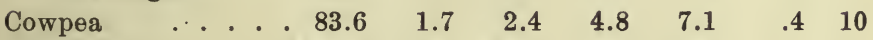

$\begin{array}{llllllll}\text { Soja bean . . . } 75.1 & 2.6 & 4 . & 6.7 & 10.6 & 1 . & 27\end{array}$

$\begin{array}{llllllll}\text { Horse bean . . . . } & 84.2 & 1.2 & 2.8 & 4.9 & 6.5 & 0.4 & 2\end{array}$

Flat pea (Lathyrus

$\begin{array}{llllllll}\text { sylvestris }) . \cdots & 66.7 & 2.9 & 8.7 & 7.9 & 12.2 & 1.6 & 2\end{array}$

$\begin{array}{llllllll}\text { Rape . . . . . . } 84.5 & 2 . & 2.3 & 2.6 & 8.4 & .5 & 2\end{array}$

\section{Silage}

$\begin{array}{llllllllll}\text { Corn silage } & \ldots & . & 79.1 & 1.4 & 1.7 & 6 . & 11 . & .8 & 99\end{array}$

$\begin{array}{lllllllll}\text { Sorghum silage } & \text {. . } & 76.1 & 1.1 & .8 & 6.4 & 15.3 & .3 & 6\end{array}$

$\begin{array}{lllllllll}\text { Red clover silage } & \text { • } 72 . & 2.6 & 4.2 & 8.4 & 11.6 & 1.2 & 5\end{array}$

$\begin{array}{llllllll}\text { 'Soja bean silage . . } 74.2 & 2.8 & 4.1 & 9.7 & 6.9 & 2.2 & 1\end{array}$

$\begin{array}{llllllll}\text { Cowpea vine silage. } & 79.3 & 2.9 & 2.7 & 6 . & 7.6 & 1.5 & 2\end{array}$

$\begin{array}{llllllll}\text { Field pea vine silage } & 50.1 & 3.5 & 5.9 & 13 . & 26 . & 1.6 & 1\end{array}$

Silage of mixture of

cowpea vines and

$\begin{array}{llllllll}\text { soja bean vines } & 69.8 & 4.5 & 3.8 & 9.5 & 11.1 & 1.3 & 1\end{array}$

$\begin{array}{lllllllll}\text { Millet and soja bean } & 79 . & 2.8 & 2.8 & 7.2 & 7.2 & 1 . & 9\end{array}$

$\begin{array}{lllllllll}\text { Corn and soja bean } & 76 . & 2.4 & 2.5 & 7.2 & 11.1 & .8 & 4\end{array}$

$\begin{array}{lllllllll}\text { Ry } \theta_{\text {. . . . . . . . } 80.8} & 1.6 & 2.4 & 5.8 & 9.2 & .3 & 1\end{array}$

$\begin{array}{llllllll}\text { Apple pomace . . . . . } 85 . & .6 & 1.2 & 3.3 & 8.8 & 1.1 & 1\end{array}$

*June Grass.

†Swedish Clover.

$\ddagger$ Lucerne. 
Hay and Dry Coarse Fodder

$\begin{array}{ccccccc}\text { Water } & \text { Ash } & \text { Protein } & \text { Fiber } & \begin{array}{c}\text { Nitrogen- } \\ \text { free ex- } \\ \text { tract }\end{array} & \begin{array}{c}\text { No. ot } \\ \text { analy } \\ \text { ses }\end{array} \\ \% & \% & \% & \% & \% & \% & \end{array}$

Corn fodder, ${ }^{*}$ field$\begin{array}{llllllll}\text { cured . . . . . } & 42.2 & 2.7 & 4.5 & 14.3 & 34.7 & 1.6 & 35\end{array}$

Corn leaves, field$\begin{array}{llllllll}\text { cured . . . . . } & 30 . & 5.5 & 6 . & 21.4 & 35.7 & 1.4 & 17\end{array}$

Corn husks, field$\begin{array}{llllllll}\text { cured . . . . . . } & 50.9 & 1.8 & 2.5 & 15.8 & 28.3 & .7 & 16\end{array}$

Corn stalks, field$\begin{array}{llllllll}\text { cured . . . . . } & 68.4 & 1.2 & 1.9 & 11 . & 17 . & .5 & 15\end{array}$

Corn stovert field$\begin{array}{llllllll}\text { cured . . . . . . } & 40.5 & 3.4 & 3.8 & 19.7 & 31.5 & 1.1 & 60\end{array}$

Barley hay, cut in

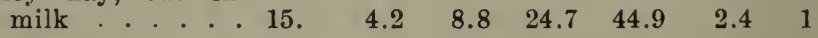
$\begin{array}{llllllll}\text { Oat hay, eut in milk } & 15 . & 5.2 & 9.3 & 29.2 & 39 . & 2.3 & 1\end{array}$ Hay from-

Redtop, $\ddagger$ cut at different stages . .

Redtop, cut in bloom $\begin{array}{lllllll}8.9 & 5.2 & 7.9 & 28.6 & 47.5 & 1.9 & 9\end{array}$ Orchard grass . . . 9.9 4.9 $\begin{array}{lllll}\text { 8. } & 29.9 & 46.4 & 2.1 & 3\end{array}$ Timothy, $;$ all analy's 13.2 $\begin{array}{llllll}6 . & 8.1 & 32.4 & 41 . & 2.6 & 10\end{array}$ Timothy, eut in full

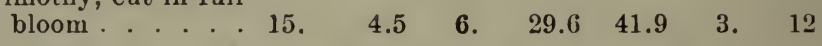

Timothy, cutsoon after bloom ....

Timothy, cut when $\begin{array}{lllllllll}\text { nearly ripe } & . & 14.1 & 3.9 & 5 . & 31.1 & 43.7 & 2.2 & 12\end{array}$ $\begin{array}{llllllll}\text { Kentucky blue grass } & 21.2 & 6.3 & 7.8 & 23 . & 37.8 & 3.9 & 10\end{array}$ Cut when seed was $\begin{array}{llllllll}\text { in milk . . } & 24.4 & 7 . & 6.3 & 24.5 & 34.2 & 3.6 & 4\end{array}$ Cut when seed was ripe . . . 27.8

$\begin{array}{llllll}6.4 & 5.8^{\prime} & 23.8 & 33.2 & 3 . & 4\end{array}$ $\begin{array}{lllllllll}\text { Hungarian grass . } & 7.7 & 6 . & 7.5 & 27.7 & 49 . & 2.1 & 13\end{array}$ $\begin{array}{lllllllll}\text { Meadow fescue } & \text {. . } & 20 . & 6.8 & 7 . & 25.9 & 38.4 & 2.7 & 9\end{array}$ $\begin{array}{lllllllll}\text { Italian rye grass . . } & 8.5 & 6.9 & 7.5 & 30.5 & 45 . & 1.7 & 4\end{array}$

* Entire plant.

t What is left after the ears are harvested.

$\ddagger$ Herd's grass of Pennsylvania.

\& Herd's grass of New England and New York. 


\section{Composition of Feeding Stuffs}

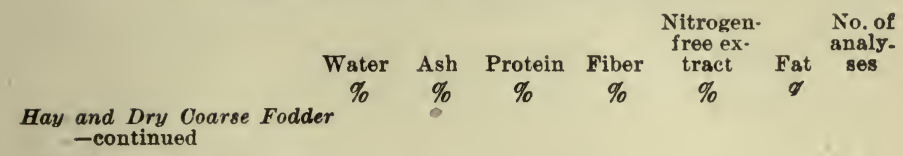

Hay from-

$\begin{array}{lllllllll}\text { Perennial rye grass . } & 14 . & 7.9 & 10.1 & 25.4 & 40.5 & 1.7 & 4\end{array}$

$\begin{array}{llllllll}\text { Mixed grasses . . } & 15.3 & 5.5 & 7.4 & 27.2 & 42.1 & 2.5 & 126\end{array}$

$\begin{array}{llllllll}\text { Rowen (mixed)* . . } & 16.6 & 6.8 & 11.6 & 22.5 & 39.4 & 3.1 & 23\end{array}$

Mixed grasses and clovers . . . 12.9

Swamp hay . . 11.6

$\begin{array}{llllll}5.5 & 10.1 & 27.6 & 41.3 & 2.6 & 17\end{array}$

Salt marsh . . . 10.4

$\begin{array}{llllll}6.7 & 7.2 & 26.6 & 45.9 & 2 . & 8\end{array}$

Red clover . . . 15.3

$\begin{array}{llll}7.7 & 5.5 & 30 . & 44.1\end{array}$

$2.4 \quad 10$

Red clover in bloom 20.8

$\begin{array}{llll}6.2 & 12.3 & 24.8 & 38.1\end{array}$

\begin{tabular}{l|l}
3.3 & 38
\end{tabular}

Alsike clover . . 9.7

6.6

12.

$21.9 \quad 33.8$

4.56

White clover . . 9.7

8.3

12.8

$25.6 \quad 40.7$

$2.9 \quad 9$

Crimson clover . . 9.6

8.3

15.7

$24.1 \quad 39.3$

$2.9 \div 7$

Japan clover . . 11.

$\begin{array}{llll}8.6 & 15.2 & 27.2 & 36.6\end{array}$

$2.8 \quad 7$

Vetch . . . . . 11.3

$\begin{array}{llll}8.5 & 13.8 & 24 . & 39 .\end{array}$

$3.7 \quad 2$

Serradella . . . 9.2

$7.9 \quad 17$

25.436 .1

2.35

Alfalfa $\dagger$. . . 8.4

$\begin{array}{ll}7.2 & 15.2\end{array}$

$21.6 \quad 44.2$

2.63

Cow pea

7.4

14.3

25. $\quad 42.7$

$2.2 \quad 21$

Soja bean .

7.5

Flat pea (Lathyrus sylvestris)....

Peanut vines (without nuts) .. .

10.7

$\begin{array}{ll}7.5 & 16.6\end{array}$

$20.1 \quad 42.2$

$2.2 \quad 8$

Pea vines . . . 15.

$8.4 \quad 7.9$

15.

$22.3 \quad 38.6$

5.26

Soja-bean straw . . 10.1

7.6
5.
0.1
9.2

10.

$\begin{array}{ll}6.7 & 13.7\end{array}$

5.8

4.6

8.7

8.3

4.2

3.4

22.9

$26.2 \quad 31.4$

$3.2 \quad 5$

$\begin{array}{lll}\text { Horse-bean straw } & \cdot & 9.2 \\ \text { Wheat straw } & \text {. . . } & 9.6\end{array}$

3.2

3

$23.6 \quad 42.7$

$4.6 \quad 6$

Rye straw

7.1

5.1

$24.7 \quad 37.6$

$2.3 \quad 1$

Oat straw . . . . . 9.2

5.1

4. 37.

$40.4 \quad 37.4$

1.74

Buckwheat straw . . 9.9

5.5

5.2

43

$37.6 \quad 34.3$

$1.4 \quad 1$

Roots and Tubers

Potatoes

$78.9 \quad 1$.

2.1

$38.1 \quad 43.4$

1.37

Sweet potatoes

71.1

1.

1.5

$\begin{array}{ll}.6 & 17.3\end{array}$

1.27

$2.3 \quad 12$

1.33

* Second eut.

†Lucerne. 
Appendix

\begin{tabular}{|c|c|c|c|c|c|c|c|c|c|}
\hline Roots and Tubers-c & cont'c & & $\begin{array}{c}\text { Water } \\
\%\end{array}$ & $\begin{array}{c}\text { Ash } \\
\%\end{array}$ & $\begin{array}{c}\text { Protein } \\
\%\end{array}$ & $\begin{array}{c}\text { Fiber } \\
\%\end{array}$ & $\begin{array}{c}\text { Nitrogen- } \\
\text { free ex- } \\
\text { tract } \\
\%\end{array}$ & $\begin{array}{c}\text { Fat } \\
\%\end{array}$ & $\begin{array}{l}\text { No. of } \\
\text { analy } \\
\text { ses }\end{array}$ \\
\hline Red beéts... & - . & . & 88.5 & 1. & 1.5 & .9 & 8. & .1 & 9 \\
\hline Sugar beets . . & - . & - & 86.5 & .9 & 1.8 & .9 & 9.8 & .1 & 19 \\
\hline Mangel-wurzels & . & . & 90.9 & 1.1 & 1.4 & .9 & 5.5 & .2 & \\
\hline Turnips . . . . & & & 90.5 & .8 & 1.1 & 1.2 & 6.2 & .2 & \\
\hline Rutabagas . . & - & - & 88.6 & 1.2 & 1.2 & 1.3 & 7.5 & .2 & \\
\hline Carrots . . . : & - . & - & 00 & 1 & 1.1 & 1.3 & 7.6 & .4 & \\
\hline Artichokes . . & . . & & 79.5 & 1. & 2.6 & .8 & 15.9 & .2 & \\
\hline
\end{tabular}

Grains and Other Seeds

Corn kernel-

Dent, all analyses • 10.6

$\begin{array}{ll}1.5 & 10.3\end{array}$

$\begin{array}{ll}2.2 & 70.4\end{array}$

5. 86

Flint, all analyses . 11.3

$1.4 \quad 10.5$

$\begin{array}{ll}1.7 & 70.1\end{array}$

5. 68

Sweet, all analyses. $\quad 8.8$

$1.9 \quad 11.6$

$2.8 \quad 66.8$

8.126

Pop varieties . . 10.7

$\begin{array}{ll}1.5 & 11.2\end{array}$

$1.8 \quad 69.6$

5.24

Soft varieties . . 9.3

All varieties and analyses . . . 10.9

$1.6 \quad 11.4$

2. 70.2

5.55

Sorghum seed . . . 12.8

$1.5 \quad 10.5$

$\begin{array}{ll}2.1 & 69.6\end{array}$

5.4208

Barley . . . . 10.9

$2.1 \quad 9.1$

$2.6 \quad 69.8$

$\begin{array}{ll}3.6 & 10\end{array}$

Oats ...... 11

$2.4 \quad 12.4$

$2.7 \quad 69.8$

$1.8 \quad 10$

Rye

3. 11.8

$9.5 \quad 59.7$

5. 30

Wheat-

Spring varieties . . 10.4 $1.9 \quad 10.6$

$\begin{array}{ll}1.7 & 72.5\end{array}$

$1.7 \quad 6$

Winter varieties, all analyses . . 10.5

$1.9 \quad 12.5$

$1.8 \quad 71.2$

$2.2 \quad 13$

All varieties . . 10.5

$\begin{array}{llll}1.8 & 11.8 & 1.8 & 72 .\end{array}$

2.1262

$\begin{array}{llllll}1.8 & 11.9 & 1.8 & 71.9 & 2.1 & 310\end{array}$

Rice . . . . . 12.4

$.4 \quad 7.4$

$\begin{array}{ll}.2 & 79.2\end{array}$

$.4 \quad 10$

Buckwheat . . . 12.6

2. 10

$8.7 \quad 64.5$

$2.2 \quad 8$

Sunflower seed (whole) 8.6

$\begin{array}{llllll}2.6 & 16.3 & 29.9 & 21.4 & 21.2 & 2\end{array}$

Flaxseed . . . . 9.2

$\begin{array}{llllll}4.3 & 22.6 & 7.1 & 23.2 & 33.7 & 50\end{array}$

Cottonseed ( $w$ hol $\theta$,

with hulls)...
Cottonseed kernels (without hulls). 10.3 3.5

6.2

$4.7 \quad 31.2$

23.2

$\begin{array}{lll}24.7 & 19.9 & 5\end{array}$

Cottonseed whole, rossted ... 


\begin{tabular}{|c|c|c|c|c|c|c|c|}
\hline \multirow[b]{3}{*}{$\begin{array}{l}\text { Grains and Other Seeds- } \\
\text { coutinued }\end{array}$} & \multirow{3}{*}{$\begin{array}{c}\text { Water } \\
\%\end{array}$} & \multirow{3}{*}{$\stackrel{\text { Ash }}{\%}$} & \multirow{3}{*}{$\begin{array}{l}\text { Protein } \\
\quad \%\end{array}$} & \multirow{3}{*}{$\begin{array}{l}\text { Fiber } \\
\%\end{array}$} & \multicolumn{2}{|l|}{$\begin{array}{l}\text { Nitrogen. } \\
\text { froe ex. }\end{array}$} & \multirow{2}{*}{$\begin{array}{c}\text { No. of of } \\
\text { analyo } \\
\text { ses }\end{array}$} \\
\hline & & & & & tract & Fat & \\
\hline & & & & & & & \\
\hline $\begin{array}{l}\text { Peanut kernel (with- } \\
\text { out bulls) }\end{array}$ & 7.5 & 2.4 & 27.9 & .7. & 15.6 & 39.6 & 7 \\
\hline Horse bean . & $11.3^{\circ}$ & 3.8 & 26.6 & 7.2 & 50.1 & 1. & 1 \\
\hline Suja bean . . . . . & 10.8 & 4.7 & 34. & 4.8 & 28.8 & 16.9 & 8 \\
\hline Cow pea . . & 14.8 & 3.2 & 20.8 & 4.1 & 55.7 & 1.4 & 5 \\
\hline \multicolumn{8}{|l|}{ Mill Products } \\
\hline orn meal & 15. & 1.4 & 9.2 & 1.9 & 68.7 & 3.8 & 77 \\
\hline Corn and cob meal. & 15.1 & 1.5 & 8.5 & 6.6 & 64.8 & 3.5 & 7 \\
\hline Oatmeal. & 7.9 & 2. & 14.7 & .9 & 67.4 & 7.1 & 6 \\
\hline Barley meal & 11.9 & 2.6 & 10.5 & 6.5 & 66.3 & 2.2 & 3 \\
\hline Rye flour & 13.1 & .7 & 6.7 & .4 & $78.3-$ & .8 & 4 \\
\hline Wheat flour, all analy's & 12.4 & .5 & 10.8 & .2 & 75. & 1.1 & 20 \\
\hline Buckwheat flour & 14.6 & 1. & 6.9 & $: 3$ & 75.8 & 1.4 & 4 \\
\hline Ground linseed & 8.1 & 4.7 & 21.6 & 7.3 & 27.9 & 30.4 & 2 \\
\hline Pen meal & 10.5 & 2.6 & 20.2 & 14.4 & 51.1 & 1.2 & 2 \\
\hline Soja-bean meal & 10.8 & 4.5 & 36.7 & 4.5 & 27.3 & 16.2 & 1 \\
\hline \multicolumn{8}{|c|}{ Ground corn and oats } \\
\hline \multicolumn{8}{|l|}{ Waste Products } \\
\hline Corneob & 10.7 & 1.4 & 2.4 & 30.1 & 54.9 & .5 & 18 \\
\hline Hominy chops. & 11.1 & 2.5 & 9.8 & 3.8 & 64.5 & 8.3 & 12 \\
\hline Corn bran & 9.1 & 1.3 & 9. & 12.7 & 62.2 & 5.8 & 5 \\
\hline Corn germ & 10.7 & 4. & 9.8 & 4.1 & 64. & 7.4 & 3 \\
\hline Corn-germ meal & 8.1 & 1.3 & 11.1 & 9.9 & 62.5 & 7.1 & 6 \\
\hline \multicolumn{8}{|l|}{ Gluten meal- } \\
\hline Cream & 10.1 & .8 & 33.7 & 1.7 & 51.1 & 2.6 & \\
\hline Chicago* & 12.3 & 1.3 & 36.5 & 1.4 & 45.8 & 2.7 & \\
\hline King & 7.4 & .5 & 33.7 & 1.2 & 52.6 & 4.6 & \\
\hline Gluten feed & 7.8 & 1.1 & 24. & 5.3 & 51.2 & 10.6 & 11 \\
\hline Buffalo* & 9.6 & 2.3 & 27.1 & 6.7 & 51.1 & 3.2 & \\
\hline Peoria* & 7.5 & .8 & 19.8 & 8.2 & 51.1 & 12.6 & 1 \\
\hline $\begin{array}{l}\text { Diamond, or Rock- } \\
\text { ford }\end{array}$ & 8.9 & .8 & 23.6 & 6.6 & 56.6 & 3.5 & \\
\hline
\end{tabular}

\footnotetext{
*Included in above average.
} 
Waste Products-continued

\begin{tabular}{|c|c|c|c|c|c|c|}
\hline Wat & Ash & Protein & Fiber & $\begin{array}{l}\text { Nitrogen- } \\
\text { free ex- } \\
\text { tract }\end{array}$ & Fat & $\begin{array}{l}\text { No. of } \\
\text { analy. } \\
\text { ses }\end{array}$ \\
\hline$\%$ & $\%$ & $\%$ & $\%$ & $\%$ & $\%$ & \\
\hline
\end{tabular}

Chicago maize feed.

$\begin{array}{lllllll}9.1 & .9 & 22.8 & 7.6 & 52.7 & 6.9 & 3\end{array}$

Glucose feed and glucose refuse...

$\begin{array}{lllllll}6.5 & 1.1 & 20.7 & 4.5 & 56.8 & 10.4 & 2\end{array}$

Dried starch feed and sugar feed . . 10.9

Starch feed, wet . . 65.4

Oat hulls . . . $\quad 7.3$

Oat feed . . . 7.7

Barley screenings . . 12.2

Malt sprouts . . . 5.

Brewers' grains, wet . 75.7

Brewers' grains, dried 8.2

Grano gluten . . : 5.8

Rye bran . . . . 11.6

Rye shorts . . . 9.3

Wheat bran from

$\begin{array}{llllllll}\text { spring wheat } \ldots & 11.5 & 5.4 & 16.1 & 8 . & 54.5 & 4.5 & 10\end{array}$

Wheat bran from winter wheat. .

12.3

5.916.

$\begin{array}{llll}8.1 & 53.7 & 4 . & \boldsymbol{\tau}\end{array}$

Wheat bran, all an'ses 11.9

$\begin{array}{ll}5.8 & 15.4\end{array}$

9. 53.9

4. 88

Wheat middlings . . 10.

$3.8 \quad 17.4$

5.258.

5.6 .

Wheat shorts . . . 11.8

$4.6 \quad 14.9$

$\begin{array}{ll}7.4 & 56.8\end{array}$

$4.5 \quad 12$

Wheat screenings . 11.6

$2.9 \quad 12.5$

4.965 .1

3. 10

Rice bran . . . . 9.7

10. $\quad 12.1$

$9.5 \quad 49.9$

$8.8 \quad 5$

Rice hulls

$8.2 \quad 13.2$

3.6

$35.7 \quad 38.6$

.73

Rice polish . . . 10.

$\begin{array}{ll}6.7 & 11.7\end{array}$

6.358 .

$7.3 \quad 4$

Buckwheat hulls . . 13.2

2.24 .6

43.5

35.3

1.12

Buckwheat bran . . 10.5

Buckwheat middlings $\mathbf{1 3 . 2}$

3. 12.4

31.9

38.8

3.32

Cottonseed meal a $\quad 6.8$

$\begin{array}{ll}4.8 & 28.9\end{array}$

$\begin{array}{ll}4.1 & 41.9\end{array}$

7.13

Cottonseed hulls . . 11.1

6.245 .6

$\begin{array}{lll}5.4 & 25.2 & 10.8\end{array}$

2.84 .2

46.3

$\begin{array}{lll}33.4 & 2.2 & 20\end{array}$

Lins'd meal, old proc's 8.3

$5.3 \quad 35.7$

7.5

36.

7.2

Lins'd meal, new proc's 10.

$5.2 \quad 36.1$

8.436 .7

3.6

Peanut meal . . . . 10.7

$4.9 \quad 47.6$

$5.1 \quad 23.7$

8. 2,480

Peanut hulls

6.6

64.3

15.1

$1.6 \cdot 5$ 


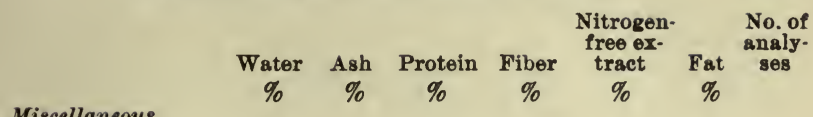

Miscellaneous

\begin{tabular}{|c|c|c|c|c|c|c|c|}
\hline Acorns & & 55.3 & 1. & 2.5 & 4.4 & 34.8 & 1.9 \\
\hline Apples & & 80.8 & .4 & .7 & 1.2 & 16.6 & .4 \\
\hline Apple pomace. & & 76.7 & .5 & 1.4 & 3.9 & 16.2 . & 1.3 \\
\hline Beet pulp . . & & 89.8 & .6 & .9 & 2.4 & 6.3 & \\
\hline Beet molasses & & 20.8 & 10.6 & $9.1(?)$ & & 59.5 & \\
\hline Cabbage & & 90.5 & 1.4 & 2.4 & 1.5 & 3.9 & .4 \\
\hline Prickly comfrey & . & 88.4 & 2.2 & 2.4 & 1.6 & 5.1 & .3 \\
\hline Pumpkin (field) & & 90.9 & .5 & 1.3 & 1.7 & 5.2 & .4 \\
\hline ugar beet leaves & & 88. & 2.4 & 2.6 & 2.2 & 4.4 & .4 \\
\hline
\end{tabular}

\section{AVERAGE COEFFICIENTS OF DIGESTION}

The coefficients of digestion which follow are mostly taken from the compilation by Jordan and Hall as published in Bulletin No. 77, Office of Experiment Stations. Others, marked $G$, are from the compilation of Dietrich and König (Composition and Digestibility of Cattle Foods, Vol. II).

\section{Digestion by Ruminants}

\begin{tabular}{|c|c|c|c|c|c|c|c|}
\hline $\begin{array}{c}\text { No, ex- } \\
\text { perim'ts }\end{array}$ & $\begin{array}{l}\text { Kind and condi- } \\
\text { tion of food }\end{array}$ & $\underset{\text { matter }}{\text { Dry }} \underset{\%}{\%}$ & $\begin{array}{c}\text { Organic } \\
\text { matter } \\
\%\end{array}$ & $\begin{array}{c}\text { Ash } \\
\%\end{array}$ & $\begin{array}{c}\text { Pro- } \\
\text { tein } \\
\%\end{array}$ & $\begin{array}{c}\text { Fiber } \\
\%\end{array}$ & $\begin{array}{c}\text { Nitrogen } \\
\text { free ex- } \\
\text { traet } \\
\%\end{array}$ \\
\hline
\end{tabular}

GREEN FODDERS

Meadow Grasses

$\begin{array}{llllllll}3 & \text {. Hungarian . . . . } 67.2 & 68.6 & 52.2 & 64.3 & 71.2 & 67.9 & 65.7\end{array}$

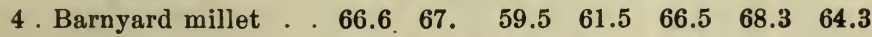

1. Timothy . . . . $6 \begin{array}{lllllll}63.5 & 65.6 & 32.2 & 48.1 & 55.6 & 65.7 & 53.1\end{array}$

$\begin{array}{lllllllll}\text { 1. Timothy rowen . . } ~ & 64.8 & 66.4 & 45.2 & 71.7 & 63.8 & 67.8 & 62.9\end{array}$

$\begin{array}{llllllllll}\text { 1. Pasture grass } & \text {. . } & 68.7 & 70 . & 49.7 & 65.5 & 74.3 & 72.5 & 54.7\end{array}$

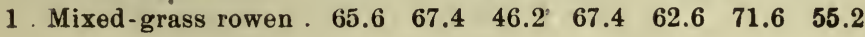




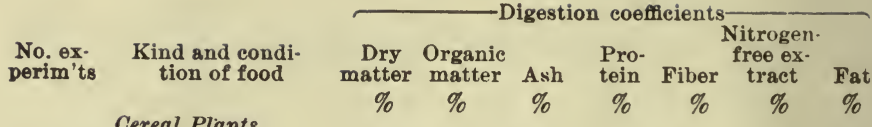

2 Barley.

$\begin{array}{lllllll}65.9 & 67.5 & 54.4 & 71.8 & 60.8 & 71.2 & 59.9\end{array}$

$\begin{array}{lllllllll}8 & \text {. Dent corn, immature } & 68.8 & 70.7 & 45.4 & 65.2 & 66.6 & 73 . & 72 .\end{array}$

$\begin{array}{lllllllll}6 & \text { Dent corn, mature } & 66.6 & 68.5 & 19.4 & 52.3 & 51.6 & 74.7 & 77 .\end{array}$

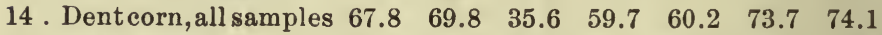

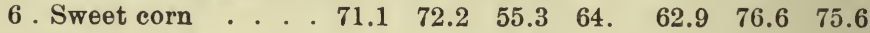

$\begin{array}{lllllllllll}3 & \text { Oats . . . . . } & 59.5 & 60.9 & 53.4 & 71.8 & 52.8 & 62.6 & 69.2\end{array}$

$\begin{array}{llllllllll}1 . & \text { Rye . . . . . . . . } 73.4 & 75.3 & 55.8 & 79.4 & 79.2 & 70.1 & 74.5\end{array}$

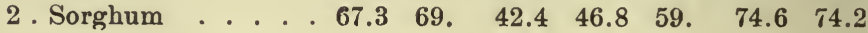

Clovers and Legumes

6. Alfalfa (G) . . . . . 64. . . 81. 41. 72.45 .

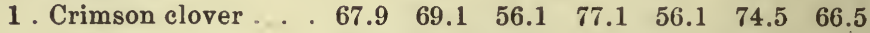

$\begin{array}{lllllllll}\text { 1. Red clover . . . . . } & 66.1 & 68.1 & 55 . & 67 . & 52.6 & 77.6 & 64.5\end{array}$

1. Red clover, before bloom (G) . . . . . 74. . . 74. $60 . \quad 83.65$.

2 . Red clover, beginning bloom (G) . . . . . 71. . . 74. 57. 79.71.

2. Red clover, bloom to end $(G)$. . . . . . 61. . . 64. 44. 71. 53 .

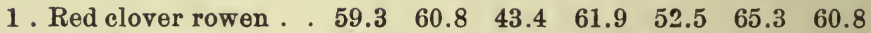

$\begin{array}{lllllllll}1 \text {. Canada peas . . . . } & 68.4 & 71.3 & 42.3 & 82 . & 62.4 & 71 . & 52.4\end{array}$

2. Cow pea . . . . . $6 \begin{array}{ccccccc}68.3 & 74.1 & 22.8 & 75.6 & 59.6 & 80.6 & 59.4\end{array}$

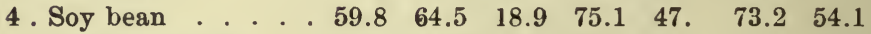

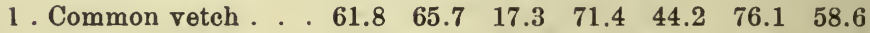

$\begin{array}{lllllllll}3 \text {. Hairy vetch } \ldots & * & 70.3 & 73.1 & 45.1 & 82.8 & 61.1 & 76.3 & 71.6\end{array}$

Mixed

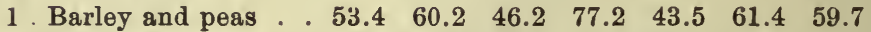

$\begin{array}{lllllllll}\text { 4. Oats and peas } & \text {. } & 65.4 & 67.2 & 45.4 & 76.1 & 59.7 & 67.7 & 67.7\end{array}$

$\begin{array}{llllllll}\text { 1. Vetch and oats . . . } 67 . & 68.4 & 52.7 & 74.8 & 68.3 & 67.9 & 47.2\end{array}$

SILAGE

Maize

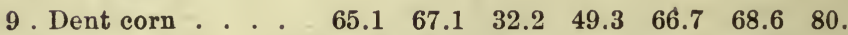

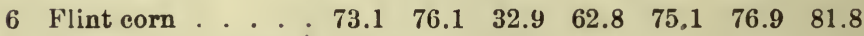

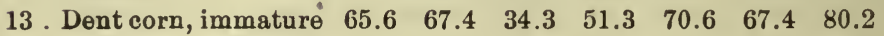




\section{Digestibility of Feeding Stuffs}

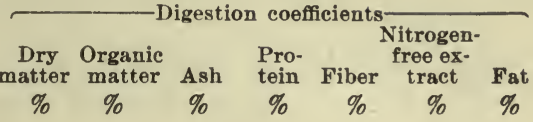

Maize-continued

\begin{tabular}{|c|c|c|c|c|c|c|c|}
\hline $\begin{array}{l}\text { No. ex- } \\
\text { perim'ts }\end{array}$ & $\begin{array}{l}\text { Kind and condi- } \\
\text { tion of food }\end{array}$ & 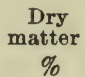 & $\begin{array}{c}\text { Organic } \\
\text { matter } \\
\%\end{array}$ & $\begin{array}{c}\text { Ash } \\
\%\end{array}$ & $\begin{array}{c}\text { Pro- } \\
\text { tein } \\
\%\end{array}$ & $\begin{array}{c}\text { Fiber } \\
\%\end{array}$ & $\begin{array}{c}\text { free ex- } \\
\text { tract } \\
\%\end{array}$ \\
\hline
\end{tabular}

10. Dent and flint corn, $\begin{array}{lllllllll}\text { mature } & \text {. . . } & 70.8 & 73.6 & 30.3 & 56 . & 70 & 76.1 & 82.4\end{array}$

$\begin{array}{lllllllll}1 . & \text { Sweet corn . . . } & 68.1 & 70.1 & 31.9 & 54 . & 71.1 & 71.8 & 83.5\end{array}$ Miscellaneous

$\begin{array}{lllllllll}1 . \text { Cow pea . . . . } & 59.6 & 63.4 & 30.3 & 57.5 & 52 . & 72.5 & 62.6\end{array}$

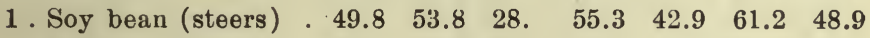

$\begin{array}{lllllllll}1 \text {. Soy bean (goats) } & \text {. } & 59 . & 59.3 & 56.7 & 75.7 & 54.8 & 52 . & 71.9\end{array}$

$\begin{array}{llllllll}1 . & \text { Corn and soy bean . 69. } & 71 .^{\circ} & \text {. . } & 65 . & 64.8 & 74.9 & 82.1\end{array}$

1. Millet and soy bean $58.8 \quad 59.9 \quad$. $58.4 \quad 69.4 \quad 59.2 \quad 72.2$

1. Corn, horse beans, and su nflower heads.....

$\begin{array}{lllllll}65.6 & 67.8 & 41.1 & 62.7 & 60.1 & 72.4 & 76.7\end{array}$

1. Corn, horse beans, and $\mathrm{sunflow}$ er $\begin{array}{lllllllll}\text { plants . . . . . . } & 65.5 & 69.3 & 25.6 & 58 . & 65.3 & 73.7 & 74.1\end{array}$

DRIED FODUERS

Meadow Grasses

1. Black grass (Juncus

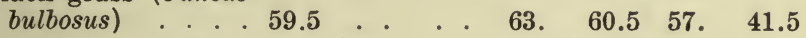

1. Black grass (Juncus

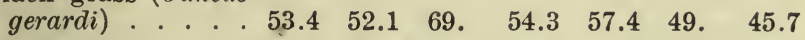

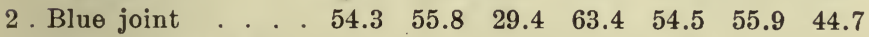

1. Branch grass (Spar-

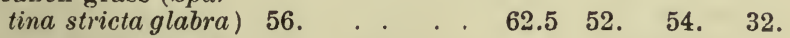

1. Branch grass (Dis$\begin{array}{llllllll}\text { tichlys spicata) . . } & 49.7 & 48.9 & 58.1 & 51.7 & 56.4 & 45.7 & 36.6\end{array}$

$\begin{array}{llllllll}1 . & \text { Chess or cheat . . } 45 . & 47.3 & 23 . & 42 . & 46 . & 49 . & 32 .\end{array}$

$\begin{array}{lllllllllll}2 & \text {. Crab grass } & \text {. } & . & 53.6 & 55 . & 37.6 & \text {. } & 59: 1 & 54.5 & 46.8\end{array}$

$\begin{array}{cccccccc}\text { 1. Fox grass (Spartina } & & & & & & & \\ \text { patens) . . . . } & 54.8 & 54.5 & 58.2 & 59.3 & 57.4 & 53.1 & 36.4\end{array}$

1. Fox grass (Spartina juncea, etc.). . . 53. . . . . 57.51 .52 .24$.

$\begin{array}{lllllllll}\text { 1. Flat sage . . . . . } 56.1 & 57.3 & 62 . & 51.8 & 60.4 & 55.1 & 36.1\end{array}$

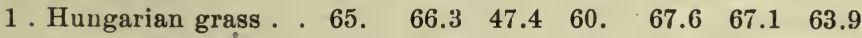

2. Johnson grass . . . $\begin{array}{llllllll}56.5 & 58.3 & 30.5 & 41.4 & 65.7 & 56.9 & 38.4\end{array}$ 


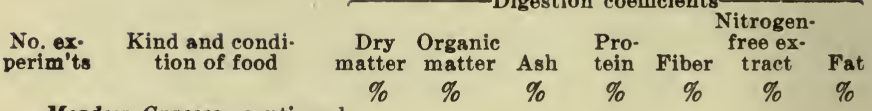
Meadow Grasses-continued

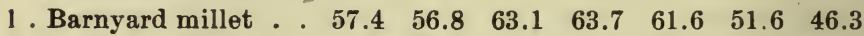

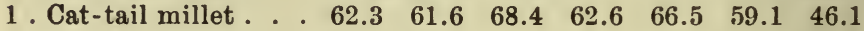

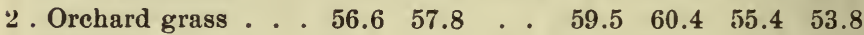

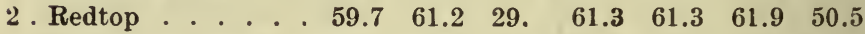

$\begin{array}{lllllllll}1 \text {. Redtop and sedge } & 46 . & 48.5 & 10.1 & 37.2 & 55.7 & 45.6 & 49 .\end{array}$

17. Timothy . . . $\quad \begin{array}{llllllll}56.6 & 57.9 & 32.8 & 46.9 & 52.5 & 62.3 & 52.2\end{array}$

3 . Timothy, before or in bloom

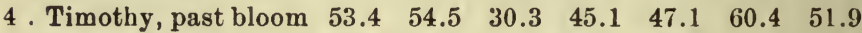

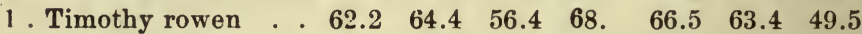

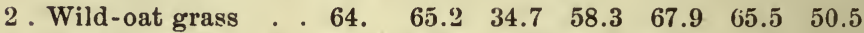

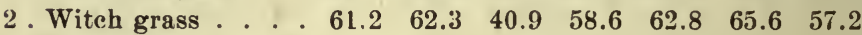

1. Black grass and red-

$\begin{array}{llllllll}\text { top (cove mixture) } & 54.6 & 54.3 & 57.5 & 47.9 & 59.7 & 53.2 & 40.3\end{array}$

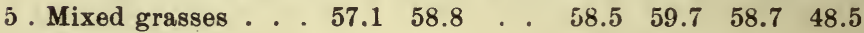

Meadow hay -

Best (G) . . . . . . 67. . . 65. 63. 68. 57 .

Medium (G) . . . . . 61. . . 57. 60. 64. 53.

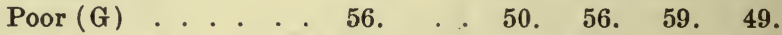

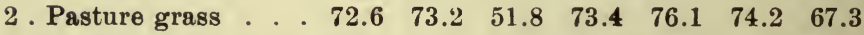

1. Swale hay . . . . 39. . . . . 34. 33. 46.44.

1. High grown salt hay 53. . . . . . $63 . \quad 50 . \quad 53.47$.

$\begin{array}{llllllll}\text { 1. Salt-hay mixture . . } & 56.4 & 54.9 & 69.8 & 42.6 & 60.7 & 54.7 & 29.7\end{array}$

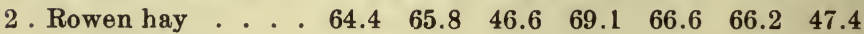

Cereal Plants

$\begin{array}{llllllllll}1 \text {. Barley hay } & * & 61.2 & 62.3 & 44.8 & 65.2 & 61.7 & 63.3 & 40.5\end{array}$

17. Dent corn fodder $\quad \begin{array}{lllllll}64.3 & 66.1 & 30.7 & 50.4 & 62.2 & 68 . & 73.6\end{array}$

$\begin{array}{lllllllll}7 \text {. Flint corn fodder } & \text {. } & 68.6 & 71.7 & 42.6 & 60 & 74.9 & 70.3 & 71.4\end{array}$

13. Dent and flint corn

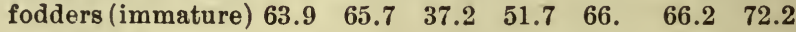

10. Dent and flint corn

$\begin{array}{llllllll}\text { fodders (mature) } & 68.2 & 70.7 & 30.6 & 56.1 & 65.8 & 72.2 & 73.9\end{array}$

$\begin{array}{lllllllll}3 \text {. Sweet corn fodder } . ~ & 67.2 & 69.8 & 35.6 & 64.1 & 73.8 & 68.2 & 73.6\end{array}$

$\begin{array}{lllllllll}5 & \text {. Corn stover }+\cdots & 57.2 & 59.1 & 32.6 & 35.9 & 64.2 & 57.9 & 70.4\end{array}$ 


\section{Digestibility of Feeding Stuffs}

No. ex- Kind and condi-

Cereal Plants-continued

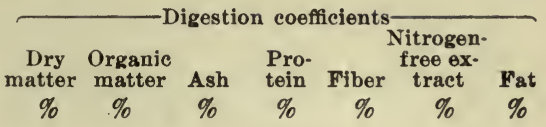

$\begin{array}{lllllllll}3 \text {. New corn product } & 58.1 & 59.2 & 38.7 & 46.7 & 57 & 60.5 & 78.2\end{array}$

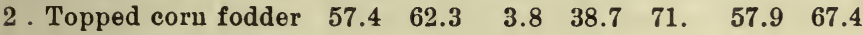

1. Corn blades and husks .....

2. Corn leaves (pulled fodder) ....

1. Corn husks . . . 72

$\begin{array}{lllllll}63.8 & 67.1 & 22.6 & 47.7 & 72.9 & 66.4 & 58.1\end{array}$

$\begin{array}{llllll}74.2 & 16 . & 29.5 & 79.5 & 75 . & 32.5\end{array}$

$\begin{array}{llllllll}\text { 1. Corn butts . . . . . } & 66.5 & 69.4 & 11.5 & 21 . & 73.5 & 69 . & 79.5\end{array}$

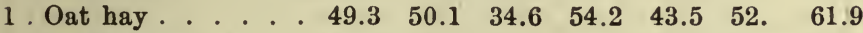

1. Oat straw . . . . $5 \begin{array}{cccccccc}50.3 & 52 . & \text {. . } & \text {. . } & 57.6 & 53.2 & 38.3\end{array}$

Bean straw $\quad . . . .55 . \quad . .49 .43 .67 .67$.

Wheat straw $(G)$. . . . 46. $\quad$. . 33 . $35 . \quad 39.36$.

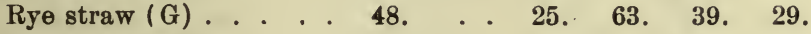

Barley straw $(G) \quad$. . . $53 . \quad$. . $25 . \quad 55 . \quad 54.42$.

Rice straw (G) . . . . 47. $47 . \quad 45 . \quad 57 . \quad 32.47$.

1. Sorghum fodder

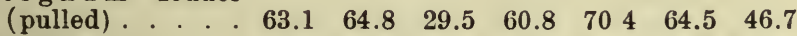

$\begin{array}{lllllllll}1 \text {. Sorghum bagasse } & \text {. } & 60.6 & 62.2 & 13.4 & 13.7 & 63.8 & 64.8 & 46.4\end{array}$

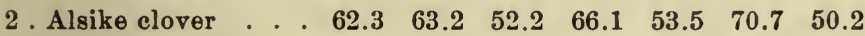

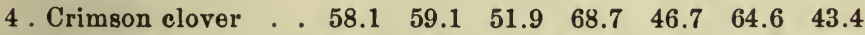

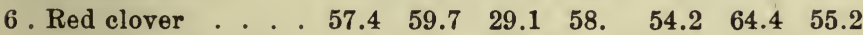

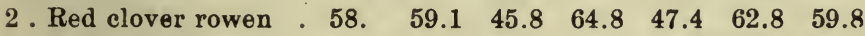

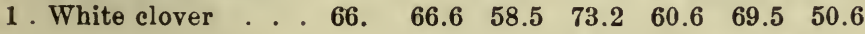

\section{Legumes other than Olovers}

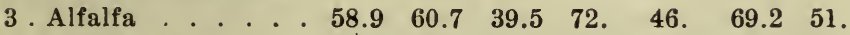

$\begin{array}{lllllllll}\text { 1. Cow pea vine } & \ldots & 59.2 & 60 & 49.5 & 64.8 & 42 . & 70.6 & 51.8\end{array}$

1. Peanut vine . . . . $5 \begin{array}{ccccccc}59.9 & 63.1 & 20.4 & 63.3 & 51.9 & 69.5 & 65.9\end{array}$

1. Soy bean . . . . . $62.4 \quad 63.9 \quad$. : $\quad \begin{array}{llllll}71.1 & 60.8 & 68.8 & 29.2\end{array}$

$\begin{array}{lllllllll}1 . \text { Hairy vetch } & \text {. . . } & 69.4 & 71.8 & 42.2 & 82.3 & 61.1 & 72.9 & 70.3\end{array}$ Bean straw (G) . . . . 55. . . 49. 43. 67.57. Pea straw, good $(G) \quad \ldots \quad 59 . \quad$. . $60.62 . \quad 64.46$. 


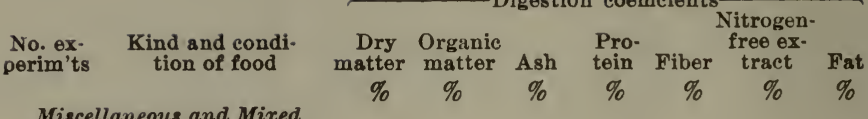

\section{Miscellaneous and Mixed}

$\begin{array}{llllllll}\text { 1. Buttercup hay . . . } & 56.1 & 56.6 & 48.1 & 56.3 & 41.1 & 66.9 & 69.7\end{array}$

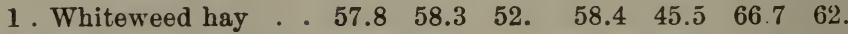

2. Clover and timothy . $54.6 \quad 53.2 \quad$. . $\quad \begin{array}{llllll}42.3 & 49.6 & 57.5 & 54 .\end{array}$

$\begin{array}{llllllll}1 \text {. Vetch and oats . . . } & 58.1 & 58.7 & \text {. } & 59.7 & 66 . & 54.2 & 18.6\end{array}$

Grains and Seeds

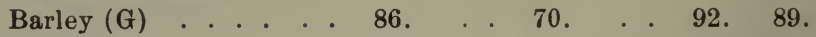

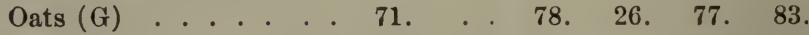

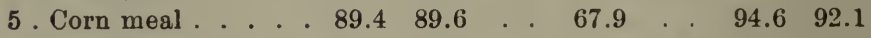

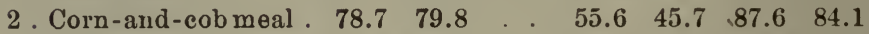

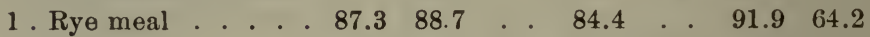

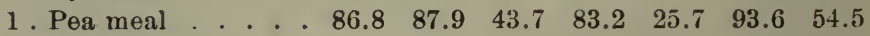

Field beans . . . . . . 89. . . 88. 72. 92.81 .

$\begin{array}{llllllll}\text { 1. Soy-bean meal : . . } 81.9 & 84 . & \text {. . } & 91 & 1.71 .2 & 76.3 & 8.3 .7\end{array}$

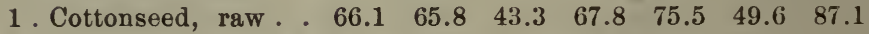

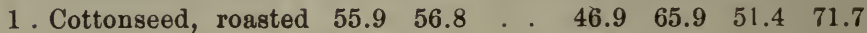

Linseed . . . . . . . . 77. . . 91. 60. 55.86.

Acorns . . . . . . 88. . . 83. 62. 91.87.

BY-PRODUCTS

Cereals

1. Atlas meal . . . . . $79.6 \quad 83.4 \quad$ • . $72.8 \quad 705.7 \quad 84.5 \quad 91.2$

1. Cerealine feed . . . $90.4 \quad 92.7 \quad$. $9 \begin{array}{llllll}76.6 & 82.2 & 95.3 & 80.6\end{array}$

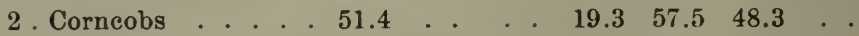

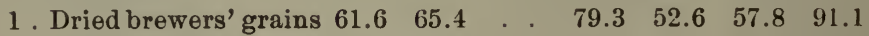

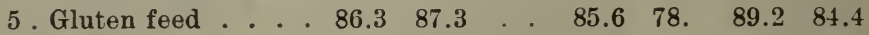

4. Gluten meal . . . $89.790 .4 \quad$. $898.2 \quad$. 88.89 .894 .4

1. H. O. dairy feed . . $65.3 \quad 68$. $\quad \begin{array}{lllllll}67.8 & 40.8 & 69.9 & 85.5\end{array}$

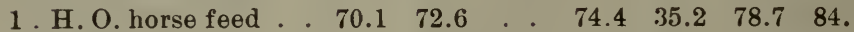

1. Maize feed . . . . $87.187 .1 \quad$. $8 \begin{array}{llllll}85.5 & 82.5 & 87.9 & 91.5\end{array}$

1. Malt sprouts . . . $.6 \begin{array}{cccccccc}67.1 & 67.2 & \ldots & 80.2 & 32.9 & 68.1 & 104.6\end{array}$

1 Quaker oat feed . . $62 . \quad 65.3 \quad \ldots .81 .1 \quad 42.6 \quad 67.4 \quad 89$.

1. Victor corn-and-oat

feed . . . . $\quad \begin{array}{llllllll} & 74.7 & 77.4 & . & 70.8 & 48.3 & 83 . & 86.8\end{array}$ 


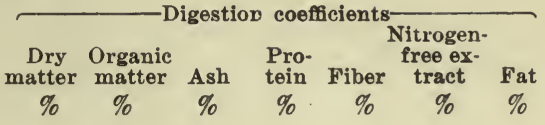

No. ex- Kind and condiperim'ts tion of food

Cereal-continued

$\% \quad \% \quad \% \quad \% \quad \% \quad \%$

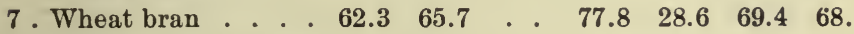

1. Wheat bran and shorts . . . . . $6 \begin{array}{ccccccc}60.2 & 60.7 & 7.5 & 75.8 & 18.3 & 64.3 & 45 .\end{array}$

$\begin{array}{lllllllll}3 \text {. Wheat middlings . . } & 75 . & 78.5 & \text {. } & 79.8 & 33.1 & 81.3 & 86.3\end{array}$ Oil-bearing Seeds

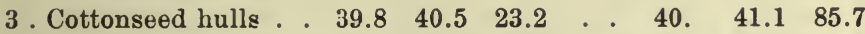

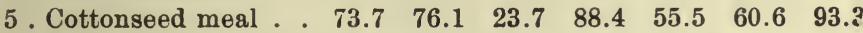

1. Linseed meal, old

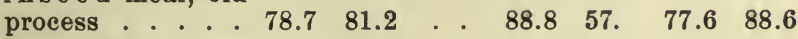

2. Linseed meal, new

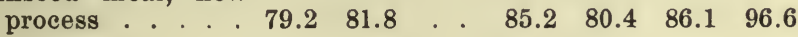
Miscellaneous

$\begin{array}{llllllllll}\text { 1. Peanut feed . . . . } & 32.1 & 32.8 & \text { • . } & 70.6 & 11.7 & 49.1 & 89.7\end{array}$

1. Rice meal . . . . . $73.8 \quad 81.6 \quad$. $61.9 \quad$. 92.391 .1 ROOTS

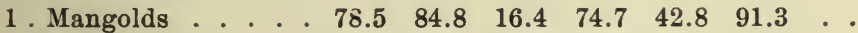

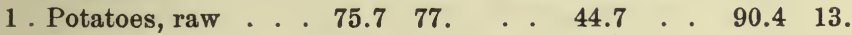

1. Potatoes, boiled . 80.181 .2 . 83.4 . 492.1 .

1. Rutabagas . . . . . $8 \begin{array}{ccccccc}87.2 & 91.1 & 31.2 & 80.3 & 74.2 & 94.7 & 84.2\end{array}$

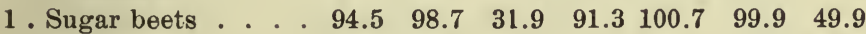

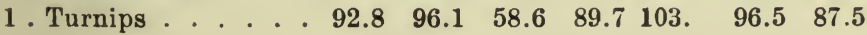

ANIMAL PRODUCTS

Cow's milk $(G)$. . . . . 98. . . 94. . . 98. 100.

Meat meal $(G)$. . . . . 93. . . 96. . . . . 99 .

Dried blood $(G)$. . . 63. . . 62. . . 100. 100.

Dried fish, ground $(G)$. . . . . 90. . . . 76 .

Dried Fodders

Digestion by Horses

2. Timothy hay in full

bloom, well cured . $\begin{array}{llllllll}43.5 & 44.1^{\circ} & 34 . & 21.2 & 42.6 & 47.3 & 47.3\end{array}$

$\begin{array}{lllllllll}2 \text {. New eorn product } & 49.9 & 51.7 & 21.7 & 67.5 & 54.6 & 46.9 & 59.8\end{array}$ 


\section{Appendix}

No. ex- Kind and condiperim'ts tion of food

Dried Fodders-continued

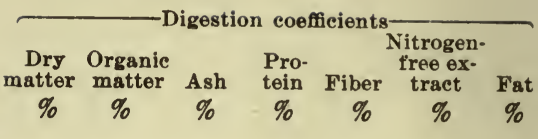

Meadow hay -

Best $(G)$

Medium (G) • . . . . 50

Poor (G)

Red elover hay (G)

Alfalfa hay ( $G$ )

Wheat straw (G)

\section{Roots}

Potatoes (G) . . . . 93

Carrots

\section{Grains}

Oats (G)

Barley (G)

Corn (G)

Field beans (G) . . . . 87.

69.

87.

89.

Peas (G) . . . . . 80 .

2. Dent corn, unground 74.475 .

2. Corn meal, same material, ground .

2 . White oats, first quality, unground

2 . Oats, same material, ground

\section{4}

72.
58.

50.

$5 i$.

58.

21.
88. 99.
63. 48.65 .22 . 57. 39.58 .18$. 55 . $38 . \quad 52.24$. 56. 37.63 .29 . 73 . 40.70 .14 . 28 . 18.28 .66 .
99.

94. 


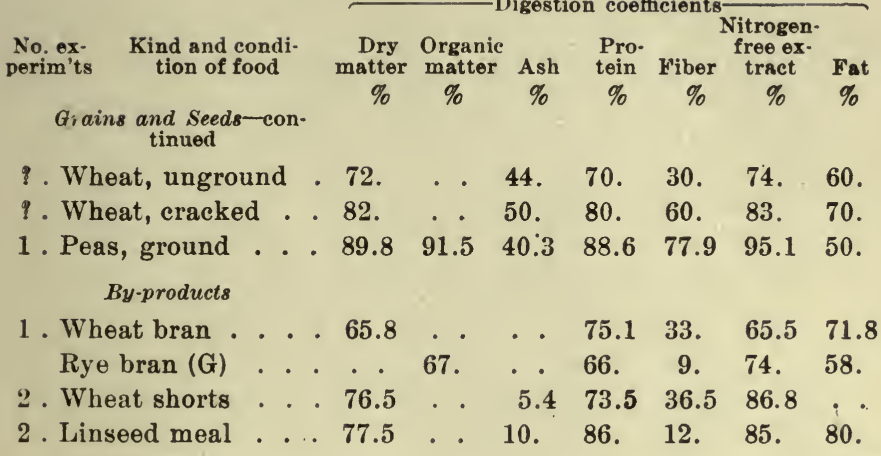

\section{Roots}

2. Potatoes, raw . . 97

2. Potatoes, cooked . . 95. . . 40.92 . $\quad$. . 97.6

Animal Products

Meat meal (G) . . . . . 92. . . 97. . . . 86.

Dried blood $(G)$. . . 72 . . 72. $\quad$. $92 . \quad$.

Sour milk (G) . . . . . 95. . . 96. . . 98. 95 .

\section{FEEDING STANDARDS .}

The feeding standards for the various elasses of farm animals are taken from Mentzel \& Lengerke's Landw. Kalender for 1899. They are intended to apply to animals of average size fed under normal conditions. They are not to be regarded as feeding recipes, but are to be varied according to circumstances. Small animals should receive proportionately more food than large ones; milch cows in proportion to the quantity and richness of the milk; growing and fattening animals according to the rapidity of increase desired; work 
animals according to the severity of labor, and individual animals according to their peculiar needs.

The quantity of "dry substance" will vary according to the digestibility of the ration, with no harm. It is important to maintain the necessary quantity of digestible dry substance. This should be somewhat more if the ration has a larger proportion of coarse materials than when it is mostly grain. The nutritive ratio may wisely vary according to the availability and price of feeding stuffs. The method of calculating a standard ration is explained in .Chapter XIX.

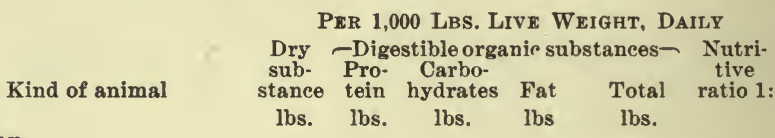

1. Oxen-

\begin{tabular}{lllllrr} 
At rest . . . . . & 18 & .7 & \multicolumn{1}{c}{8.} & .1 & 8.8 & 11.8 \\
Light work . . . . & 22 & 1.4 & 10. & .3 & 11.7 & 7.7 \\
Moderate work . . . & 25 & 2. & 11.5 & .5 & 14. & 6.5 \\
Severe work . . . . & 28 & 2.8 & 13. & .8 & 16.6 & 5.3
\end{tabular}

2. Fattening bovines-

First period . . . 30

$\begin{array}{llll}2.5 & 15 & .5 & 18\end{array}$

6.5

Second period . . 30

$\begin{array}{lll}3 . & 14.5 & .7\end{array}$

18.2

5.4

Third period . . . 26

$\begin{array}{llll}2.7 & 15 . & .7 & 18.4\end{array}$

6.2

3. Milch cows-

Daily milk yield 11

lbs. . . . . . 25

Daily milk yield $161 / 2$

lbs. . . . .

Daily milk yield 22

lbs.

$25 \quad 1.6 \quad 10$.

$.3 \quad 11.9$

6.7

Daily milk yield $27 \frac{1}{2}$

$27 \quad 2$

2. 11 .

.4

13.4

6.

lbs. ..... 32

2.513

$.5 \quad 16$

5.7

4. Sheep-

3.313.

$.8 \quad 17.1$

4.5

Coarse wool ... 2

$\begin{array}{llll}1.2 & 10.5 & .2 & 11.9\end{array}$

9.1

Fine wool ..... 2

1.512

, $3 \quad 13.8$

8.5 
Per 1,000 LBs. Live Weight, DAILY

Kind of animal Dry -Digestible organic substances- Nutri-
sub. Pro- Carbosub- Pro-
stance tein hydrates fat Total ratio 1:

lbs. lbs. lbs. lbs. lbs.

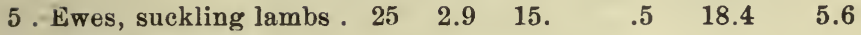

6. Fattening sheep-

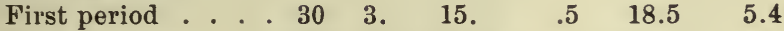

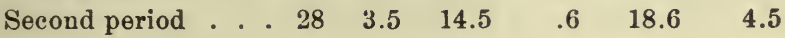

7 . Horses-

$\begin{array}{llllllll}\text { Light work . . . . . } 20 & 20 & 1.5 & 9.5 & .4 & 11.4 & 7 .\end{array}$

$\begin{array}{llllll}\text { Moderate work . . . } 24 & 2 . & 11 . & .6 & 13.6 & 6.2\end{array}$

$\begin{array}{lllllll}\text { Severe work . . . . } & 26 & 2.5 & 13.3 & .8 & 16.6 & 6 .\end{array}$

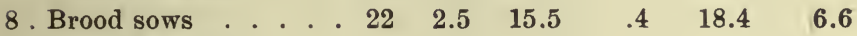

9. Fattening swine-

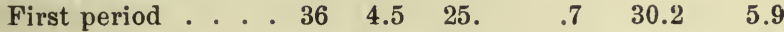

$\begin{array}{lllllll}\text { Second period . . . } 32 & 4 . & 24 . & .5 & 28.5 & 6.3\end{array}$

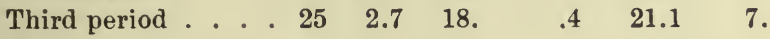

10 GROWING CATTLE

Dairy Breeds

\begin{tabular}{|c|c|c|c|c|c|c|c|c|c|}
\hline $\begin{array}{l}\text { Age in } \\
\text { months }\end{array}$ & • & & $\begin{array}{l}\text { Live weigl } \\
\text { per head } \\
\text { lbs. }\end{array}$ & & & & & & \\
\hline $2-3$ & . & & . 150 . & . 23 & 4. & 13. & 2. & 21. & 4.5 \\
\hline $3-6$ & . & • & . 300 . & . 24 & 3. & 12.8 & 1. & 16.8 & 5.1 \\
\hline $6-12$ & . & & . 500 . & . 27 & 2. & 12.5 & .5 & 15. & 6.8 \\
\hline $12-: 8$ & . & . & . 700 . & . 26 & 1.8 & 12.5 & .4 & 14.7 & 7.5 \\
\hline $18-24$ & . & . & . 900 . & . 26 & 1.5 & ב. & .3 & 13.8 & 8.5 \\
\hline $2-3$ & Beef & Breed & ds 165 & . 23 & 4.2 & 13. & 2. & 19.2 & 4.2 \\
\hline $3-6$ & . . & . & . 330 . & . 24 & 3.5 & 12.8 & 1.5 & 17.8 & 4.7 \\
\hline $6-12$ & . . & . & . 550 . & . 25 & 2.5 & 13.2 & .7 & 16.4 & 6. \\
\hline $12-18$ & 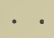 & & . 750 & . 24 & 2. & 12.5 & .5 & 15. & 6.8 \\
\hline $18-24$ & . . & & 935 & . 24 & 1.8 & 12. & .4 & 14.2 & 7.2 \\
\hline
\end{tabular}

GROWING SHEEP

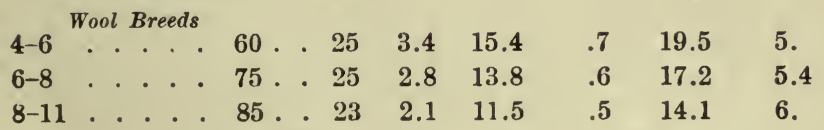




\section{Appendix}

PxR 1,000 Lbs. Live Weight, DaIly

Kind of animal

Wool Breeds-continued

Live weight

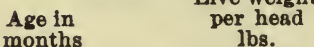

Dry -Digestible organic substances - Nntrisub- Pro- Carbo-
stance tein hydrates Fat Total ratio

lbs. lbs, lbs. lbs. lbs.

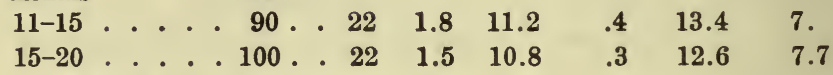

Mutton Breeds

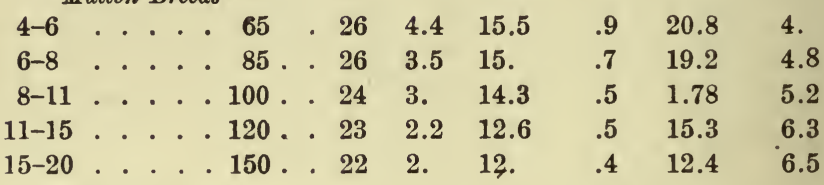

GROWING SWINE

Breeding Stock

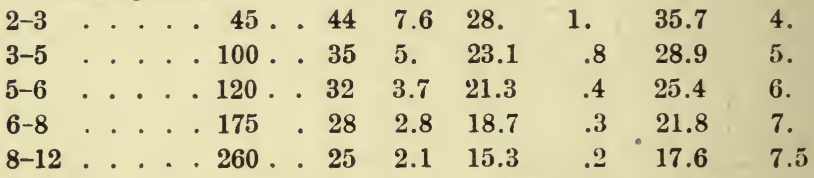

Growing Fattening Animals

\begin{tabular}{|c|c|c|c|c|c|c|c|}
\hline $2-3$ & . & 45 & 44 & 7.6 & 28. & 1. & 35.7 \\
\hline 3-5 & . & . 110 & . 35 & 5. & 23.1 & .8 & 28.9 \\
\hline-6 & - . & . 150 & . 33 & 4.3 & 22.3 & .6 & 27.2 \\
\hline $6-8$ & . & . 200 & . 30 & 3.6 & 20.5 & .4 & 24.5 \\
\hline $3-12$ & . . & . 275 & . 26 & 3. & 18.3 & .3 & 21.6 \\
\hline
\end{tabular}




\section{FERTILIZING CONSTITUENTS OF AMERICAN FEEDING STUFFS}

This table is the one prepared by the Office of Experiment Stations, U. S. Department of Agriculture, and published in the Handbook of Experiment Station Work, Bulletin No. 15.

$\begin{array}{ccccc}\text { Moisture } & \text { Ash } & \text { Nitrogen } & \begin{array}{c}\text { Phos- } \\ \text { phoric } \\ \text { acid }\end{array} & \begin{array}{c}\text { Potas. } \\ \text { sium } \\ \text { oxide }\end{array} \\ \text { \% } & \% & \% & \% & \%\end{array}$

Corn fodder $\quad \begin{array}{lllll}78.61 & 4.84 & .41 & .15\end{array}$

Sorghum fodder . . . 82.19

Rye fodder ..... 62.11

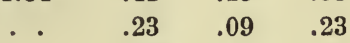

Oat fodder . . . . . 83.36

$\cdots$

Common millet . . . . . $\quad 62.58$

1.31

$\begin{array}{lll}.49 & .13 & .38\end{array}$

Japanese millet . . . . 71.05

.61

$.19 \quad .41$

Hungarian grass (German millet) .......

74.31

Orchard grass (Dactylis glomerata $)^{*}$......

73.14

2.09

.39

.16

.55

Timothy grass (Phleum pratense $)^{*} \ldots \ldots \ldots$

Perennial rye grass (Lolium perenne $)^{*} \ldots \ldots \ldots$

Italian rye grass (Lolium italicum $)^{*} \ldots . .$.

Mixed pasture grasses . .

Red clover (Trifolium pra-

tense) ...... 80.

66.9

2.15

$.43 \quad .16$

.76

White clover (Trifolium repens)........

Alsike clover (Trifolium hybridum) .......

Searlet clover (Trifolium incarnatum)

75.2

2.6

.48

.26

.76

74.85

2.84

.47

$.28 \quad 1.1$

63.12

3.27

$.54 \quad .29$

1.14

$.91 \quad .23$

.75

$.53 \quad .13$

.46

81.

.56

.2

.24

$\begin{array}{lllll}81.8 & 1.47 & .44 & .11 & .2\end{array}$

82.5

$\begin{array}{rrr}\cdot & .43 & .13 \\ 2.25 & .72 & .13\end{array}$

Alfalfa (Medicago sativa)

75.3

2.25

13

.56

*Dietrich and König: Zusamensetzung und Verdaulichkeit der Futtermittei. 
Green Fodders-continued

$\begin{array}{ccccc}\begin{array}{c}\text { Moisture } \\ \%\end{array} & \begin{array}{c}\text { Ash } \\ \%\end{array} & \begin{array}{c}\text { Nitrogen } \\ \%\end{array} & \begin{array}{c}\text { Phos- } \\ \text { phoric } \\ \text { 8cld } \\ \%\end{array} & \begin{array}{c}\text { Potas. } \\ \text { sium } \\ \text { oxide } \\ \%\end{array} \\ 78.81 & 1.47 & .27 & .1 & .31 \\ 82.59 & 1.82 & .41 & .14 & .42 \\ 73.2 & . . & .29 & .15 & .53 \\ 74.71 & . . & .68 & .33 & 1.37 \\ 85.35 & . . & .44 & .35 & 1.73 \\ 83.15 & .96 & .51 & .11 & .15 \\ 71.6 & 1.93 & 1.13 & .18 & .58 \\ 84.5 & 1.94 & .59 & 1.19 & .7 \\ 84.36 & 2.45 & .42 & .11 & .75 \\ 77.95 & . . & .28 & .11 & .37 \\ 71.03 & . . & .79 & .42 & .44 \\ 75 . & 1.05 & .32 & .15 & .4\end{array}$

Hay and Dry Coarse Fodders

Corn fodder (with ears). .

Corn stover (without ears).

Teosinte(Euchloena luxurians)

Common millet . . . . . 9.75

6.53

1.46

Japanese millet.

10.45

. .

1.28

Hungarian grass . . . . 7.69

5.8

1.11

.4

1.22

Hay of mixed grasses . . 11.99

6.18

1.2

.35

1.3

Rowen of mixed grasses.

6.34

1.41

.27

1.55

Redtop (Agrostis vulgaris).

9.57

1.61

.43

1.49

Timothy

7.71

4.59

1.15

.36

1.02

Orchard grass

7.52

4.93

1.26

.53

Kentucky blue-grass (Poa pratensis)

8.84

6.42

1.31

.41

1.88

Meadow fescue (Festuca pratensis) .......

Tall meadow oat grass ( $A r$ rhenatarum avenaceum) .

$$
10.35
$$

4.16

1.19

.4

1.57

8.89

8.08

.99

.4

2.1

15.35
4.92 
Fertilizing Constituents

Hay and Dry Coarse Fodders-

Moisture

Ash Nitrogen

Phos- Potasphoric sium

$\%$

$\%$

$\%$

$\%$

oxide continued

Meadow foxtail (Alopecurus pratensis) ....... . 15.35

$\begin{array}{lll}5.24 & 1.54 \quad .44\end{array}$

1.99

Perennial rye grass . . . .

9.13

6.79

1.23

.56

1.55

Italian rye grass

8.71

1.19

.56

1.27

Salt marsh hay

5.36

1.18

.25

.72

Japanese buckwheat

5.72

1.63

.85

3.32

Red clover . . . . . . 11.33

6.93

2.07

.38

2.2

Mammoth red elover ( $T r i$ folium medium) . . . 11.41

8.72

$2.23 \quad .55$

1.22

White clove

Scarlet elover ${ }^{*}$.....

Alsike clover

18.3

7.7

2.75

.52

1.81

Alfalfa

9.94

7.7

2.05

.4

1.31

11.11

2.34

2.23

6.55

7.07

2.19

1.68

Blue melilot (Melilotus cceruleus)

\section{$\begin{array}{lllll}8.22 & 13.65 & 1.92 & .54 & 2.8\end{array}$}

Bokhara clover (Melilotus alba)

7.43

7.7

$1.98 \quad .56$

1.83

Sainfoin (Onobrychis sativa)

12.17

7.55

$2.63 \quad .76$

2.02

Sulla (Hedysarum coronarium) ......

Lotus villosus . . . . . . . 11.52

. $\quad 2.46 \quad .45$

2.09

Soja bean (whole plant)

6.3

8.23

2.1

.59

1.81

Soja bean (straw) ...

13.

Cow pea (whole plant) . 10.95

6.47

2.32

.67

1.08

Serradella

7.39

8.4

1.75

.4

1.32

Scotch tares

15.8

106

1.95

.52

1.47

$\begin{array}{ll}2.7 & .78\end{array}$

Oxeye daisy (Chrysanthemum leucanthemum). .

9.65

2.96

.82

3.

Dry carrot tops . . . . 9.76

\subsection{7}

.28

.44

1.25

Barley straw . . . . . 11.44

12.52

3.13

.61

4.88

Barley chaff ..... 13.08

5.3

1.31

.3

2.09

Wheat straw

12.56

·.

1.01

.99

Wheat chaff

8.05

7.18

.59

.27

.51

$\begin{array}{ll}.79 & .7\end{array}$ 


\begin{tabular}{|c|c|c|c|c|c|c|c|}
\hline $\begin{array}{l}\text { Iay and Dry } \\
\text { continued }\end{array}$ & Coarse & Fodder - & $\begin{array}{c}\text { Moisture } \\
\%\end{array}$ & $\begin{array}{c}\text { Ash } \\
\%\end{array}$ & $\begin{array}{c}\text { Nitrogen } \\
\%\end{array}$ & $\begin{array}{l}\text { Phos- } \\
\text { phoric } \\
\text { acid } \\
\%\end{array}$ & $\begin{array}{c}\text { Potas- } \\
\text { sium } \\
\text { oxide } \\
\%\end{array}$ \\
\hline straw. & . . . & . . . . & 7.61 & 3.25 & .46 & .28 & .79 \\
\hline $\begin{array}{l}\text { straw } \\
\text { kwheat hu }\end{array}$ & alls & $\begin{array}{l}\cdot \cdot \cdot \cdot \\
.\end{array}$ & $\begin{array}{r}9.09 \\
11.9\end{array}$ & $\begin{array}{c}4.76 \\
. \quad .\end{array}$ & $\begin{array}{l}.62 \\
.49\end{array}$ & $\begin{array}{l}.2 \\
.07\end{array}$ & $\begin{array}{r}1.24 \\
.52\end{array}$ \\
\hline
\end{tabular}

Roots, Bulbs, Tubers, etc.

\begin{tabular}{|c|c|c|c|c|c|c|}
\hline Potatoes & & . & 79.75 & .99 & .21 & .07 \\
\hline Red beets & & 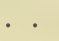 & 87.73 & 1.13 & .24 & .09 \\
\hline Yellow fodder beet & & & 90.6 & .95 & .19 & .09 \\
\hline Sugar beets & & & 86.95 & 1.04 & .22 & .1 \\
\hline Mangel-wurzels & 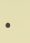 & & 87.29 & 1.22 & .19 & .09 \\
\hline Turnips . . . & • & & 89.49 & 1.01 & .18 & .1 \\
\hline Rutabagas . . & & . & 89.13 & 1.06 & .19 & .12 \\
\hline Carrots. & 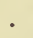 & & 89.79 & 9.22 & .15 & .09 \\
\hline
\end{tabular}

Grains and Other Seeds

\begin{tabular}{|c|c|c|c|c|c|c|c|c|}
\hline Corn kernels . . & . & & . & 10.88 & 1.53 & $\cdot 1.82$ & .7 & .4 \\
\hline Sorghum seed & 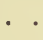 & - & . & 14. & & 1.48 & .81 & .42 \\
\hline Barley* ... & • & . & 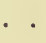 & 14.3 & 2.48 & 1.51 & .79 & .48 \\
\hline Oats . . . & - & . & . & 18.17 & 2.98 & 2.06 & .82 & .62 \\
\hline Wheat (spring) & 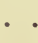 & & . . & 14.35 & 1.57 & 2.36 & .7 & .39 \\
\hline Wheat (winter). & . & 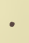 & . . & 14.75 & . & 2.36 & .89 & .61 \\
\hline Rye . . . & 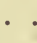 & & • & 14.9 & & 1.76 & .82 & .54 \\
\hline Common millet. & - & 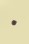 & 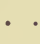 & 12.68 & - & 2.04 & .85 & .36 \\
\hline Japanese millet & 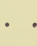 & - & 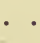 & 13.68 & . . & 1.73 & .69 & .38 \\
\hline Rice . . & & - & 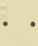 & 12.6 & .82 & 1.08 & .18 & .09 \\
\hline Buckwheat . . & & - & • & 14.1 & . & 1.44 & .44 & .21 \\
\hline Soja beans. . & & . & & .18 .33 & 4.99 & 5.3 & 1.87 & 1.99 \\
\hline
\end{tabular}

\section{Mill Products}

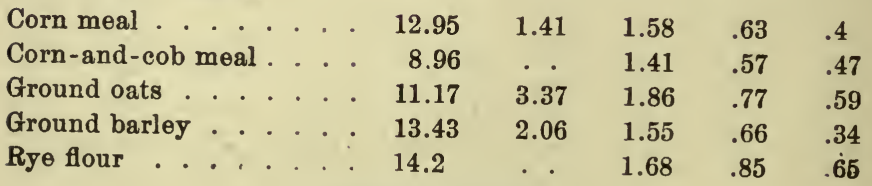

*Dietrich and König. 


$\begin{array}{cccccc} & & & \begin{array}{c}\text { Phos- } \\ \text { phoric }\end{array} & \begin{array}{c}\text { Potas- } \\ \text { sium } \\ \text { oxide }\end{array} \\ \text { Mill Products - continued } & \% & \% & \% & \% & \%\end{array}$

$\begin{array}{lllll}9.88 & 1.22 & 2.21 & .57 & .54\end{array}$

$\begin{array}{lllllllllll}\text { Pea meal } & . & . & . & . & & 8.85 & 8.68 & 3.08 & .82 & .99\end{array}$

By-products and Waste Materials

$\begin{array}{lllllll}\text { Corn cobs . . . . . . . . } & 12.09 & .82 & .5 & .06 & .6\end{array}$

Hominy feed . . . . . . $\begin{array}{llllll} & 8.93 & 2.21 & 1.63 & .98 & .49\end{array}$

Gluten meal . . . . . . $\quad 8.59 \quad \begin{array}{lllll}73 & 5.03 & .33 & .05\end{array}$

$\begin{array}{llllll}\text { Starch feed (glucose refuse) } & 8.1 & \ldots & 2.62 & .29 & .15\end{array}$

$\begin{array}{llllll}\text { Malt sprouts . . . . . . . } & 10.38 & 12.48 & 3.55 & 1.43 & 1.63\end{array}$

$\begin{array}{llllll}\text { Brewers' grains (dry) . . . } & 6.98 & 6.15 & 3.05 & 1.26 & 1.55\end{array}$

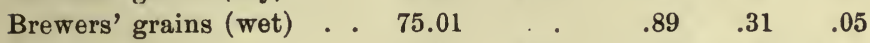

$\begin{array}{lllllll}\text { Rye bran . . . . . . . } & 12.5 & 4.6 & 2.32 & 2.28 & 1.4\end{array}$

$\begin{array}{lllllll}\text { Rye middlings* } & \text {. . . . } & 12.54 & 3.52 & 1.84 & 1.26 & .81\end{array}$

$\begin{array}{lllllll}\text { Wheat bran . . . . . } & 11.74 & 6.25 & 2.67 & 2.89 & 1.61\end{array}$

$\begin{array}{llllll}\text { Wheat middlings . . . . } & 9.18 & 2.3 & 2.63 & .95 & .63\end{array}$

$\begin{array}{lllllll}\text { Rice bran . . . . . . . } & 10.2 & 12.94 & .71 & .29 & .24\end{array}$

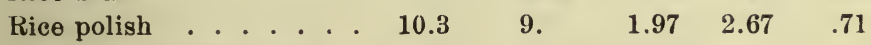

$\begin{array}{lllllll}\text { Buckwheat middlings* } & \text {. . } & 14.7 & 1.4 & 1.38 & .68 & .34\end{array}$

$\begin{array}{lllllll}\text { Cottonseed meal . . . . . } & 9.9 & 6.82 & 6.64 & 2.68 & 1.79\end{array}$

$\begin{array}{lllllll}\text { Cottonseed hulls . . . . . } & 10.63 & 2.61 & .75 & .18 & 1.08\end{array}$

$\begin{array}{llllll}\text { Linseed meal (old process) } & 8.88 & 6.08 & 5.43 & 1.66 & 1.37\end{array}$

$\begin{array}{llllll}\text { Linseed meal (new process) } & 7.77 & 5.37 & 5.78 & 1.83 & 1.39\end{array}$

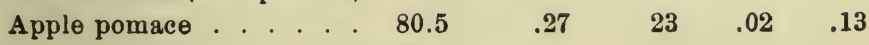

* Dietrich and König 



\section{INDEX}

A bsorption of food, 119 .

Acids, 83 ; action on albuminoids, 65 ; action on carbohydrates, 86; fatty, 90 ; influence on digestion, 139.

Age, influence on production, 411.

Air, carbon in, 13; hydrogen in, 15; nitrogen in, 16; oxygen in, 14.

Albuminoids, 57; action of acids and alkalies on, 65; action of heat on, 64 ; action of ferments on, 63,65 ; comparative energy values of, 173 ; compounds among, 57; energy of, 162; modified, 62.

Albumins, 58; in milk, meat, eggs, 58; in plants, 59; properties of, 58 ; where found, 58 .

Alfalfa, as soiling crop, 266; productivity of, 261.

Alkalies, action on albuminoids, 65 .

Amides, 69; value of, 179 .

Animal, globulins in, 60; water in, 38 .

Animal body, distribution of ash com. pounds in, 49.

Arimal heat, source of, 9.

Animal life, relation of oxygen to, 14; relation of plant to, 7 ; relation to man, 1.

Animal meal, 256.

Animals, composition of bodies, 93 ; mineral compounds in, 48; problems in feeding, 3; proportions of elements in, 22; selection of, 411; treatment of, 416 .

Ash, compounds of, 41; compounds in different species, 44; distribution compounds of in plants, 45 ; in animsl, 49; elements of, 30; influence of manufacturing processes on, 47; in plants, 43; variations in species, 43. Assimilation, definitions of, 99.

Beef, feeding for production of, 339 .

Beet sugar, residues from manufacture of, 240.

Bile, 115; function of, 116.

Blood, 142; corpuscles in, 143; mineral compounds of, 50.

Bone, formation of, 152.

Bovines, maintenance food for, 297, maintenance rations for, 299.

Butter-milk, 254, 255; as food for swine, 363.

Breakfast foods, residues from, 232.

Breed, influence on digestion, 138; influence on production, 409, 411.

Brewer's grains, 236; residues, 236.

Butter, effect of foods on, 319.

Calcium, sources of, 20; in nutrition, 20. Calf, growth of, 324; metabolism of, 324.

Calorie, definition of, 161.

Calorimeter, 162; respiration form, 201.

Calves, composition of, 403; feeding of, 328: production with, 404, 405; skimmilk for, 329.

Capillaries, blood, 119.

Carbohydrates, 75; action of acids on, 86; action of ferments, 86; animal, 84; characteristics of, 85 ; energy of, 162 ; elements in, 30; functions of, 155; influence of excess of, 135; relative energy values of, 172; variations in digestibility, 123. 
Carbon, 12; in crops, 13; supply of, 12, 13.

Carbonic acid, elimination of, 149.

Casein, 66.

Cattle foods, 203; chemical differences in, 248; classification of, 249; commercial, 227; production of, 258.

Cellulose, 73; action of ferments on, 118; energy value of, 172.

Chemical studies, knowledge from, 191.

Chicks, food mixtures for, 396; rations for, 395 .

Chlorine, in nutrition, 19; sources of, 19.

Coarse foods vs. grains, 249.

Colts, feeding of, 333 ; foods for, 337 ; mixtures for, 338; oats as food for, 335.

Combustion, measurement of, 200.

Compounds, elasses of, 28 ; elements in classes, 30.

Cooking, influence on digestion, 132.

Corn bran, 240.

Cottonseed, 242; cake, 243; hulls, 243; meal, 242; oil, 243.

Cows, production with, 404, 405; selection of, 409.

Crops, carbon in, 13 ; forage, 204; leguminous, 262; productive capacity, 260; soiling, 263; succession for soiling, 265.

Crude fiber, 72; digestibility of, 124.

Curing, changes in, 205; conditions of, 206; vs. ensiling, 217.

Dairy by-products, 254.

Dextrose, 82.

Diastase, function of, 87.

Digestibility, determination of, 139; influence of combination of nutrients on, 135; conditions influencing, 126.

Digestion, energy required for, 165 ; of food, 98.

Dried blood, 256.

Ducks, food mixtures for, 396; rations for, 395 .
Elements, chemical, of nutrition, 11; proportions in animals, 22; proportions in plants, 21; sources of, 12.

Energy, available, 163; carbohydrates as source of, 155; expended by work horses, 369; fats as source of, 157; food as source of, 157; in various food compounds, 162; manifestations of 159; measurement of available, 174 : net, 164 ; of albuminoids, 173 ; of carbohydrates, 172; of cellulose, 172; of digested nutrients, 199; of fats, 173; of gums, 173; of ration, calculation of, 198; protein as source of 155; required for chewing, 165; source of, 8 ; unit of, 161; uses of, 157 .

Ensilage, 212; crops for, 218.

Ensiling vs. field curing, 217.

Enzyms, 103.

Ether extract, 89 ; composition of, 92 ; digestibility of, 124.

Ewes, feeding of, 331.

Exercise, need of, 415 .

Extractives, 70; value of, 179.

Fat, of milk, 91 ; study of formation, 195.

Fats, 88 ; absorption of, 120; comparative energy values of, 173; digestibility of, 124; elements in, 30; energy of, 162 ; functions of, 157; influence on digestion, 137; neutral, 90 ; of body, source of, 154, 156; production value of, 176.

Fattening, feeding for, 341, 351.

Feces, 121.

Feeding, frequeney of, 134.

Feeding animals, problems in, 3.

Feeding standards, 282.

Feeding experiments, utility of, 188 .

Feeding stuffs, classification of, 251; commercial, 227; commercial values of, 269 ; composition of, 419 ; digestible substance in, 276; digestibility of 427; energy of, 163; fertilizing constituents of, 439 ; physiological values 
of, 272; popular valuation, 277 ; relation to digestive processes, 121 ; selection of, 273 ; valuation by cow, 279; valuation by experiments, 278 ; valuations of, 268; variations, water in, 37; water in, 36; water in air dry, 37; water in green, 36.

Feeds, ash in, 47.

Fermentations, in alimentary canal, 118.

Ferments, 99; action on carbohydrates, 86 ; coagulating, 63 ; of digestion, 65 ; organized, 100; unorganized, 100, 103.

Fibrinogen, 61.

Fish offals, 256.

Fodders, dried, 205; green, 205.

Food, absorption of, 119; digestion of , 98; distribution of, 142; influences on flavor of milk, 321; relation to growth, 324 ; relation to milk, 316; relation to production, 194, 400; units of value, 401; use of, $142,147$.

Foods, of animal origin, 252.

Forage erops, 204; for fattening sheep, 357; influence of stage of growth on composition, 209; influence of stage of growth on yield, 208; harvesting of, 207.

Fowls, composition of bodies of, 387 , 403; digestive apparatus of, 383 ; feed. ing of, 379; production with, 404, 405.

Fruit sugar, 83.

Gases, of digestion, 164.

Gastric juice, 112.

Gelatinoids, 68.

Germ oil meal, 240.

Globulins, 59; in animal, 60; in seeds, 59; properties of, 59.

Glucose manufacture, residues from, 236.

Gluten, energy of, 175 ; productive value of, 177.

Gluten feed, 239.

Gluten meal, 239.

Glycogen, 84; formation of, 150.

Grains (and seeds), 225.
Grape sugar, 82.

Grasses, 204.

Grinding grains, influence on digestion, 133.

Growing animals, feeding of, 324 .

Growth, relation to food, 325; sustained by plant, 8 .

Gums, energy value of, 173; digestibility of, 124; vegetable, 78 .

Hay, water in, 37.

Heart, the, 144.

Heat, body, regulation of, 168 ; effect on albuminoids, 64 ; effect on carbo. hydrates, 86.

Hens, laying, rations for, 393.

Hogs, fattening, growth of, 358 .

Horses, influence of speed on work of, 370 ; maintenance food for, 300 ; maintenance rations for, 302 : work performed by, 368; working, feeding of, 367 ; working, foods for, 376 ; working, food needs of, 371; working, rations for, 377 ; working, source of rations, 374.

Hydrochloric acid, in stomach, 112.

Hydrogen, 15; in air, 15; in water, 15; source to animal, 16.

Intestinal juice, function of, 118.

Intestines, the, 114.

Investigation, methods of, 192.

Iron, compounds of, 20; in nutrition, 20.

Keratin, 69.

Knowledge, sources of, 186.

Lact-albumin, 59.

Lacteals, 119.

Lambs, fattening, experiments with, 353 ; feeding of, 331 .

Laws of nutrition, 182.

Legumes, 204.

Levulose, 83.

Lime, in animal, 48 ; for poultry, 390 : in plants, 45 . 
Linseed meal, 245 ; new process, 246 ; old process, 246.

Linseed oil, 245.

Liver, the, 150.

Lungs, the, 146.

Maintenance food for bovines, 297; for horses, 300.

Maintenance rations, 295; for bovines, 299; for horses, 302; for poultry, 393; sources of, 296; uses of, 295.

Maize, influence stage of growth, 211; productivity of, 261.

Maize kernel, 237.

Malt sprouts, 236.

Maltose, 82.

Man, relation to animal, $\mathbf{i}$.

Mares, feeding of, 334.

Matter, classes of, 26 ; combustible, 26 ; incombustible, 26; inorganic, 28 ; organic, 28.

Meat, albumin in, 58 ; production of, 339.

Neat meal, 256.

Metabolic wastes, errors caused by, 136, 140.

Milk, composition of, 305 ; as cattle food, 252; demands for secretion of, 309; effect of food on, 316, 321; formation solids, 308 ; of various species, 253 ; production of, 304; protein needs for production of, 310; ration for producing, 309, 312; secretion of, 306; source of solids, 307 ; sources protein in ration for, 313 .

Milk sugar, 85.

Mineral compounds, elimination of, 149; function of, 152.

Molasses, energy of, 175; production value of, 177.

Mouth, the, 104.

Mutton, production of, 349.

Muscular power, source in plants, 9.

Muscular tíssue, 153.

Mastication, ener $\mathbf{g y}$ requirements, 165.
Nitrogen, 16; compounds, 16, 51; in air, 16 ; in soil, 16.

Nitrogen-free compounds, 71.

Nitrogen-free extract, 74; energy values of compounds, 171.

Nuclein, 67; special value of, 180 .

Nutrients, combustion of, 147; energy relations of, 166; functions of, 151; physiological values of, 170; production values of, 175 ; relative energy values of, 171; storage of, 147 .

Nutrition, chemical elements of, 11: compounds of, 25; laws of, 182.

Nutritive ratio, 283.

Oat feeds, 233; grain, 233; hulls, 233; kernel, 233.

Oats, as food for colts, 335 .

Oils, energy of, 175 ; productive value of, 177 .

Oil meals, 241 .

Oils, the, 88.

Ova-albumen, 59 .

Oxygen, 14; in air, 14; in earth, 14; in lungs, 146; in water, 14 ; relation to animal life, 14 ; relation to energy. 15 ; use of, 147.

Oxen, fattening, experiments with 343.

Palatableness, importance of, 280; in fluence on digestion, 126.

Pancreatic juice, 117; function of, 117 .

Pectin bodies, 80 .

Pentosans, energy value of, 173.

Pepsin, 113.

Peptones, absorption of, 120.

Phosphoric acid, in animal, 48; variations in plants, 45.

Phosphorus, in nutrition, 19; sources of, 18.

Physiological studies, knowledge from, 191.

Pig, fat, composition of, 359 ; feeding of, 361 ; foods for, 363 , 365 ; relation of food to growth, 36 ? 
Plants, relation to animal life, $7,8,9$; albumin in, 59; distribution ash compounds in, 45; living, water in, 33; mineral compounds of, 43; proportions of elements in, 21.

Potash, variations in plants, 45.

Pork, production of, 357.

Potassium, where found, 19; in nutrition, 19.

Poultry, effects of food with, 382; feeding of, 379; foods for, 379 ; food needs of, 389 ; food mixtures for, 396 ; maintenance rations for, 393; rations for chicks, 394; rations for laying hens, 393.

Practice, conclusions of, 187.

Preservation of fodders, influence on digestion, 129.

Preparation of foods, infiuence on digestion, 129.

Production, relation of food to, 194, 400; unit of, 401.

Proteids, 55; composition, 56 ; compound, 66; examples of, 57 .

Protein, classification compounds of, 54; combustion of, 147; definition of, 52: elements in, 30; functions of, 153; how estimated, 53; in fattening ration, 341, 352; in work horse ration, 375; influence on digestion, 137; need of in milk ration, 310 ; production value of, 175 ; proportion in ration, 291; relation to muscular effort, 167; relative importance of compound, 178; supply of, 262; sources of for milk ration, 313; variations in digestibility of, 122.

Ptyalin, 107.

Ration, influence of quantity on digestibility, 127.

Rations, adaptation of, 281; calculation of, 285; compounding of, 280; fattening, selection of, 347 ; for fattening steers, 342, 348; for laying hens, 393; for wilk production, 309, 312; for poultry, 392; for work horses, 374,377 ; for young birds, 394; maintenance, 295; maintenance for bovines, 299; maintenance for horses, 302; maintenance for poultry, 393; manipulation of, 413; palatableness of, 280 ; proportion of protein, 291 ; quantity of, 414 ; relation to quality of product, 292 ; relation to prices and supply, 293; relation to weight of animal, 289; selection of, 280 ; standards for, $282,342,345$.

Rennin, 113.

Respiration apparatus, 196.

Rigor mortis, cause of, 61 .

Roots (and tubers), 224.

Roots, productivity of, 261; storage of, 225.

Saccharose, 81.

Saliva, 106; function of, 107.

Salt, in feeding poultry, 391 ; influence on digestion, 133.

Salts, absorption of, 120.

Sand, in feeding poultry, 391.

Serum albumin, 59.

Sheep, composition of, 403; fattening, experiments with, 353; fattening, food needs of, 351; fattening, food standards, 352; fattening, growth of, 350 ; production with, 404,405 ; selection of ration for, 355 .

Silage, 212; changes in, 213; eutting material for, 221; formation of, 213; maturity crop for, 220.

Silo, construction of, 219; changes in, 213 ; extent of loss from, 215; filling of, 220; nature of loss from, 214; rate of filling, 221.

Skim-milk, 254, 255; as food for swine, 363.

Slaughter-house refuses, 256.

Sodium, in nutrition, 20; sources of, 19. Soil, nitrogen in, 16.

Soiling, 263; crops for, 265; succession of crops, 266; systems of, 265. 
Soiling erops, for swine, 366.

Sows, feeding of, 360 .

Species, influence on digestion, 137.

Stage of growth, influence on digestion, 130 ; influence on forage crons, 208.

Standards, German, 282.

Starch, energy of, 175; distribution in seeds, 77 ; productive value of, 176. 177; properties of, 76 ; residues from manufacture of, 236.

Starch (sugar corn) feed, 239.

Starch grains, forms of, 76 .

Starches, the, 75.

Steers, composition of, 403 ; composition of increase of, 340 ; fattening, experiments with, 343,345 ; fattening, food needs of, 341 ; fattening, food for, 344; produetion with, 404, 405.

Stomach, 108; of horse, 113; of pig, 113; of ruminants, 108.

Storage, influence on digestibility, 135.

Straw, energy of, 175; production value of, 177.

Straws, the, 223.

Sngar, absorption of, 120 .

Sugar beet molasses, 241.

Sugar beet pulp, 240 .

Sugars, the, 80.

Sulfur, in nutrition, 18; sources of, 18.
Swine, composition of, 403، production, $404,405$.

Teeth, the, 105.

Temperature of stable, 415.

Trypsin, 11:.

Urea, elimination of, 149.

Valuation feeding stuffs, 268; basis of, 274 ; commereially, 269: physiologi. cally, 272; popular standards, 277.

Vitellin, 62.

Water, 30; amount required by plants, 36; elimination of, 149; hydrogen in, 15 ; in animal, 38 ; in fattening in. crease, 40 ; in feeding poultry, 389 ; in feeding stuffs, 36; in hay, 37; in living plants, 33; oxygen in, 14; variations in feeding stuffs, 37 ; in plants, 33.

Watering, frequency of, 134 .

Wastes, elimination of, 148.

Wheat, offals from, 228 .

Wheat kernel, 228; proportion of parts, 230.

Wheat offals, composition of, 231 .

Whey, 254, 255. 
The following pages contain advertisements of books on kindred subjects 


\section{RURAL SCIENCE SERIES}

\section{Editod by L. H. BAILEY}

On Selection of Land, etc. Isaac P. Roberts' The Farmstead . . . . . \$1 50 net

On Tillage, etc.

E. G. Cheyney's Farm Forestry - . . . (Preparing)

F. H. King's The Soil : : : 150 net

Isaac P. Roberts' The Fertility of the Land : : 150 net

F. H. King's Irrigation and Drainage . . . . 150 net

Edward B. Voorhees' Fertilizers . . . . . 125 net

Edward B. Voorhees' Forage Crops : : : : 150 net

S. M. Tracy's Forage Crops for the South : . . (Preparing)

J. A. Widtsoe's Dry Farming . . . . 150 net

L. H. Bailey's Principles of Agriculture : : : 125 net

On Plant Diseases, etc.

E. C. Lodeman's The Spraying of Plants . . . 125 net

On Garden-Making

L. H. Bailey's Garden-Making . . . . . 150 net

L. H. Bailey's Vegetable-Gardening : : : : 150 net

L. H. Bailey's Forcing Book • • • . . . 125 net

On Fruit-Growing, etc.

L. H. Bailey's Nursery Book . . . . . . 150 net

L. H. Bailey's Fruit-Growing . • . . . . 150 net

L. H. Bailey's The Pruning Book . . . . . 150 net

F. W. Card's Bush Fruits . . . . . . 150 net

On the Care of Live-Stock

John A. Craig's Sheep Farming . . . . . 150 nut

Nelson S. Mayo's The Diseases of Animals : : : 150 net

W. H. Jordan's The Feeding of Animals : . . 150 net

I. P. Roberts' The Horse . . 125 net

M. W. Harper's Breaking and Training of Horses : 150 net

George C. Watson's Farm Poultry. New edition : 150 net

On Dairy Work, Farm Chemistry, etc.

Henry H. Wing's Milk and Its Products. .New Editior. 150 net

J. G. Lipman's Bacteria and Country Life . . . 150 net

On Economics and Organization

G. Harold Powell's Coöperation in Agriculture . . 150 net

W. A. McKeever's Farm Boys and Girls : : 150 net

I. P. Roberts' The Farmer's Business Handbook ${ }^{\circ}$ : 125 net

George T. Fairchild's Rural Wealth and Welfare : 125 net

H. N. Ogden's Rural Hygiene . . . . . 150 net

J. Green's Law for the American Farmer : . . 150 net

\section{THE MACMILLAN COMPANY}




\section{Warren's Elements of Agriculture}

By G.F.WARREN, Professor of Farm Management and Farm Crops, New York State College of Agriculture at Cornell University.

Clcth, $12 m o, 456$ pages, $\$ 1.10$ net

Written by Professor G. F. Warren, who is in charge of the Department of Farm Management and Farm Crops in the New York State College of Agriculture, Cornell University, an authority on questions pertaining to practical agriculture.

Professor Warren is, moreover, a farmer. He grew up on a farm in the middle West and is living at the present time on a farm of three hundred and eighteen acres, which he supervises in connection with his work at the University.

The "Elements of Agriculture" is a text that does not "talk down" to the pupil. It gives agriculture rank beside physics, mathematics, and the languages as a dignified subject for the course of study.

In Warren's "Elements of Agriculture" there is no waste space. It is written with the ease that characterizes a writer at home in his subject, and it is written in a style pedagogically correct. The author has been a teacher of high-school boys and girls and knows how to present his subject to them.

Experts in the teaching of agriculture the country over have been unanimous in praise of the text.

Mr. J. E. Blair, Supt. of Schools, Corsicana, Texas.

“An examination of Warren's 'Elements of Agriculture' convinces me that it is a book of uncommon merit for secondary schools as well as for the private student. It is thoroughly scientific in matter, and is written in an attractive style, that cannot fail to please as well as instruct."

Supt. E. S. SмIтH, Whiting, Iowa.

"I am very much pleased with Warren's 'Elements of Agriculture.' In my opinion it is the only book on the market that presents the work of agriculture suitably for high schools; too many books are too simple and do not give enough work; a book for high schools must be more than a primer."

\section{Material and Methods in High School Agriculture}

By WILLIAM GRANVILLE HUMMEL, M. S., Assistant Professor of Agricultural Education, University of California, and Bertha Royce Hummel, B. L. S.

Illustrated. 120 pages, $\$ 1.25$ net

This work meets the needs of persons interested in the introduction or in the teaching of agriculture in high schools of towns, cities, or rural communities, where large numbers of students are drawn from the farming population, or where the prosperity of the high-school community is largely dependent upon agriculture.

\section{THE MACMILLAN COMPANY}

PUBLISHERS

64-66 Fifth Avenue

NEW YORK 


\title{
OF KINDRED INTEREST
}

\section{The Farmer of Tomorrow}

\author{
By F. I. ANDERSON
}

Cloth, $12 \mathrm{mo}, \$ 1.50$ net

There has been a great deal of theorizing about the "back-tothe-land" movement. It is the purpose of this book to crystalize and to make practical all of the vague generalizations which have so far been expressed on this subject. To this end the first part of Mr. Anderson's book is given over to a consideration of the land itself as a factor in the movement, primarily its economic bearing on the question. The second half takes up the soil with a detailed exposition of soil sanitation, the author confining himself, however, to only the broad principles. In presenting these two main thoughts the author touches upon such important and interesting topics as Why Europe Raises Three Bushels of Grain to Our One, Why Soils Become Unproductive, Why the Farmer of Yesterday is Rich, Why There Has Been No Increase in Acreage Productivity, and Why Irrigated Land Pays Interest on a Capitalization of Two Thousand Dollars an Acre. The book is one which should be of interest alike to those who are actively engaged in some form of agriculture and to those who are trying to solve the problem of the high cost of living.

\section{Malaria: Cause and Control}

\section{By WILLIAM B. HERMS}

Illustrated. Cloth, 8vo, $\$ 1.50$ net

The awakening of the general public to the necessity and possibility of the control of malaria, indicated by the incessant demand for information, makes the publication of Professor Herm's concise treatment of the subject an important and timely event. The question of malaria control is deserving of the most careful attention, particularly in these days when so much is heard of the "back-to-thesoil" movement. For malaria is notably a disease of rural districts. Those who are familiar with the situation know very well that malaria is too of ten responsible for farm desertion. Professor Herms writes of the conditions attending the disease as he has found and studied them during the past few years himself, and the suggestions for control which he makes are such as he has applied and found successful.

\section{THE MACMILLAN COMPANY}




\section{Farm Management}

By G. F. WARREN, Ph.D., Professor of Farm Management, New York State College of Agriculture at Cornell University.

Illustrated. Cloth, 12mo, $x x+592$ pages, $\$ 1.75$ net

"Farm Management is the study of the business principles in farming. It may be defined as the science of the organization and management of a farm enterprise for the purpose of securing the greatest continuous profit.

"Successful farming requires good judgment in choosing a farm and in deciding on a type of farming. It demands clear business organization and management for the efficient use of capital, labor, horses, and machinery. It requires good judgment in buying and selling.

"The change from cheap land, hand tools, and farming to raise one's own food and clothing, to farming as a commercial undertaking has come upon us so suddenly that business principles are not always well understood by farmers. Nor do those who understand the application of such principles to city conditions often know how to apply them on the farm.

"Long ages of experience and a generation of scientific research have resulted in a fund of popular knowledge on how to raise crops and animals. But there is less background of tradition concerning business methods on the farm, and colleges have given little attention to this kind of problem. The success of the individual farmer is as much dependent on the application of business principles as it is on crop yields and production of animals.

"The best way to find out what methods of farm organization and management are most successful is to study the methods now used and the profits secured on large numbers of farms, and determine how the more successful ones differ from the less successful, and find to which of the differences the success is due. After such principles are found, they need to be tested by use in reorganizing farms.

"The conclusions in this book are based on investigations of the kind given above, and on cost accounts, census data, travel and study in different parts of the United States and experience in farming. It is hoped that the conclusions may be of use to farmers and students."-Preface.

\section{THE MACMILLAN COMPANY}




\section{AN IMPORTANT CYCLOPEDIA}

\section{The Standard Cyclopedia of Horticulture}

Edited by L. H. BAILEY

With over 4,000 illustrations, 24 colored plates. Six volumes. Preparing.

This monumental work is introduced by nearly 200 pages of prefatory matter, comprising preface, a general introductory account of the vegetable kingdom as a whole, describing the families that are most important in a horticultural way, and also a key to all the leading genera that are described in the work. This key will enable the student to trace out the plant and refer it to its proper genus; by the aid of the generic key he can run it down to its species.

Special effort has been made to include the leading plants cultivated in the tropics, inasmuch as the scattered island territories of the United States are now bringing our people in touch with tropical conditions. Careful treatment has been given to such articles as Insects, Diseases, Greenhouses, Conservatories, Fertilizers, Alpine Gardening, Vegetable-Growing, The Cut-Flower Interests, Storage and Handling of Horticultural Products, The Planting of Trees and Shrubs, Pruning, Cost-Accounting in Horticultural Operations. Many lists of plants for special purposes and also extensive planting lists have been included.

With the elaborate introductory part, which is well illustrated by diagrams representing the structure of the different families, and with the extended accounts of the different genera, the work will be in effect a great Cyclopedia of botany as well as of horticulture.

The contributors include the very best botanists and cultivators in the country.

\section{THE MACMILLAN COMPANY}




\title{
NEWEST ADDITIONS TO THE RURAL SCIENCE SERIES
}

\author{
Edited by Professor L. H. BAILEY \\ Formerly Director of the New York State School of Agriculture at \\ Cornell University
}

\section{Sheep Farming}

By JOHN A. CRAIG and F. R. MARSHALL

Illustrated. Cloth, 12mo, $\$ 1.50$ net

This book deals with sheep husbandry as a phase of intensive farming. Recognizing that it is likely to be used by persons unfamiliar with sheep, the authors have worked from the standpoint of the producer of the market stock rather than from the standpoint of the professional breeder. The various breeds are discussed in such a way as to enable the reader to select the kind that is most likely to do well under his conditions and to acquaint him with the care it is accustomed to and needs. The management of the flock in the fall, winter, spring, and summer seasons, the formation of the flock, the selection of foundation stock, and the means of maintaining a high standard of flock efficiency are all discussed in subsequent chapters.

\section{Principles of Fruit-Growing}

\section{By Professor L. H. BAILEY}

New edition. Cloth, 12mo, Preparing

Since the original publication of this book, in 1897, it has gone through many editions. The progress of fruit-growing in the meantime has been very marked and it has been necessary to completely rewrite the work. The present issue of it brings the aceounts of the new practices and discoveries as they relate to fruit-growing up to date. All of the text and practically all of the illustrations are new.

\section{THE MACMILLAN COMPANY}




\section{RURAL SCIENCE SERIES-Continued}

\section{Co-operation in Agriculture \\ By G. HAROLD POWELL \\ Illustrated. Cloth, $12 \mathrm{mo}, \$ 1.50$ net}

This book deals with the general principles of coöperation. How to organize coöperative societies, how to finance them, simple organizations and constitutional documents, by-laws, and general advice as to the administration of the associations or societies are all considered. The author describes at some length the most famous organizations, such as those which are handling citrus fruits in California, the farmers' grain elevators systems, and the present coöperation in the creamery and butter business. It is, in other words, a practical guide for those who desire to organize coöperative societies and who wish to escape the usual pitfalls.

\section{Farm Forestry}

\section{By E. G. CHEYNEY}

Illustrated. Cloth, 12mo. Preparing

This book deals with the place of the woodlot or farm forest in the scheme of farming, with the planting, care, and harvesting of timber on lands, with the different species of trees that may be used, their relations or associations in a forest plantation, the rate of growth, the profits to be expected and the principal difficulties that are usually encountered. It is profusely illustrated.

\section{Forage Crops for the South}

\section{By S. M. TRACY}

Illustrated. Cloth, 12mo. Preparing

Professor Tracy has long experience in southern agriculture, both in application and in teaching. He was formerly Professor of Agriculture in the Mississippi Agricultural College, and now conducts a branch station for arm for the United States Department of Agriculture. He is a botanist of note, and has traveled extensively in the South as a collector. His book is not only authentic, but practical. In it is contained a discussion of all kinds of plants and crops adapted to the Southern States for fodder, soiling, pasturing, and hay. The text is abundantly illustrated.

\section{THE MACMILLAN COMPANY}




\section{RURAL SCIENCE SERIES-Continued}

\section{Fruit Insects}

\section{By M. V. SLINGERLAND and C. R. CROSBY}

New edition. Illustrated. Cloth, 12mo. Preparing

This is a practical account of the principal insects in this country which attack the different kinds of fruits - tree-fruits, small fruits, cranberries, grapes, and the like. It presents a full but brief outline life history of the leading insects together with the methods of control.

\section{Milk and Its Products}

By HENRY H. WING, Professor of Dairy Husbandry in Cornell University.

New Revised Edition, with new illustrations. Cloth, $12 \mathrm{mo}, \$ 1.50$ net

The revolution in dairy practice, brought about by the introduction of the centrifugal cream separator and the Babcock test for fat, by a more definite knowledge regarding the various fermentations that so greatly influence milk and the manufacture of its products, have demanded the publication of a book that shall give to the dairyman, and particularly to the dairy student, in simple, concise form, the principles underlying modern dairy practice. Such has been Professor Wing's purpose in this work. This is not a new edition of the author's very successful volume published under the same title many years ago; it is, in reality, an entirely new book, having been wholly reset and enlarged by the addition of new matter, both text and illustrations. The author's aim has been at all times to give the present state of knowledge as supported by the weight of evidence and the opinions of those whose authority is highest.

\section{THE MACMILLAN COMPANY}


Edited by Professor L. H. BAILEY

Formerly Director of the New York State School of Agriculture at Cornell University

\section{Manures and Fertilizers}

By H. J. WHEELER, Ph.D., D.Sc., Formerly Director of the Rhode Island Experiment Station.

Illustrated. Cloth, 12mo. Preparing

The clear and unusually full discussion of the practical utilization of manures and fertilizers of all kinds, and of their relations to the plant and to the soil, makes this book not only an excellent text for col!ege students, but also one which will be generally welcomed by all up-to-date agriculturists. All the animal manures, litter and waste nitrogeneous materials of every sort are discussed. A helpful feature for the student is the extended treatment of the availability of organic nitrogen and of the organisms contained in barnyard manure wiich give rise to the various fermentations taking place therein. The well-known and also the new, nitrogenous manures such as calcium cyanamid and calcium nitrate, are considered in detail. The chapters devoted to the potash salts, phosphates, lime, ragnesia, soda, gypsum, iron, and manganese are exceptionally complete, and chlorin, sulfur, silica carbon disulfid, toluene, and other substances exerting catalytic and other effects are described. Much of the material in this book, which will be new to students and other readers, has suggested itself to the author in the course of twenty-two years of continuous research.

\section{Corn Crops}

By E. G. MONTGOMERY, Professor of Farm Crops in the College of Agriculture at Cornell University.

Illustrated. Cloth, $12 \mathrm{mo}, \$ 1.60$ net

This is a text-book on corn and the sorghum crops, including the grain sorghums, the sweet sorghums for syrup or forage, and the broom corns. In it plant structures, physiology, and the other technical phases of the subject are separated from the more practical phases which might be classed as cultural methods. Hence, the entire book is adapted to use as a text in an advanced course, and the treatment of cultural methods is adapted to use in more elementary courses. The book is also an excellent handbook for farmers and others interested in the production or handling of corn or sorghums.

\section{Animal Husbandry for Schools}

By MERRITT W. HARPER, Assistant Professor of Animal Husbandry in the New York State College.

Illustrated. Cloth, $12 \mathrm{mo}, \$ 1.40$ net

This is a simple, concrete presentation of the essential facts concerning farm animals, adapted for use in secondary schools.

\section{THE MACMILLAN COMPANY \\ PUBLISHERS \\ 64-66 Fifth Avenue \\ NEW YORK}


$-1$

.

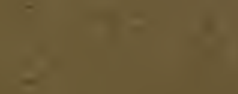

II

s

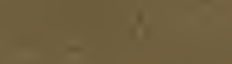

I. 
RETURN TO the circulation desk of any

University of California Library

or to the

NORTHERN REGIONAL LIBRARY FACILITY

Bldg. 400, Richmond Field Station

University of California

Richmond, CA 94804-4698

ALL BOOKS MAY BE RECALLED AFTER 7 DAYS

2-month loans may be renewed by calling

(510) $642-6753$

1-year loans may be recharged by bringing books to NRLF

Renewals and recharges may be made 4 days prior to due date

DUE AS STAMPED BELOW

JUN 11994 


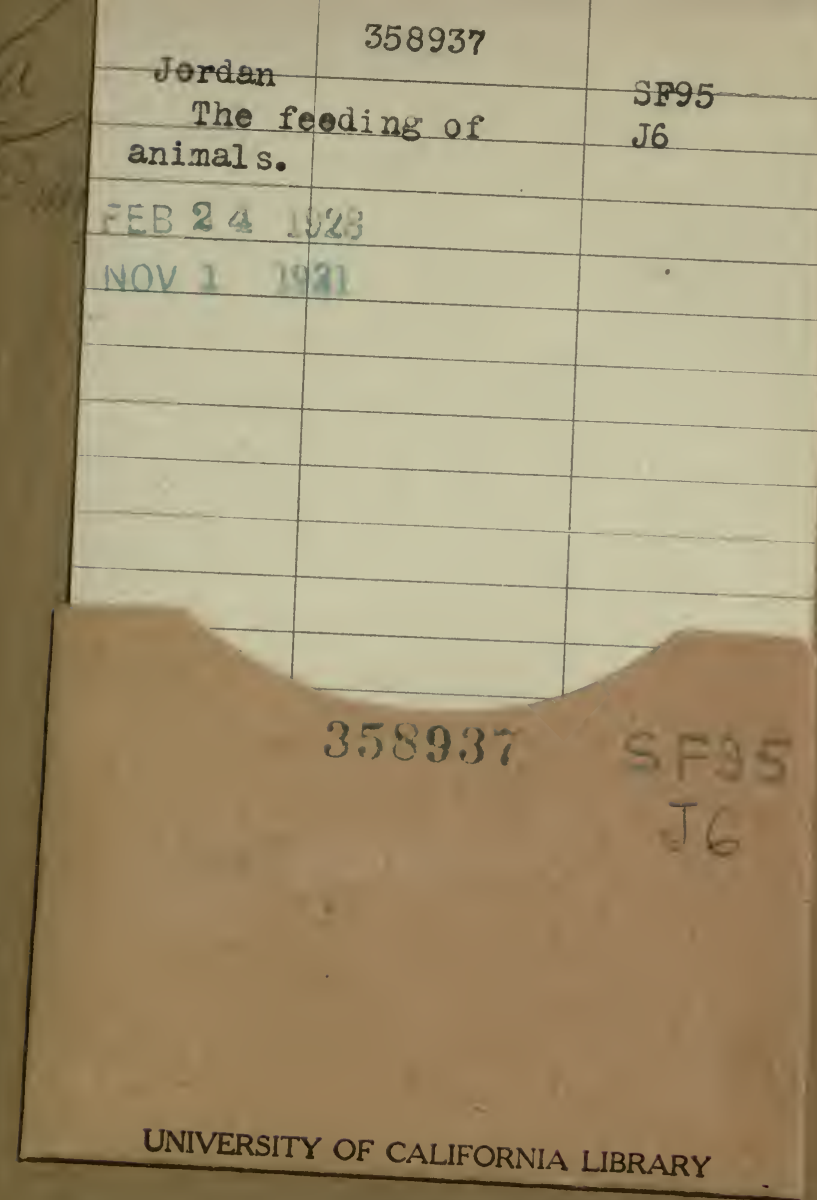


